\title{
The Urban Data Justice Case Study Collection
}

\section{Document Version}

Final published version

Link to publication record in Manchester Research Explorer

\section{Citation for published version (APA):}

Heeks, R. (2020). The Urban Data Justice Case Study Collection. (GDI Digital Development Working Papers; No. 88).

\section{Citing this paper}

Please note that where the full-text provided on Manchester Research Explorer is the Author Accepted Manuscript or Proof version this may differ from the final Published version. If citing, it is advised that you check and use the publisher's definitive version.

\section{General rights}

Copyright and moral rights for the publications made accessible in the Research Explorer are retained by the authors and/or other copyright owners and it is a condition of accessing publications that users recognise and abide by the legal requirements associated with these rights.

\section{Takedown policy}

If you believe that this document breaches copyright please refer to the University of Manchester's Takedown Procedures [http://man.ac.uk/04Y6Bo] or contact uml.scholarlycommunications@manchester.ac.uk providing relevant details, so we can investigate your claim.

\section{OPEN ACCESS}




\title{
Digital Development
}

\section{Working Paper Series}

The Digital Development (formerly Development Informatics) working paper series discusses the broad issues surrounding digital data, information, knowledge, information systems, and information and communication technologies in the process of socio-economic development

Paper No. 88

\section{The Urban Data Justice Case Study Collection}

\author{
2020 \\ Published in collaboration with, and with the \\ financial support of, the University of Manchester's \\ Sustainable Consumption Institute and Canada's \\ International Development Research Centre
}

ISBN: 978-1-905469-91-8

Published Centre for Digital Development

by: $\quad$ Global Development Institute, SEED

University of Manchester, Arthur Lewis Building, Manchester, M13 9PL, UK

Email: cdd@manchester.ac.uk Web: http://www.cdd.manchester.ac.uk

View/Download from:

http://www.gdi.manchester.ac.uk/research/publications/di/ 


\section{Table of Contents}

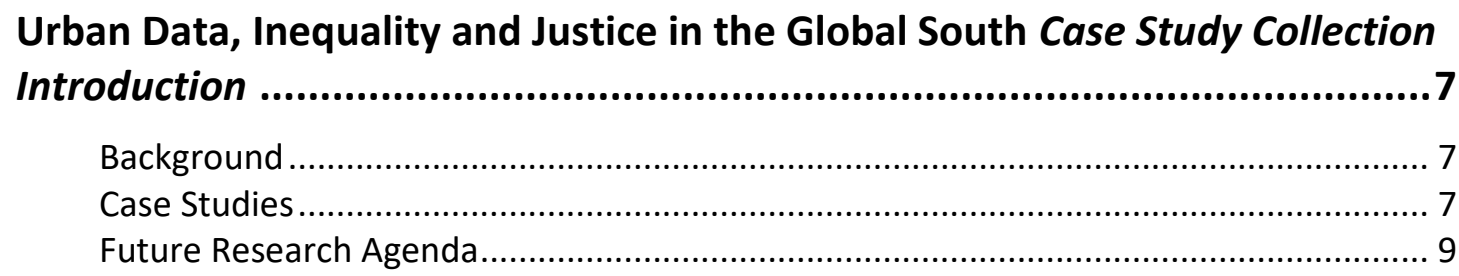

\section{Case 1: An Applied Data Justice Framework Analysing Datafication and} Marginalised Communities in Cities of the Global South

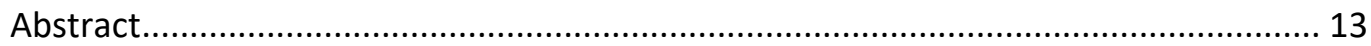

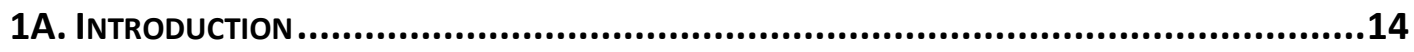

1B. Datafication, (URBAN) DeVElopment ANd Data Justice...............................15

1C. CASE Background ANd Methods .........................................................18

1C1. Background: Data Injustice and its Consequences ............................................. 19

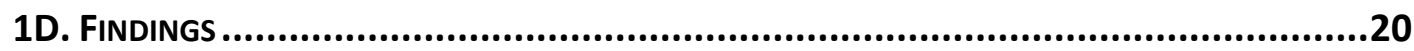

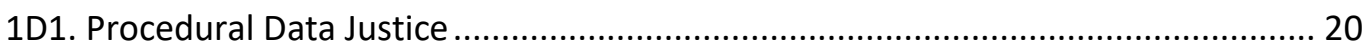

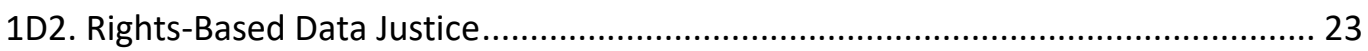

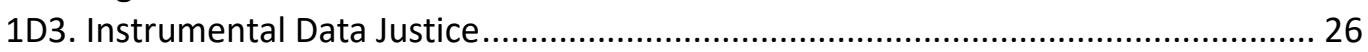

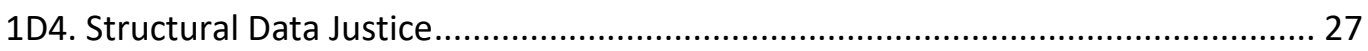

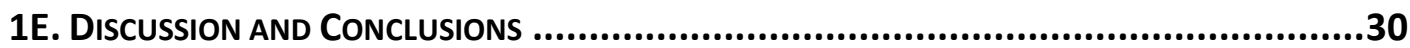

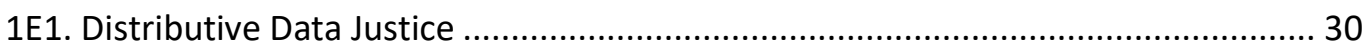

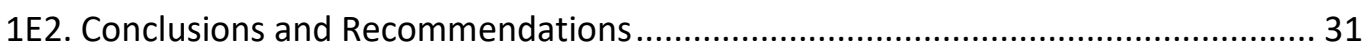

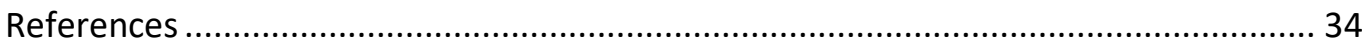

Case 2: Visual Data Justice? Datafication of Urban Informality in South Africa

Using $360^{\circ}$ Imaging Technologies .....................................................37

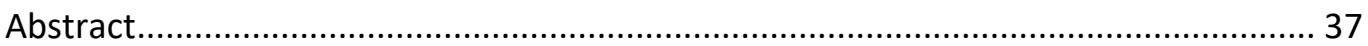

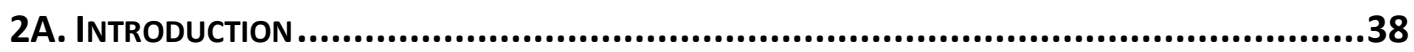

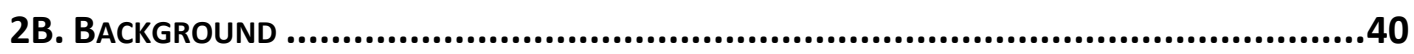

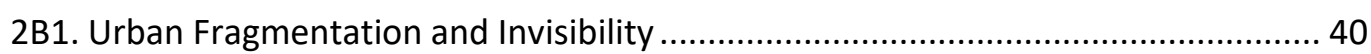

2B2. The Datafication of Injustice in Informal Settlements......................................... 40

2B3. Visualizing Informality: Vertical, Oblique, Horizontal.......................................... 42

2B4. From Socioeconomic to Sociocultural Injustice in Informal Settlements............... 45

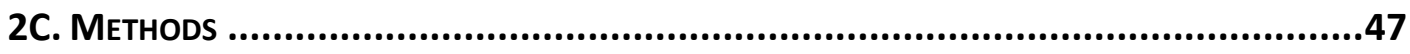

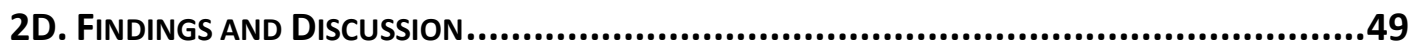

2D1. Datafication and its Limits for Contesting Injustice ............................................ 49

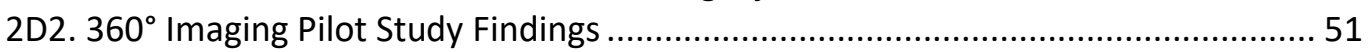

2D3. Framing, Linear Perspective, and Visibility in $360^{\circ}$............................................... 53

2D4. Distribution and Recognition through $360^{\circ}$ Street Views .................................... 55

2D5. $360^{\circ}$ Imagery, Exaggerated Seeing, and Misrecognition....................................... 58

2E. Conclusions: Visual Data Justice?........................................................60

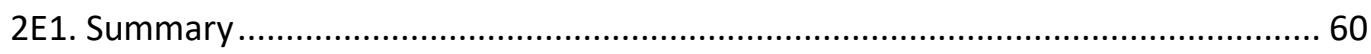

2E2. Recommendations and Future Research Agenda .......................................... 62

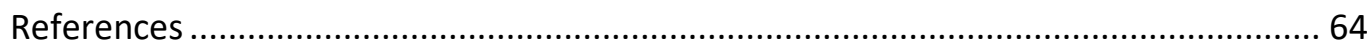

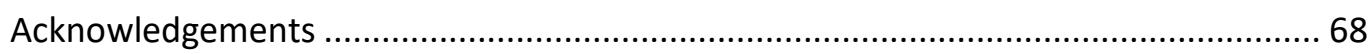

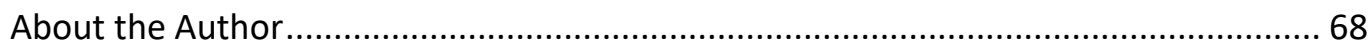




\section{Case 3: Spatial| Data Justice Mapping and Digitised Strolling against Moral}

Police in Iran

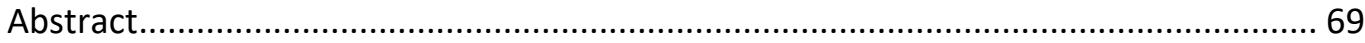

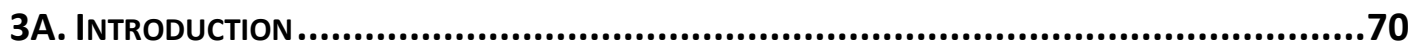

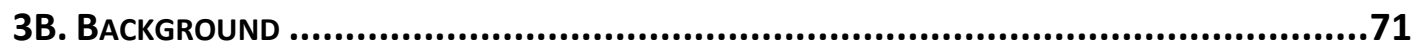

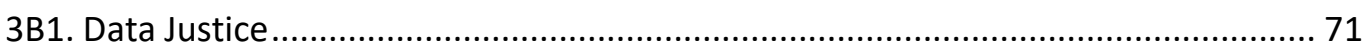

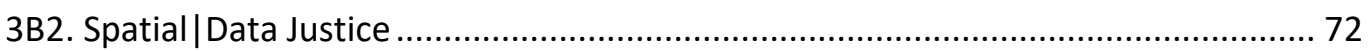

3В3. Compulsory Hijab and Surveillance of Women .................................................... 74

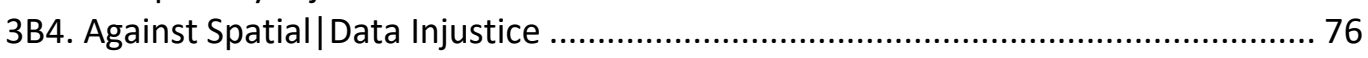

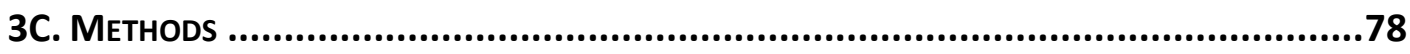

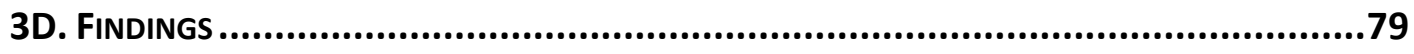

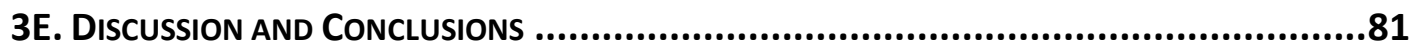

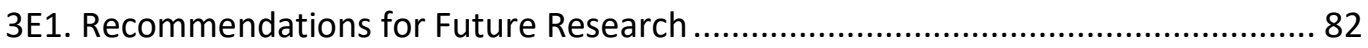

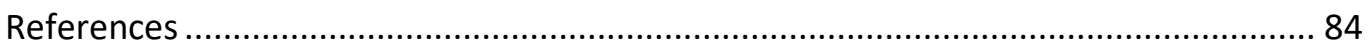

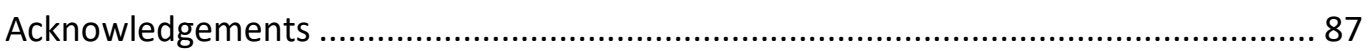

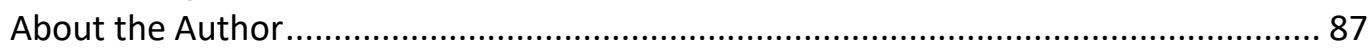

Case 4: Urban Slums in a Datafying Milieu Challenges for Data-Driven

Research Practice ...............................................................................88

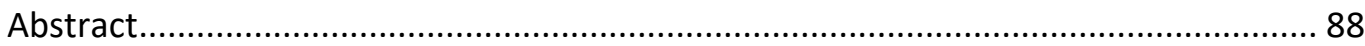

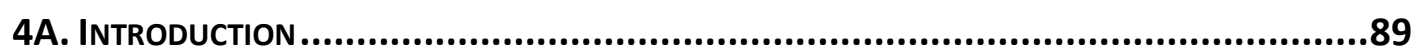

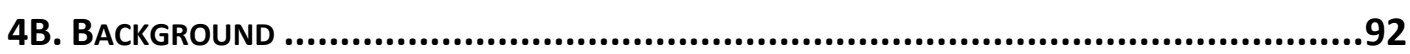

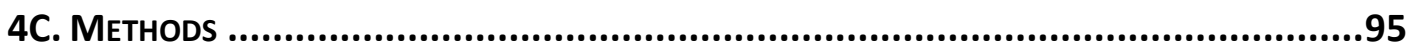

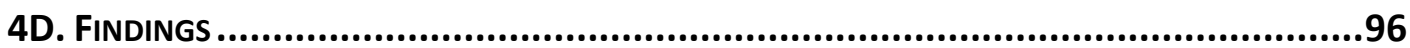

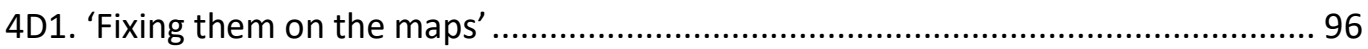

4D2. Data ownership and translating data/evidence into action ............................... 99

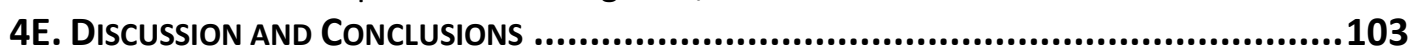

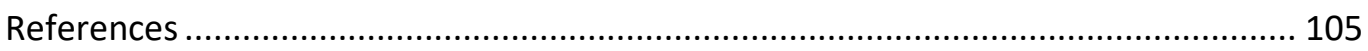

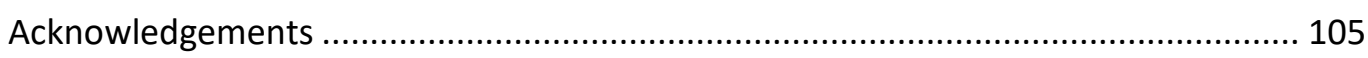

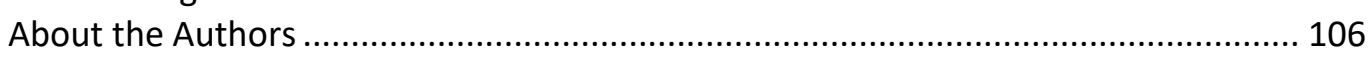

Appendix: Slum Mapping Steps and Challenges................................................. 107

Case 5: Data Justice through the Prism of Information Politics and Resource Injustice A Case Study from Hyderabad's Urban Frontier ....................... 111

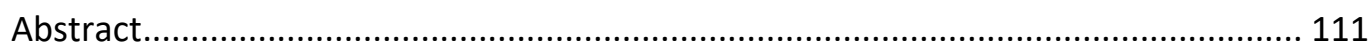

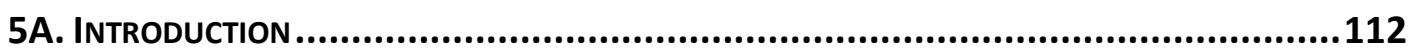

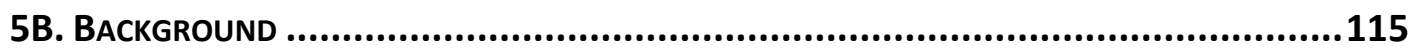

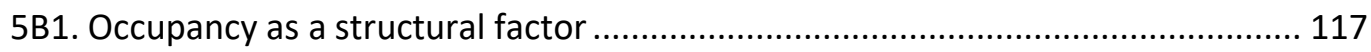

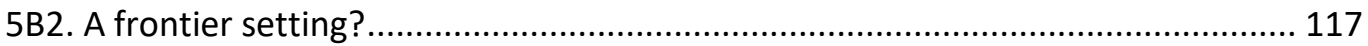

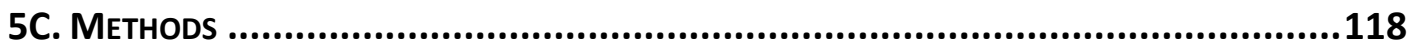

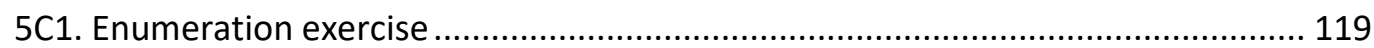

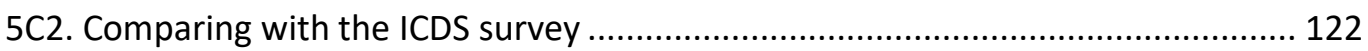

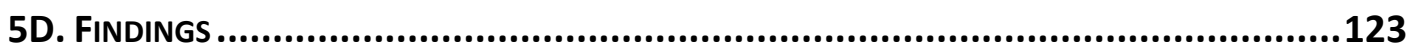

5D1. Datafication processes are influenced by wider structures of power, which mediate information politics ................................................................................. 123

$5 D 2$. The assessment of downstream effects shapes receptivity to upstream activities, but only to a degree. 
5D3. Digital audio-video technologies are increasingly available in the basti, but they have not disrupted the regulation of information flows by powerful actors............. 128

5E. Discussion AND Conclusions .............................................................130

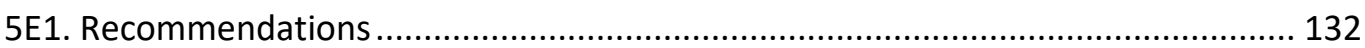

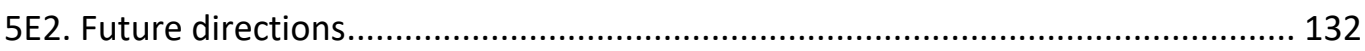

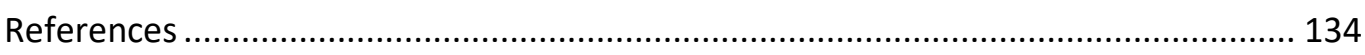

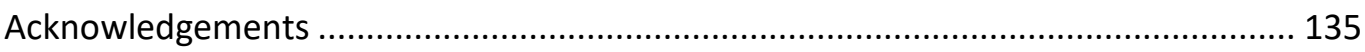

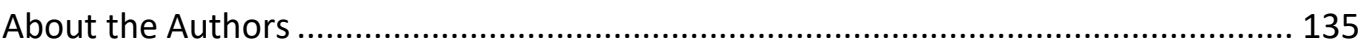

Case 6: Aadhaar-Led Identification and Datafication Among Informal Workers in South India A Data-Justice Perspective.................................... 136

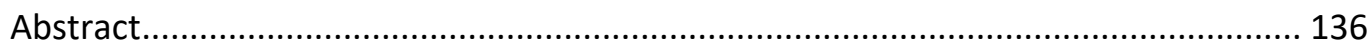

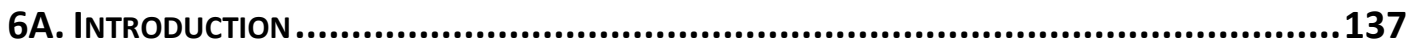

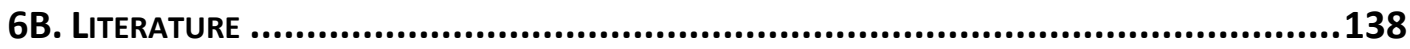

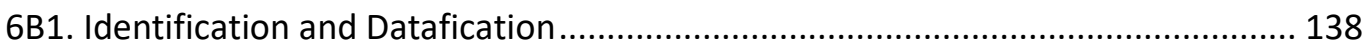

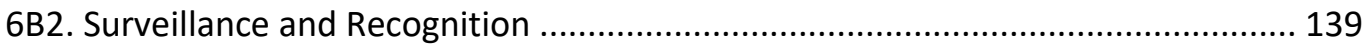

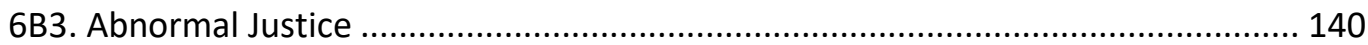

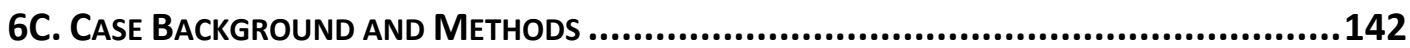

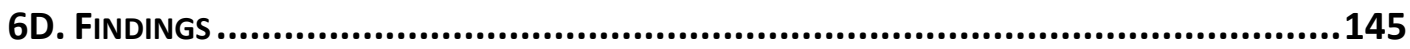

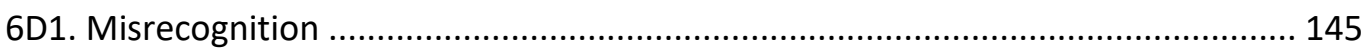

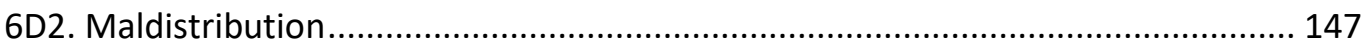

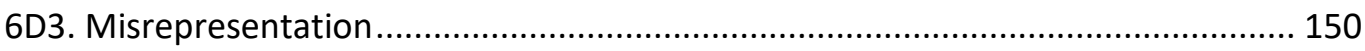

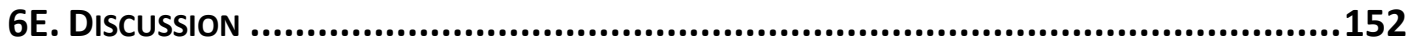

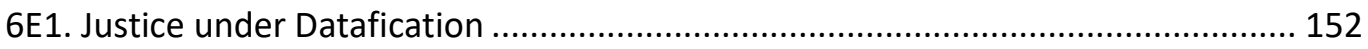

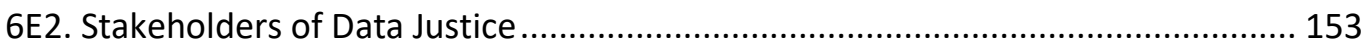

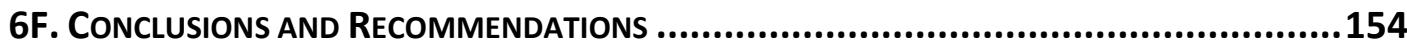

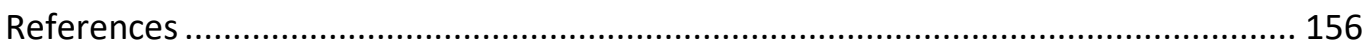

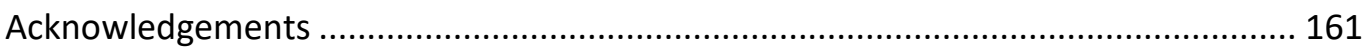

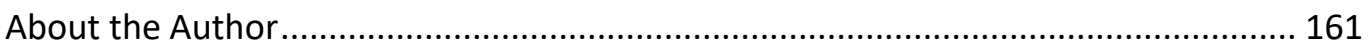

Case 7: Data Gathering and Justice in the Urban Informal Sector Views from the Frontline ............................................................................................ 162

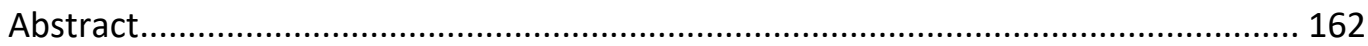

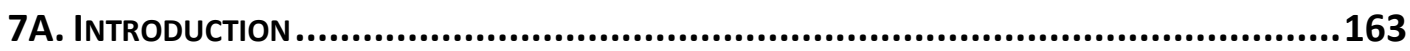

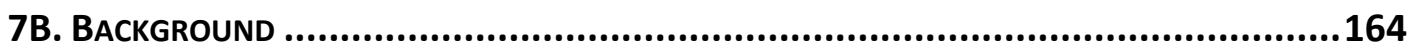

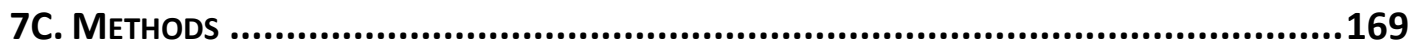

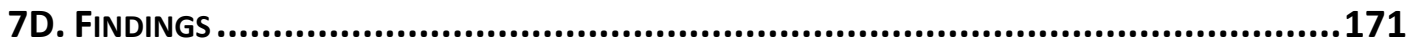

7D1. Implementation and Development of the 'Views from the Frontline' Programme

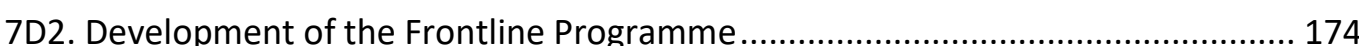

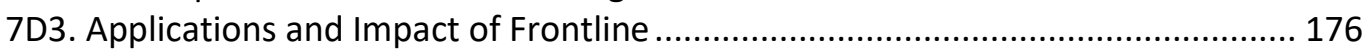

7D4. Return to Views from the Frontline .................................................................... 180

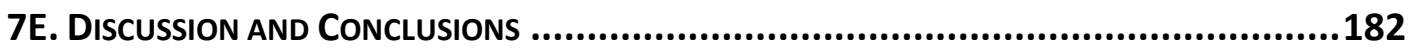

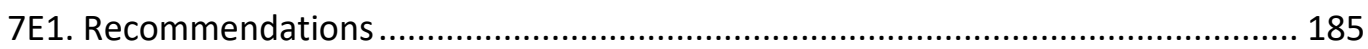

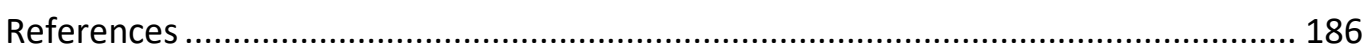

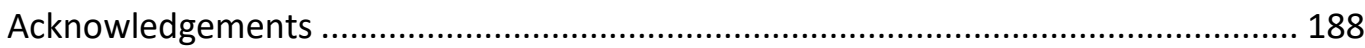

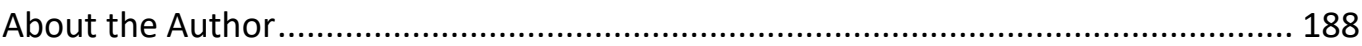


Case 8: Capturing Gender and Class Inequities The CCTVisation of Delhi ... 189

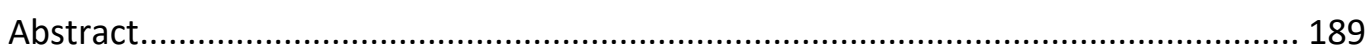

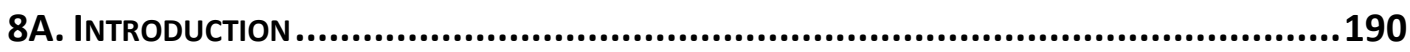

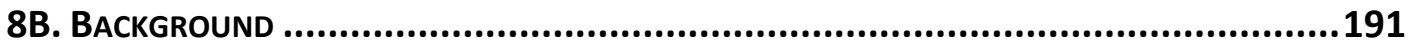

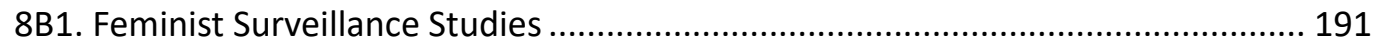

8B2. Privacy and the Gaze through a Critical Feminist Lens...................................... 192

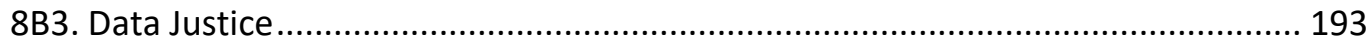

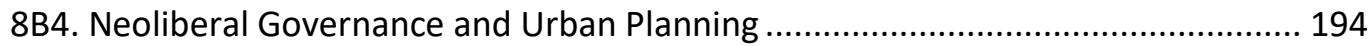

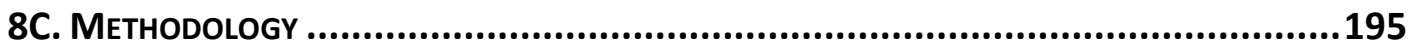

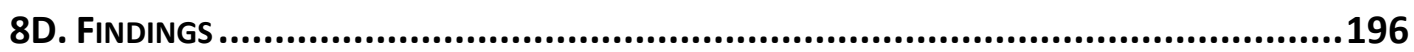

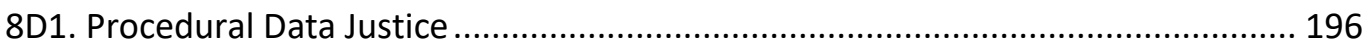

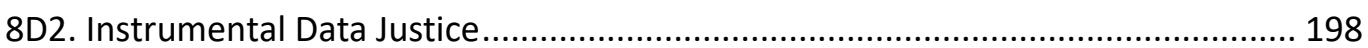

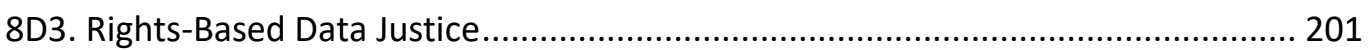

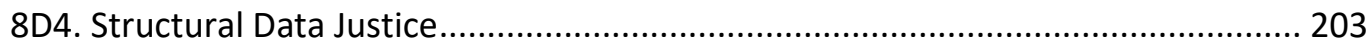

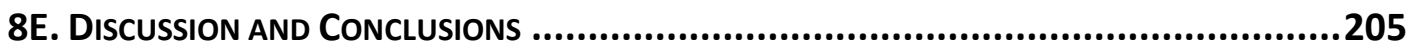

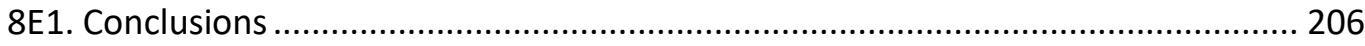

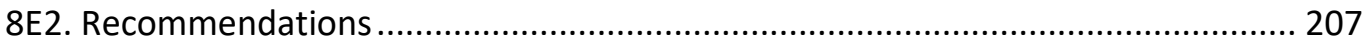

References

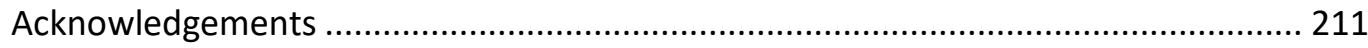

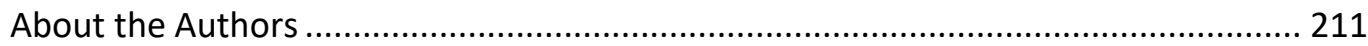

Case 9: Community-Based Data Justice A Model for Data Collection in Informal Urban Settlements .....................................................................212

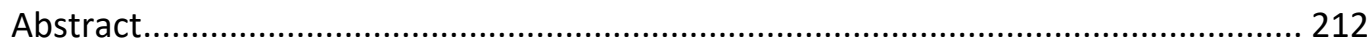

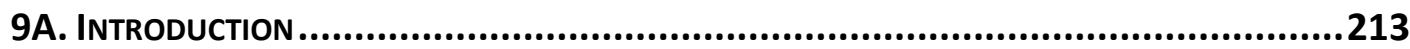

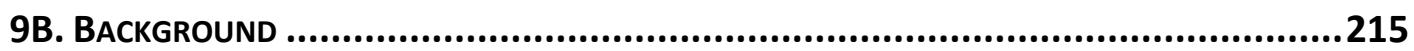

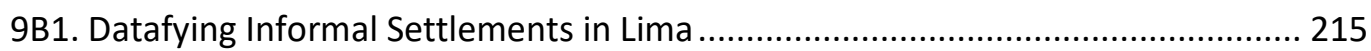

9B2. Investigating Data Justice using Concepts Developed by Iris Marion Young ....... 218

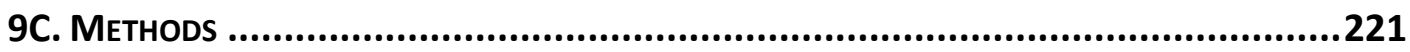

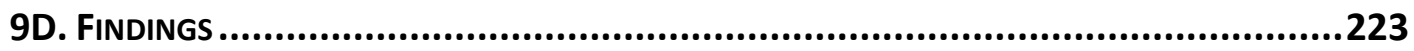

9D1. Datafication as a Process to Access Justice ….................................................... 223

9D2. Datafication as a Process to Develop Capabilities and Take Action..................... 229

9E. DiSCUSSION AND CONCLUSIONS ................................................................231

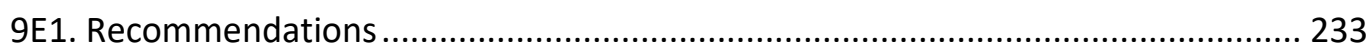

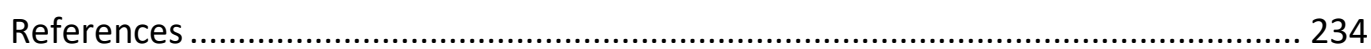

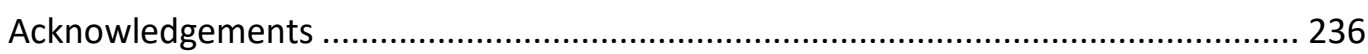

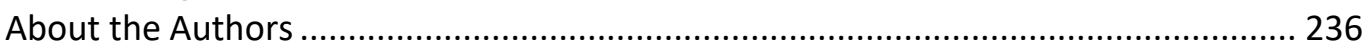

Annex: Social Connection Model by Iris Marion Young.............................................. 237

Case 10: Making Informal Settlements 'Visible' Through Datafication A Case Study of Quarry Road West Informal Settlement, Durban, South Africa ....238

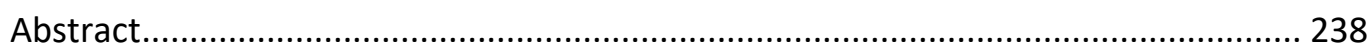

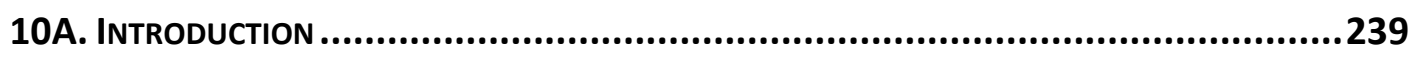

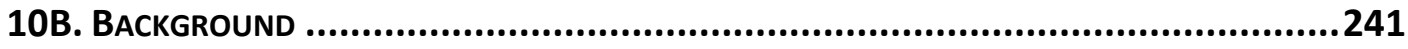

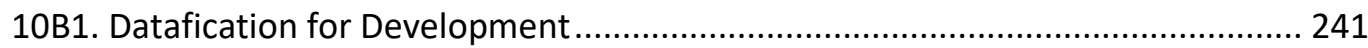

10B2. A Framework to Assess Data Justice for Development .................................... 243

10B3. Informality and Datafication in Cities in the South ........................................ 245 
10C. Methods

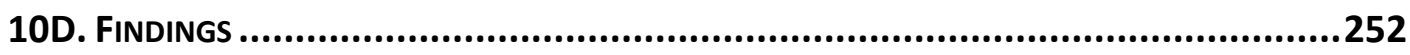

10D1. Valuing Different Forms of Data in Different Contexts for City Datafication..... 253

10D2. The Value of the Datafication Process …….................................................. 257

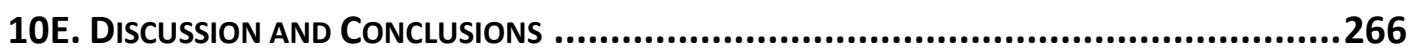

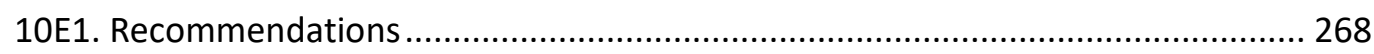

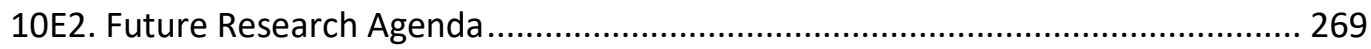

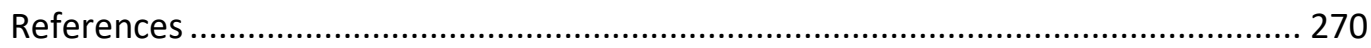

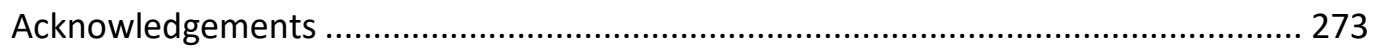

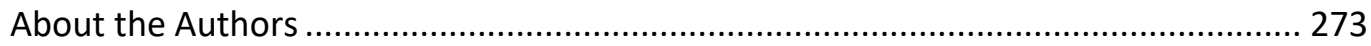




\section{Urban Data, Inequality and Justice in the Global South Case Study Collection Introduction}

\author{
Richard Heeks \\ Centre for Digital \\ Development, Global \\ Development Institute, \\ University of Manchester, \\ UK \\ Mark Graham \\ Oxford Internet Institute, \\ University of Oxford, UK
}

\author{
James Evans \\ Department of Geography, \\ University of Manchester, \\ UK
}

\&

\author{
Linnet Taylor \\ Tilburg Institute for Law, \\ Technology, and Society, \\ Tilburg University, The \\ Netherlands
}

\section{Background}

Cities in the global South are being "datafied", with increasing presence of digital data of all kinds: from mobile phones, remote sensing, ground-level sensors, community mapping, etc. This datafication of the city means growing velocity, volume and variety of data used in urban decision-making; and expanding presence for the city's "data twin": a virtual but skewed simulacrum through which the city is increasingly planned and even experienced.

Such datafication can bring significant benefits: improving the speed and quality of urban decision-making, or making visible issues or groups which have previously been invisible to formal decision-makers. But data is a source of power: a resource that may readily flow along and widen the existing urban fault-lines of socio-political inequality. Hence the growing interest in "data justice" in urban locations: the way in which data intersects with questions of social justice - who wins and who loses from the new digital datasets and data flows, and the relationship of data to power and inequality; particularly for those already marginalised in the physical city.

As yet, however, too little has been understood about this latter issue, creating the imperative for more work on urban data justice.

\section{Case Studies}

To help fill this knowledge gap, we commissioned - with financial support from the University of Manchester's Sustainable Consumption Institute and Canada's International Development Research Centre - a set of urban data justice case studies. These were intended to analyse from a data justice/rights or critical data perspective an initiative or phenomenon relating to growing availability and use of data in urban areas in the global South. 
From 73 submitted proposals, we selected nine for development; taking these through iterative rounds of discussion and revision. The papers were presented at an international workshop held in Manchester in 2019, alongside a foundational case study paper on urban data justice that had served as a conceptual reference point for a number of the case studies. In total, then, ten case studies are presented in this collection; each of which has previously been published separately in this working paper series:

1. An Applied Data Justice Framework: Analysing Datafication and Marginalised Communities in Cities of the Global South (Richard Heeks and Satyarupa Shekhar). This presents a systematic data justice framework and uses it to analyse the impact of community mapping in four global South cities, with a particular focus on inequality.

2. Visual Data Justice? Datafication of Urban Informality in South Africa Using $\mathbf{3 6 0 ^ { \circ }}$ Imaging Technologies (Jonathan Cinnamon). This analyses the possibilities and limitations of $360^{\circ}$ geovisual imaging of urban informal settlements; identifying an emerging research agenda on visual data justice.

3. Spatial/Data Justice: Mapping and Digitised Strolling against Moral Police in Iran (Azadeh Akbari). This scrutinises the intersection of data and spatial injustice in Iranian cities; looking at data initiatives both of the state and of citizen counter-surveillance.

4. Urban Slums in a Datafying Milieu: Challenges for Data-Driven Research Practice (Bijal Brahmbhatt, Siraz Hirani, Neha Lal \& Bhumika Chauhan). This reviews on-the-ground experience of data-related projects in Indian slum communities, highlighting emergent issues including data accuracy and ownership.

5. Data Justice through the Prism of Information Politics and Resource Injustice: A Case Study from Hyderabad's Urban Frontier (Loraine Kennedy, Ashima Sood, Debdatta Chakraborty \& Ram Mohan Chitta). This examines enumeration and community mapping exercises in a low-income neighbourhood in Hyderabad; exposing the associated politics of distribution of information resources, risks and rewards.

6. Aadhaar-Led Identification and Datafication Among Informal Workers in South India: A Data-Justice Perspective (Shyam Krishna). This uses the notion of 'abnormal justice' to analyse how Aadhaar - India's digital identity programme - is experienced by informal workers in urban settings, and how it impacts current inequalities.

7. Data Gathering and Justice in the Urban Informal Sector: Views from the Frontline (Terry Gibson). This analyses a sequence of large-scale participatory data gathering programmes focused on urban disaster reduction; highlighting the impact of power structures on the knowledge created.

8. Capturing Gender and Class Inequities: The CCTVisation of Delhi (Aayush Rathi \& Ambika Tandon). This analyses roll-out of CCTV in Delhi, demonstrating how the experience of surveillance is intersectionally mediated along the axes of class and gender.

9. Community-Based Data Justice: A Model for Data Collection in Informal Urban Settlements (Denisse Albornoz, Katherine Reilly \& Marieliv Flores). This analyses NGOmediated production of data about informal urban settlements in Peru, arguing that such processes may deepen inequalities unless undertaken with greater concern for capability development and collaborative implementation.

10. Making Informal Settlements 'Visible' Through Datafication: A Case Study of Quarry Road West Informal Settlement, Durban, South Africa (Catherine Sutherland, Bahle Mazeka, Sibongile Buthelezi, Duduzile Khumalo and Patrick Martel). This argues that 
data initiatives to make urban informal settlements more visible may not immediately secure tangible improvements but can begin to shift discourses and power relations.

Three messages, among others, stand out. There is increasing resistance to datafication among marginalised urban communities; tired of being enumerated with no obvious benefit. Where data is gathered, it is processes and structures that matter more than the data or technology: shaping and constraining what datafication can achieve, but with evidence of new hopes, imaginaries, relations, etc brought into being. Most successful are initiatives that gather new digital data but combine this with longer-term, qualitative actions that truly listen to the concerns and priorities of these communities.

\section{Future Research Agenda}

Building from the foundational findings of these case studies, what should be the priorities for future research on urban data justice? Group and plenary discussion the international workshop held in Manchester developed a research agenda, as summarised in Figure 1. We look forward to further research - action research particularly - that addresses these and related issues around urban data justice. 


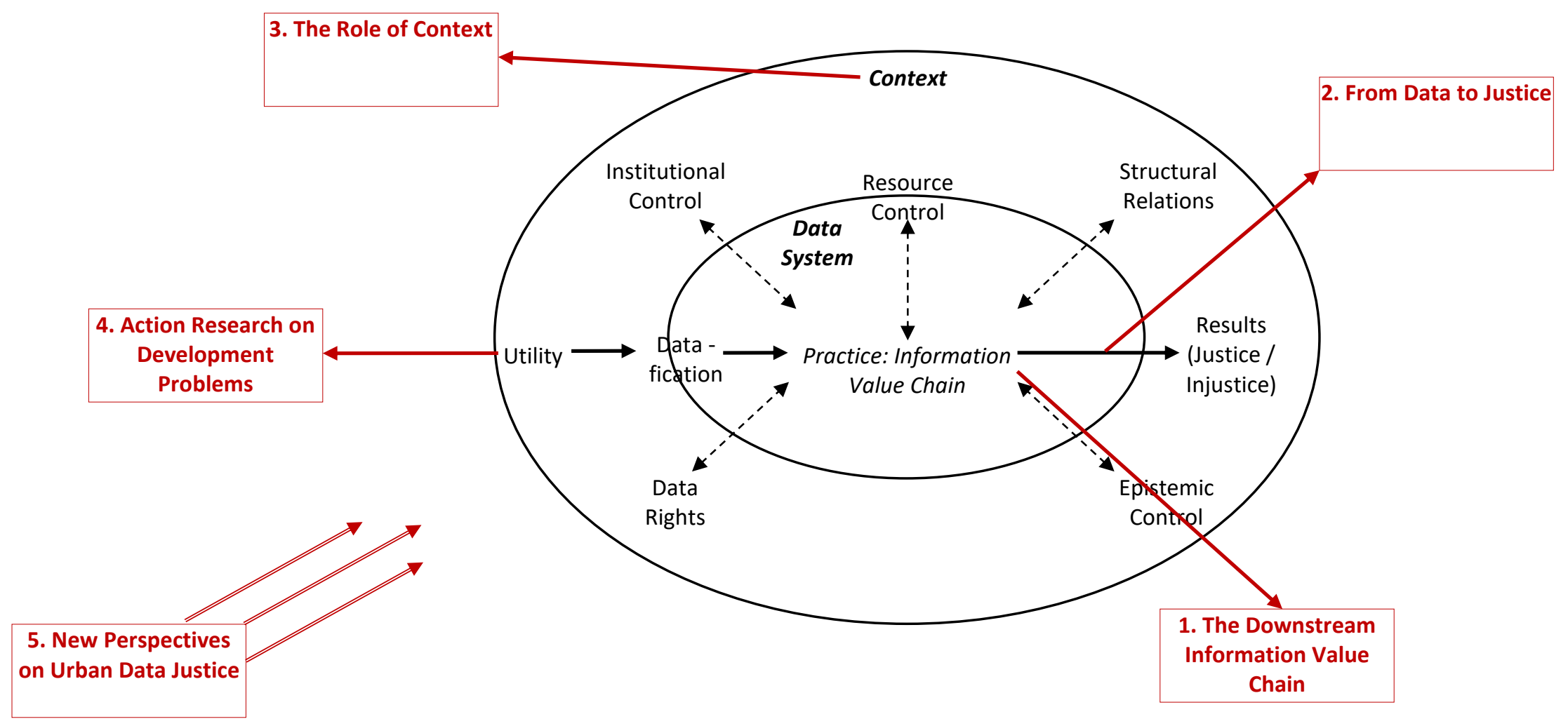

Figure 1: Urban Data Justice Research Agenda 


\section{The Downstream Information Value Chain}

- Data Uptake: to date there has been a lot of focus on the creation and visualisation of data on marginalised groups/communities in global South cities. More research is needed on downstream issues such as data uptake: tracking use of data; identifying barriers to use; understanding the factors shaping data needs and use of urban decision-makers.

- Engaging New Urban Data: urban decision-makers are often resistant to community mapping/survey data. Such resistance often has broader political and institutional foundations, but what new forms of data might engage them: images (if so what type); audio-visual; oral histories; auto-collected from sensors, mobiles, remote sensing, etc?

\section{From Data to Justice}

- Impact of Data: what subjective and objective development impacts does new urban data have? Cui bono: who wins and who loses from new urban data?

- Theory of Change: what is our theory of change to move from data to social justice? How exactly do we get from new urban data to ... greater inequality; fewer evictions; fewer persecutions; etc?

- Differentiating Data: how do the affordances of data link to concepts of justice? How do different types of data link differently to justice?

- Scaling and Sustaining: many pro-equity data initiatives have been constrained in scope:

e.g. pilots or restricted to a single slum area. We need to understand how best to scale and sustain these initiatives.

- Promoting Small Data/"Scaling Down": how can data gathered from or about marginalised urban groups/communities be effectively used by these groups/communities?

- Data Justice Agents: who are "data justice champions" driving forward pro-equity data initiatives and what do they do? How do other actors enable and constrain achievement of just outcomes from new urban data systems?

- Data-Enabled Authoritarianism: data justice overall has tended to focus attention on data uses in democratic contexts. An arguable greater threat is use in authoritarian contexts and for authoritarian purposes. How are these spreading in global South cities? How can they be resisted?

\section{The Role of Context}

A continuous finding was the way in which context shapes the trajectory and impact of urban data systems in the global South:

- The Role of Data Markets: urban data increasingly cascades into or creates data markets both commercial markets (e.g. monetisation of data by private firms) and social markets (e.g. competitive use of data by NGOs). What is the role and development impact of these markets? How are these markets shaped?

- The Political Economy of Urban Data: how, specifically, do urban contexts of power and interests shape the outcomes of new urban data flows and pro-equity data initiatives? How best should we seek to govern urban data to ensure just outcomes?

- The New Urban Data Intermediaries: new data intermediaries - actors that own and control data about marginalised groups/communities and intermediate from these sources to other urban actors - are emerging in private, public and NGO sectors. Who are they? What role do they play? 


\section{Action Research on Development Problems}

Research can be driven from the key development problems that impact the lives of marginalised groups/communities in global South cities. Recurrent themes include:

- Invisibility: how to navigate the ambivalence of legibility and enable just representation that does not open up groups/communities to external exploitative agendas?

- Gender Inequality: how can urban data system design, processes and uses ensure reduction rather than reproduction of gender inequalities?

- Flooding: how can new ground-level and remote data be effectively utilised for flood response, recovery, mitigation and preparation?

\section{New Perspectives on Urban Data Justice}

- What's New About Digital Data: what is new about the current wave of digitally-enabled data? What lessons and results are familiar from community mapping, surveillance, information systems, etc. studies; and what is novel? Can digital data be disruptive and transformative in a pro-equity way?

- What's New About Data Justice: again, what lessons and results are familiar from community mapping, surveillance, information systems, etc. studies; and what is novel? Can data justice be fruitfully combined with existing perspectives: feminist studies, urban geography, infrastructure studies, etc?

- Governing the Algorithm: how can we govern urban data systems in which guiding principles and decisions are increasingly invisible? 


\title{
Case 1: An Applied Data Justice Framework Analysing Datafication and Marginalised Communities in Cities of the Global South
}

\author{
Richard Heeks \\ Centre for Development \\ Informatics, University of \\ Manchester, UK
}

\&

\author{
Satyarupa Shekhar \\ Citizen Consumer and Civic \\ Action Group, Chennai, \\ India
}

\begin{abstract}
Rapid recent growth in the role of data within international development has meant analysis of this phenomenon has been lagging; particularly, analysis of broader impacts of real-world initiatives. Addressing this gap through a focus on data's increasing presence in urban development, this paper makes two contributions. First - drawing from the emerging literature on "data justice" - it presents an explicit, systematic and comprehensive new framework that can be used for analysis of datafication. Second, it applies the framework to four initiatives in cities of the global South that capture and visualise new data about marginalised communities: residents living in slums and other informal settlements. Analysing across procedural, rights, instrumental and structural dimensions, it finds these initiatives deliver real incremental gains for their target communities. But it is external actors and wealthier communities that gain more; thus increasing relative inequality.
\end{abstract}




\section{A. Introduction}

Datafication - the presence, use and impact of data in social processes - is a growing phenomenon worldwide, including in the domain of international development (Taylor \& Broeders 2015). This growth has seen both hopes and concerns for the developmental impact of new data streams (Spratt \& Baker 2015). But, because of the novelty of the phenomenon, writing has sometimes had to be based on overviews or extrapolations from pilot projects or experiences in the global North (ibid., Lokanathan 2017). There have been relatively few analyses to date of real-world initiatives, and the field is still assessing analytical approaches to use (Sengupta et al 2017).

This paper thus aims to do two things. First, to introduce a conceptual framework drawn from the sub-field of data justice that can be used for analysis of data initiatives. Second, to utilise that framework to analyse a set of data initiatives within the domain of urban development; in particular seeking to understand the full breadth of impact of such initiatives on those who are already marginalised within the physical city.

There follows next a review of datafication, particularly in relation to urban development, and presentation of the data justice analytical framework. Then the methods used for this paper - study of urban data initiatives in Chennai, Nairobi, Pune and Solo through primary and secondary sources - are explained. Findings and conclusions follow. 


\section{B. Datafication, (Urban) Development and Data Justice}

Data has always been part of international development as it - or at least its processed and utilised form, information - is essential and integral to all decisions, including developmentrelated decisions. But the advent of digital technologies and their significant diffusion in developing countries during the $21^{\text {st }}$ century have led to a step change. The increasing datafication of development can be described in terms of a growing volume, velocity, variety and visibility of data (Heeks 2018). This increasing presence of data within development is part-encouraging, part-driven-by greater use of new forms and streams of data in decision-making; in turn leading to emergent developmental impacts associated with this datafication (ibid.).

This broader picture is instantiated in the various development domains, including the particular focus here: urban development, with the expanding role and importance of data recognised within the New Urban Agenda that is intended to guide future development (UN-Habitat 2017). New forms and flows of data are especially associated with growth of the "smart city" agenda in the global South (Shekhar 2016) and with the affordances of digital technologies: mapping cities by remote sensing, gathering environmental and other data via ground-based sensors, creation of "data twins" of urban areas such as mobility maps created by tracking mobile phone use (Lokanathan et al 2016, Willis 2017).

These initiatives come with much promise around the benefits they will bring to urban planning and development; improving its efficiency by enabling decisions and results to occur more quickly and/or more cheaply; and improving its effectiveness by enabling better decisions and results: better-informed, more objective, more transparent, better-able to meet citizens' needs (van Veenstra et al 2014, Samarajiva et al 2015). But alongside this have been concerns about datafication of the city (Townsend 2013, Kitchin 2014, Taylor \& Richter 2015, Baud 2016): procedurally that initiatives are not being implemented right; instrumentally that the promised results are not being achieved; and critically that there are problematic distributive impacts. Main critical concerns are that urban datafication is associated with growing inequality; especially, in developing countries, with the exclusion or adverse incorporation of those already marginalised within the physical city, such as those living in slums and other forms of informal settlement (Donovan 2012, Pfeffer \& Verrest 2016).

Given the extent of urban inequality - 30\% of the urban population in developing countries lives in slums (UN-Habitat 2016) - and the history of this population being excluded from or marginalised by new initiatives, some development actors have begun what we may call pro-equity data initiatives (PEDIs). Though coming with other labels attached, an essence of these activities has been creation of new dataflows and datasets by and/or about and/or for slum communities. Examples include community wi-fi that enables new dataflows within, into and out of slum communities; open data / right-to-information that enables new dataflows into slum communities; and community mapping that creates new datasets about slum communities (Chakraborty et al 2015, Willis 2017).

But how should these (and other) data initiatives be understood and evaluated, given recent recognition of a lack of evaluative frameworks to analyse datafication and development 
(Hagen 2017, Sengupta et al 2017)? One approach would follow descriptors used for the datafication concerns expressed above: "injustice" (Townsend 2013), "ethical concerns" (Kitchin 2014), "ethical challenges" (Taylor \& Richter 2015). This would suggest analysis using ideas within the emerging literature on "data justice": "the specification and pursuit of ethical standards for data-related resources, processes and structures" (Heeks 2017a); a small body of work within critical data studies echoing our specific interests around equity.

This has been conceptualised from a capabilities perspective (Taylor 2017, Heeks \& Renken 2018) but we wanted to take a broader view of data justice that specifically encompassed three things highlighted in recent literature. First, the concerns about urban datafication expressed earlier: procedural, instrumental, critical. Second, a specific focus on data and data praxis and data rights given the understanding from critical data studies that any social injustices may relate more to forms and flows and use of data than to specifics of the technologies that carry and process and display that data (Taylor \& Broeders 2015, Neff et al 2017). Third, the argument of other critical data studies literature that broader social structure must be incorporated into any analysis because of its role in shaping data-related outcomes (Dalton \& Thatcher 2014, Kitchin \& Lauriault 2018).

The model developed from these principles is summarised in Figure 1 (adapted from Heeks $2017 b$, which should be referred to for further details of its development) and examines five dimensions of data justice:

- Procedural: fairness in the way in which data is handled. This handling is understood in terms of the information value chain: the steps by which data is transformed into developmental results (see Figure 2).

- Instrumental: fairness in the results of data being used.

- Rights-based: adherence to basic data rights such as representation, privacy, access and ownership.

- Structural: the degree to which the interests and power in wider society support fair outcomes in other forms of data justice.

- Distributive: an overarching dimension relating to the (in)equality of data-related outcomes that can be applied to each of the other dimensions of data justice. 


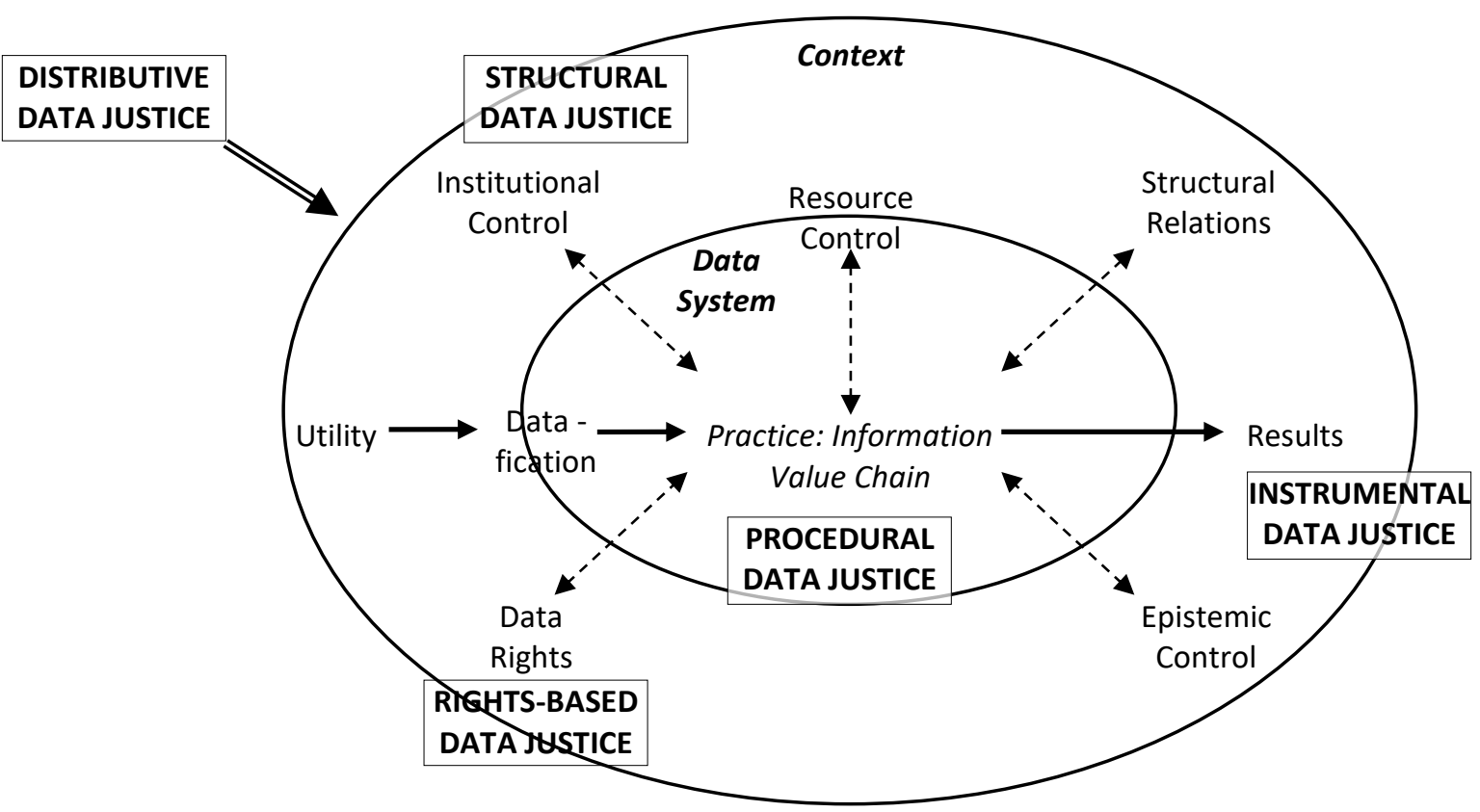

Figure 1: Conceptual Model of Data Justice (adapted from Heeks 2017b)

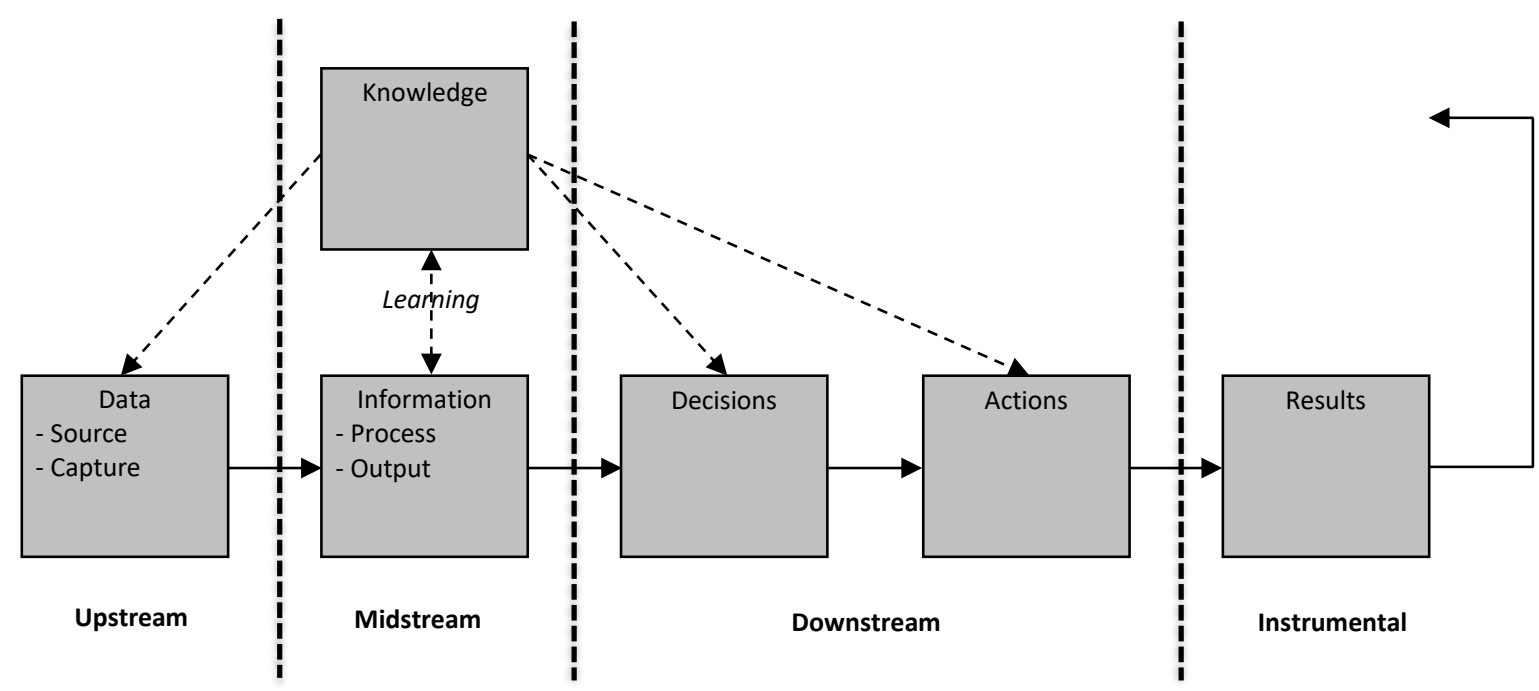

Figure 2: The Information Value Chain (adapted from Heeks 2017b) ${ }^{1}$

Further explanation of the two models will follow below through their use as analytical frameworks for evaluation of four urban PEDIs, following an outline of the initiatives and methods used for evidence-gathering.

\footnotetext{
${ }^{1}$ Knowledge links to all steps of the chain and therefore is not associated with any individual stage: up-, midor downstream.
} 


\section{C. Case Background and Methods}

Among the possible types of pro-equity data initiative, we chose those involving community mapping, which aims to counter the relative invisibility of (i.e. lack of data about) marginalised communities by gathering, visualising and utilising new data on locations, assets and issues within those communities. Mapping was chosen because it is quite wellestablished and widespread as a PEDI in cities of the global South (Patel \& Baptist 2012, Panek \& Sobotova 2015). While the analysis here speaks to broader trends of datafication, this means there is a ready direct literature and constituency of relevance.

The four initiatives chosen for analysis are:

- Map Kibera (MK): begun in 2009 by two Americans, this used local young people to gather data on Kibera, a slum roughly estimated at 250,000 people located in SouthWest Nairobi, and then mapped that data. Via creation of social enterprise GroundTruth Initiative, expertise from Kibera has subsequently been applied to other slum areas in Africa and the Middle East.

- Our Pune Our Budget (OPOB): begun in 2006 by local NGO, the Centre for Environment Education (CEE), this sought to bring greater objectivity and fairness into the city's budgeting process, as a foundation for which, it organised a city-wide data-gathering and mapping exercise.

- Solo Kota Kita (SKK): begun in 2010 Kota Kita is an Indonesian NGO based in the city of Solo (official name, Surakarta). Its Solo Kota Kita project sought to enable citizen participation in the participatory budgeting process initiated by mayor (currently Indonesian President) Joko Widodo. It did this by gathering and mapping data across all city neighbourhoods. Kota Kita has subsequently rolled out its methodology to other cities across Asia.

- Transparent Chennai (TC): begun in 2009, this involved a series of projects to gather and map data on issues within the city's marginalised communities including lack of public services, homelessness, and informal livelihoods (specifically of waste-pickers). In 2014, Transparent Chennai was rolled into a wider initiative, the Transparent Cities Network housed in local NGO Citizen Consumer and Civic Action Group - that focuses on data and the urban poor.

These were chosen because they were relatively long-standing PEDIs ${ }^{2}$, which - unlike many initiatives - moved well beyond pilot stage; because there existed some secondary literature for each; and because they operated in cities with substantial slum populations: $50 \%$ of the city population in the case of Nairobi (Kovacic \& Lundine 2013), $40 \%$ in Pune (Jobst \& Malherbe 2017), at least $8 \%$ in Solo (Obermayr 2017), and $28 \%$ in Chennai (Krishnamurthy \& Desouza 2015).

The findings below are drawn from four sources which were combined and then analysed through the thematic lens of the data justice model presented above. First, nine interviews

\footnotetext{
${ }^{2} \mathrm{MK}, \mathrm{OPOB}$ and TC are 'targeted' pro-equity initiatives that specifically sought to reduce marginalisation of slum communities; though in OPOB's case this was seen to require city-wide data. SKK is an 'inclusive' proequity initiative in seeking to ensure those in informal housing were included within a wider pro-equity goal of "levelling the playing field" between citizens and government so that citizens could shape urban budgeting decisions.
} 
with senior figures in the data intermediary organisations (MK, CEE, SKK, TC) associated with each of the four projects, structured around the concepts of data justice ${ }^{3}$. Second, evaluation documents from the projects which are reflective, to some degree self-critical, and sometimes themselves based on primary fieldwork (e.g. Menon 2013, Padmanabhan et al 2013, Rifai et al 2016, Hagen 2017). Third, independent secondary sources of research specifically on these projects, most of which are based on primary fieldwork (e.g. Berdou 2011, Grillos 2017, Jobst \& Malherbe 2017). Fourth, broader independent sources that incorporate analysis of these projects among a number of others (e.g. Donovan 2012, Haklay 2013, Shkabatur 2014, Baud 2016).

\section{C1. Background: Data Injustice and its Consequences}

Before analysing the cases in terms of data justice, we first outline the rationale behind the initiatives: the data injustices and consequences thereof which obtained prior to the PEDIs being undertaken.

The communities studied suffer a range of injustices but of specific attention here was the data rights injustice relating to representation: that the physical marginalisation of these communities was mirrored by a virtual marginalisation within urban datasets. The communities were invisible or poorly visible: not merely that the areas themselves were unmapped as locations but that data on the assets, services, voices and livelihoods of citizen were absent (iMK1b, iOPOB2, iSKK). Data had sometimes been gathered - by NGOs and academics in Kibera, by government in Chennai and Pune - but it fell short on the five "OCARA" measures of data quality: openness, completeness, accuracy, relevance, appropriateness of presentation (Heeks 2018). Data on slums was generally treated as proprietary, and was inaccessible to the community or to other organisations (iMK2, iTC1, Shekhar \& Padmanabhan 2015). Where it might be accessed, the data covered only part of the settlement, or was many years out-of-date, or was held on paper forms and records scattered across many different government departments (iOPOB2, iTC2, Shekhar \& Padmanabhan 2015).

This marginalisation within the data twin of the city - an inequality compared to the better representation of more prosperous and formalised settlements (iTC2, Patel \& Baptist 2012) - underpinned infrastructural and political marginalisation. The lack and poor quality of slum data "directly results in poor planning and maintenance of public infrastructure, and poor provision of public services" (Shekhar \& Padmanabhan 2015:3); for instance, with lack of data on concentrations of population leading new toilets in Chennai to be planned and placed where government had available, accessible land rather than where they were needed (iTC3), or with water points in Kibera poorly maintained due to lack of data on their functioning (iMK1b), and with every type of public service - water, sanitation, roads, lighting, health, education, policing, etc - provided to a very limited degree or poorly provided or simply not provided at all, in part due to lack of data about locations, needs, existing infrastructure, etc (iMK1a, iOPOB1, iSKK, iTC3).

\footnotetext{
${ }^{3}$ These will be referred to below as iMK1a, iMK1b, iMK2, iOPOB1, iOPOB2, iSKK, iTC1, iTC2 and iTC3.
} 
Lack of data also marginalised communities politically, ceding and skewing power within decision-making and service provision to political elites and their interests. With data on neither what the community already had nor on what it needed, there was no basis for engagement with urban planning decisions, nor a basis to challenge the decisions already being made, leading to political exclusion (iOPOB2, iTC2). Those who are data-less in the city - the slum dwellers, the homeless, the waste pickers - could be treated much worse than other citizens - subject to police raids or evictions - with few consequences for those guiding these actions (iTC2, iTC3, Otiso 2002, Padmanabhan et al 2013). Likewise there was a lack of political accountability around provision of public services given the absence of data on provision decisions or on provision itself (iTC1, Menon 2013, Feruglio \& Rifai 2017).

\section{D. Findings}

As per the model shown in Figure 1, the findings here will be presented in terms of each of the dimensions of data justice in turn, with distributive data justice considered in the final section.

\section{D1. Procedural Data Justice}

Because of the sampling or transect approaches used, only a minority of community members could be direct respondents within the four projects. In only one case - Map Kibera - were community members used to capture data (iMK1b). In other cases, data capture was undertaken by students (in Solo and Pune and one Chennai project) or by NGO or local government staff in the other Chennai projects (iOPOB2, iSKK, iTC1, iTC2, iTC3). The young people employed from Kibera were able to upload the data captured on their GPS devices but in this and in all other cases, the "midstream" (see Figure 2) activities of recording data onto a geographic information system, processing it, and visualising - for example printing out as a paper-based map - were generally undertaken by voluntary or paid professionals from outside the community (iMK2, iOPOB2, iSKK, iTC1, Hagen 2011).

The data produced by PEDIs is not always used: sometimes data is gathered without downstream information value chain processes existing that could feed that data into decisions and actions (iMK1b, Shkabatur 2014, Hagen 2017); sometimes those processes exist but they are not accessible, such as government decisions about urban planning or service delivery or evictions for which data from the community is not wanted, or for which officials are unaware of data being available (iOPOB1, iSKK). It may also be used only indirectly: as part of general advocacy, such as pressure on government by NGOs or local media for slum improvements (iOPOB2, iSKK, iTC1).

Where data was directly used, those involved in downstream processes might either be within or outside the community. For the latter, impact was understood mainly in terms of visibility and results, discussed below. Regarding the former then, for the Pune and Transparent Chennai initiatives, it was not the intention that data would be used by the community. For Map Kibera, this was an aspiration but one that was not realised (iMK1a). In all these cases, then, any tracked use of community data was by organisations outside the 
community. In Solo, data was fed back to communities in the form of a "mini-atlas" (see Figure 3; a translation of the actual map provided in Bahasa Indonesia). This was present in community meetings held as part of the overall process of participatory budgeting in the city. However, the minority of informal settlements and poorer residents in each neighbourhood plus time, confidence, literacy and other barriers to participation of the poor meant any use of the data for prioritisation decisions was dominated by richer residents (iSKK, Grillos 2017). And these meetings were in any case only the first in a chain of budget decisions that were taken outside the community.

In general then, although all of these were intended as pro-equity data initiatives that would counteract the marginalisation of informal settlements, they were somewhat "extractive" in utilising some community residents as data sources but largely excluding them from all other information value chain processes. Exclusion from up-and midstream processes tended to be on instrumental grounds that they lacked skills or motivation and/or that mapping had to meet a short time-scale. Exclusion from downstream processes tended to be for more systemic or political reasons, such as an absence of mechanisms for involving citizens in service provision or urban development decisions. Exceptions only occurred through deliberate efforts of data intermediary organisations; and took quite some effort to achieve.

It would be normal to decry this limited usage and to seek prioritisation of the $180^{\circ}$ approach that extracts data from communities but then feeds it back into those communities so that residents and community-based organisations (CBOs) can improve their decision-making (Sanchez et al 2013). Of course this has merit but Berdou (2011) observes that such prioritisation may be an external imposition. Kiberans themselves prioritised the downstream use of their data not by the community, which may already know itself to some extent, but by outside agencies which do not know the community; believing this was the best way to bring in what they wanted, which was money - via visitors or donor funding or even business investment.

Nor should one ignore the procedural benefits for communities and their members. Indeed, one argument has been that these benefits have tended to be relatively ignored or downplayed compared to the instrumental impact of community data projects (iMK1b, Shkabatur 2014). Even where not directly used for decisions and actions, data has value if fed back into the community e.g. via posters displayed at meetings or on public buildings (Patel \& Baptist 2012, Hagen 2017, Jobst \& Malherbe 2017). There was an interpretive value: giving residents a feeling of pride and of greater legitimacy as citizens. And there was an epistemic value: making residents aware of issues that need addressing, and giving them knowledge of local services they might previously have been unaware of e.g. the nearby presence of a school, clinic, water point, toilet, etc. 


\section{GILINGAN ATLAS}

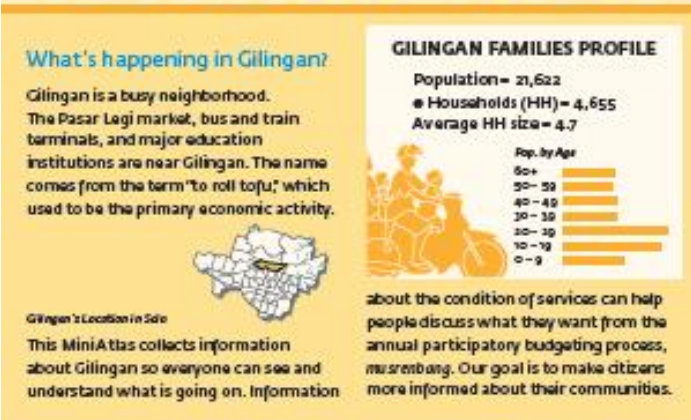

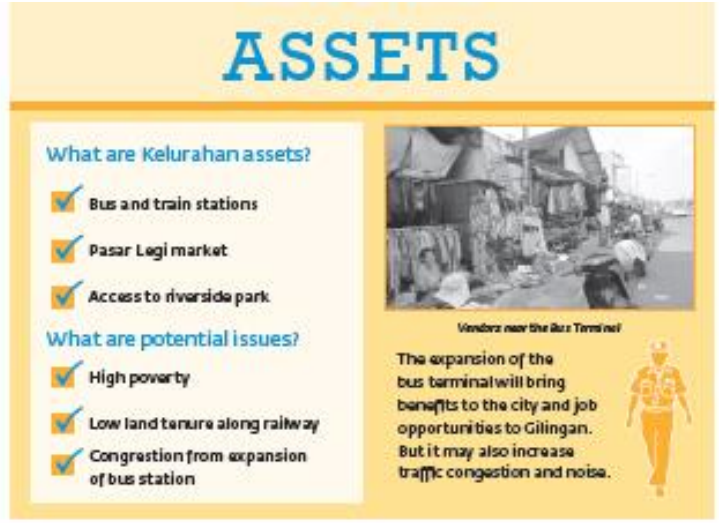

\section{ASSETS}

\section{GILINGAN NEIGHBORHOOD MAP}

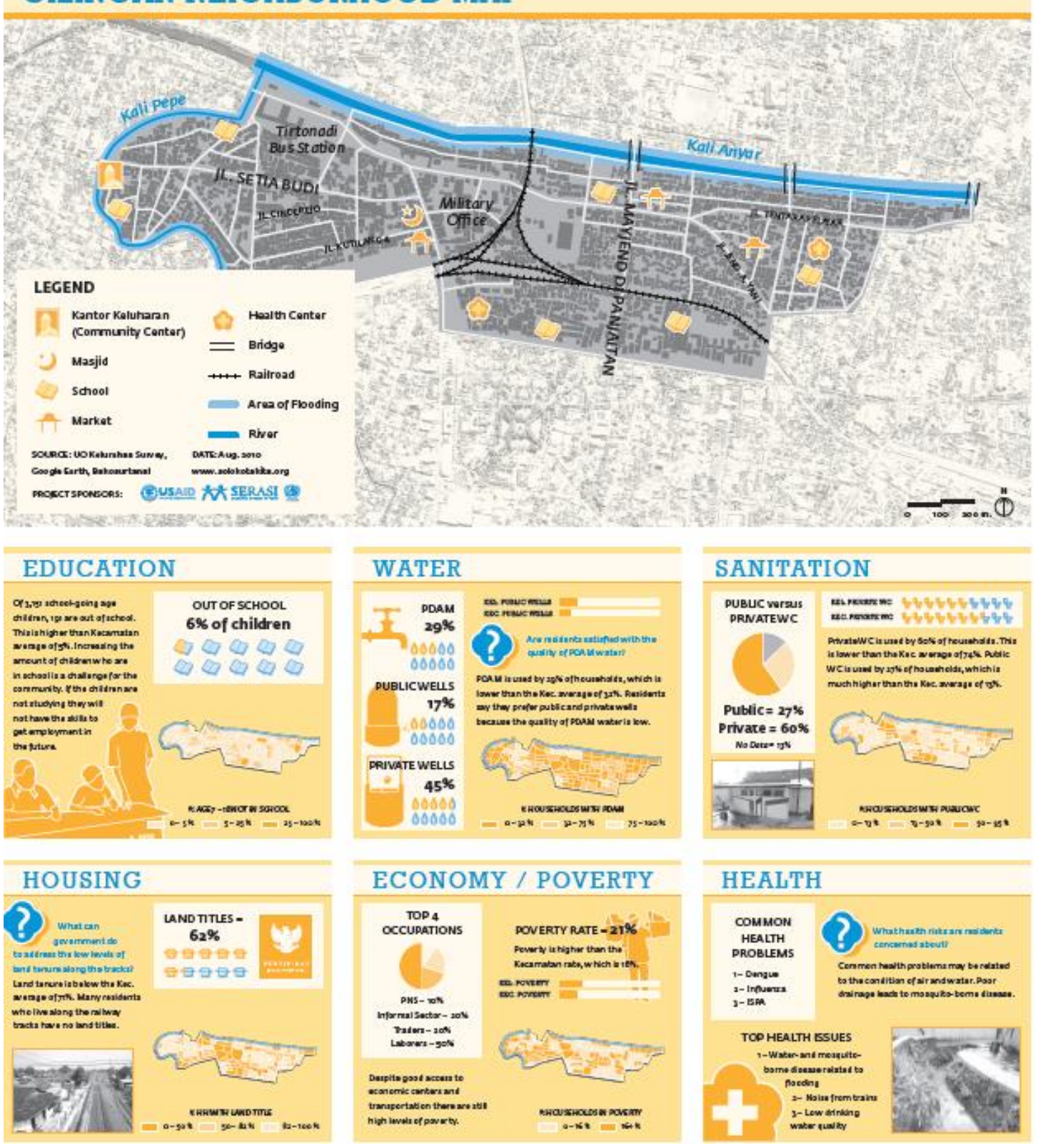

Figure 3: Example Mini-Atlas from Solo Kota Kita (SKK 2010) 
This broad but shallow impact of data capture and dissemination ran alongside reports of deeper but much narrower impacts on those who were gathering the data. They gained human capital in the form of technical skills and confidence and greater knowledge of the community, and social capital - both quantum of connections and qualitative gains of greater trust - in the form of a network of contacts in the community, intermediary organisation and more widely (iMK1b, iTC1, Berdou 2011). But, of course, only in the case of Map Kibera were these gains for community members, and the social capital then only arose due to deliberate efforts to send the Kiberan mappers to academic conferences, tech workshops and so forth (Hagen 2017).

There were other process gains but they always lay outside the community: higher-level technical skills developed by the data professionals involved in midstream activities (iMK2, Haklay 2013), and a combination of human and social capital developed by those within the intermediary organisation involved in using the data for advocacy purposes and in encouraging data-utilising activities by government such as budgeting or other urban planning decisions (iMK1a, iSKK, iTC1). While these external stakeholders continued their relation with the informal settlements, these capital accumulations might be applied on behalf of the community. So, also, for the interpretive impact of data on external stakeholders. This was most often expressed as the changed worldview or "slum imaginary" of government officials; from perceiving Solo residents as passive and ignorant to seeing them as active and knowledgeable (iSKK); from seeing Chennai slums as illegitimate to accepting if not ownership rights than at least rights to basic services (iTC1); from seeing Kibera as asset-poor to asset-richer (iMK1b) ${ }^{4}$.

\section{D2. Rights-Based Data Justice}

Data rights - particularly the right to be fairly represented in datasets and the right to hold some aspects private; but also rights of data access and ownership - were most often discussed in terms of who and what was visible, and to whom.

Informal settlements have been partly-sometimes wholly-invisible within the city; denying them right of representation. All of the PEDIs render these settlements more visible in some way, mapping or otherwise recording their locations, boundaries, buildings, roads, paths; their assets: e.g. clinics, water points, public toilets, schools, businesses, markets, religious buildings, community offices, lighting; and their issues: e.g. health problems, crime hotspots, levels of poverty (iMK1b, iOPOB1, iSKK, iTC1, iTC2, iTC3). An illustrative comparison can be made, for instance, between Kibera's appearance on Google Maps and on OpenStreetMap; the latter used to record some of Map Kibera's data (see Figure 4).

\footnotetext{
${ }^{4}$ Hagen (2017) cites the example of the District Education Officer expecting there to be around 100 schools in Kibera where the data mapped from the community showed her that there were more than 330.
} 

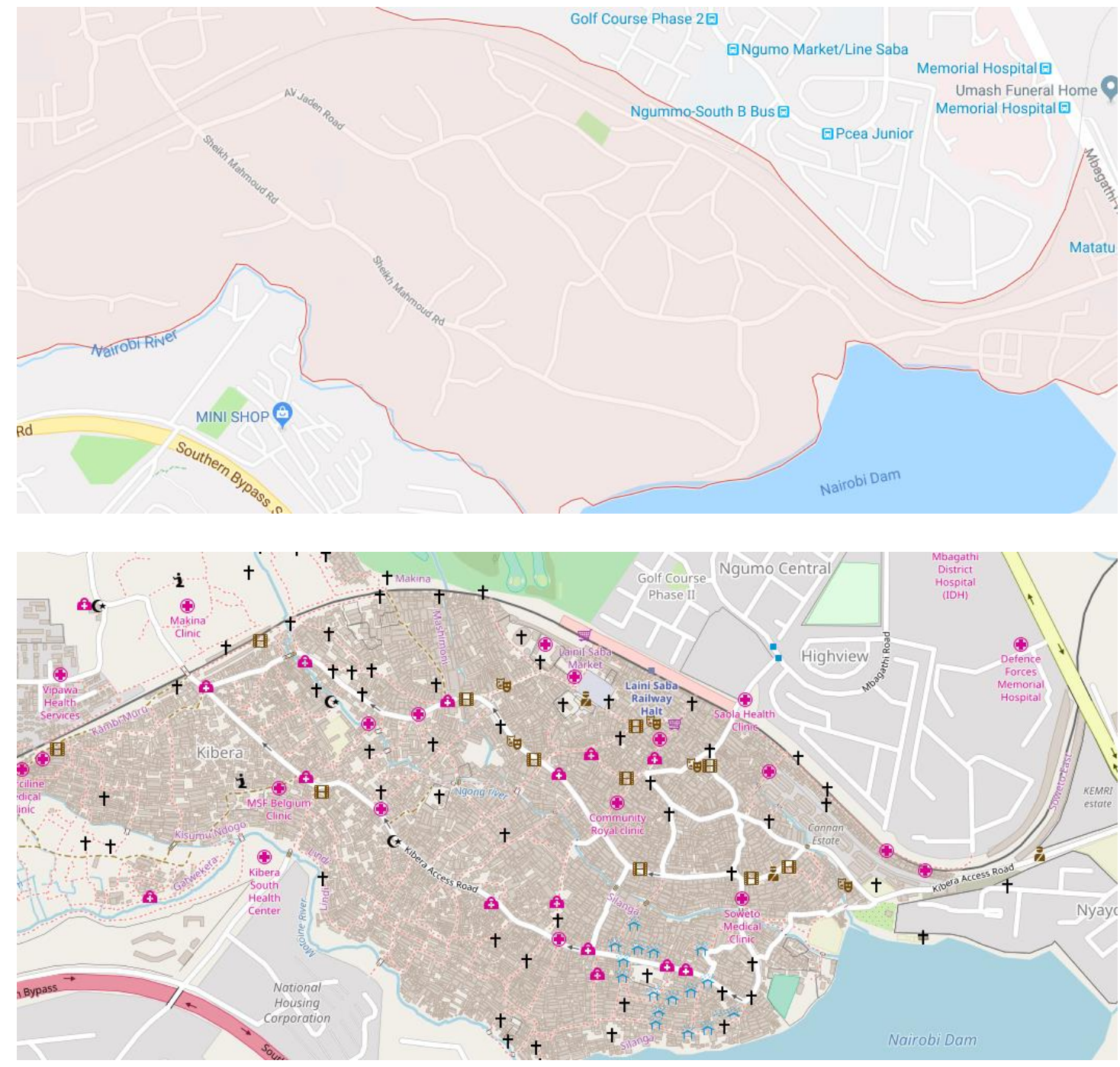

Figure 4: Visible Slums: Google Street Map (top) vs. OpenStreetMap (bottom) views of Kibera

Right of access to these digital representations of the community was skewed. Although growing over time, absence or high cost of mobile let alone fixed-line internet was notable in the communities. As a result, they had to access data in paper-based form; which is more limited in utility (iMK2, iSKK). For external stakeholders, digital access was much easier.

This external visibility - an exercised right to more accurate representation - brought with it various perceived values. As noted above, there were changed perceptions of slums, and some resident felt this gave them some type of legitimacy and would offer them protection, for example from eviction (Padmanabhan et al 2013, Hagen 2017). This wider visibility even impacted some government officials where they felt that open availability of data via the web might attract national or even international attention to their actions (Kovacic \& Lundine 2013). And, as discussed in the next section, there was a perceived instrumental value: the more complete, accurate and objective data now available was seen as the basis to replace or to challenge past decision-making processes that were variously regarded as non-existent and/or of poor quality and/or driven by the politics of external stakeholder interests (iMK1b, iOPOB2, iSKK, iTC2). 
But this external visibility draws in Scott's (1998) notion of legibility: the process by which states simplify and standardise data about their citizens in order to control them. Legibility disrupts local control over data and knowledge, undermining the power and the value of local understandings within slums (Donovan 2012, Sanchez et al 2013). When data is owned and held within the local community, there is local control; no doubt skewed and imperfect but localised nonetheless. As data becomes more widely circulated - up to the point where web-based digital forms are available to anyone, anywhere with internet connectivity - that local control is lost. These slum areas - all of which now exist virtually in some form of webbased map - are now legible not just to the state but to local and international NGOs, donor agencies, media organisations, academics (iMK1b, iSKK); all of whom can know the slum to some extent and make decisions and actions using data about the slum without the permission or even the knowledge of anyone living there. The right to be represented can thus mean that the right to own and control is ceded to these external agents and to their particular interests and agendas, benevolent or otherwise.

This loss of control and histories of data extraction to the benefit of others but not the community have led to resistance to data capture; with rights to privacy being asserted. Residents in Kibera were often antagonistic to data being captured by video after years of NGOs, movie-makers, tourists, media organisations coming to the area, and making it visible to external audiences for their own rather than the residents' advantage (Hagen 2011, Benequista 2015). Some businesses - schools, pharmacies - in Kibera did not wish to be mapped, fearing their visibility to the state might lead to closure if their location became known and their informal status or activities (e.g. sales of stolen drugs) were then discovered (Berdou 2011). Particular settlements in Chennai refused to participate in datagathering as they believed drawing attention to their existence and informal status - being under the "gaze of the state" - would increase the likelihood of eviction (iTC1). Transparent Chennai itself had concerns about this - for example, capturing data on issues facing informal waste-pickers in the city but not their location or legal status, in order to protect them from state action (iTC3). If given a choice (which many were not) most slum dwellers had expressed primacy of their right of representation: to be incorporated into urban datasets. But for some this was seen to be in tension with their right to privacy, and for a few who wished to fly under the state's radar the latter was dominant.

While varying across projects, local residents could sometimes shape the balance between rights of representation and privacy, making an input to determination of what data should be captured and, hence conversely, what remained invisible. More broadly, there should be recognition of who and what remain invisible, without a realised right to representation. Transient populations (e.g. labourers or street sellers who come daily into the city to make a living but then leave), the homeless ${ }^{5}$ and in some cases those without legal citizenship were excluded from data gathering and hence from representation (Feruglio \& Rifai 2017). Qualitative data was lost: what is captured is simplified and deracinated, stripping away the local meanings and histories and relations and all other aspects of local knowledge into which data is always embedded, leaving knowledge-less data that is mobile and readily inserted into external contexts and processes (Hagen 2011).

\footnotetext{
${ }^{5}$ Save one Transparent Chennai project specifically mapping homelessness (iTC1).
} 
If we look at urban decisions, then data can be provided about four elements: background, priorities, process and results. Background data - location, assets, etc - about slum communities was universally provided. The needs and priorities of those communities were sometimes made visible and sometimes not. But other aspects often stayed invisible with community members being granted no right to access: the process by which decisions were made e.g. by government officials; the final decisions; and the extent of implementation of those decisions. As a result, community members were unable to either participate in or monitor the decisions being made about them unless the data intermediary organisations undertook specific actions to counteract this (iTC2, Menon 2013, Feruglio \& Rifai 2017).

Finally, we observed what may be called "spotlight and shadow": by rendering some issues more visible, others can be rendered relatively more invisible. This was most notable in the Transparent Chennai case where TC itself and other groups had collected and published data about the resettlement tenement blocks into which some slum residents had been moved following eviction. They saw some limited improvements in those blocks but that this data activity "would also legitimise or validate these tenements and the approach of the government to evict slum dwellers and resettle them in far-flung, poor quality tenements" (iTC1). By highlighting the tenements, data-gathering was seen to adumbrate the eviction process and to encourage an increased rate of tenement building and eviction in the city: representation of one group and issue thus 'unrepresenting' another group and issue. As a result, TC had stopped gathering this type of data.

\section{D3. Instrumental Data Justice}

The evidence available is of relatively few results arising from direct decisions and actions by community residents and community-based organisations. These results likely exist residents using a school or clinic they were previously unaware of; residents attending a community meeting having seen a map of issues - but they were not captured. This reflects the more general point noted above. Users of the open data twin of communities whether on a public poster or loaded onto a web site - and any resulting actions within the community are untraceable unless they contact or otherwise come to the attention of data intermediaries (Hagen 2017).

In all four cases, government was a downstream presence. Systematic tracking of the value chain through to results seemed, unfortunately, to be rather rare; let alone independent verification. Evidence was thus based more on anecdotes and claims than one would have wished, and more on decisions such as plans than on implemented actions:

- Gathered data - in the form of community "mini-atlases" - was fed into community decision making to set priorities for spending of devolved budgets in Solo. The actual use of the data as information for prioritisation appears to have been somewhat limited (iSKK). Rifai et al (2016:63) describe this process as "challenging", in part because it is management committees that then make final decisions on which projects will be funded. While the end result is community development projects, the link to data is unclear, and analysis shows spending to flow disproportionately to the least-poor areas (Grillos 2017). 
- Community data was used in Pune as the basis to set an objective, needs-based budget that took account of the prevalence of poverty and inadequate housing across the city. Unfortunately that budget was then "unset" by local politicians (iOPOB1). Slum areas did see some investment but there was a skew towards middle-class issues (e.g. road building/improvement) and areas: $40 \%$ of Pune's population lives in slums but only $10 \%$ of the budget was allocated for slum improvement (Menon 2013).

- Data from Map Kibera was used to improve government resource flows into Kibera schools, including involvement of informal school teachers in government-run activities such as a teachers' retreat (Hagen 2017). But the resource flow was, as expected, mainly to the $25 \%$ of schools that were government-run, while the extent and sustainability of wider results was unclear.

- Transparent Chennai engaged more with government from the start of the project but the reported outcomes were rather circumscribed: the city built 15 homeless shelters not the 75 that the data had shown to be required (iTC1), or laid on a ceremony to present a few waste-pickers with entry cards to the local waste site, but not the ID cards they had been seeking (iTC2).

Other uses were also limited, and examples only given for Kibera: of international development agencies and NGOs using the data for improved planning of education resource flows, or for siting of water and sanitation facilities (iMK1b, Hagen 2017). These and the government usage descriptions highlight an issue raised by interviewees: that the upstream activity of data gathering and processing and visualisation is fairly quick, easy and "clean" in terms of local politics; but ensuring downstream use of the data let alone actual results is much more difficult, time-consuming, costly and "dirty" (iMK1a, iSKK, iTC1). Data intermediary organisations must identify potential users; build links and trust with them over time, seeking to persuade them of the value of new data; work alongside them during often-protracted and politicised sequences and iterations of decision making; and then not merely monitor results but have the power to act if implementation falls short of plans (iSKK, iTC1, iTC2, Hagen 2011).

\section{D4. Structural Data Justice}

There is evidence of some level of structural determinism in the case studies: of these proequity initiatives to still reflect structural inequalities, and for data to flow along the faultlines of power in society.

A consistent theme across all initiatives was that operation of the full information value chain depended on whether or not the data had utility for powerful local actors; particularly those in local government. In Solo, the mini-atlases became an officially-mandated part of participatory budgeting because Mayor Widodo wanted his urban development innovations to work (iSKK, Bunnell et al 2013). By contrast, government officials in Pune were resistant to the participatory budgeting process, making it much harder for new data to be utilised (iOPOB1, Jobst \& Malherbe 2017).

In relation to institutional forces, formal control of urban development decision processes rested with external agencies; particularly local government. Hence, it was their perception of the utility of that data which determined whether or not it would be used, in what 
manner and to what end. Data also flowed according to the topography of trust in the city. Notwithstanding examples of government officials changing their view of the assets and issues in slum areas, they still tended to mistrust those communities (iSKK, iTC3). At best, substantial investment in advocacy and "bridge-building" activities by the data intermediaries was required to enable those officials to use the data provided; but at worst, even this did not stop officials from devaluing data about the community and being reluctant to use it.

All four initiatives were funded to a significant degree by international donors. That control of resources meant the initiatives were shaped by the agenda of those donors, which were for highly-visible, short-term results (iMK2, iTC1, Hagen 2017). This meant activity in all projects was a right-skewed distribution curve with rapid early growth but then tailing off to much lower levels that struggled to sustain (iMK2, iTC1). And it meant an upstreamdownstream disconnect: donors would pay for production of data artefacts, especially physical and digital maps, but were much less interested in paying for the longer-term, lessvisible activity of getting that data used to change urban decisions; in particular, not funding use of data by communities themselves (iMK1b, iOPOB2).

Conversely, the lack of resources among community members - mainly their financial poverty but also lack of knowledge and skills - shaped their engagement with the PEDIs. For many it meant non-engagement because of the opportunity cost that time invested in the project was time lost from earning a livelihood. So people: did not respond to requests for data, did not join in mapping of their community, did not engage in community use of data (Grillos 2017, Hagen 2017, Jobst \& Malherbe 2017). And where they did engage, they brought an instrumental rather altruistic agenda; thus Map Kibera mappers came forward because the work was paid and even volunteer mappers were focused on the skill- and job opportunity-developments the work could offer (iMK1b, Berdou 2011, Lundine et al 2012).

Structural relations were most often understood in terms of the relation between state and citizens. For Map Kibera, the state's monopoly of legitimate violence had shaped data use. They avoided "provocative" uses of data that might antagonise state actors and lead to "vengeance" (iMK1b). For example, they did not gather or use data relating to housing demolitions and evictions. They saw this would potentially lead to protests that would be violently suppressed by the authorities and - reflecting state control over NGOs - lead to Map Kibera Trust being shut down. For Transparent Chennai, the lack of accountability of state institutions to citizens shaped data use. As an example, the local Slum Clearance Board and Water Corporation had no elected representatives, no public hearings, no open reporting policies (iTC1, iTC2). As a result, there were no incentives for them to change their practices and make use of new streams of community data.

Finally, in terms of epistemics, the strength of smart-city discourse shapes outcomes. With its emphasis on data and technology, it drives the idea among funders and other stakeholders that an upstream focus will be sufficient; that the addition of digital technologies into urban processes is enough to deliver urban development (iMK1b, Shekhar 2016). This makes it more difficult to engage funds and actors in the more difficult aspects of downstream processes and socio-political factors. 
On the "input" side, then, there was evidence of structural determinism but looking at the "output" side this was not quite a story of full path dependency. No social structure is stable and, while there was substantial reproduction of the structures of power, datafication had enabled some incremental changes to the architecture of urban development, as discussed next.

Regarding utility, there are always competing agendas and interests in any urban development setting. The new data streams from the PEDIs assist those looking to make more open and/or more objective decisions ${ }^{6}$. Interests in openness were rarely found: it applied only and to only some degree to the mayoralty of Joko Widodo in Solo (Bunnell et al 2013). There were more interests in objectivity: an occasional presence in local government in Pune and Chennai; more strongly felt by external development agencies such as UNICEF and GOAL working with Map Kibera (iMK1b, iOPOB1, iTC2, Hagen 2017). And data itself via its advocacy use by data intermediary organisations, local NGOs and local media and/or via concerns that urban decisions were visible to a wider world - could modify the perceived interests of decision-makers, nudging them in a few cases and temporarily towards greater concern for slum residents (iSKK, iTC1, Kovacic \& Lundine 2013).

Institutional change was minor: in formal terms, the only regulatory change was the Solo mini-atlas incorporation; there were no examples of legal recognition of rights to land or even occupancy. In informal terms, there was some trust-building but less between citizens and government direct than between some community members and the data intermediary organisation; and then between the intermediary and some government officials.

Structurally, too, insertion of the data intermediary into the landscape was the most notable feature - acting as that trust-building bridge, translating epistemes and logics, to some degree equalising the power inequalities between citizens and outside agencies (iMK1b, iTC3, Song 2016). But these intermediating relations were contingent: broken off or downgraded, for example, when new government officials came into office (iOPOB1, iTC3). And they were bounded. There were "no-go" areas that were deemed too politicallysensitive, for example if touching on corruption (iTC1, Swain 2012). They could have been the basis for holding state and other actors to account except, as noted, data on actions and results - on the extent to which new infrastructure, services and resources were being delivered into the slums - was not being gathered (iTC2, Menon 2013, Feruglio \& Rifai 2017).

Epistemic change was also bounded. Communities to some extent, and external actors to a greater extent, had better knowledge of these informal settlements. We noted evidence of "slum imaginaries" of some of those external actors changing to a more positive view. But negative images persisted, at least among some local government officials (iTC3, Menon 2013).

Lastly, the key resource change is the availability of data. There were barriers to this flowing to slum residents; having to be converted to a less-valuable analogue (i.e. paper-based) form due to lack of access to digital technologies within slums. Meanwhile, being open and

\footnotetext{
${ }^{6}$ Data is never completely open or neutral or objective, but it is the perception that PEDI data is more open and more objective than previous data that matters here.
} 
digital, it flowed more readily to others outside the community. And as a usable resource, it favoured those with the other resources - skills, knowledge, time, confidence, money necessary to make the value chain operate; resources which the marginalised community lacked. The impact of that use could benefit the community: the data intermediaries empowered to better advocacy on behalf of communities; the international NGOs empowered to planning better interventions. But control and empowerment still resided outside the community. In particular, it is the data intermediary organisations that are empowered - interrogating openness, one finds that it is often sub-sets or summaries or visualisations of data that are being circulated. Control over the foundational dataset including ownership and rights to update typically rests with the data intermediaries.

\section{E. Discussion and Conclusions}

\section{E1. Distributive Data Justice}

Distributive data justice - the concern for who gets what as a result of data systems - is a lens applied across the other dimensions (see Figure 1). It has particular relevance here given the foundational concern about marginalisation, and the injustices of data-based inequality suffered by the slum communities: their location, assets, issues are less visible than those of more affluent areas and residents, with a knock-on to inequality of infrastructure, service provision and political role.

Procedurally, the overall picture could be seen as a pyramid. At the base, the majority of community members are not involved in the data-information-decision-action processes of the information value chain. Above them, the largest number of beneficiaries are within the community but gain only the interpretive value of data; the mappers who capture data are far fewer but gain more; the midstream professionals are fewer still but gain greater capabilities; and the intermediary organisations benefit most of all.

A similar picture can be seen in terms of visibility. The most marginalised - those without homes, those without identification, those residing on the physical margins who come in to the city to make their living - are rarely made visible by these data initiatives. Conversely, data that might truly challenge political elites e.g. enabling them to be held to account, remained largely invisible. The communities which are made visible reap some benefit directly but they lose control of their representation; becoming legible to others who can make use of the community's data twin for their own purposes. From this, we can see the ambivalence of legibility. Slums must be legible to government, NGOs, development agencies, etc if they are to benefit from the resources, services, support, etc that these external organisations offer. But that same legibility exposes slum residents to any other agendas these organisations may hold; agendas that may be orthogonal to slum interests or even counter to those interests: extractive, persecutory or predatory. Even if direct evidence of the latter was limited, the fear of it led some data intermediaries to avoid gathering certain types of data, and led some groups to prioritise their right to privacy and either resist or refuse to engage with data gathering. 
External agendas have served the slums: these data initiatives bring better-planned and more resources and services. But alongside the glass half-full is a glass half-empty. These absolute improvements are always less than intended or needed, and sometimes merely symbolic or temporary. Marginalised groups find some greater voice and place in urban decision making than previously thanks to these data initiatives. But, particularly in citywide initiatives as in Pune and Solo, relative inequality still grows as more formalised areas and wealthier residents retain a stronger voice and benefit more.

This overall picture is both explained by and reflected in the structural data justice evidence. Path dependency is the main narrative: the wider structural inequalities of power-interest significantly shape the data systems and operations of the information value chain. In turn, the value chain largely reproduces that wider configuration and constrains pro-equity aspirations. This is not a completely static picture: the value chain does reshape - subtly, incrementally - the structural determinants of power and utility. There is an incremental empowerment in terms of new data access, external perceptions of self-interest and of slums and their residents, and the landscape of organisations and trust. But there is no evidence of a wider transformation of the substrates of urban inequality, with communities potentially more dependent on external forces as a result of their heightened legibility.

\section{E2. Conclusions and Recommendations}

Datafication is a key trend within international development; with effects seen in every development sector and effects growing every day. Yet analysis of real-world experiences and their breadth of impact has to date been limited; in part due to a lack of analytical frameworks.

This paper therefore makes two significant contributions. First, it exposes a full picture of the impact of one type of pro-equity data initiative - community mapping - on those who are marginalised within the city. New data flows do have an impact but disproportionately serve those with the motivation and power to use that data. Results are certainly beneficial for slum communities and other marginalised citizens, and these initiatives can be justified on that basis. However, though there can be no exact calibration from qualitative research, it is likely that these pro-equity initiatives actually increase relative inequalities. Ordinary community members have seen some benefits but external actors who find the data to match their agenda and capabilities, benefit more. It is the latter who are more empowered to access, use and control the new data.

Second, and in order to perform this evaluation, the paper presents and demonstrates an explicit, systematic and comprehensive framework for the analysis of data systems and initiatives. The framework is data-based: acknowledging the important growth in both reality and discourse around datafication by placing data at the heart of the model. But it simultaneously decentres data and digital technology by guiding attention to wider processes, impacts and structures. There was some overlap in the dimensions used; with the rights discussion particularly touching on procedural, instrumental and structural issues. However, in general the perspectives were additive; offering new insights and particularly substantiating the need to incorporate and understand context - rights, structures, interests - in order to fully understand the implications of datafication. 
The framework was applied here to analyse just one type of data initiative. It should be equally applicable to all types of datafication - urban and otherwise - but that application must form part of a future research agenda. Another part will be action research; working with data intermediary and other organisations in using the framework to guide design and implementation of data initiatives. In advance of that, one can - building from Fox (2015) identify three approaches to pro-equity data initiatives: technical, social and critical.

A technical approach focuses just on the digital data and technology, and the findings here show this to be too limited a view that falls short both in terms of conceptualisation and impact. A social approach focuses on achievement of development results. Findings here suggest such an approach should recognise the procedural benefits that can emerge alongside instrumental results. And they suggest that such projects need a clear theory of change, with the information value chain providing the basis for that. Project design can either look for or seek to create a functioning information value chain; one that has utility as its driver and the necessary resources present as enablers.

A critical approach would encompass the wider context of rights, power and interests. The findings suggest value in modesty of expectations for what can be achieved through proequity data initiatives; accepting incremental rather than transformational outcomes; accepting absolute improvements in informal settlements, even if broader inequalities may widen. They highlight the importance of identifying tensions and disjunctures within the context: seeking out NGOs that see an advantage over others within the competitive funding environment if they make use of new or more-objective data; looking for newlyappointed mayors or urban commissioners or development agency directors who bring a new agenda that new or more-objective data could be seen to assist. And they highlight the important structural role performed by data intermediary organisations: as channels through which citizens can influence the balance of representation/privacy and the nature of data ownership and access; as important determinants of the constitution and distributive benefits of information value chains.

More generally, the findings support the value of imbuing data projects with the values of data justice; ensuring their design and implementation follow principles of procedural, rights-based, instrumental, structural and distributive justice. Such principles may be found, for example, in the "Data-Justice-for-Development Manifesto" (see Box 1; Heeks 2017b). These can be a guiding framework, particularly for data intermediary organisations given they are focal nodes for emancipatory action. 


\section{Box 1. A Data-Justice-for-Development Manifesto}

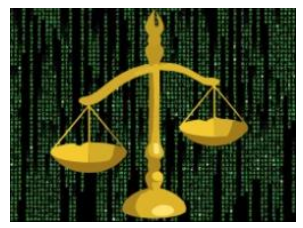

1. Demand just and legal uses of development data.

2. Demand data consent of citizens that is truly informed.

3. Build upstream and downstream data-related capabilities among those who lack them in developing countries.

4. Promote rights of data access, data privacy, data ownership and data representation.

5. Promote data system outcomes that address international development goals and priorities; including the goals and priorities of data subjects.

6. Support "small data" uses by individuals and communities in developing countries.

7. Advocate sustainable use of data and data systems.

8. Create a social movement for the "data subalterns" of the global South.

9. Stimulate an alternative discourse around data-intensive development that places issues of justice at its heart.

10. Develop new organisational forms such as data-intensive development cooperatives.

11. Lobby for new data justice-based laws and policies in developing countries (including action on data monopolies).

12. Open up, challenge and provide alternatives to the data-related technical structures (code, algorithms, standards, etc) that increasingly control international development. 


\section{References}

Baud, I. (2016). Digitisation and participation in urban governance. In Local Governance, Economic Development and Institutions, G.M. Gomez \& P. Knorringa (eds), Palgrave Macmillan, Basingstoke, UK, 86-97.

Benequista, N. (2015). Journalism from the 'Silicon Savannah'. Stability, 4(1), 1-16. Berdou, E. (2011) Mediating Voices and Communicating Realities. IDS, Brighton, UK. Bunnell, T., Miller, M.A., Phelps, N.A. \& Taylor, J. (2013). Urban development in a decentralized Indonesia. Pacific Affairs, 86(4), 857-876.

Chakraborty, A., Wilson, B., Sarraf, S. \& Jana, A. (2015). Open data for informal settlements. Journal of Urban Management, 4(2), 74-91.

Dalton, C. \& Thatcher, J. (2014). What does a critical data studies look like, and why do we care? Society + Space, 29.

Donovan, K. (2012). Seeing like a slum. Georgetown Journal of International Affairs, Winter/Spring, 97-104.

Feruglio, F. \& Rifai, A. (2017). Participatory Budgeting in Indonesia. Making All Voices Count. Fox, J.A. (2015). Social accountability. World Development, 72, 346-361.

Grillos, T. (2017). Participatory budgeting and the poor. World Development, 96, 343-358.

Hagen, E. (2011). Mapping change. Innovations, 6(1), 69-94.

Hagen, E. (2017). Open Mapping from the Ground Up. Making All Voices Count.

Haklay, M. (2013). Neogeography and the delusion of democratisation. Environment and Planning A, 45(1), 55-69.

Heeks, R. (2017a). Data justice, presentation at IFIP WG9.4 conference ICTs for Promoting Social Harmony, Yogyakarta, Indonesia, 22-24 May.

Heeks, R. (2017b). A Structural Model and Manifesto for Data Justice for International Development, GDI Development Informatics Working Paper no.69. University of Manchester, UK.

Heeks, R. (2018). Information and Communication Technology for Development. Routledge, Abingdon, UK.

Heeks, R. \& Renken, J. (2018). Data justice for development. Information Development, 34(1), 90-102.

Jobst, M. \& Malherbe, M. (2017). Participatory Budgeting in Pune. Uppsala University, Sweden.

Kitchin, R. (2014). The real-time city? GeoJournal, 79(1), 1-14.

Kitchin, R. \& Lauriault, T. (2018). Towards critical data studies. In Thinking Big Data in Geography, J. Thatcher, J. Eckert \& A. Shears (eds), University of Nebraska Press, Lincoln, NE, 3-20.

Kovacic, P. \& Lundine, J. (2013). Mapping Kibera. In Bits and Atoms, S. Livingston \& G. Walter-Drop (eds), Oxford University Press, Oxford, 115-129.

Krishnamurthy, R. \& Desouza, K.C. (2015). Chennai, India. Cities, 42, 118-129.

Lokanathan, S. (2017) Mapping Big Data for Development and the Global Goals. LIRNEasia, Colombo.

Lokanathan, S., Kreindler, G.E., de Silva, N.N., Miyauchi, Y., Dhananjaya, D. \& Samarajiva, R. (2016). The potential of mobile network big data as a tool in Colombo's transportation and urban planning. Information Technologies \& International Development, 12(2), 6373. 
Lundine, J., Kovacic, P. \& Poggiali, L. (2012). Youth and digital mapping in urban informal settlements. Children Youth and Environments, 22(2), 214-233.

Menon, S. (2013). Participatory Budgeting in Pune. Centre for Environment Education, Pune. Neff, G., Tanweer, A., Fiore-Gartland, B. \& Osburn, L. (2017). Critique and contribute. Big Data, 5(2), 85-97.

Obermayr, C. (2017). Sustainable City Management. Springer, Cham.

Otiso, K.M. (2002). Forced evictions in Kenyan cities. Singapore Journal of Tropical Geography, 23(3), 252-267.

Padmanabhan, V., Raman, N.V. \& Shekhar, S. (2013). Plan B: Practical Strategies to Improve Planning in Indian Cities. Indian Council for Research on International Economic Relations, New Delhi.

Panek, J. \& Sobotova, L. (2015). Community mapping in urban informal settlements. Electronic Journal of Information Systems in Developing Countries, 68(1), 1-13.

Patel, S. \& Baptist, C. (2012). Documenting by the undocumented. Environment and Urbanization, 24(1), 3-12.

Pfeffer, K. \& Verrest, H. (2016). Perspectives on the role of geo-technologies for addressing contemporary urban issues. European Journal of Development Research, 28(2), 154-166.

Rifai, A., Asterina, N. \& Hidayani, R. (2016). Improving the Transparency, Inclusivity and Impact of Participatory Budgeting in Indonesian Cities. Making All Voices Count.

Samarajiva, R., Lokanathan, S., Madhawa, K., Kreindler, G. \& Maldeniya, D. (2015). Big data to improve urban planning. Economic \& Political Weekly, 50(22), 43-48.

Sanchez, C., Mackaness, W. \& McLaren, R. (2013). Sustainable mapping projects, paper presented at GISRUK 2013, Liverpool, 3-5 Apr.

Scott, J.C. (1998). Seeing like a State. Yale University Press, New Haven, CT.

Sengupta, R., Heeks, R., Chattapadhyay, S. \& Foster, C. (2017). Exploring Big Data for Development, GDI Development Informatics Working Paper no.66. University of Manchester, UK.

Shekhar, S. (2016). Introduction: (re)prioritising citizenship in smart cities governance. In (Re)Prioritizing Citizenship: Setting a New Agenda for Smart Cities Governance, S. Shekhar (ed), CAG, Chennai, 5-8.

Shekhar, S. \& Padmanabhan, V. (2015). The Quality of Civic Data in India And the Implications on the Push for Open Data. Transparent Chennai, Institute for Financial Management and Research, Chennai, India.

Shkabatur, J. (2014). Interactive community mapping. In Closing the Feedback Loop, S. Bailur \& B. Gigler (eds), World Bank, Washington, DC, 71-106.

SKK (2010). Gilingan Neighbourhood Map. Solo Kota Kita, Solo.

Song, L.K. (2016). Planning with urban informality. International Development Planning Review, 38(4), 359-381.

Spratt, S. \& Baker, J. (2015). Big Data and International Development. IDS, University of Sussex, UK.

Swain, S.S. (2012). The unequal access to municipal services and the role of local elected representatives, paper presented at N-AERIS XIII, Paris, 22-24 Nov.

Taylor, L. (2017). What is data justice? Big Data \& Society, 4(2).

Taylor, L. \& Broeders, D. (2015). In the name of development. Geoforum, 64, 229-237.

Taylor, L. \& Richter, C. (2015). Big data and urban governance. In Geographies of Urban Governance, J. Gupta, K. Pfeffer, H. Verrest \& M. Ros-Tonen (eds), Springer, Cham, 175191. 
Townsend, A.M. (2013). Smart Cities. W.W. Norton, New York, NY.

UN-Habitat (2016). World Cities Report 2016. UN-Habitat, Nairobi, Kenya.

UN-Habitat (2017). New Urban Agenda. UN-Habitat, Nairobi, Kenya.

van Veenstra, A.F., Esmeijer, J., Bakker, T. \& Kotterink, B. (2014). Data and the City. TNO, Delft.

Willis, K. (ed) (2017). Whose Right to the Smart City? Plymouth University, UK.

\section{Acknowledgements}

The authors thank Jaco Renken for comments on an earlier draft of this paper. 


\title{
Case 2: Visual Data Justice? Datafication of Urban Informality in South Africa Using $360^{\circ}$ Imaging Technologies
}

\author{
Jonathan Cinnamon \\ University of Exeter
}

\begin{abstract}
Uneven economic development is closely associated with the proliferation of informal settlements in the global South, a process generally understood to harbour injustices according to a resource access view of society. An understanding of social justice in terms of distribution provides a powerful framework for challenging uneven development, however, a key contention of this paper is that further forms of injustice accrue to the residents of these places over and above issues of distribution. With its focus on sociocultural representations, recognition provides a basis for 'making visible' further injustices that threaten dignity and self-identification, which may also act as a preliminary step towards advancing socioeconomic justice for informal settlements.
\end{abstract}

This paper draws on ongoing research into the datafication of informal settlements in South Africa, including interviews with data activists and experiences of conducting a $360^{\circ}$ geovisual imagery pilot study in Kya Sands informal settlement in Johannesburg. In first drawing attention to the limitations of quantitative data for representing injustice, and the problematic effects of conventional framed photographs of informality from aerial and ground-level perspectives, this paper explores the possibilities of ground-level $360^{\circ}$ imagery as a realist, non-reductionist form of representation for informal settlements. Three $360^{\circ}$ street views were produced to illustrate key possibilities and limitations for advancing recognition, based on the notion that visibility is essential for recognition. Further, the piece reflexively critiques how - through new advancements in image analytics - informal settlement visibility projects risk further engendering injustices of misrecognition for these highly marginalized urban spaces.

As such, this paper provides a basis for further inquiry into the relationship between visual data and the social justice principle of recognition, towards an emerging research agenda on visual data justice. The paper concludes with recommendations for practitioners and key topics for research. Important items on the agenda include: determining the forms and examples of injustice that can be remedied through datafication, the relationship between misrecognition and maldistribution in the context of datafication, and the acceleration of new injustices due to advances in computer vision applied to ground-level imagery. 


\section{A. Introduction}

"In contemporary discussions, recognition is often accompanied by visibility as its political partner. Demands for recognition are also demands for visibility" (Oliver, 2001, p.147)

Uneven development is a significant challenge to cities around the world, particularly in lowand middle-income countries with extreme levels of socioeconomic inequality. In many global South cities, recent patterns of urbanization and inward migration have produced a highly variegated and disconnected urban fabric. Nowhere is this more evident than in South Africa, where the world's highest rates of inequality and uneven development are both a consequence of current socioeconomic injustices and a resolutely visible reminder of past apartheid racial policies. The longstanding and intransigent nature of uneven urban development means that injustice is often defined in specifically spatial terms in South Africa. However, as data becomes a key focus of urban governance in the country, injustice is also increasingly understood in the context of datafication, which draws attention to how uneven patterns of data render marginalized spaces and their inhabitants invisible to outsiders.

Cities in South Africa actively pursue datafication discourses and 'smart' agendas in the globally circulating model (Odendaal, 2015); however for residents and grassroots organizations in Cape Town and Johannesburg, data has also become a means by which everyday injustices can be 'made visible' (Odendaal, 2006) in a country with a complex politics of visibility that requires one to be "seen by the state' before benefitting from it" (Parnell and Pieterse, 2010, p.153). Data activism has emerged in this context as a strategy to contest disparities in the provision of basic services guaranteed by the country's rightsbased constitution, including water, sanitation, housing, and education. Quantitative, evidence-driven activism provides an alternative or supplement to the widespread deployment of 'service delivery' protests by civil society organizations and residents of informal settlements, which can often be ignored by municipal governments. Growing interest in data activism suggests a tactical shift from the legacy of 'people power' in South Africa (Bénit-Gbaffou, 2015), to a new focus on 'data power' (Kennedy and Bates, 2017) based on an understanding of data as a powerful actor that can inform effective governance and policy decisions.

In the context of datafication in governance, business, and wider society, 'data justice' (e.g. Dencik et al., 2016; Taylor, 2017; Heeks and Renken, 2018) has emerged as a field of theory and praxis that broadly seeks to draw attention to the complex ways that data and social justice are interwoven. This includes efforts to trace how data production, accumulation and analytics (re)produce social injustice (Cinnamon, 2017; Redden, 2018), and work that actively engages with these practices towards the advancement of normative social justice aims, such as emancipation, empowerment, equity, and fairness (Johnson, 2014; Milan and van der Velden, 2016). Engaging both of these dimensions, this piece adds to the literature on data justice in two ways. First, the piece develops the notion of visual data justice for advancing the social justice principle of 'recognition' (Honneth, 2004; Fraser, 2008). Justiceas-recognition provides a means of identifying and contesting injustices other than those that arise as a consequence of socioeconomic inequalities, the primary target of distributive 
social justice reparations. Instead, as a sociocultural consideration, recognition is concerned with the ability to self-identify and to participate as an equal in society. Although economic inequities are important in this context, a focus here on spatial recognition foregrounds the more-than-economic causes and consequences of urban marginality. Doing so

acknowledges that while urban spatial injustices are clearly aligned with patterns of uneven economic development, further forms of injustice accrue to the residents of these places over and above inadequate provision of basic services. Thus, making injustices of misrecognition visible can be a first step towards remedying injustices of maldistribution.

This project was undertaken in Kya Sands, an informal settlement on the northern periphery of Johannesburg. An effectively invisible space unrecorded and unaccounted for in official maps, databases, and archives, Kya Sands is known to outsiders primarily though visual imagery depicting extreme poverty and hardship (see Figure 1). Taken from above or at a considerable distance, these forms of imagery serve as a symbolic representation that further marginalizes the residents of these spaces (Hecker, 2010; Dovey and King, 2011). The aim of this project was to 'make visible' the settlement in a very literal, panoramic way that might overcome some of the limitations and harms of conventionally-framed images. Further, the project is driven by a more general critique of datafication in contexts of informality - that quantitative data are inadequate for representing injustice in its full texture. Three research questions guide this paper:

- What is the role of quantitative data in representing injustice and advancing the needs of marginalized people and places?

- How can consumer-grade $360^{\circ}$ imaging technologies be used to produce street-level imagery of informal settlements?

- Can a potentially more progressive form of datafication be realised through streetlevel $360^{\circ}$ imagery?
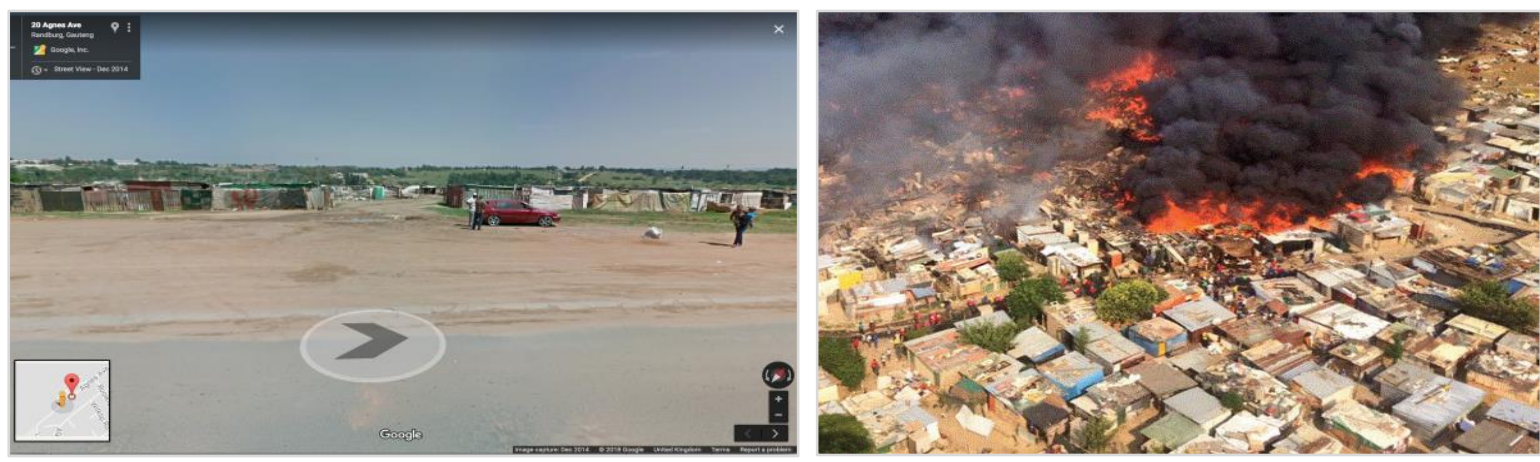

Figure 1: Visually imagining Kya Sands. Google Street View image taken from a distance, and image of a fire taken from a low-oblique aerial perspective.

To answer the first question, the paper draws on interviews with 'data activists' working in informal settlements in Johannesburg and Cape Town. Experiences of conducting the streetlevel imagery pilot study in Kya Sands are used to answer the next two questions.

The following section provides a background and conceptual framework for the paper. The Methods section explains the study site and data collection activities. The Findings and Discussion section initially provides the results of the interviews and pilot study. Through an 
exploration of three street views produced about the community, this section then develops the notion of visual data justice, by tracing the possibilities, limitations, and risks of $360^{\circ}$ imagery for advancing recognition for invisible urban spaces. This piece concludes with recommendations for practitioners interested in using $360^{\circ}$ imagery for informal settlement representation, and a consideration of the future research agenda for visual data justice in light of this project.

\section{B. Background}

\section{B1. Urban Fragmentation and Invisibility}

In global South cities, new urban dwellers often take up residence in informal settlements on the outskirts of cities, extending municipal boundaries outward, or infilling interstitial spaces along transport infrastructure routes, on land unsuitable for formal structures, or other underused or unwanted urban spaces (Dovey and King, 2011). The notion of urban informal settlements as 'fragments' (McFarlane, 2018) both separate from and intimately interconnected with the city draws attention to their highly dynamic, shifting, and heterogeneous spatial arrangement both internally and in relation to the surrounding city.

While the spatial contours of fragmented spaces can be ascertained with relative ease, often little is known about the internal spatial structure of informal settlements nor of the people who live there. For municipal governments, lack of information on informal settlements on the one hand presents an opportunity to ignore the needs of these spaces, and on the other, a significant challenge when intervention is necessary. For residents of informal settlements, life in an urban fragment is similarly ambivalent. Informal settlement living is often defined by precarity and a sense of invisibility and disconnection from the rest of the city. These spaces generally have few municipal, social, or health services provided, and residents working or enrolled in school or university are often required to travel considerable distances. Yet dis-integration from the wider urban fabric may have positive implications for residents seeking affordable temporary shelter or to avoid being caught up in the machinery of the state.

\section{B2. The Datafication of Injustice in Informal Settlements}

Advancements in digital technologies and data production have opened up new opportunities to 'know' informal settlements. The term 'datafication' is often described as a process of "rendering into data aspects of the world not previously quantified" (Kennedy et al., 2015, p.1), although it is also profitably interrogated in terms of the wider beliefs and motivations underlying data and data analytics. Van Dijck's (2014) notion of 'dataism' captures the discursive underpinnings of datafication based on an understanding of quantitative data as an objective representation of the world, and also a tool of action and change. Beer (2019) draws attention to a 'data imaginary' that frames data analytics as speedy (rapid insights), accessible (easily interpreted), revealing (extracting hidden knowledge), panoramic (all-seeing), prophetic (able to foresee and shape the future), and smart (possessing latent intelligence). 
In the case of urban data and the wider smart urbanism agenda, data and data analytics are thusly pursued by governments as the solution for urban challenges. As Kitchin explains, smart city advocates believe that data "provides the raw material for envisioning and enacting more efficient, sustainable, competitive, productive, open and transparent cities" $(2014$, p.1). For urban residents and civil society organizations, similar beliefs about data and data analytics are powering new modes of data-driven civic action, taking advantage of accessible data production technologies (e.g. mobile phones) and processes (e.g. crowdsourcing, citizen science). As part of this wider phenomenon, diverse forms of 'data activism' have emerged in cities around the globe, including in South Africa. Data activism demonstrates an ambivalent resist/embrace relationship with datafication - as Milan and van der Velden explain, the term comprises both "affirmative engagement with data and resistance to massive data collection" (2016, p.61).

Informed by wider datafication discourses, efforts to address urban invisibility through datafication have come in two main forms. The first, on-the-ground mapping and surveying initiatives with varying degrees of local resident participation, is exemplified by the Map Kibera project in Nairobi (Donovan, 2012). This initiative engaged local residents to produce spatial data and thematic maps (e.g. location of hospitals, points of interest, perceptions of safety) of this huge informal settlement in Nairobi which was previously unmapped and largely ignored, despite being home to as many as 1 million people. In South Africa, one form of data activism called a 'social audit' has gained widespread uptake within the activist communities in Johannesburg and Cape Town. Social audits are collaborative data collection initiatives between an organization and local residents which aim to draw attention to inadequate service provision. Since 2013, over a dozen social audits have been undertaken, collecting data on infrastructure, services, and hazards in informal settlements, highlighting gaps between expected allocations and the reality on the ground (Social Audit Network, 2016).

A second form of datafication for informal settlements uses aerial remote sensing to capture imagery for conversion into spatial data - the 'slums from space' approach (Kuffer et al., 2016). While satellite imagery has a long history of use for mapping cities, unmanned aerial vehicles (UAVs) present new opportunities for mapping these dense and highly dynamic spaces in much higher spatial and temporal resolution. For instance, Gevaert et al. (2017) used UAV imagery to algorithmically classify informal settlements for the purposes of upgrading, and Mansell (2018) described the use of DIY balloon-based aerial imaging techniques in a Palestinian refugee camp to assert residents' 'right to the city'. With both approaches however, datafication of informal settlements based only on aerial imagery has practical limitations in terms of what can be known about these spaces. It can provide proxy estimates of socioeconomic conditions (e.g. population size, deprivation), but is primarily used only for the production of geospatial framework data (e.g. vector datasets of roads, paths, building footprints, spatial boundaries) (Williams et al., 2016; Mahabir et al., 2018).

Critics of mapping and quantitative data have long drawn attention to the way these forms of representation shape a limited and partial understanding of the world (e.g. Harley, 1989; Crampton, 2001; Aalbers, 2014). For many feminist and diversity theorists, quantitative representation serves to advance the interests of those people and things that are more readily captured by numbers, static categories, and hegemonic forms of knowledge (e.g. 
Lawson, 1995). In a study of participatory efforts to include Rio de Janeiro's favelas in Google Maps, Luque-Ayala and Neves Maya observed considerable "distance between the richness of the mental map of favela dwellers and the spatial simplification and standardization required by the global digital map" (2019, p.456). With this understanding, quantitative representation will have only limited use for capturing the dynamics and lived realities of life on the ground in informal settlements, which calls into question a variety of data-led strategies that seek to advance justice through datafication.

\section{B3. Visualizing Informality: Vertical, Oblique, Horizontal}

Against this backdrop, constructivist and interpretivist forms of knowledge production are also undertaken in an effort to more accurately 'know' informal spaces, including interviews, participatory methods, and ethnographic research. Within this epistemological framing, visual imagery is advanced as a way to represent informal settlements with a degree of objectivity, while avoiding the abstractions of quantification. The privileging of imagery as an instrument of empirical fact is based on a "naturalistic understanding of vision [which] claims that objectivity is achieved by a correspondence between an image and its external referent" (Campbell, 2007, p.379). This linking of seeing with knowing facilitates the now widespread use of aerial images as evidence of on-the-ground conditions, even without converting the imagery to quantitative spatial vector data. The power of vertical aerial images (see Figure 2a) to enable access to remote locations without local grounding provides new opportunities to know these spaces, but they also serve to reinforce power asymmetries with other peoples and cultures, through the subjectifying and dominating effects of the 'god's eye view' (Parks, 2009).

Tilting the camera angle from the vertical (nadir) plane of perspective of most satellite imagery to an oblique (angled) perspective has become common, especially with the advancement of UAVs. Oblique imagery is generally not used to produce quantitative vector data, since the scale of the imagery is different from the image's foreground to background, meaning distance and direction vary. Beyond these practical limitations, oblique imagery can have powerful effects in terms of how spaces are understood, distinct from the effects of vertical imagery's powerful downward gaze. The 'high-oblique' perspective tilts the camera angle to a midway point between nadir and ground-level horizontal, providing the viewer with both a sense of size and context, as well as local detail and nuance. But the 'low-oblique' perspective tilts the camera to a point that captures the ground at around $30^{\circ}$ off the nadir view but excludes the horizon altogether (see Figure $2 b$ ). This subtle adjustment to the plane of perspective produces imagery that captures the scale of the settlements but excludes the anchoring point of the horizon. As Hecker (2010) explains, this limits the potential for documentary realism - the effect on the viewer is to depoliticize informality and poverty, offering only abstraction and aestheticization ${ }^{7}$ of the social realities below:

"the oblique aerial view uses the horizon to seam together the void of the sky and the full of the distant landscape. But what happens when the plane of sight turns

\footnotetext{
${ }^{7}$ Here, aestheticization is understood as a process in conflict with politicization. For visual imagery, particular artistic elements and decisions can serve to neuter the political potential of representation. Through such a process, politics and power relations "are obscured, becoming incorporated into categories of lifestyle, taste, and patterns of consumption and appreciation of the visual, the sensual, and the unique" (Duncan and Duncan 2001, p.377). This draws in particular on Walter Benjamin's notion of the 'aestheticization of politics', as well as ideas about the political potential of representation developed in the field of visual studies.
} 
toward the ground to bracket off the horizon itself? ... This low-oblique plane of vision refocuses the dialectic between immensity and an ordering line of sight, away from optics of stability and order toward the immensity of the ground below. This technique of closing off the horizon... could also be seen to occupy another interstitial position - existing in between the lofty god-powers of the vertical omniscient view and the horizontal comfort of being in the world" (Hecker, 2010, p.260).

Further tilting the camera lens down to ground-level, the horizontal plane of perspective offers a form of visuality that may be more attuned to the politics and lived realities of those living in informal settlements (see Figure 2c). As Dodge explains, "the action of tilting the camera through 90 degrees and the reduction of verticality can be read as a move from the disembodied 'view from nowhere' to a more human-scale and embodied sense of place" (2018, p.955). Taken at the scale of the social, and at a vantage point closer to the subject matter, conventional ground-level photography provides an opportunity for documentary realism that captures the realities of informal settlement living in a way that illustrates injustice but negates abstraction and aestheticization.

Yet Linke (2012) describes how ground-level informal settlement photography is often itself an idealist art form, consumed by global elites drawn in by a carefully-crafted aesthetic of resourcefulness and sustainability that occludes the social disadvantage that a more realist approach might exude. As the author explains, "the conditions of displacement and the impact of poverty on families or communities are expunged from the visual field by transforming poverty artefacts into aestheticized art objects" (p.303-304). The ability to shape a slum imaginary of 'bare life' (Agamben, 1998) liberated of any political meaning is made possible through the process of 'framing'. Frames are a necessary, though powerful and performative aspect of photographs, whether the plane of perspective is nadir, oblique, or horizontal. Framing is an act of inclusion and exclusion; as Judith Butler puts it, it is a "delimiting function, bringing into focus an image on the condition that some portion of the visual field is ruled out" (2007, p.953). Choosing the frame and linear perspective determines the arrangement of objects and composition of the photograph, which, as Cosgrove explains, "determines - in both senses - the 'point of view' to be taken by the observer, and ... the scope of reality revealed" (1985, p.48). 


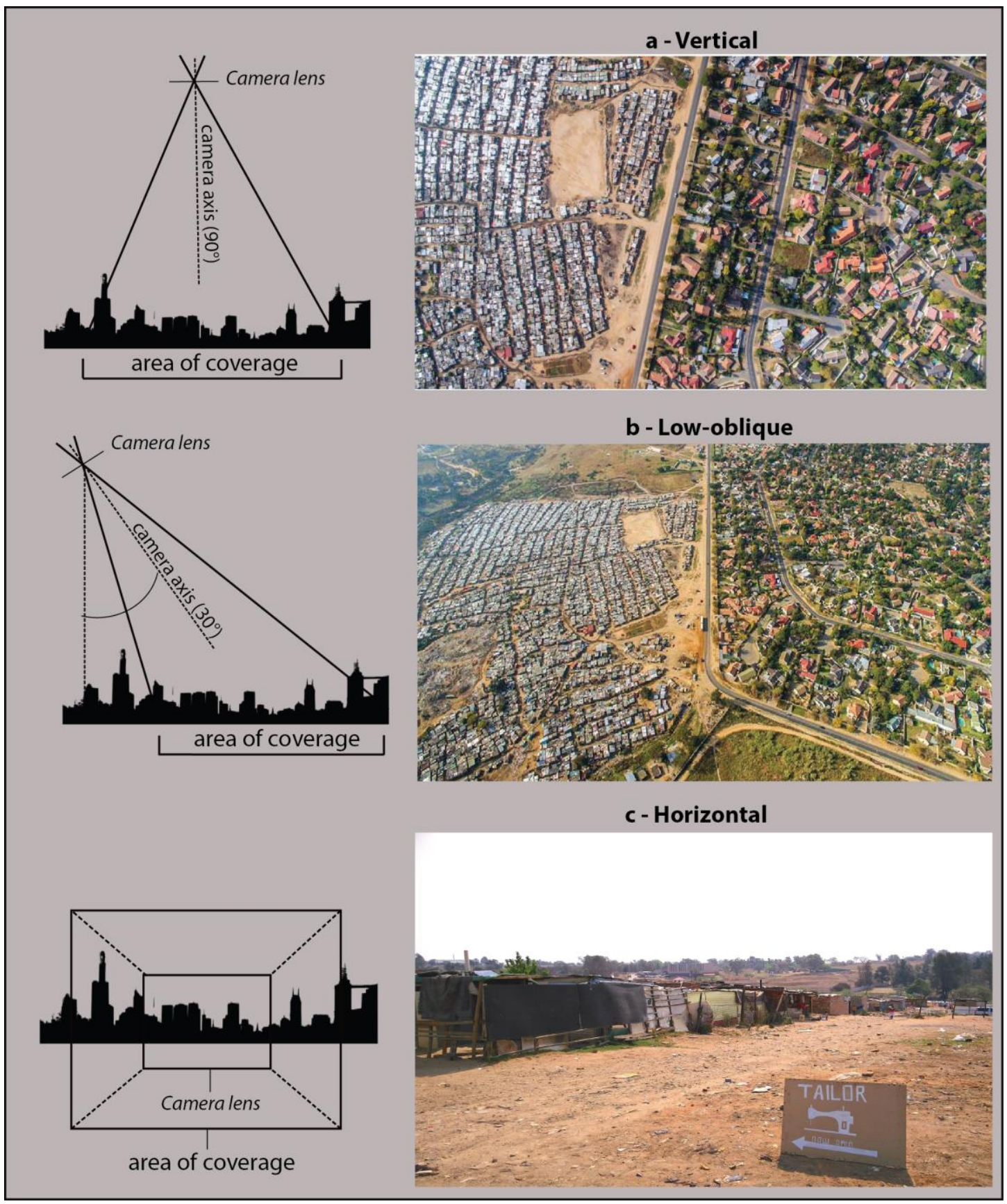

Figure $2 a, b$, $c$ Tilting the camera lens - Kya Sands through vertical, low-oblique, and horizontal planes of perspective. Aerial photos in $2 a$ and $2 b$ from Unequal Scenes project (https://unequalscenes.com/kya-sandsbloubosrand). Ground-level photo in $2 c$ by author.

Through avoiding the need to frame the visual field and allowing the viewer to choose the visual perspective, developments in $360^{\circ}$ photography suggest new possibilities for visually representing informal settlements, and a potential move away from aestheticization and abstraction towards realist representation (see Figure 3). 

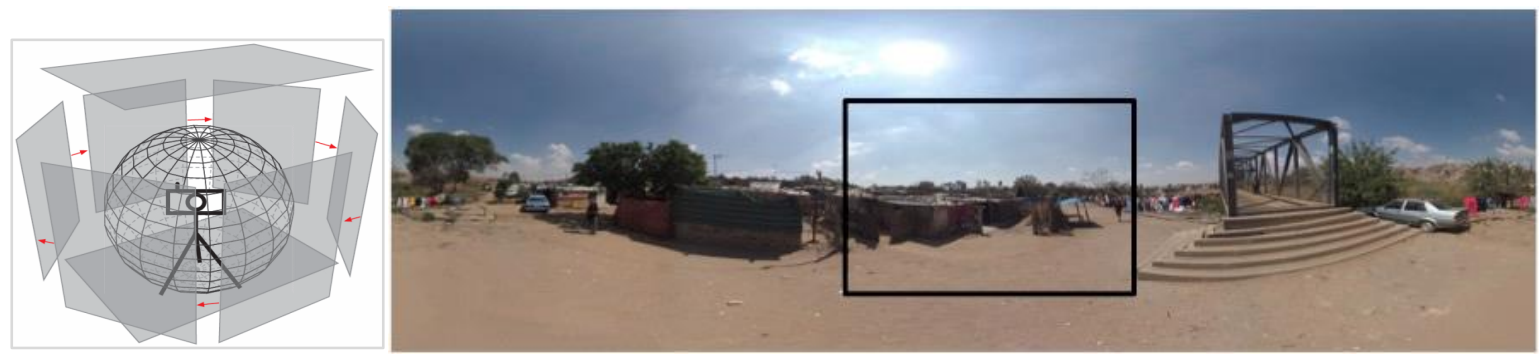

Figure 3: Ground-level photo of Kya Sands in $360^{\circ}$ (rendered as a flat projection here), and a conventional photo frame as reference. $360^{\circ}$ photo by author. $360^{\circ}$ perspective diagram from: https://www.fotografie-tutorials.de/2011/03/18/panoramafotografie-teil-01einfuhrung-blickwinkel-und-asthetik/

Google Street View (GSV) is "practically synonymous" (Alvarez León and Quinn, 2019, p.2) with $360^{\circ}$ street-level representation in most settings. GSV was initially released in 2007 in 5 cities in the US, and since has expanded to all continents, however the platform's coverage is both spatially and temporally uneven. GSV first visited the African continent in advance of the 2010 World Cup in South Africa. A decade later, much of the imagery collected from more marginalized areas of Cape Town and Johannesburg has yet to be updated, meaning users of GSV are presented with an inaccurate representation of these highly dynamic and mutable urban spaces. In contrast, regular updating is standard procedure in many places in the global North. For Kya Sands and many informal settlements in South Africa and beyond, coverage is generally absent altogether. The landscape of $360^{\circ}$ imagery production is rapidly expanding however, spurred on by new actors producing imagery for the autonomous vehicle market, the recent availability of low-cost consumer grade cameras and software, and the development of alternative platforms for hosting this imagery outside of GSV (Alvarez León and Quinn, 2019). Since 2013, 360 photo/video cameras have become widely available, from entry-level models that attach to a smart phone, higher spec versions for outdoor sports, to professional grade models used in industry. ${ }^{8}$

\section{B4. From Socioeconomic to Sociocultural Injustice in Informal Settlements}

The social justice principle of 'recognition' provides the framework for analysis of this case study. Depending on the nuances of how the principle is interpreted, recognition describes a form of justice bound up in contestations over social status and identity at the level of individuals and societal groups, based on the belief that "human dignity comprises a central principle of social justice" (Honneth, 2004, p.352). An interest in recognition arose in the 1990 s as justice theorists identified the limitations in the prevailing normative focus of social justice, distribution. Associated in particular with the influential work of John Rawls (1971), distributive justice efforts often identify injustices in society resulting from the unequal allocation of 'goods' and 'bads' in society, which could be as broad as income, resources, rights, and freedoms, but in practice, material resources and economic wealth are the most widely recognized focus of distributive justice reparations (Miller, 1999). Justice-asrecognition provides a framework for identifying and addressing forms of injustice associated with sociocultural processes of indignity, disrespect, and stigmatization, which

\footnotetext{
${ }^{8}$ An overview of developments in consumer, intermediate, and professional grade $360^{\circ}$ imaging, virtual tour software, and related technologies is available here: $\mathrm{http}$ ://blogs.exeter.ac.uk/360/developments-in-360-imaging-technology/
} 
might be related to issues of distributive injustice, but which manifest as status inequalities and threats to agency and identity formation (see Fraser and Honneth, 2003).

Misrecognition then is the paradigmatic injustice under this principle. For Honneth's identity-based model, to be misrecognized by others is a threat to self-realization, autonomy, and the development of an intact identity (Honneth, 2004). Here, (mis)recognition is produced in intersubjective relations, through (lack of) "respect in the political sphere, esteem in the social sphere, and care in the intimate sphere of the family" (Kompridis, 2007, p.278). Alternatively, for Fraser's status-based model, to be misrecognized is a threat to parity of participation in social life caused by institutionalized patterns of subordination (Fraser, 2005). In this interpretation, misrecognition aligns with and is connected to distributive justice in its focus on inequality - misrecognition produces uneven patterns of societal participation, which could mirror or supplement uneven allocations of material resources. Although the two models have been said to be incompatible, Thompson (2009) explains how the ability to participate as an equal in society can be understood as a necessary element to achieving identity recognition in the eyes of others. Thus, full recognition can be achieved by designing institutions and opportunities that ensure parity of participation, which will set up the parameters of a society that fosters relationships of dignity and respect, ensuring self-realization for all identity groups.

Irrespective of a focus on status equality, identity, or their interconnections, misrecognition is understood as a deeply embedded injustice that impacts marginalized individuals, groups, and indeed places, over and above distributive forms of injustice. Visual imagery plays an important role in shaping who is recognized, and who recognizes. Whether aerial or at ground-level, techniques of framing and linear perspective in conventional photographs are performative acts of misrecognition, accelerating the 'othering' of already marginalized people and places. Campbell (2007, p.359) explains the symbolic potency of photographs of the Darfur conflict for how outsiders imagine Africa - not as a vast continent with a diversity of landscapes and people but as "a single entity marked by an iconography of despair, disaster and disease".

At the urban scale, conventional photography can contribute to the symbolic discrediting of places, as part of a specifically geographic process of misrecognition referred to as territorial, or spatial stigma (Wacquant et al., 2014). Like Goffman's theory of personal stigma as 'spoiled identities' shaped through intersubjective stereotyping, spatial stigma explains the processes by which residents of defamed places come to be regarded by outsiders as embodied manifestations of them. As Slater explains, "urban dwellers at the bottom of the class structure are discredited and devalued not simply because of their poverty, class position, ethnoracial origin, or religious affiliation, but because of the places with which they are associated" (2017, p.113). The effects of this form of misrecognition are both physical and material; research has demonstrated how residents of stigmatized places face additional health challenges (Tabuchi et al., 2012; Keene and Padilla, 2014) and reduced employment prospects (Kallin and Slater, 2014) independent of other factors (e.g. socioeconomic status). Visual imagery is central to the advancement of stigmatizing discourses about informal settlements, because this is typically the key way that outsiders come to know these spaces, diffracted through the power relations, abstractions, and aestheticizations inherent to conventional photographic representation. 
Recognition is thus intimately bound up with present and historical patterns of differential visibility, "which has positioned certain bodies as objects of recognition and granted others the power to confer recognition", meaning "[s]truggles for recognition are also struggles for visibility" (Hesford, 2015, p.536-537, emphasis added). This paper develops the concept of visual data justice as a way of connecting digital visual representation to recognition, foregrounding the power of visual imagery in shaping how people come to understand other people and places. Enhanced visibility through visual representation provides opportunities for neglected and marginalized peoples and places to achieve recognition in the eyes of others; however, central to any notion of visual data justice must be an understanding that visibility itself is essentially neutral - it is in its intentions, effects, and contestations that recognition or misrecognition are advanced. In this paper, this understanding of visual data justice is developed through a $360^{\circ}$ street-level imagery pilot project. Findings described below shed light on the potential of non-framed visual perspectives for advancing recognition, and more generally provide a basis for application of the concept to a variety of existing and emerging forms of ground-level visual representation.

\section{C. Methods}

The empirical evidence for this piece is drawn from interviews with data activists, and experiences of conducting a $360^{\circ}$ imagery research project in Kya Sands, Johannesburg. Kya Sands is a typical informal settlement in sub-Saharan Africa, with shack housing, limited public infrastructure and services, and a presence that is largely invisible in government and private sector maps and databases (see Figure 4). The settlement was initially established in the early 1990s, and is now home to an estimated 20,000 people. Kya Sands is divided into four sub-areas $(A, B, C, D)$ located on a combination of private and state-owned land. State provision (and maintenance) of services is minimal, including communal water standpipes, chemical toilets, and high mast lighting.

Interviews with over 25 data activists in Johannesburg and Cape Town were conducted to gather perspectives on the value of quantitative data for representing and drawing attention to service provision needs in informal settlements. 


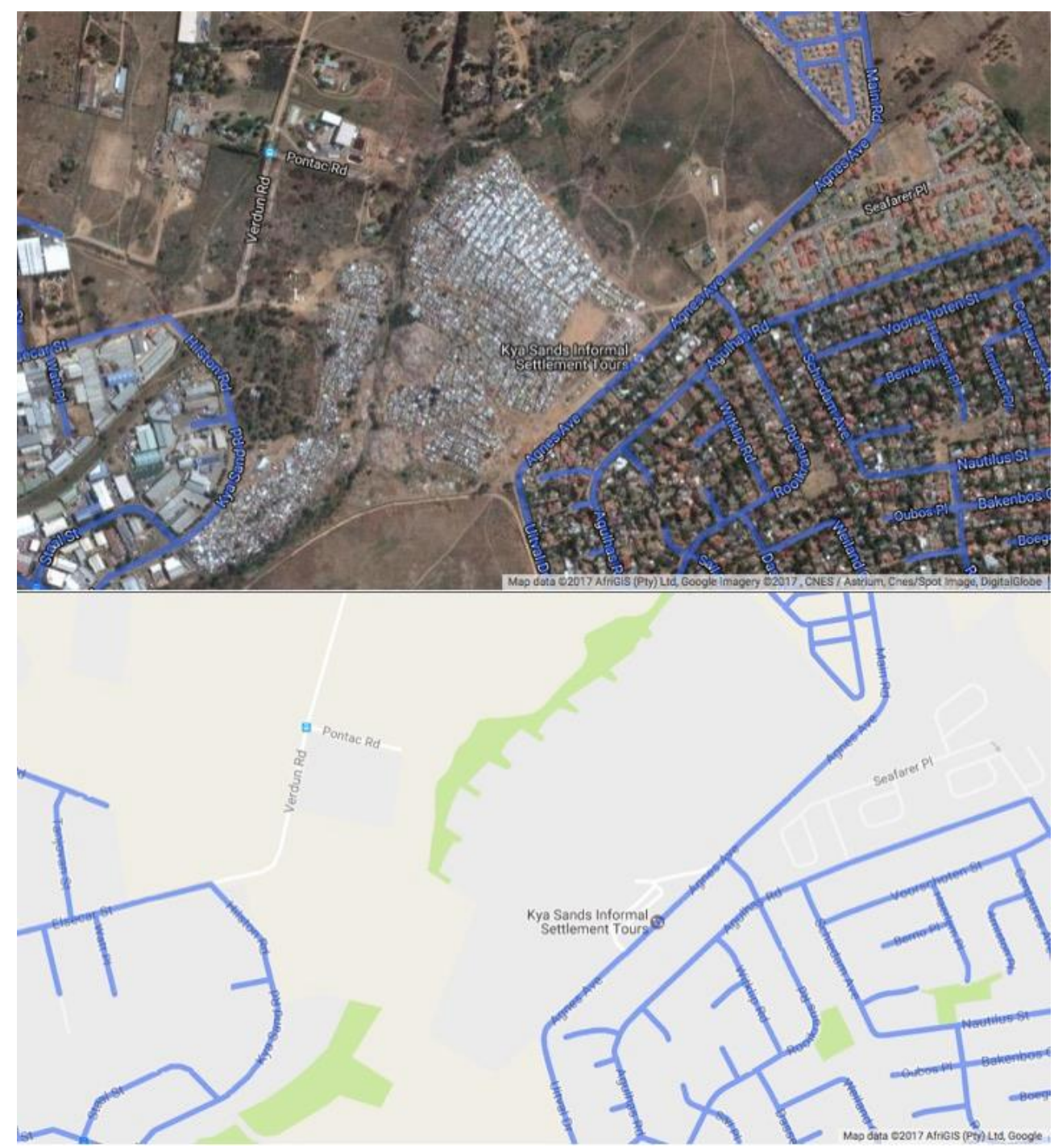

Figure 4: Kya Sands in Google Maps. The map view depicts the settlement as a blank space, while the satellite view shows the basic spatial structure of the settlement. The blue lines indicate Google Street View coverage. To the east of Kya Sands is the wealthy suburb of Bloubosrand, and to the west is the Kya Sand industrial area.

Next, a $360^{\circ}$ imagery pilot study was conducted, as part of a multi-strand, mixed methods project involving researchers from universities in Johannesburg and beyond, with varying degrees of participation from local residents and community leaders. The imagery project used consumer-grade cameras and software to capture the settlement in $360^{\circ}$. Images were taken with a Garmin VIRB360 camera, a mid-range option that features two $180^{\circ}$ lenses, automatic in-camera image stitching, and a GPS sensor to record geographic coordinates. Since the settlement is comprised of narrow paths and rough terrain, imagery was captured on foot using a hand held monopod positioned over the photographer's head, who was later edited out.

Images were captured over five days in April, September, and October 2017. The aim was to capture images at regular intervals throughout all of the paths and common spaces of the 
settlement, however this was not possible given time constraints and because of concerns over environmental health conditions in some areas (open waste, dirty water). A pragmatic, ad-hoc strategy was developed, capturing key common spaces in the settlement and larger paths. A local resident involved in the larger project accompanied the photographer, assisting with navigation and providing input on the optimal locations to take the photographs and appropriate features to record. The project was discussed with several groups of community leaders who provided permission for the research. A larger public meeting was then held at a local childcare facility to introduce the research team and project to the wider community. Our aim was to engage more fully with any interested community members; generally there was support for the project however there was little interest in developing a participatory research design.

Adobe Photoshop was used for minor post-processing tasks, including general imagery enhancements and removal of the photographer and monopod using the Polar Coordinates projection and Clone Stamp tool. The next step was to assemble the imagery to produce immersive views of the settlement. $360^{\circ}$ photos can now be hosted on a small number of Web platforms including Facebook and Flickr, but specialized 'virtual tour' software is required to link the images together for navigation between the images and on an accompanying interactive map. The project initially tested three options; two desktop-based packages, Panotour Pro from Kolor/GoPro and the open source krpano, and the lightweight Roundme web-based platform. Roundme was chosen for its intuitive development interface, social web-style sharing and commenting features, integration with a web based interactive map (Google Maps), imagery and tour hosting, embedding of tours on blogs and websites, and the ability to embed additional text and multimedia to imagery as 'hotspots'.

\section{D. Findings and Discussion}

The Findings and Discussion section provides the basis for addressing the three research questions: 1) What is the role of quantitative data in representing injustice and advancing the needs of marginalized people and places? 2) How can consumer-grade $360^{\circ}$ imaging technologies be used to produce street-level imagery of informal settlements? 3) Can a potentially more progressive form of datafication be realised through street-level $360^{\circ}$ imagery?

\section{D1. Datafication and its Limits for Contesting Injustice}

Informed by distributive notions of social justice and discourses of datafication, quantitative, data-driven social audits have become a key strategy for making uneven service provision visible and actionable in informal settlements in South Africa. Interviews with a wide variety of activists and civic data champions provide insight into the aims and outcomes of data-led activism. Data activists aim to provide 'factual' evidence of spatial discrepancies in service provision. One interviewee explained, "we're not working with, like, opinion and subjectivity, well, not necessarily, you know, we're working with data" (Employee, civic data organization). These 'counter-data' (Currie et al., 2016; Dalton et al., 2016; Meng and DiSalvo, 2018) actions are driven by a belief that policymaking requires quantitative evidence. As an interviewee noted, "taking an evidence based approach 
enables us to speak on the same terms as government" (Employee, social auditing organization). Quantitative representations of informality are pursued as powerful leverage for drawing attention to distributive injustices, as another interviewee explained:

"You are showing them their facts, to say - it's a fact that you are paying [a contractor] to do this and we are saying we don't see the value for that money. So, you need to stop it, or you need to rectify it, or you need to take some people to task to make sure that this money is spent properly" (Interviewee, activist organization, emphasis added).

The findings of social audits are highly contested however, and overall, they have had little success in convincing policymakers to address the serious issues raised. Officials have challenged and dismissed findings by claiming the results are not a real representation of service provision, focusing their critique on technical considerations such as data quality, sample size, and suitability of methods (Rossouw, 2015). An interviewee from an activist organization explains the resistance tactics: "[ $t$ ] here are various ways that they tried to undercut a piece of evidence that was actually factually true. Attack the sender. [Attack] your method... And once a powerful figure says 'that's not true', where do you go with that?"

A government response to a social audit conducted by the activist organization Equal Education (2016) on school infrastructure sums up the wider official response to social audits: "The WCED [Western Cape Education Department] is always open to constructive critique and analysis of how we operate... This critique and analysis should, however, be grounded in realism" (emphasis added). This government response to social audit findings is typical; though initially, the resistance took many activists by surprise. One activist described his astonishment:

"I certainly believed this quite naively in the first few years that, if only you can prove people wrong in the public domain that, in this war of ideas, you put this idea, they put this idea, you tell them that they're wrong and then somehow that leads to them saying 'you know what, you're right, you convinced us and we're going to change what we do here. We had no idea, you're absolutely right"” (Interviewee, activist organization).

Overall, the interviews illustrate how attempts to make injustice visible through quantitative evidence have been easily dismissed by governments, with their "greater claims to data" (Rossouw, 2015, p.79). This finding adds further dimensionality to the notion that quantitative data may be unsuitable for representing the lived realities and complexities of informal settlements. It is not just that quantitative data are reductive and shape a partial understanding of the world; when produced by the grassroots, quantitative data are also an easy target upon which governments can focus their resistance and deflection tactics (Cinnamon, forthcoming). Findings here provided the rationale for the $360^{\circ}$ imaging pilot study. $360^{\circ}$ visual imagery suggests possibilities for digital forms of informal settlement representation that may overcome the limitations of quantitative data and conventionally framed imagery, a contention that is considered in detail below. 


\section{D2. $360^{\circ}$ Imaging Pilot Study Findings}

The $360^{\circ}$ imagery pilot study produced a total of 112 panoramic images of the settlement across all four sub-areas (A-D). Selected images were used to produce three separate street views using the Roundme platform. Figure 5 shows the platform in edit mode, with the $360^{\circ}$ image viewing panel on the left and the interactive map (Google Map satellite view) showing the position of the images on the right. Navigation between images is possible by clicking on the image ribbon, on the links embedded in the $360^{\circ}$ images, or on the thumbnails on the map. The first street view, the Kya Sands Tour, was designed as a virtual tour of the settlement, starting from one of the main entry points in to Kya Sands from Agnes Ave (see Figure 6 and https://roundme.com/tour/258779/info). The tour is comprised of 27 images from all sub-areas of the settlement. The tour approximates the experience of GSV, although in most places there are larger distances between each image, and fewer opportunities to choose the direction to navigate through the settlement.

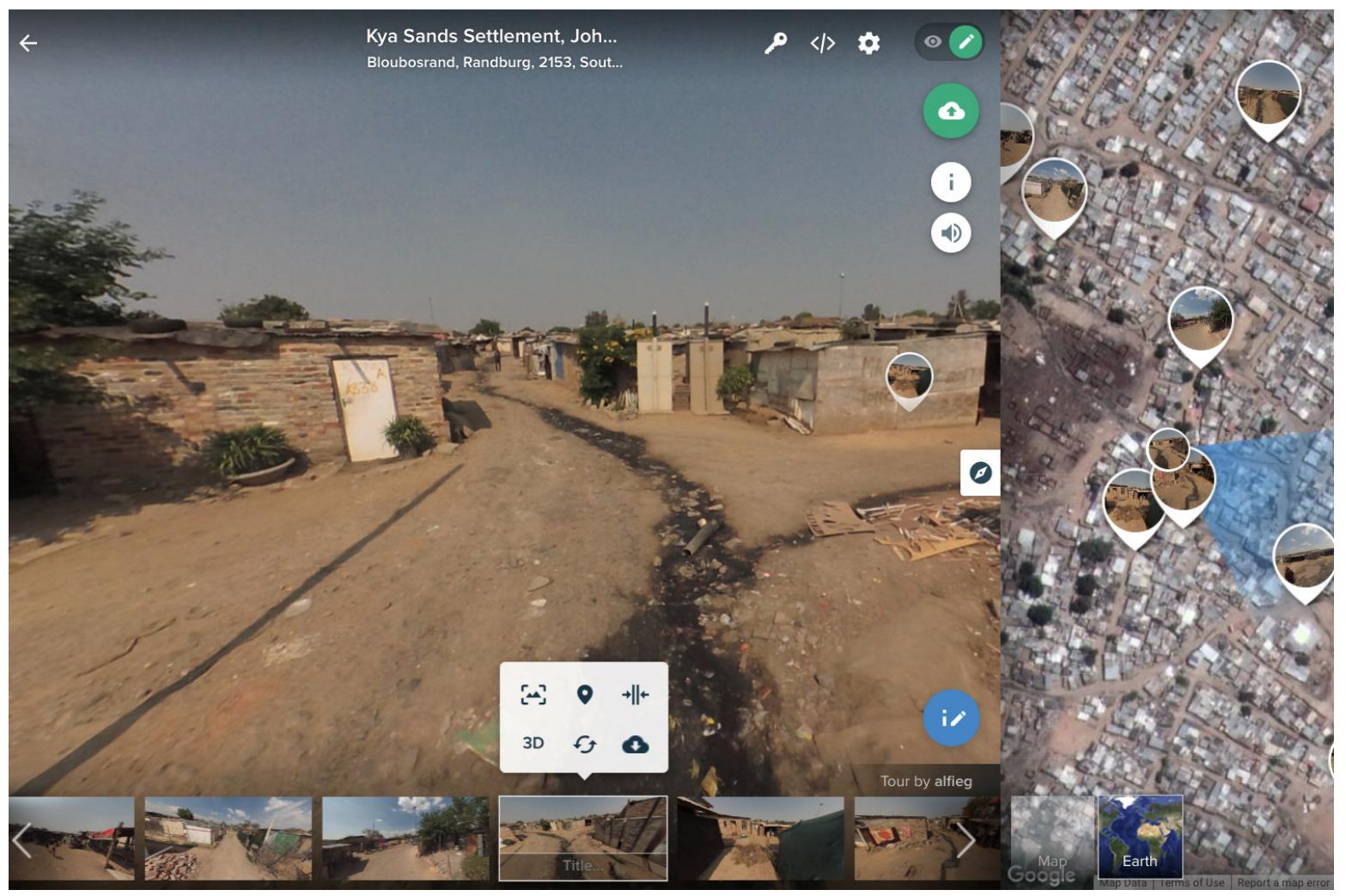

Figure 5: Screenshot of the Roundme interface, in edit mode. 


\section{Kya Sands Settlement, Johannesburg}

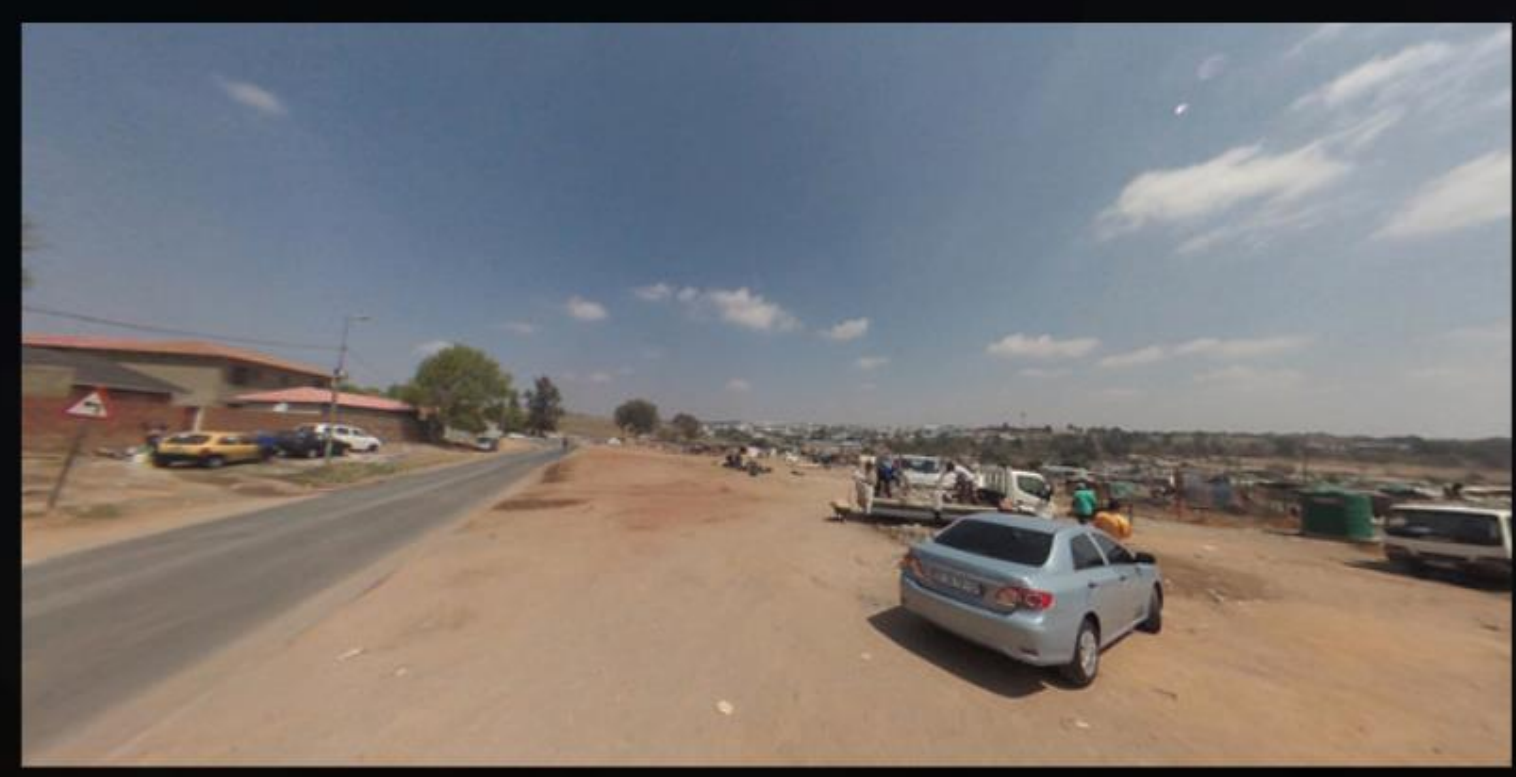

Kya Sands is an informal settlement in the north of the city of Johannesburg, Gauteng Province, South Africa. The settlement was initially established around the early 1990 s period, and is now home to an estimated 20,000 people. Kya Sands is divided into four sub-areas (A,B,C,D) located on a combination of private and state-owned land. State provision of services is minimal, including communal water standpipes, chemical toilets, and high mast lighting. Kya Sands is a typical informal peripheral urban space in Sub-Saharan Africa, with shack housing, limited public infrastructure and services, and, because it is largely invisible in government and private sector maps and databases. Google Street View captures imagery of the industrial estate to the west, and the wealthy suburb of Bloubosrand directly to the east, but does not venture into Kya Sands. This tour begins where Google Street View ends, where the pavement turns to dirt, providing an opportunity to see this informal settlement in 360 degrees at ground level. Follow the links through the four sub areas of the settlement.

\section{START}

Figure 6: Entry page for the Kya Sands 'virtual tour' street view.

Following the overall aims of those engaging in social audit activism in South Africa, and informal discussions with residents about their key concerns about living in Kya Sands, the second street view highlights service provision, infrastructural, and environmental hazard issues in Kya Sands. This Kya Sands - Services and Hazards street view includes 10 images from around the settlement (see https://roundme.com/tour/391902/info). Images show the placement of municipal services including water standpipes, outhouse toilets, and high mast lighting, as well as informal electricity connections, open water and waste, a recently installed bridge over the stream, and several informal childcare and community facilities.

The third street view was produced to illustrate the nuance and diversity of the settlement, highlighting not only hazards and limited infrastructure but also the broader story of Kya 
Sands. Information gathered from the wider research project, as well as the limited amount of information about Kya Sands on the web, were used to compile the Kya Sands Story, which made use of Roundme's interactive 'hotspot' functionality to embed text, web links, conventional photographs, and videos into the street view's thirteen $360^{\circ}$ images (see https://roundme.com/tour/391926/view/1354277/). The story contains various details about the settlement, its history, information about its residents, employment and entrepreneurial activities, the range of building materials used, and the local markets, shops, and community facilities. Rather than using a linear tour structure, no links are provided within the imagery, to encourage the user to navigate more freely by clicking on the image ribbon and map.

\section{D3. Framing, Linear Perspective, and Visibility in $360^{\circ}$}

Wider access to $360^{\circ}$ imagery production provides new opportunities to represent marginalized areas that might avoid the consequences of framing and fixed linear perspective. Positioned perpendicularly (and imagined oppositionally) to the vertical, ground-level $360^{\circ}$ imagery offers an alternative to the subjectifying gaze of the nadir perspective and the abstractions of low-oblique (see Harris, 2015), while also enabling the viewer to navigate through a full panoramic field of vision. This form of imagery may also counter the limitations of quantitative data; as Shapiro $(2017$, p.2) explains in the context of GSV, "its emphasis on the particularities of place rather than cartographic abstractions of space makes it seem progressive, absolved from the visual-semiotics of scientific rationality or objectivity".

However, as the de facto platform for $360^{\circ}$ urban representation, GSV has additional powers that can lead to injustices for urban spaces and the people who live there. GSV is generally understood as a "simulation of the city of the present" (Campkin and Ross, 2012, p.148), however its uneven coverage is complicit in shaping perceptions of economic and cultural value. Absent imagery is a signal to viewers that places are not worthy of our virtual or physical attention. Power et al. (2012) describe how GSV's peripheral coverage of a marginalized Irish housing estate - which initially made the area visible only from the distance of a main road - served to advance negative perceptions of the area in the minds of outsiders. Such processes of intersubjective stereotyping are central to injustices of misrecognition, whereby less powerful groups are subject to 'distorted identities' which can impact their dignity and sense of self (Zurn, 2003).

Kya Sands, and many informal settlements in South Africa and beyond, are similarly only visible in GSV from the vantage point of peripheral roads. As a demonstration of the potential for producing street view imagery outside of the GSV platform, the Kya Sands Tour provides an immersive, $360^{\circ}$ visual representation of the settlement, picking up where GSV coverage ends. The tour leads the viewer through the settlement, proceeding first through Area A, along the path that crosses Kya Sands stream, through Areas B and C on the west side, and then back over the stream on the footbridge and through Area D. Although the tour does enable the viewer to visually explore all four sub-areas of the settlement, coverage is fragmented; this was due to practical reasons, however the viewer may interpret uneven coverage in ways that could have negative implications for parts of the settlement not covered, similar to the effects of uneven GSV coverage. 
The Kya Sands Tour could be made accessible for public viewing on the Roundme platform; doing so would demand more consideration about how such imagery could be used as virtual form of 'slum tourism'. Slum tourism is a highly contested activity held up as both an example of the exploitation of the urban poor for the entertainment of outsiders, and an effective way to draw attention to hidden injustices. If conventional images of informality are understood to aestheticize and depoliticize poverty, slum tourism is often legitimized by claiming that exposing outsiders to lived realities first hand might avoid this - they are not only an aesthetic encounter, but also a moral and epistemological one (Dovey and King, 2012). If recognition is formed through intersubjective relations of respect and understanding, careful slum tourism provides an opportunity to advance not only distributive but also justice-as-recognition claims for informal settlements and their residents. Frenzel et al. (2014, p.431) claim that while slum tours in South Africa expose economic injustices to outsiders including policy makers, they also have symbolic power to challenge sociocultural misrecognition, through "addressing invisibility, overcoming territorial stigma and [the] empowerment of the urban poor". But will virtual slum tours have the same effect, without the benefit of physical presence and a tour guide? $360^{\circ}$ imagery potentially provides an opportunity for outsiders to experience these spaces in a way that may be sympathetic to reality, but at what point does realism descend into spectacle, and then to misrecognition?

With regards to framing and linear perspective, the viewer is able to manipulate the imagery in any direction, approximating the human eye's position above ground-level and dynamic plane of perspective, which enables an effectively seamless upward, downward, and sideways gaze. Cosgrove $(1985$, p.48) explains how realist representation of threedimensional space on two-dimensional surfaces "gives the eye absolute mastery over space" through the rules of geometry, which draws the viewer to the artist or photographer located outside of the image. Although the viewer of $360^{\circ}$ imagery is empowered to continually change the frame and perspective, the photo capture-position seemingly within the image amplifies the sense of the photographer or viewer's 'mastery over space', as inseparable from it. Gazing downward in the images solidifies this sense of being in the image, since the photographer has been edited out and the viewpoint appears to hover above the ground (see Figure 7). Thus it may be said that, akin to the power of aerial imagery, $360^{\circ}$ imagery may also exhibit a god's eye view, but much nearer to ground-level. From a visual-cognitive perspective, more attention to how viewers perceive space through this seemingly 'immersive' imagery is needed. From a social and political perspective, more attention is needed to the particular power geometries of immersive imagery, when the geometries of linear perspective are not fixed yet the viewer is still drawn to the photographer located ambivalently outside and within the image. 


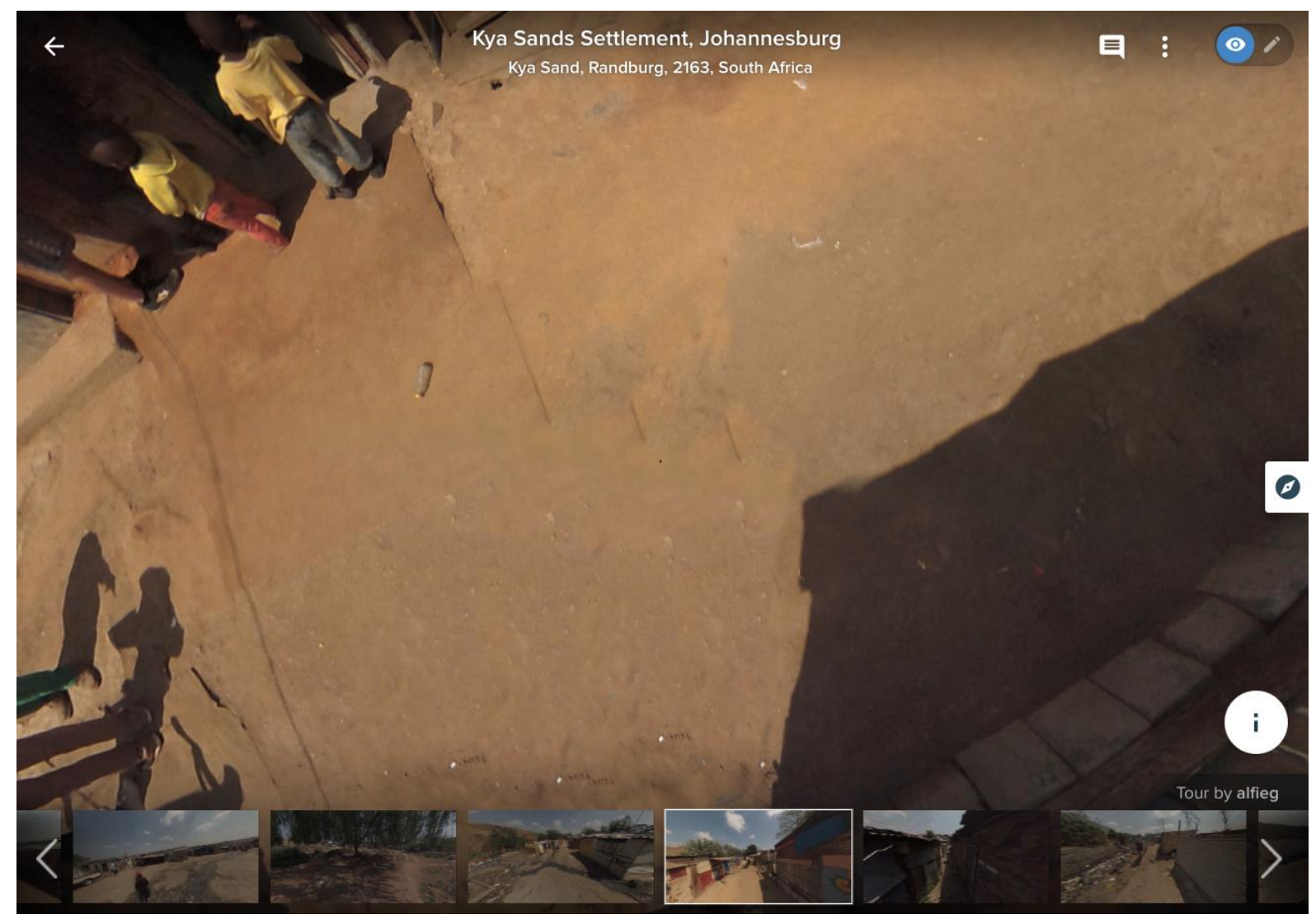

Figure 7: The downward gaze of $360^{\circ}$ imagery.

\section{D4. Distribution and Recognition through $360^{\circ}$ Street Views}

As illustrated in the Kya Sands - Services and Hazards street view, $360^{\circ}$ imagery could be used to fulfil similar objectives as quantitative social audits, to draw attention to uneven service provision as an issue of distributive injustice. For many social audits, the typical approach has been to 'let the data speak for themselves', although as those engaged in this form of data activism have discovered, data are a relatively easy target to contest. Moreover, data may have little to say about injustice in its full texture. Quantitative data is limited in the way that it represents space as a container comprised of discrete objects devoid of context, which is limiting in any setting, but may be particularly incompatible with the fluid, dynamic, and ultimately horizontal ontology of informality.

Dovey and King's $(2011 ; 2012)$ work articulates this slippage. As the authors explain with reference to Kevin Lynch's pioneering work on urban imaginaries, instead of discretized representations, "[t]he image of the informal city... is often found in the interstices of Lynch's categories of 'paths', 'edges' and 'landmarks'" (2011, p.26), which suggests a need for representations that capture informal settlements as continuous, fully textured places. The Kya Sands - Services and Hazards street view was designed to document the services, infrastructure, and environmental hazard issues in the settlement in a way that might more effectively represent real-world impacts and wider contexts. Through immersive $360^{\circ}$ imagery, the viewer is exposed to the lived realities of collecting water at communal standpipes, open water from leaking standpipes flowing down dirt paths, the dilapidated condition of outhouse toilets, household waste disposed in open spaces, and electricity and flooding hazards (e.g., see Figure 8). 


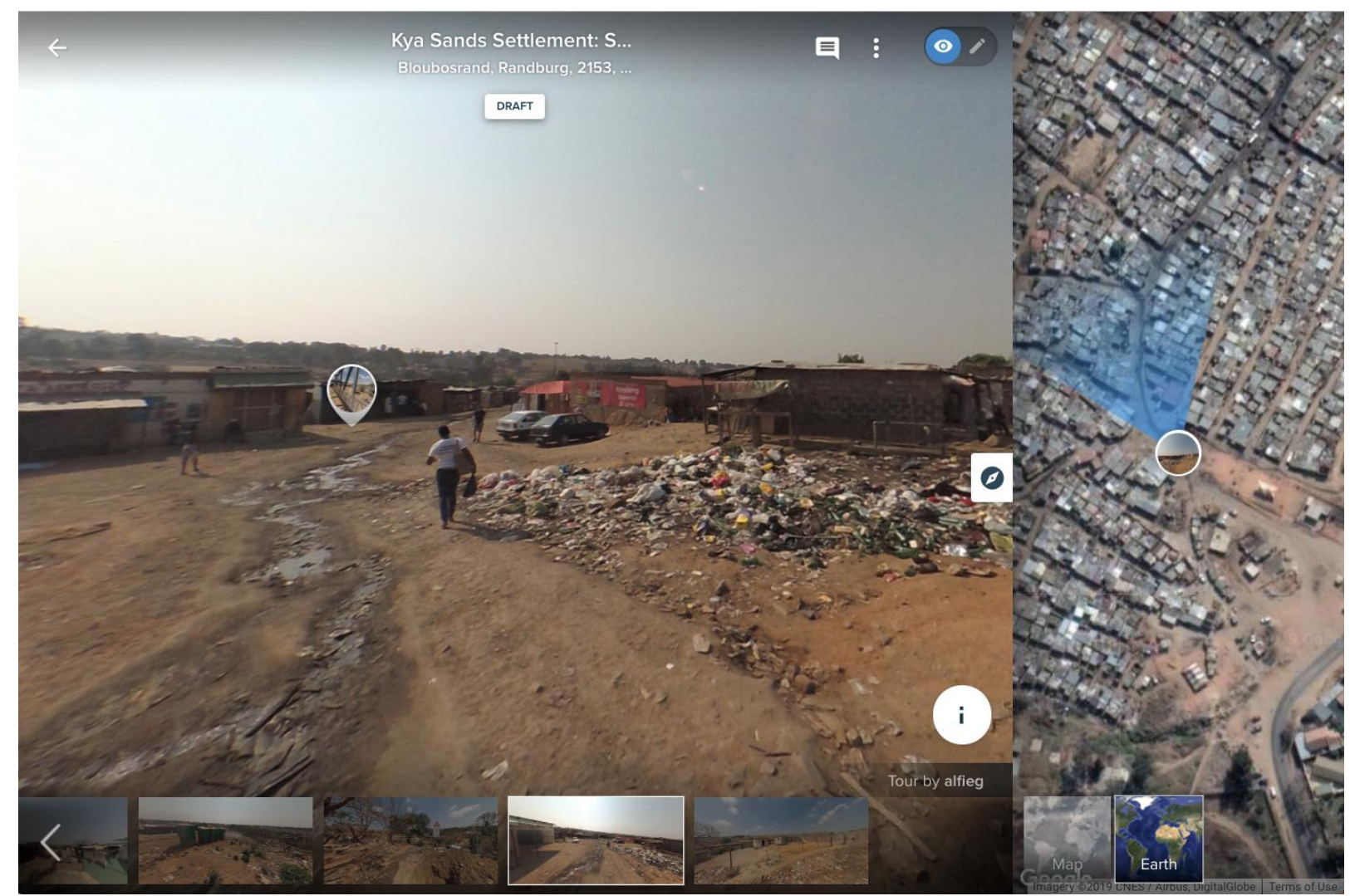

Figure 8: Screenshot of the Kya Sands-Services and Hazards street view showing waste disposal and open water from leaking standpipe.

Although further evidence is needed, this less reductive and abstract form of datafication may prove more convincing and less easy to dismiss by government officials. Social audit findings are typically widely circulated to government officials and online upon completion of the project. The Services and Hazards street view could help to provide the wider context and real-world impacts of distributive injustices, especially if combined with the voices of residents themselves. Instead of a standalone approach, the street views may be best suited to represent distributive injustices alongside other forms of representation. However, a key argument of this piece is that any attempt to advance distributive justice for marginalized places must first seek to establish spatial recognition for such places, particularly in settings in which being 'seen by the state' is a necessary first step towards obtaining basic services (Parnell and Pieterse, 2010).

This argument provides the basis for the Kya Sands Story. As Taylor (1994, p.25, emphasis added) argues, because identities are often shaped by relations of misrecognition, "a person or group of people can suffer real damage, real distortion, if the people or society around them mirror back to them a confining or demeaning or contemptible picture of themselves." Drawing on research in a marginalized area of Berlin, Cuny (2018) identifies three visualrepresentational strategies residents employ for managing and contesting such demeaning representations of the place they live. First, some residents of defamed areas internalize stigma, submitting to outsiders' perceptions but distancing themselves from other residents they deem to embody the negative characteristics. Second, residents counter and resist negative representations, through production of counternarratives. Thirdly, residents can try to reverse the stigma, by constructing stigmatizing representations of the majority. 
Following the second strategy, the aim of the Kya Sands Story was to develop "counterstigmatizing images" (Cuny, 2018, p.4) that reveal a more detailed and nuanced picture of the settlement through $360^{\circ}$ imagery and further text and multimedia embedded as 'hotspots' (see Figure 9). The Kya Sands Story can be compared with another visual imagery project designed to tell a hidden story about urban inequalities. The 'Unequal Scenes' (https://unequalscenes.com/) drone project produces vertical and oblique aerial photos and videos documenting gross spatial disparities in South Africa. These 'dialectical images' (Dovey and King, 2012) typically depict urban decay and informal settlements butting up awkwardly against wealthy suburbs and golf courses (including Kya Sands/Bloubosrand, see Figures $2 \mathrm{a}$ and $2 \mathrm{~b}$ ). The photographer explains the motivation:

"Inequalities in our social fabric are oftentimes hidden, and hard to see from ground-level... I defy the traditional power structures that keep these inequalities hidden so well from every direction except directly above. If the images provoke uncomfortable feelings of fear, despair, or an unsettling realization of complicity - good. They are intended to." (Miller, 2018).

These images certainly provoke uncomfortable feelings through a novel visual perspective, and there is a political potency that could be useful for drawing attention to the country's spatial inequalities. However I argue that their power to make these inequalities visible must be weighed against their power to aestheticize and depoliticize poverty, which can reduce the complexities of life in informal settlements to a universalizing story of suffering and hardship. In the Kya Sands/Bloubosrand Unequal Scenes aerial video

(https://unequalscenes.com/kya-sandsbloubosrand), the opening text - splashed across a low-oblique perspective of the settlement - declares, "The story of Kya Sands is a story of ash, smoke, and broken promises". This text, combined with the specific aerial perspective chosen, offers little possibility for viewer agency, and little chance of a nuanced understanding of the settlement.

The story of Kya Sands is partially one of poverty and informality, but it is also a relatively well-established residential area with residents that come from a variety of backgrounds and occupations, which may not align with common perceptions of informal settlements. The objective of producing the Kya Sands Story was to make visible the rather more complex and diverse realities of informal settlement living, which the viewer can experience in a selective, non-linear, and interactive way. By self-navigating through the settlement, choosing the linear perspective of the $360^{\circ}$ imagery, interacting with the additional multimedia content and web links provided in the hotspots, I argue that the viewer is provided greater opportunity to form an opinion of the settlement beyond the suffering trope. 


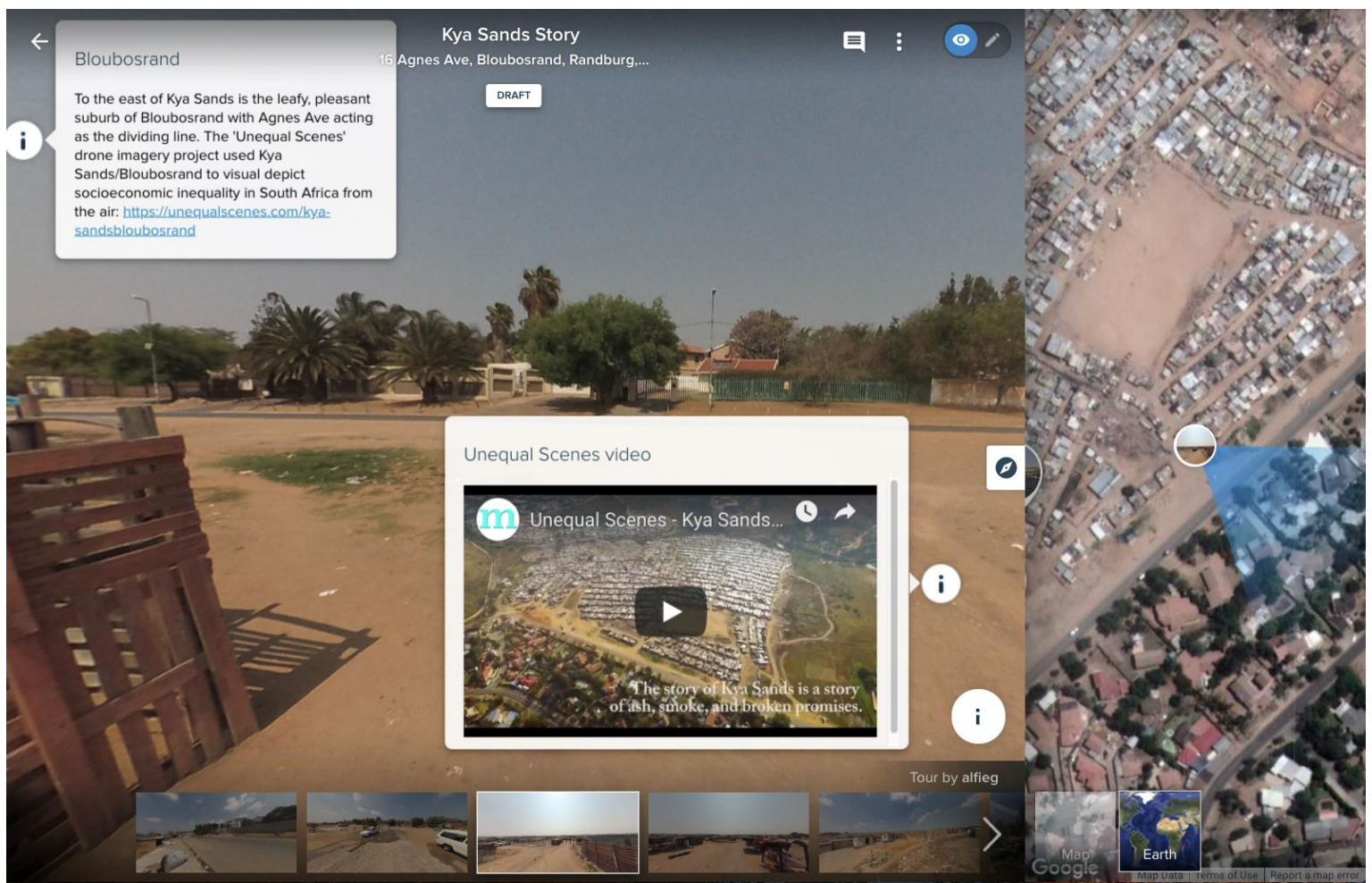

Figure 9: Screenshot of Kya Sands Story showing a $360^{\circ}$ image taken at the boundary between the settlement and the neighbouring suburb of Bloubosrand. The image is embedded with two interactive 'hotspots' with text, links to further web content, and a video depicting the visual inequalities between the residential areas, as captured by the Unequal Scenes drone aerial imagery project.

\section{D5. $360^{\circ}$ Imagery, Exaggerated Seeing, and Misrecognition}

The notion that $360^{\circ}$ visual representation can lead to recognition rests on at least two key assumptions. The first assumption is that any form of visibility is desirable or at least necessary to draw attention to highly marginalized urban fragments. The second assumption is that this specific type of visual imagery could enable a less reductive form of datafication that might align better with an ontology of informality, sidestepping the limitations of quantitative representation and aerial perspectives. Although the previous section considers these ideas with caution, future research should also pay attention to the potential for additional harms in which enhanced $360^{\circ}$ visibility leads to advanced injustices of misrecognition. Here, feminist philosopher Kelly Oliver's (2001) distinction between good and bad forms of visibility for marginalized groups is useful. Oliver describes good visibility as 'responsible vision'; bad visibility, however is more complex - it may simply involve invisibility, or it may involve various forms of 'exaggerated seeing' including hypervisibility, stereotyping, and making a spectacle (p.149). Here I briefly consider one potential unintended use of these Kya Sands street views to illustrate how $360^{\circ}$ imaging might be implicated in one form of exaggerated seeing, hypervisibility.

With little information available about the settlement from government or private sector sources, the $360^{\circ}$ street views are perhaps the most extensive collection of representational artefacts for Kya Sands. But in moving toward visibility and (potentially) recognition, there is the risk of going too far, of hypervisibility. With the proliferation of digital imaging technologies and image hosting platforms, combined with deep learning artificial 
intelligence (Al), imagery is poised to become the biggest source of quantitative data about cities. The status of street views as a potentially less reductive form of datafication disregards the possibility of quantification through emerging forms of image analytics and computer vision, which are ironically referred to as 'recognition' techniques. As with aerial imagery, automated feature recognition for ground-level imagery is rapidly developing within an emerging field labelled 'urban science', partly due to the push to produce threedimensional models of urban space for autonomous and smart vehicle markets.

The use of GSV as a tool for virtual auditing of the built environment is well-established (Rundle et al., 2011; lannelli and Dell'Acqua, 2017), however significant advances in image analytics now enable highly detailed, automated extraction and quantification of objects and people. Some image recognition techniques, such as convolutional neural networks, require little if any human training or oversight. These techniques have been used to estimate land use and socioeconomic characteristics of urban neighbourhoods in fine grain detail (Law et al., 2018; Srivastava et al., 2018). Gebru et al. (2017) analyzed 50 million GSV images using computer vision recognition techniques, claiming to be able to accurately predict local income, race, education, and voting patterns by identifying the make, model, and year of all motor vehicles in a neighbourhood. Dodge describes these processes as "analogous to the use of overhead imagery and remote sensing, but for urban streetscapes" (2018, p.955). However, I argue that undertaking these processes on $360^{\circ}$ street-level imagery of formerly invisible spaces could accelerate their hypervisibility to a degree not possible with aerial imagery, precisely because of the detail captured at the ground-level plane of perspective.

Governments and private sector are collaborating on urban analytics problems, with the aim of reducing the cost of data collection using conventional in-situ approaches. While these techniques may provide opportunities to 'know' invisible spaces in a rapid and cost effective way, this extreme form of datafication and hypervisibility could accelerate the abstract and reductive understanding of urban spaces, with harmful consequences for residents. Scholars in surveillance studies have drawn attention to the goals of surveillance in the digital era, explaining how contemporary forms of surveillance are rarely concerned with monitoring and disciplining individual bodies. Rather, contemporary 'dataveillance' is about segmenting society for capitalist and social control objectives, a process referred to as 'social sorting' (Lyon, 2003). Image analytics in urban science is effectively concerned with analogous processes of 'spatial sorting' - segmenting space into highly refined categories for capitalist exploitation, or to target and profile the people associated with them (Wood, 2017).

Even though the shift 90 degrees - from vertical, to oblique, to street-level - is conceptualized as a shift from quantitative to qualitative forms of datafication, from abstraction to human experience, from aestheticization to realism, street-level image analytics introduces the possibility of advancing injustices of misrecognition as places (and the people associated with them) are defined, categorized, and ranked according to socioeconomic worth or risk. For example, it has become well known that predictive analytics advances processes of social and racial stereotyping, which leads to misrecognition for already marginalized people (Jefferson, 2018). Taylor (2017) describes how machine learning approaches applied to aerial imagery of migrants could be used to categorize behaviours, predict migration patterns, and restrict potential 'undesirables' from claiming 
asylum. Naik et al.'s (2016) application of these techniques to GSV imagery demonstrates how these forms of analytics, but applied to urban features and based in criminological theory (e.g. Broken Windows Theory), could be accelerated via the ground-level visual perspective, at an "unprecedented resolution and scale" (p.129). In a situation of computer vision, "street-level ceases to be a progressive antidote to the spatial abstractions of aerial imaging, but instead has its own set of power geometries, stemming not from the abstraction of vertical perspective but from abstraction by 'datafication'” (Shapiro, 2017, 3).

For informal settlements, predictive analytics derived from highly detailed $360^{\circ}$ imagery will pose considerable threats to the community's ability to self-identify, suggesting caution is needed when engaging in this form of datafication. For the purposes of this pilot study, imagery is likely too low-resolution for these forms of image analytics, and it has not yet been shared widely beyond the project team. Further research will be required to determine whether such imagery advances responsible vision or exaggerated seeing.

\section{E. Conclusions: Visual Data Justice?}

\section{E1. Summary}

Beyond the distribution of 'goods' and 'bads' in society, further forms of injustice accrue to the residents of informal settlements over and above inadequate access to basic services and exposure to environmental risks. In foregrounding the importance of identity formation and the status hierarchy, recognition provides a basis for considering injustices that threaten the dignity of residents of informal settlements through invisibility, in a country in which visibility is considered a basic prerequisite for equality. This paper draws on interviews from data activists about the role of quantitative data in advancing distributive justice aims, and a pilot study to reflexively consider the potential of immersive, $360^{\circ}$ street views for advancing recognition for informal settlements. Through exploration of key issues emerging from the production of three different types of street views for the settlement, the paper provides a basis for further enquiry into the role of $360^{\circ}$ imagery and other immersive visual technologies in shaping how informal spaces are recognized by outsiders. Findings from the project provide answers to the three guiding questions.

The first question was what is the role of quantitative data in representing injustice and advancing the needs of marginalized people and places? Interviews with data activists suggested that quantitative data on its own has limited potential as a 'tool' of visibility. Since informal settlements often "disappear from the cognitive map of those who allocate resources" (Dovey and King, 2011, p.22), social audits in South Africa are pragmatically designed to make them visible to policy makers, and in doing so, they often highlight gaps between budgeted allocation of services and the reality on the ground. Yet the data themselves have become the target of resistance, providing an opportunity for governments to deflect attention away from the substantive issues, rendering the realities of informal settlement living further invisibilized. Because of this, the findings suggest that quantitative data, on their own, have limited potential to 'make visible' service delivery injustices. This finding adds further dimensionality to a growing understanding that conventional forms of quantitative representation (e.g. statistics, maps, static categories) may be unsuited to an 
ultimately horizontal, fuzzy, and dynamic ontology of informality. More broadly, it calls into question the limitations of any attempt to datafy injustice.

The second question was how can consumer-grade $360^{\circ}$ imaging technologies be used to produce street-level imagery of informal settlements? The idea for the $360^{\circ}$ imagery pilot study emerged from three observations: the limitations of quantitative data as described above, wider critiques of aerial approaches to representing informal spaces, and the uneven coverage of Google Street View. Against this backdrop, the pilot study sought to advance the potential for newly-accessible technologies to be used to produce ground-level immersive $360^{\circ}$ imagery of informal settlements. The project answered the question by demonstrating how street-level imagery of Kya Sands could be produced using consumergrade hardware and software and a systematic imagery collection strategy. Three street views were produced for the settlement, the Kya Sands Tour, Kya Sands - Services and Hazards, and the Kya Sands Story. These findings provide a basis for further research and practice into the production of $360^{\circ}$ imagery for representing not only informal settlements, but other less visible urban spaces.

The third question was can a potentially more progressive form of datafication be realised through street-level $360^{\circ}$ imagery? This pilot study provides preliminary evidence of the potential for progressive datafication through panoramic visual representation, but it also raises further questions about the risks of image-based datafication. The Kya Sands Tour was designed to broadly resemble the Google Street View aesthetic and mode of user interaction, providing a 'virtual tour' through the four sub-areas of the settlement. Picking up where Street View ends, such tours could provide outsiders a deeper understanding of informal settlements, and more speculatively, they might help to register such spaces as not separate from but intimately interconnected with the wider city. This tour does however raise questions about the potential benefits or harms of virtual slum tourism.

The Services and Hazards street view was designed to illustrate the realities of living in areas subject to limited provision of basic services and exposure to hazards, a goal akin to those of quantitative social audits, demonstrating distributive injustice. Yet, this street view may be less open to resistance and deflection from policy makers compared to the abstractions and reductionism of data-driven forms of representation. The Kya Sands Story specifically diverges from the GSV aesthetic and mode of user interaction, with the goal of telling a more detailed and nuanced story of the settlement compared to the reductionist narrative propagated by framed aerial and ground-level imagery. The lack of framing and linear perspective arguably provides the viewer with a degree of agency and greater chance of a nuanced understanding of the settlement.

These findings thus point to the potential of this imagery for advancing the social justice principle of recognition for informal settlements - a possibility that might more broadly be referred to as spatial recognition (cf. Luque-Ayala and Neves Maia, 2019). Yet, as speculated in the final section, when highly detailed, panoramic ground-level imagery is used for other purposes - including automated urban space classification using computer vision techniques - it may have the opposite effect of rapidly accelerating spatial misrecognition, which calls into question the notion of such imagery as a more realistic, sympathetic, or progressive form of datafication. 


\section{E2. Recommendations and Future Research Agenda}

This piece is driven by the notion that ground-level $360^{\circ}$ geovisualities might offer new opportunities to advance recognition for marginalized people and places, however potential is largely speculative at this stage. As a key topic of future enquiry, research should engage potential viewers of such representations (e.g. citizens, officials, policy makers) to understand what the imagery invokes in both residents and outsiders, and what it makes possible in terms of visibility and recognition. This aligns with a call by Harris $(2015, p .611)$; as the author implores, "[t]here is ... a need for more engagement with how different people actually respond to and experience aerial (and ground-level) views, and how different distances from the ground and different planes of vision (vertical, oblique, or lowoblique) shape contrasting relationships with cities". This paper however suggests a further dimension of enquiry, focusing on how different people respond to and experience immersive $360^{\circ}$ views when the frame and fixed plane of perspective are discarded. A follow-on project is in planning, designed around research questions about the added value of a street-level imagery approach for advancing visibility and recognition for informal settlements, compared with quantitative representation strategies. These questions could be answered through a full research study involving participatory design and data collection, sharing of imagery with the community and municipal government, as well interviews with all stakeholders including participants, residents, activist organizations, and public officials.

More generally, findings of the project suggest the following core questions for future research and practice on visual representation of informal settlements:

- How can digital representations be produced in a more participatory way, given the technical nature of imagery collection and management and the lack of formal governance structures in many informal settlements?

- How might a truly 'insider' view diverge from a version diffracted through a research process?

- What processes are appropriate for engaging wider stakeholders such as 'virtual tourists' and policy makers?

- What forms of image ownership and sharing are appropriate, and is it possible to prevent harms from unintended uses of imagery?

This paper also suggests at least three topics that must be central to the wider research agenda for data justice. First, and perhaps foremost, it points to the limitations of conventional forms of quantitative data for representing injustice. Since a considerable portion of the emerging literature on data justice - particularly the 'data activism' strains hinge on the idea that (in)justice can be datafied (see discussions in Dourish and Gómez Cruz, 2018; Gutierrez and Milan, 2018; Kennedy, 2018), findings from the interviews suggest that more consideration of this basic tenet is needed. Of course, the beliefs of those working in this area are more nuanced, however I suggest that the future agenda for data justice must look more carefully to a much longer history of critical enquiry on the societal impacts of data (e.g. Westin and Baker, 1972). The field of smart cities and data-driven urbanism provides a current, parallel area of enquiry that could be more closely integrated with urban data justice. Amongst other things, work in this area draws attention to a disconnect between perceptions of what data are and what data can achieve, and the reality in practice - their 'imagined affordances' (Nagy and Neff, 2015; Baack, 2018). A key 
future research question for data justice then is, what forms and examples of injustice can be remedied through datafication, and which are left invisible by it? For activism-related practices specifically, what is gained and lost when energies are shifted from 'people power' to 'data power'?

Second, in drawing a connection between state inattention to distributive injustices and community invisibility, this research suggests that recognition must be a core concern of data justice, if only as a preliminary step towards addressing inequities in material resources and basic services. A future research agenda should seek to address questions such as what is the relationship between misrecognition and maldistribution in the context of datafication? Yet recognition is a contested and often vaguely described notion, with considerable discord over the meaning even in those who espouse it. How and when recognition is achieved (or not) is not objectively and widely agreed upon between stakeholders. Because of the ambiguity, a future agenda for recognition within data justice should seek to develop normative frameworks for assessing data-related (mis)recognition. Fraser's notion of 'participatory parity' (2008) provides one such normative ideal that could be used to judge when recognition has been achieved. This suggests further research questions: what does parity of participation look like in a datafying world, and what is the relevance of this concept amidst growing resistance to participating in processes of datafication?

Thirdly, in relation to the above two points, this research suggests that more attention as to the status of visual imagery in relation to datafication must be on the agenda of future work in data justice. A key aim of this pilot study was to develop a non-quantitative digital representational strategy that might overcome limitations of surveys, maps, and other reductive forms of representation. While the findings and discussion suggest meaningful possibilities for representing informality in a way that is sympathetic to informal spaces and their residents, the status of imagery as a somehow more realist and less reductive form of datafication might be highly naïve. This project specifically grappled with a growing sense of unease about the imagery, in part because a limited degree of participation risked our speaking on behalf of the community, but more so because of the potential for unintended uses of the imagery once released for wider access.

The first concern could be addressed with a future project based on a fully participatory design, however addressing the second concern will require considerably more attention. There is growing evidence of individual- and group-level injustices derived from big data surveillance (Dencik et al., 2016), from commercial analysis of digital behavioural data gleaned from use of the web, mobile phones, and smart technologies (Zuboff, 2015; Taylor et al., 2017), and through processes of 'function creep' whereby data collected for one reason is then analyzed for another unjust purpose (Cinnamon et al., 2016; Heeks and Renken, 2018). A small amount of attention has been paid to data injustice in the context of aerial imagery analytics (e.g. Taylor, 2017) however a future agenda for data justice must give more credence to the notion of images-as-data, and specifically, the new forms of analytics they make possible. This will soon become a more 'visible' problem, as Al and computer vision techniques are increasingly applied to photos of people and places in rich, ground-level detail, rendering 'born quantitative' data merely a drop in the urban data bucket. 


\section{References}

Aalbers, M. B. (2014). Do maps make geography? Part 1: redlining, planned shrinkage, and the places of decline. ACME: An International E-Journal for Critical Geographies, 13(4), 525-556.

Agamben, G. (1998). Homo sacer: Sovereign power and bare life. Redwood City, CA: Stanford University Press.

Alvarez León, L. F. \& Quinn, S. (2019). The value of crowdsourced street-level imagery: Examining the shifting property regimes of OpenStreetCam and Mapillary. GeoJournal, 84(2), 395-414.

Baack, S. (2018). Civic Tech at mySociety: How the Imagined Affordances of data shape data activism. Krisis: Journal for Contemporary Philosophy, (1), 44-56.

Beer, D. (2019). The data gaze: Capitalism, power and perception. London: Sage.

Bénit-Gbaffou, C. (2015). Introduction: Politicising and politicking community participation in urban governance. In Bénit-Gbaffou, C. (Ed.) Popular politics in South African cities: Unpacking community participation. 1-17. Cape Town: HSRC Press.

Butler, J. (2007). Torture and the ethics of photography. Environment and Planning D: Society and Space, 25(6), 951-966.

Campbell, D. (2007). Geopolitics and visuality: Sighting the Darfur conflict. Political Geography, 26(4), 357-382.

Campkin, B. \& Ross, R. (2012). Negotiating the city through Google Street View. In Higgott, A. \& Wray, T. (Eds.) Camera constructs: Photography, architecture and the modern city. 147-158. Farnham: Ashgate.

Cinnamon, J. (2017). Social injustice in surveillance capitalism. Surveillance \& Society, 15(5), 609-625.

Cinnamon, J. (forthcoming). Attack the data: Agency, power, and technopolitics in South African data activism. Annals of the American Association of Geographers.

Cinnamon, J., Jones, S. K. \& Adger, W. N. (2016). Evidence and future potential of mobile phone data for disease disaster management. Geoforum, 75 253-264.

Cosgrove, D. (1985). Prospect, perspective and the evolution of the landscape idea. Transactions of the Institute of British Geographers, 10(1), 45-62.

Crampton, J. W. (2001). Maps as social constructions: Power, communication and visualization. Progress in Human Geography, 25(2), 235-252.

Cuny, C. (2018). Residents' responses to 'territorial stigmatization': visual research in Berlin. International Journal of Urban and Regional Research, In press.

Currie, M., Paris, B. S., Pasquetto, I. \& Pierre, J. (2016). The conundrum of police officerinvolved homicides: counter-data in Los Angeles County. Big Data \& Society, 3(2), 1-14.

Dalton, C. M., Taylor, L. \& Thatcher , J. (2016). Critical Data Studies: A dialog on data and space. Big Data \& Society, 3(1), 1-9.

Dencik, L., Hintz, A. \& Cable, J. (2016). Towards data justice? The ambiguity of antisurveillance resistance in political activism. Big Data \& Society, 3(2), 1-12.

Dodge, M. (2018). Mapping II: News media mapping, new mediated geovisualities, mapping and verticality. Progress in Human Geography, 42(6), 949-958.

Donovan, K. (2012). Seeing like a slum: Towards open, deliberative development. Georgetown Journal of International Affairs, 13(1), 97-104.

Dourish, P. \& Gómez Cruz, E. (2018). Datafication and data fiction: narrating data and narrating with data. Big Data \& Society, 5(2), 1-10. 
Dovey, K. \& King, R. (2011). Forms of informality: Morphology and visibility of informal settlements. Built Environment, 37(1), 11-29.

Dovey, K. \& King, R. (2012). Informal urbanism and the taste for slums. Tourism Geographies, 14(2), 275-293.

Duncan, J. S. \& Duncan, N. G. (2001). The aestheticization of the politics of landscape preservation. Annals of the Association of American Geographers, 91(2), 387-409.

Equal Education (2016). Of "loose papers and vague allegations": A social audit report on the safety and sanitation crisis in Western Cape Schools. Cape Town: Equal Education.

Fraser, N. (2005). Reframing justice in a globalizing world. New Left Review, 3669-88.

Fraser, N. (2008). Abnormal justice. Critical Inquiry, 34(3), 393-422.

Fraser, N. \& Honneth, A. (2003). Redistribution or recognition?: A political-philosophical exchange. Brooklyn, NY: Verso.

Frenzel, F. (2014). Slum tourism and urban regeneration: Touring inner Johannesburg. Urban Forum, 25(4), 431-447.

Gebru, T., Krause, J., Wang, Y., Chen, D., Deng, J., Aiden, E. L. \& Fei-Fei, L. (2017). Using deep learning and Google Street View to estimate the demographic makeup of neighborhoods across the United States. Proceedings of the National Academy of Sciences, 114(50), 13108-13113.

Geissler, R. C. (2011). Private eyes watching you: Google Street View and the right to an inviolate personality. Hastings Law Journal, 63 897-926.

Gevaert, C. M., Persello, C., Sliuzas, R. \& Vosselman, G. (2017). Informal settlement classification using point-cloud and image-based features from UAV data. ISPRS Journal of Photogrammetry and Remote Sensing, 125 225-236.

Gutierrez, M. \& Milan, S. (2018). Technopolitics in the age of big data: The rise of proactive data activism in Latin America. In Cabellero, F. S. \& Gravante, T. (Eds.) Networks, movements and technopolitics in Latin America: Critical analysis and current chalenges. 95-109. London: Springer.

Harley, J. B. (1989). Deconstructing the map. Cartographica, 26(2), 1-20.

Harris, A. (2015). Vertical urbanisms: Opening up geographies of the three-dimensional city. Progress in Human Geography, 39(5), 601-620.

Hecker, T. (2010). The slum pastoral: Helicopter visuality and Koolhaas's Lagos. Space and Culture, 13(3), 256-269.

Heeks, R. \& Renken, J. (2018). Data justice for development: What would it mean? Information Development, 34(1), 90-102.

Hesford, W. S. (2015). Surviving recognition and racial in/justice. Philosophy \& Rhetoric, 48(4), 536-560.

Honneth, A. (2004). Recognition and justice: Outline of a plural theory of justice. Acta Sociologica, 47(4), 351-364.

Iannelli, G. \& Dell'Acqua, F. (2017). Extensive exposure mapping in urban areas through deep analysis of street-level pictures for floor count determination. Urban Science, 1(2), 1-13.

Jefferson, B. J. (2018). Predictable policing: Predictive crime mapping and geographies of policing and race. Annals of the American Association of Geographers, 108(1), 1-16.

Johnson, J. A. (2014). From open data to information justice. Ethics and Information Technology, 16(4), 263-274.

Kallin, H. \& Slater, T. (2014). Activating territorial stigma: Gentrifying marginality on Edinburgh's periphery. Environment and Planning A, 46(6), 1351-1368. 
Keene, D. E. \& Padilla, M. B. (2014). Spatial stigma and health inequality. Critical Public Health, 24(4), 392-404.

Kennedy, H. (2018). Living with data: Aligning data studies and data activism through a focus on everyday experiences of datafication. Krisis: Journal for Contemporary Philosophy, (1), 18-30.

Kennedy, H. \& Bates, J. (2017). Data power in material contexts: Introduction. Television \& New Media, 18(8), 701-705.

Kennedy, H., Poell, T. \& van Dijck, J. (2015). Data and agency. Big Data \& Society, 2(2), 1-7. Kitchin, R. (2014). The real-time city? big data and smart urbanism. GeoJournal, 79(1), 1-14. Kompridis, N. (2007). Struggling over the meaning of recognition: A matter of identity, justice, or freedom? European Journal of Political Theory, 6(3), 277-289.

Kuffer, M., Pfeffer, K. \& Sliuzas, R. (2016). Slums from space-15 years of slum mapping using remote sensing. Remote Sensing, 8(6), 1-29.

Law, S., Seresinhe, C. I., Shen, Y. \& Gutierrez-Roig, M. (2018). Street-Frontage-Net: urban image classification using deep convolutional neural networks. International Journal of Geographical Information Science, In press

Lawson, V. (1995). The politics of difference: Examining the quantitative/qualitative dualism in post-structuralist feminist research. The Professional Geographer, 47(4), 449-457.

Linke, U. (2012). Mobile imaginaries, portable signs: Global consumption and representations of slum life. Tourism Geographies, 14(2), 294-319.

Luque-Ayala, A. \& Neves Maia, F. (2019). Digital territories: Google maps as a political technique in the re-making of urban informality. Environment and Planning D: Society and Space, 37(3), 449-467.

Lyon, D. (Ed.) (2003). Surveillance as social sorting: Privacy, risk, and digital discrimination, London: Routledge.

Mahabir, R., Croitoru, A., Crooks, A., Agouris, P. \& Stefanidis, A. (2018). A critical review of high and very high-resolution remote sensing approaches for detecting and mapping slums: Trends, challenges and emerging opportunities. Urban Science, 2(1), 1-38.

Mansell, C. M. (2018). A change of perspective: Aerial photography and "the right to the city" in a Palestinian refugee camp. In Ristovska, S. \& Price, M. (Eds.) Visual imagery and human rights practice. 213-228. London: Palgrave Macmillan.

McFarlane, C. (2018). Fragment urbanism: Politics at the margins of the city. Environment and Planning D: Society and Space, 36(6), 1007-1025.

Meng, A. \& DiSalvo, C. (2018). Grassroots resource mobilization through counter-data action. Big Data \& Society, 5(2), 1-12.

Milan, S. \& van der Velden, L. (2016). The alternative epistemologies of data activism. Digital Culture \& Society, 2(2), 57-74.

Miller, D. (1999). Principles of social justice. Cambridge, MA: Harvard University Press.

Miller, J. (2018). Unequal scenes - by Johnny Miller. Available from:

https://unequalscenes.com/about-contact.

Nagy, P. \& Neff, G. (2015). Imagined affordance: Reconstructing a keyword for communication theory. Social Media + Society, 1(2), 1-9.

Naik, N., Raskar, R. \& Hidalgo, C. A. (2016). Cities are physical too: Using computer vision to measure the quality and impact of urban appearance. American Economic Review, 106(5), 128-32.

Odendaal, N. (2006). Towards the digital city in South Africa: Issues and constraints. Journal of Urban Technology, 13(3), 29-48. 
Odendaal, N. (2015). Getting smart about smart cities in Cape Town: Beyond the rhetoric. In Marvin, S., Luque-Ayala, A. \& McFarlane, C. (Eds.) Smart urbanism: Utopian vision or false dawn? 87-103. London: Routledge.

Oliver, K. (2001). Witnessing: Beyond recognition. Minneapolis: University of Minnesota Press.

Parks, L. (2009). Digging into Google Earth: An analysis of "Crisis in Darfur". Geoforum, 40(4), 535-545.

Parnell, S. \& Pieterse, E. (2010). The 'right to the city': institutional imperatives of a developmental state. International Journal of Urban and Regional Research, 34(1), 146162.

Power, M. J., Neville, P., Devereux, E., Haynes, A. \& Barnes, C. (2012). 'Why bother seeing the world for real?': Google Street View and the representation of a stigmatised neighbourhood. New Media \& Society, 15(7), 1022-1040.

Rawls, J. (1971). A theory of justice. Cambridge, MA: Harvard University Press.

Redden, J. (2018). The harm that data do. Available from: https://www.scientificamerican.com/article/the-harm-that-data-do/.

Rossouw, J. (2015). "True, reliable and valid?" Data and community experience in the case of the janitorial service social audit. Master of Philosophy. Department of Development Studies, University of Cape Town.

Rundle, A. G., Bader, M. D. M., Richards, C. A., Neckerman, K. M. \& Teitler, J. O. (2011). Using Google Street View to audit neighborhood environments. American Journal of Preventive Medicine, 40(1), 94-100.

Shapiro, A. (2017). Street-level: Google Street View's abstraction by datafication. New Media \& Society, 20(3), 1201-1219.

Slater, T. (2017). Territorial stigmatization: Symbolic defamation and the contemporary metropolis. In Hannigan, J. \& Richards, G. (Eds.) The Sage handbook of new urban studies. 111-125. London: Sage Publications Ltd.

Social Audit Network (2016). About Social Audit Network. Available from: http://socialaudits.org.za/about/.

Srivastava, S., Vargas Muñoz, J. E., Lobry, S. \& Tuia, D. (2018). Fine-grained landuse characterization using ground-based pictures: A deep learning solution based on globally available data. International Journal of Geographical Information Science, In press.

Tabuchi, T., Fukuhara, H. \& Iso, H. (2012). Geographically-based discrimination is a social determinant of mental health in a deprived or stigmatized area in Japan: A crosssectional study. Social Science \& Medicine, 75(6), 1015-1021.

Taylor, C. (1994). The politics of recognition. In Guttman, A. (Ed.) Multiculturalism: Examining the politics of recognition. 25-74. Princeton, NJ: Princeton University Press.

Taylor, L. (2017). What is data justice? The case for connecting digital rights and freedoms globally. Big Data \& Society, 4(2), 1-14.

Taylor, L., Floridi, L. \& van der Sloot, B. (Eds.) (2017). Group privacy: New challenges of data technologies, Dordrecht: Springer.

Thompson, S. (2009). Participatory parity and self-realisation. Good Society Journal, 18(1), 57-62.

van Dijck, J. (2014). Datafication, dataism and dataveillance: big data between scientific paradigm and ideology. Surveillance \& Society, 12(2), 197-208.

Wacquant, L., Slater, T. \& Pereira, V. B. (2014). Territorial stigmatization in action. Environment and Planning A, 46(6), 1270-1280. 
Westin, A. F. \& Baker, M. A. (1972). Databanks in a free society: Computers, record-keeping and privacy. New York: Quadrangle.

Williams, N., Quincey, D. \& Stillwell, J. (2016). Automatic classification of roof objects from aerial imagery of informal settlements in Johannesburg. Applied Spatial Analysis and Policy, 9(2), 269-281.

Wood, D. M. (2017). Spatial profiling, sorting and prediction. In kitchin, R., Lauriault, T. P. \& Wilson, M. W. (Eds.) Understanding spatial media. 225-234. London: Sage.

Zuboff, S. (2015). Big other: surveillance capitalism and the prospects of an information civilization. Journal of Information Technology, 30(1), 75-89.

Zurn, C. F. (2003). Identity or status? Struggles over 'recognition' in Fraser, Honneth, and Taylor. Constellations, 10(4), 519-537.

\section{Acknowledgements}

The "Urban Data, Inequality and Justice in the Global South" case studies form part of a Senior Research Fellowship funded by the University of Manchester's Sustainable Consumption Institute with additional financial support from Canada's International Development Research Centre. The empirical research was conducted during the author's visiting fellowship at Wits University, which was funded by the South African National Research Foundation and UK Newton Fund. Thanks to research participants and residents of Kya Sands.

\section{About the Author}

Jonathan Cinnamon is a broadly trained human geographer and geographic information scientist with a research focus on datafication and the expansion of digital technologies in urban, health, and development contexts. His work develops methods for data production and visualization for low-resource settings, and attends to the ethical and political implications of data and technologies in processes of social change. This research has been funded by research councils in Canada, South Africa, and the United Kingdom. 


\title{
Case 3: Spatial|Data Justice Mapping and Digitised Strolling against Moral Police in Iran
}

\author{
Azadeh Akbari \\ Heidelberg University
}

\begin{abstract}
Through a case study of women's resistance against the moral police in Iran, this paper contends that claims to data justice cannot be investigated unless they are situated in broader political frames. Whilst the current literature uses a single axis analysis of data justice as well as conceptual tools that are appropriated for democratic power relations, this research positions data justice in a matrix of injustices in an unequal and undemocratic political apparatus.
\end{abstract}

The paper scrutinises the intersection of data and spatial injustice in Iran by analysing the way traffic camera footage is used against female drivers with improper veiling. Considering compulsory hijab and policing of it as a spatial injustice that limits and disturbs women's access to public places, the case study examines ways of resistance that address spatial|data injustice: firstly, a mobile phone application called Gershad that uses collective mapping to pin moral police patrols on maps by users; secondly, a social media campaign called White Wednesdays that encourages women to film and share their public strolls without hijab, their confrontations with religious pro-regime people, and videos of singing, dancing and cycling in public spaces.

Using Fraser's theory of "abnormal justice", this research draws attention to particularities of each case of data justice; taking into account the intersections of socio-political axes of injustice in different layers of local, regional and global analysis. The paper offers a "situated" analytical framework by bringing in space as an inquisitive component and moves from a sole discussion of data justice to a more intersectional study of spatial and data justice combined. Participation in "small data" projects is introduced as one resistance strategy against injustices of big data systems, fulfilling the principle of "parity of participation" to achieve justice, especially in undemocratic political contexts. 


\section{A. Introduction}

This paper is written as part of a collection of case studies on urban data, inequality and justice in the global South. On its journey to apply a lens of data justice to urban data, this case study has taken a step back to engage itself critically with a broader question, 'can any claim to data justice be studied without addressing its intersection with other forms of injustice?' In doing so, this case study has immediately exposed itself to immense political questions and therefore conceptualises a framework for data justice (section 3B.1) based on Fraser's theory of abnormal justice (Fraser 2008). According to this theory, the first criteria for achieving justice, namely distribution, recognition, and representation cannot be discussed when a group of people are deprived from participation in "authorized contests over justice"(Fraser 2008, 408). Hence, this research puts the question of data justice firstly, inside a political agenda and secondly, in intersection with other forms of injustice.

As a case study of such formulation of data justice this paper analyses the way traffic camera footage is used in Iran to criminalise women who drive without proper hijab. This paper posits compulsory hijab as a form of spatial injustice (Soja 2010) as it affects women's freedom of movement, their feeling of security and meaningful participation in social life. Spatial |Data Justice is then introduced as a way to examine the intersection of these two forms of justice (section 3B.2) providing a short introduction to the history, challenges and contestations over the issue of hijab in Iran. The essay then proceeds to a more detailed discussion of surveillance of women and its interrelations to issues of spatial/ data justice (section 3B.3) and aims to contribute to the shortcoming of surveillance studies' literature by addressing surveillance of women as a large group of population. Section 3B.4 introduces two case studies of resistance against spatial|data justice: firstly, a mobile phone application called Gershad that uses collective mapping to pin moral police patrols on maps by users; secondly, a social media campaign called White Wednesdays that encourages women to film and share their public strolls without hijab, their confrontations with religious pro-regime people, and videos of singing, dancing and cycling in public spaces.

Using thematic analysis methods (section $3 \mathrm{C}$ ), some of the recurring themes in Gershad's twitter account and also videos posted on the White Wednesdays' campaign's Instagram account are explored. The findings of this analysis (section 3D) demonstrate strong connections between hijab activism, spatial justice and wider political agendas. Here, these two small data projects are portrayed as a possible way to tackle the injustices in larger data sets. Finally, the paper recommends integration of other forms of injustice as an axis of analysis in studying data justice (section 3E). Taking a political and critical approach to data justice, this case study aims to draw attention to the inadequacy of any discussion on data justice without its situatedness in a broader political framework, and recommends a scrutiny of data justice in an intersectional matrix of injustices with different layers of local, regional and global analysis. 


\section{B. Background}

\section{B1. Data Justice}

With the unbelievable speed of developments in the field of data technologies and their significant impact on the transformation of our lives, debating data justice is timely if not late. Several studies have focused on ways that could make data ethically just, such as making machine learning fairer by mitigating discrimination without collecting sensitive data (Veale and Binns 2017), preventing biases in educational data mining (Ben Shahar 2017) or, excavating representations of minorities and outliers in big data (Welles 2014). Although a significant effort, other academic enquiries take a more holistic approach and situate data in already-existing discourses of justice. Heeks and Renken (2018) divide approaches to data justice into three categories of 'instrumental data justice' to ensure fair use of data, 'procedural data justice' to ensure fair handling of data, and 'distributive rights-based justice' to ensure rights of privacy, access, ownership and representation. Although these approaches clarify incidents of injustice in data systems, they do "not encompass the social structures which at least partly determine data uses, processes, distributions, and rights" (Heeks and Renken 2018, 96).

The authors then define structural data justice as "the degree to which society contains and supports the data-related institutions, relations and knowledge systems necessary for realisation of the values comprised in a good life" (Heeks and Renken 2018, 96). Albeit they immediately recognise the importance of defining what a good life means, the discussion around it stops at the recognition of the problem. Similarly, existing data justice discourses emphasise more on the individual level of justice. For example, an ecosystemic approach based on Sen's capabilities theory defines data justice based on three pillars of visibility, digital (dis)engagement and countering data-driven discrimination (Taylor 2017) and hence provides universal answers to a particular question. Taylor develops her model by asking, "What are good governance principles for the use of big data in a democratic context, and who should be responsible for determining them?" (Taylor 2017, 10); a question that brings about a completely different set of answers if asked in an undemocratic context. This paper then aims to elaborate on the political aspects of data justice by situating itself in the context of critical data studies (Dalton and Thatcher 2015) and by shedding "light on political struggles and social processes that precede artefacts... [r]evealing the political and social interests embedded in technology" (Silva 2007, 175).

In such critical approaches to data justice, surveillance is understood as an "active social process" (Jiwani 2015) that upholds social structures. Such disciplinary roles could also be assigned to data systems. Johnson argues that databases have a normalising function and theorises "data systems as disciplinary surveillance" (Johnson 2014, 268). He shows for example how educational databases of students' performance are used to cut underperforming programs and affect educational choices of students or the financial funds available to them. Although his observations are made in a democratic context to achieve 'information justice' through open data (Johnson 2014), his observations can be well used in undemocratic environments. Other researchers have highlighted the relation between datadriven governance and broader social justice agendas (Dencik, Hintz, and Cable 2016, 1) but their work covers mainly activists resisting government surveillance at user level and does 
not include surveillance on large groups of people. Regardless, the aforementioned research recognises the urgency to "examine the ideological basis of data-driven processes, situating this form of governance within a political agenda [...] scrutinis[ing] the interests and power relations at play in 'datafied' societies that enfranchise some and disenfranchise others" (Dencik, Hintz, and Cable 2016, 9).

In order to include the above-mentioned political aspect in conceptualising data justice, this study uses the concept of 'abnormal justice' (Fraser 2008). The theory of abnormal justice argues that the 'what', the 'who', and the 'how' of justice remain disputed in our time. Consequently, there is no shared understanding of "what justice claimants can look like (individuals or groups, fellow citizens or all human beings), the substantive focus of justice claims (economic redistribution only, or other ontologically different forms of redress), which social divides possess injustice (e.g., nationality, ethnicity, class, gender, sexuality), and the agencies and scales of arbitration and redress (state or non-state actors, territorial or supraterritorial bodies)" (Cinnamon 2017, 612-3). In order to achieve justice under such circumstances, Fraser defines "the normative principle of parity of participation. According to this principle, justice requires social arrangements that permit all to participate as peers in social life" (Fraser 2008, 405). She then identifies three main obstacles of justice in an "ordinary-political" way (Fraser 2008, 407), as distribution, recognition, and representation. These obstacles were also addressed in one way or the other in the studies on data justice mentioned above. The outstanding difference is, however, Fraser's reflection on the milieus that make justice realisable, acknowledging the fact that, "in order to apply the principle of participatory parity to first-order questions of distribution, recognition, and representation, one must be able to jump to the next level, where the frame itself is in dispute" (Fraser 2008 , 407). Fraser introduces then a new level of "metapolitical injustice" comprehending "injustices of misframing. Such injustices occur when a polity's boundaries are drawn in such a way as to wrongly deny some people the chance to participate at all in its authorized contests over justice" (Fraser 2008, 408).

\section{B2. Spatial| Data Justice}

In addition to integration of political dimensions to any discussion of justice, this paper argues that data justice cannot be fully comprehended unless in an intersection with other forms of injustice. Data justice has been discussed in conjunction with other social agendas, such as development (Heeks and Renken 2018), economic justice (Newman 2015), legality of surveillance (Cinnamon 2017), etc. In a more metapolitical level, following Fraser's formulation of justice, this case study takes an intersectional approach (Cho, Crenshaw, and McCall 2013) to data justice in conjunction with spatial justice. This claim is based on understanding two basic principles: that "the political organization of space is a particularly powerful source of spatial injustice" (Soja 2009, 3), and that "a focus on data justice is [...] not only on the justness of data practices [but also on] the biases and inequalities baked directly into data" (Cinnamon 2017, 622). It is needless to say, that the same set of data could have been studied through the lens of, for example, class discrimination against poor cyclists that act as messengers and food deliveries in metropolitan Tehran and their income is extremely dependent on breaking traffic rules. In the current case study, the spatial aspect is only one axis of the matrix of injustices that shape the debated data injustice. 
In his book Seeking Spatial Justice, Edward Soja (2010) offers a detailed chronological study of the concept of spatial justice in works of different geographers, but majorly focuses on the 'right to the city' in works of French philosopher Henri Lefebvre (Lefebvre 1968) and Marxist geographer David Harvey (Harvey 2003). Lefebvre's transformative formulation of space as reflective 'and' constructive of social relations, changed the way 'space' was understood, and scrutinised the social organisation of space in capitalist times (Lefebvre 1991). The formerly mentioned authors all emphasise the "socio-spatial dialectic [meaning that] the spatial shapes the social as much as the social shapes the spatial" (Soja 2009, 2). In order to shed some light on the concept of 'spatial justice' in a more concrete and actionoriented approach, this paper follows the propositions of the Journal of Spatial Justice, a pioneer in publishing in the field:

"I. There are two cardinal forms of spatial injustice:

A. The involuntary confinement of any group to a limited space - segregation, ghettoization - the unfreedom argument.

B. The allocation of resources unequally over space - the unfair resources argument. II. Spatial injustice is derivative of broader social injustice - the derivative argument. III. Social injustices always have a spatial aspect, and social injustices cannot be addressed without also addressing their spatial aspect - the spatial remedies argument.

IV. Spatial remedies are necessary but not sufficient to remedy spatial injustices - let alone social injustice - the partial remedy argument.

$V$. The role of spatial injustice relative to social injustice is dependent on changing social, political, and economic conditions, and today there are trends that tend both to decrease and to increase the importance of the spatial - the historical embeddedness argument" (Marcuse 2009, 3).

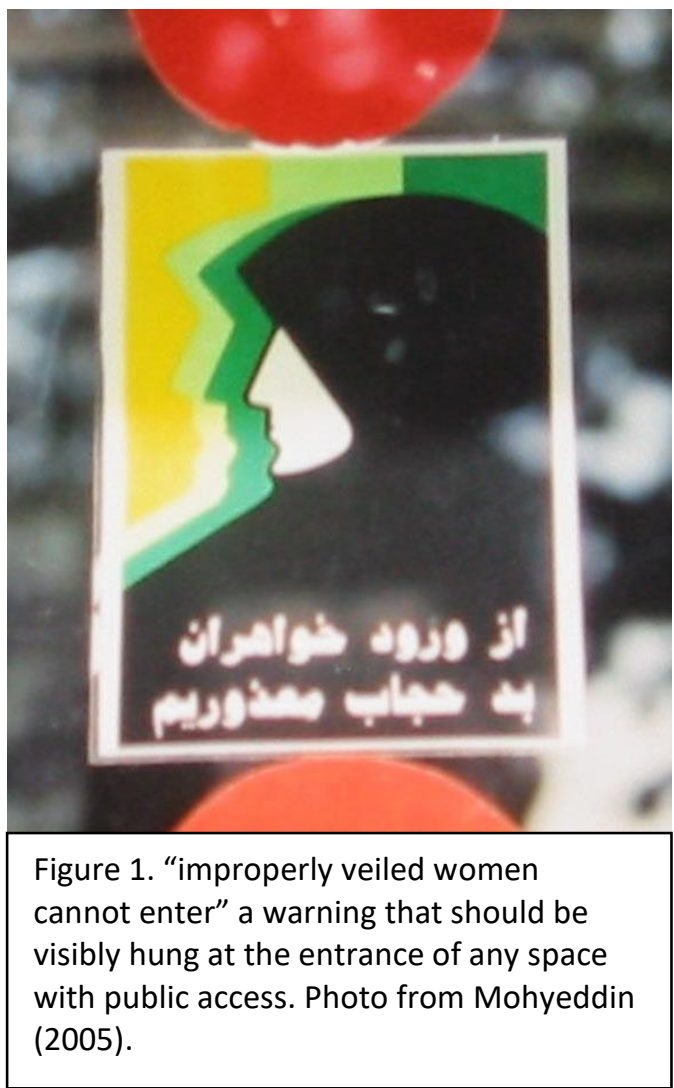

According to the above-mentioned formulation of spatial justice, this paper frames compulsory hijab as an issue of spatial injustice, which deprives women, fully or partially, from accessing public spaces (Justice for Iran 2014), limits their freedom of movement, affects their feeling of security and well-being in public (Gould 2014) and gravely restricts their participation in different aspects of social life. On 22 June 1980, just a year after the victory of Iranian revolution, women were banned from entering governmental and public service buildings without hijab (covering of their hair and body) (Shojaie 2014). Women's demonstrations against compulsory hijab did not receive any support from their former comrades (Sedghi 2007) and their voices got lost in the revolutionary haze of the days. With the invasion of Iraq in September 1980 and beginning of an 8-year gruelling war, the issue of hijab seemed even more irrelevant. Finally in 1983 and with the ratification of the Islamic Punitive Law in the Iranian Parliament, not having proper hijab in all public places was considered an 
offence punishable with 74 lashes (Justice for Iran 2014, 12). The punishment was later changed in 1997 to 10-60 days of imprisonment or a fine (ibid, 14).

From the violent suppression of women's largest rally against compulsory hijab on 8 March 1979 to the legal and social establishment of controlling women's clothing in the years afterwards, street patrols of "revolutionary committees" played an important role in harassing women who were deemed not properly covered (Kar 2017). By the ratification of the new Islamic Punitive Law and disbanding of committees in 1993 (Justice for Iran 2014, 13), police forces were then legally required to arrest women who disobeyed the compulsory hijab law. This commenced police surveillance of women in all public spaces of Iran until today. In addition to patrolling public spaces such as parks, streets and public transportation, every university, hospital, government office, public service bureau, shopping mall and similar is staffed to control women's clothing (see Figure 1). In 2005, special police forces called "Guidance Patrol" [Gasht-e-Ershad] were installed to observe compliance with compulsory hijab code (Erdbrink 2014). The Guidance Patrols aim mainly to bar improperly veiled women from entering public spaces and increase the risk of defiance. For example, in Tehran $^{9}$, arrested women are transferred to the Bureau against Social Corruption, part of the Police Forces for Social Security. There, their photos are taken and their personal information is archived. Arrested women should fill up forms about their psychological well-being and then wait for family members to bring them proper clothes. Before leaving the police station, they have to destroy their 'bad' clothes with scissors. If a woman resists at any stage of the process or repeats the 'crime' frequently, a legal case will be made and she would be sent to the courts of law.

\section{B3. Compulsory Hijab and Surveillance of Women}

Taking the political aspect of spatial|data justice into account unfolds another important interrelation. After the controversial presidential elections in 2009 and the subsequent uprising, CCTV cameras became compulsory in cafes, universities and even kindergartens. Traffic control cameras mushroomed in big cities and although it was publicly announced that police and security forces could only have access to footage of these cameras upon judicial request, it was revealed in 2015 that the entire country's urban CCTV cameras transmit their footage to the headquarters of Special Police Forces, who are mandated to deal with insurgency (Voice of America Persian Service 2015). Using data gathered through traffic cameras for other purposes soon proved useful in controlling women's hijab.

In continuation with strict control of women's clothing in public spaces, as of June 2017, women who do not properly cover their hair while driving are legally prosecuted and their cars are impounded (Mizan News Agency 2017). In December 2017 twitter users reported that 'improper hijab' was being captured on traffic cameras (see Figure 2). Just a day after the reports, the head of traffic police denied the rumours (Tasnim News 2017). Amid such denials, improper hijab fines and impounding of cars is so customary that legal consultation websites publish step by step guides for women who receive text messages with a code $14 / 15$ as a warning for improper hijab in a vehicle (Bidbarg Legal Consultancy 2018). It is not clear if the 'crime' is spotted by a guidance patrol or a CCTV/traffic camera. As mentioned

\footnotetext{
${ }^{9}$ There are many documented accounts of women who have been arrested by the Guidance Patrols, see for example, (Pardis 2011) (M 2015) (Bidarzani website 2015).
} 


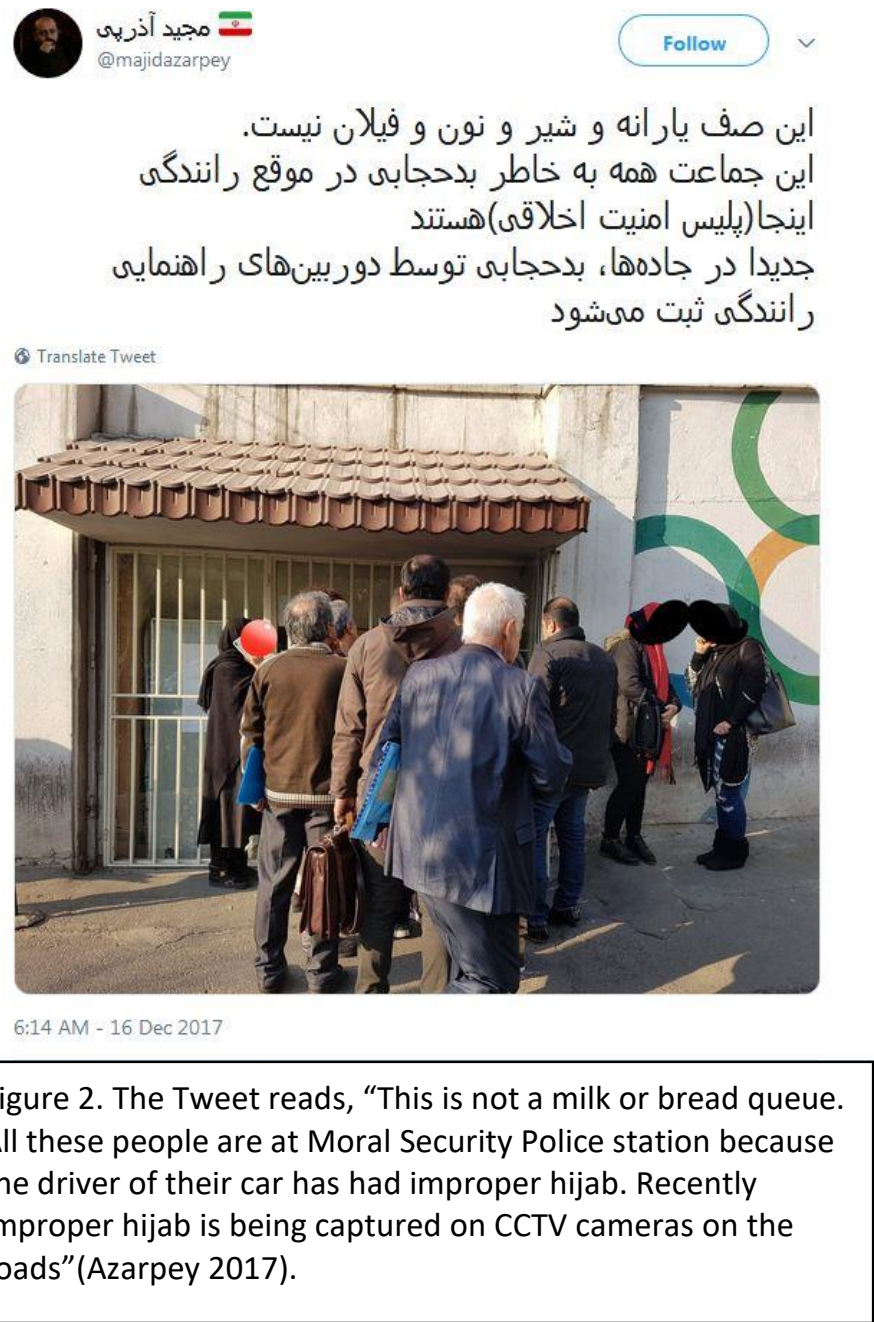

before, the government actively uses the footage of traffic cameras in tackling political dissent. It is therefore not unexpected that similar methods would be used against women. By doing so, the traffic data is not solely gathered to facilitate road safety and traffic control but also it gathers, classifies and uses data for other purposes, such as surveillance, sorting, disciplining and punishing women.

Surveillance of specific groups inside a bigger population has been long a subject of study in the field of surveillance studies. Surveillance has even been considered "as a means of social sorting" (Lyon 2003, 8). This sorting function has been studied in a variety of areas such as database marketing targeting specific categories of consumers (Gandy 1993), colonialism (Sa'di 2012), race (Browne 2015), using heteronormative paradigms for justification of the 'war on terror' (Puar 2007), etc. However, this paper focuses on sorting practices that not only reflect the already existing discriminatory power relations but also consolidate them through surveillance. The overlapping of two fields of gender studies and surveillance studies had not received much attention until recently. In 2009, some of the main researchers in the field of surveillance studies stated firmly that, "surveillance studies needs gender and sexuality" (Ball et al. 2009). Such need has resulted in more thorough examination of surveillance apparatuses through the lens of gender and race (Van der Meulen and Heynen 2016) (Dubrofsky and Magnet 2015) but the research remains overwhelmingly in the global North.

The current literature on the subject could be roughly divided to three categories:

a) Surveillance that specifically targets women, for example voyeuristically through CCTV cameras in public urban spaces (Koskela 2002), monitoring the appeal of cocktail waitresses in casinos (Bayard de Volo 2003), controlling strippers not to get any unreported tips (Egan 2004), limiting women's activity in outdoor recreational parks (Wesely and Gaardner 2004), etc.

b) Surveillance that is built on other unequal power relations, for example surveillance of African American young women and their fear of sexual harassment by police officers (Brunson and Miller 2006), violence against women and the contradictory role of surveillance in prevention of violence and control by case workers (Campbell 2000) 
(Gordon 2000) (Mason and Magnet 2012) or how shelters for victims of domestic violence tailor their services in a way that excludes some racial categories or undocumented immigrants (Smith 2015), surveillance of non-gender-normative bodies (Conrad 2009) (Beauchamp 2009) or exclusion of transgender people from state-issued birth certificates (Moore and Currah 2015).

c) Surveillance as a gendered practice, for example how surveillance systems "operate on ideals of masculine control at a distance and as a result enforce a masculinization of space and practice" (Monahan 2009, 299), or how surveillance expands the male gaze (Van der Meulen and Heynen 2016).

In continuation to the above-mentioned studies, this paper examines not only the surveillance of female drivers by a strictly controlling and oppressive male gaze, but also investigates the "masculinisation of space" (Koskela 2002) through surveillance. The aforementioned concept was coined to explain that the installation of CCTV cameras, not only does not prevent harassment of women, but also contributes to masculinisation of space, since most of the camera room operators are men. Taking this concept to a context that women's public presence is severely controlled through law, police forces and, surveillance, gives it new meanings and effects.

Consequently, here, surveillance is understood as an infraction of "social justice", that sorts "people into categories, assigning worth or risk, in ways that have real effects on their lifechances (Lyon 2003,1). Therefore, this paper studies compulsory hijab not only as surveillance of women but also as a way of producing public space that is not tolerant towards specific female bodies. It must be noted here that compulsory hijab is only one of a number of legal freedoms that Iranian women lost after the revolution. The Iranian progressive family law was one of the first laws that were abolished after the 1979 revolution, leaving married women with no rights to education, work, and travel. Other patriarchal laws prohibited women to work in occupations that were deemed masculine such as being a judge, pilot, president, etc. As clearly reflected in the definition of spatial justice, 'justice' in such situations cannot be achieved with just spatial remedies. Social justice and consequently spatial justice require a strong political will for change.

\section{B4. Against Spatial|Data Injustice}

As mentioned earlier in this paper, resistance against compulsory hijab dates back to the first months after the 1979 revolution in Iran. Although the resistance initially had a legal, political and rights-based approach, after the violent suppression of demonstrations and arresting, torture and execution of political activists, resistance against compulsory hijab was transformed to ongoing everyday acts of resistance, which focused on intentional improper veiling, e.g. putting on makeup, leaving hair out, wearing short or tight clothing, etc. These everyday strategies have been the subject of numerous studies and popular journalism (for academic examples see (Sedghi 2007), (Bayat 2010) and (Sadeghi 2010)). Following a global trend, urban governance in Iran is on the path to digitalisation and many government services are now delivered through electronic systems. These governmental systems work based on large databases that gather, classify, summon and archive data. The data gathered through traffic cameras reflects the already existing spatial injustice against women and as a result, in addition to the old resistance strategies, there are new trends of resistance that take a data approach. 


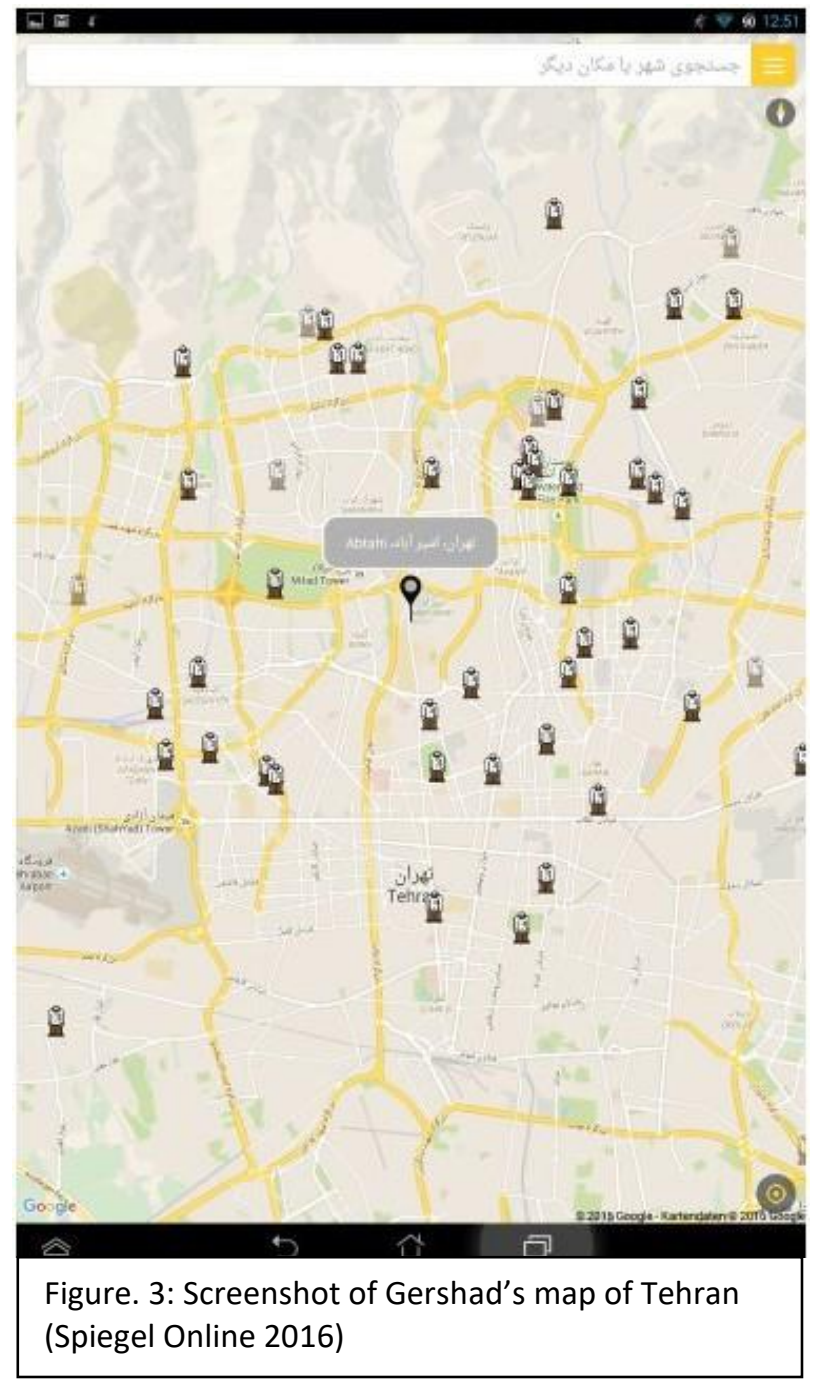

Small data has been contemplated as a tool of justice that would go beyond the usage of data by others and would concentrate on how individuals, groups or communities use data for themselves "in order to live the life they value" (Heeks and Renken 2018, 95). In a structural view, small data is theorised through data intermediary organisations, "as channels through which citizens can influence the balance of representation/privacy and the nature of data ownership and access ... important determinants of the constitution and distributive benefits of information value chains" (Heeks and Shekhar 2019, 1008). In a more networked view and with a political understanding of data systems, small data initiatives by groups of people, who are themselves affected by data injustices are rather considered as active resistance. This case study examines two different small data projects that aim to tackle the issue of Spatial|Data injustice.

Although surveillance of such a large group of people seems practically impossible, in 2013 three million women received "injunctions" through police patrols in Tehran for their improper hijab (Gershad n/a) . In 2017, 207,000 women undertook written promises to correct their behaviour, while 18,000 women were sent to court (ibid.). In response, an anonymous group of activists created "Gershad 10", a collective mapping application that allowed users to pin moral police patrols on the map (see Figure 3). The application soon attracted younger tech savvy women and men that helped each other avoid prosecution and aggressive police behaviour.

Another recent development is the White Wednesdays' campaign that encourages women to walk in public spaces without headscarves, film the walk and possible confrontations, and post it on social media (https://www.instagram.com/masih.alinejad). The videos have caused heated national debates and the number of anonymous participants is growing by the day. The White Wednesdays' campaign stands not only as a claim to physical space but also occupies digital space by publishing its own narrative of how space should be organised justly. The videos also act as returning the gaze of surveillance and its normalising effect on women that have been systemically controlled, surveilled and criminalised. In doing so, although they do not gather data as systematically as a mapping application such as

\footnotetext{
${ }^{10}$ Literally means going around moral police patrols
} 
Gershad, they protest the unjust collection of women's data by using the same tool as the authorities: their cameras. Though the identification of police officials or documentation of the aggressive behaviour of pro-regime passers-by is not collected in a data system per se, the White Wednesdays' campaign succeeds in highlighting the disciplinary power of surveillance and the intersection of spatial and data justices.

\section{C. Methods}

In order to shed light on the concepts introduced in this paper, and the interrelation between them, the case study uses thematic analysis of Gershad's twitter account, and videos posted on the White Wednesdays' campaign's Instagram account. The tweets from Gershad's twitter account, in the year preceding 25 May 2019, were downloaded and after cleaning, coded and categorised based on their content. Also, the last 300 videos of White Wednesdays' Instagram, preceding 25 May 2019, were coded and categorised.

Braun and Clarke $(2006,79)$ define thematic analysis as "a method for identifying, analysing and reporting patterns (themes) within data". In this research, hijab activism and different modes of resistance against policing of women's clothing, have been considered as key themes. Other themes were understood in relation to the key themes. Thus, the thematic analysis has been conducted in a 'theoretical' manner, meaning that the themes identified "tend to be driven by the researcher's theoretical or analytic interest" (Braun and Clarke $2006,84)$.

Therefore, driven by the theoretical framework of abnormal justice, general political commentary at the level of "metapolitical injustice" (Fraser 2008, 408) has been coded as a theme. Following the paper's understanding of intersectional justice, other instances of injustice, such as activism on labour rights, teachers' unions, violence against women, religious minorities, etc. have been coded as relevant themes. The other thematic codes mainly cover the objectives and functions of the application or the social media campaign. Additionally, this paper has analysed the social media posts on a semantic level and has not taken a discourse-analysis approach, as the limited scope of this case study does not allow a more detailed study of the reasons behind the formation of the specific messages posted on social media. All the themes and subsequent categories will be discussed in detail in the following section. 


\section{D. Findings}

This paper has introduced the concept of spatial|data justice in order to put emphasis on the intersection of data justice with other forms of justice, when justice is envisaged in a broader political framework. Such intersections, overlaps, associations and references between spatial justice - here the case of compulsory hijab - data justice and the general political situation can be clearly demonstrated through the thematic analysis of two main resistance trends against compulsory hijab. A thematic analysis of Gershad's tweets (see Figure 4) shows a major involvement with the application's main purpose as a collective mapping tool with $56 \%$ of the posts dedicated to sharing the location of guidance patrols in Tehran. Together with location maps in other towns (8\%) and, guidelines, technical information and update alarms (11\%), $75 \%$ of the twitter activities address the pursuit of the application itself. Eight percent of the tweets tackle the issue of compulsory hijab by debating news, interviews, official statements, and public policies. The rest of the tweets (16\%) contribute to the more general political discussions in Iran, specifically those that question the undemocratic nature of ideological imposition on people, such as police violence against people who publicly eat or drink during the month of Ramadan.

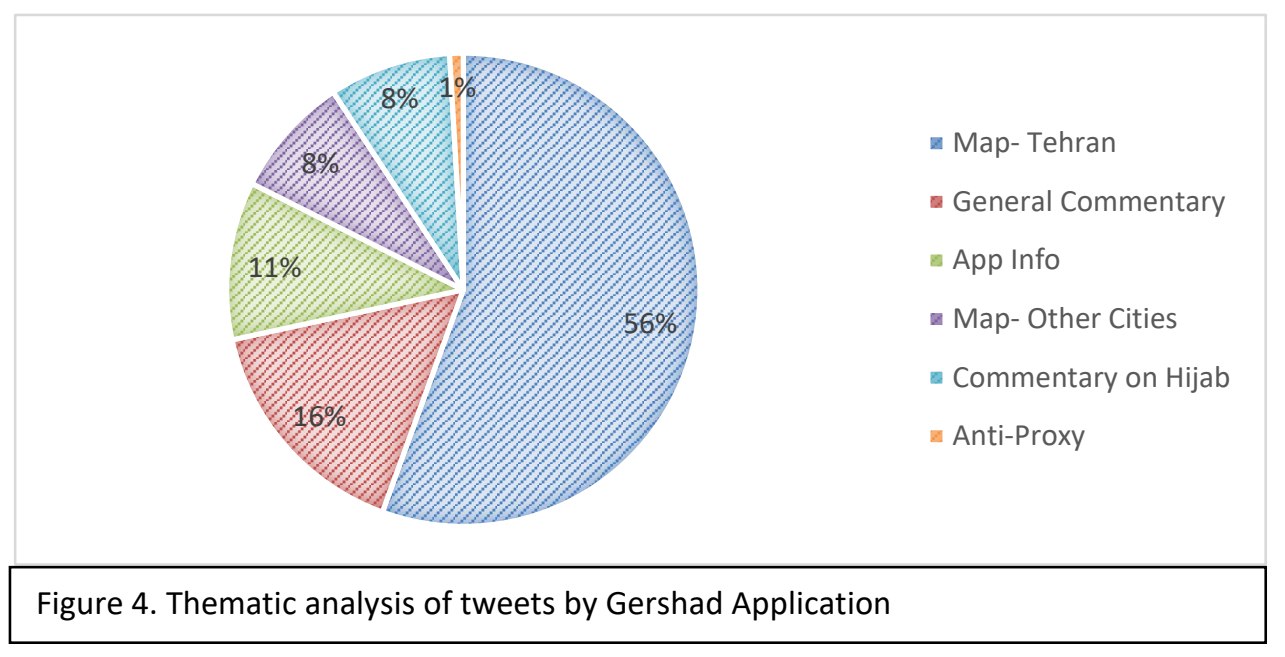

Such overlap between resistance to different forms of policing is also clear in the application's recommendation of anti-proxy technologies. Since the application was filtered by the Iranian authorities, the app developers regularly shared free anti-proxy applications for their users, but as off April 2019 the anti-proxy settings are integrated into the application configurations. Although such technologies would enable users to benefit from the application, they also pave the way for users to circumvent the strict policing and control of the cyber space ${ }^{11}$. Gershad, as a small data project, not only challenges the spatial injustice against women but also provokes resistance against other forms of injustice by confronting the strict control and policing that affect the daily life of Iranians. In doing so, the application goes beyond a mapping experience and targets the political foundations that are used to justify policing.

\footnotetext{
${ }^{11}$ Reporters Without Borders listed Iran as one of the 15 enemies of the Internet in 2016 (Reporters Without Borders 2016).
} 


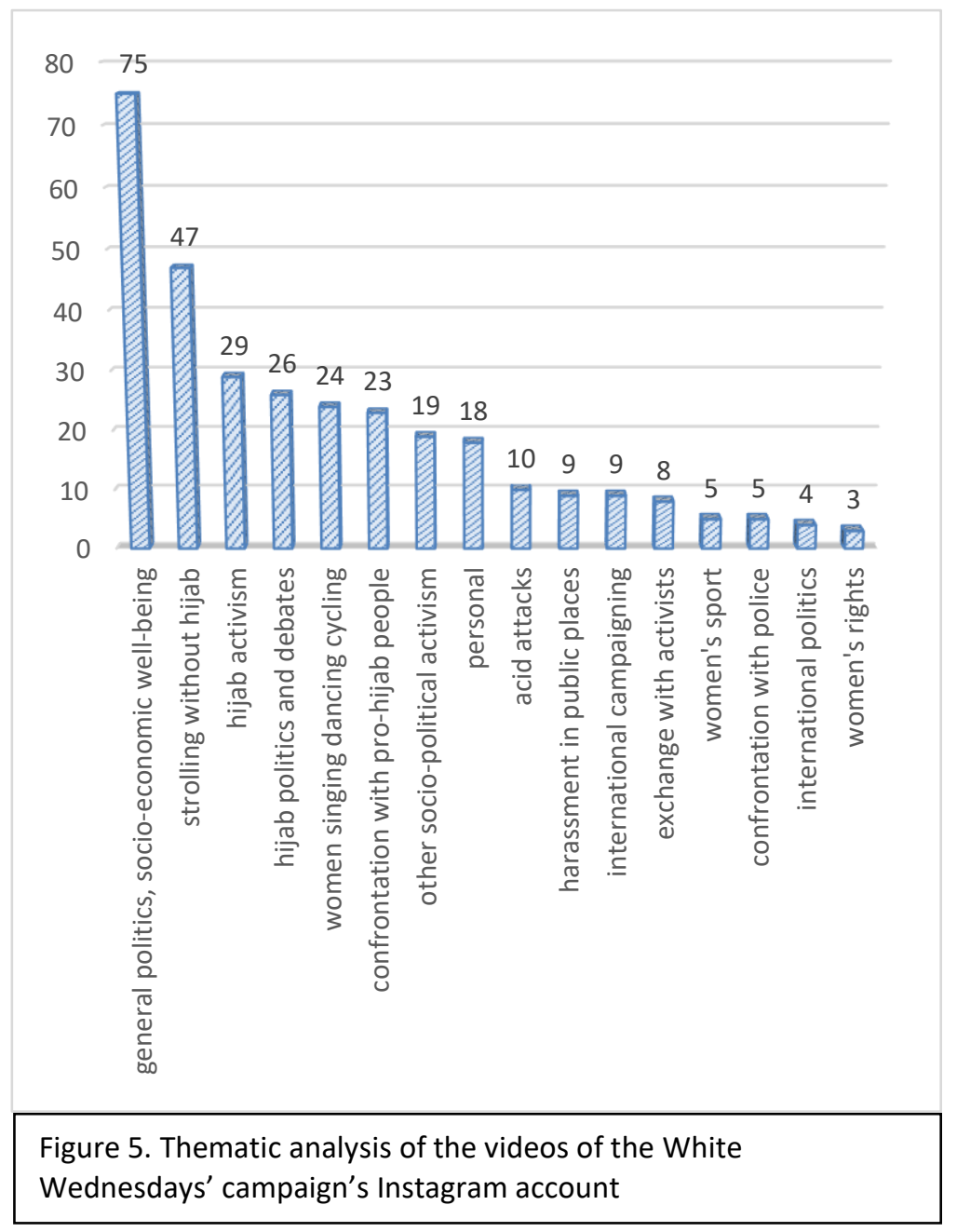

Such a political engagement is even more observable in the videos posted on the Instagram account of the founder of White Wednesdays' campaign. As portrayed in Figure 5, the most frequent theme in these videos is the commentary on general politics and a harsh critique of the socio-economic circumstances of Iranians. The campaign also takes a solid stance in advocating women's right to public spaces by frequently posting videos of women dancing, singing or cycling in public spaces - which are all forbidden. Although hijab is being frequently discussed as women's right to choose their clothing, the links to spatial injustice are evident. Here, the right to the city entails more substantial political elements, which problematises the dominant discourses on female

bodies, women's role in the family and society and their public engagements. Consequently, issues of prohibiting women to enter football stadiums or to compete in international sports events addresses simultaneously other forms of discrimination in conjunction with spatial justice. Harassment in public spaces and acid attacks also emerge as themes that highlight not only women's lack of access to public spaces but also the violence they experience trespassing the established boundaries. Among the videos of women's confrontation with people opposing their hijab-free strolling, most videos depict confrontations with religious people. The videos demonstrate a larger ongoing debate at the public level about the religious justifications of ideological organisation of space. Most of the videos in this category are hashtagged with "my_camera_my_weapon," accentuating the act of resistance by reciprocating the violence with returning the gaze. 


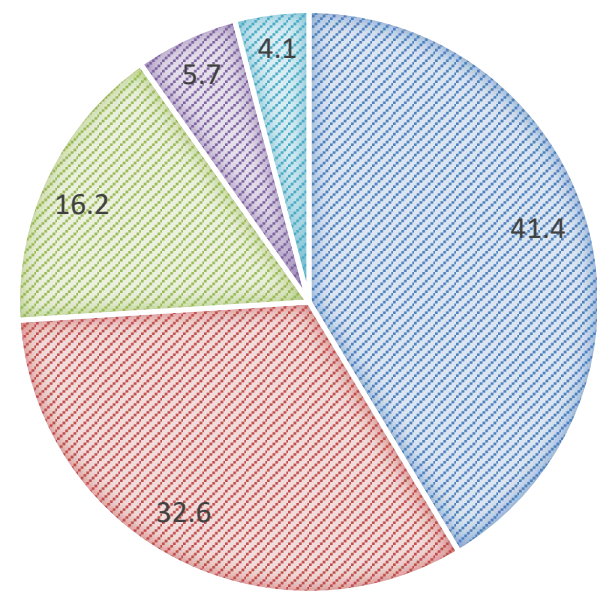

- Hijab-related activism

- Links to other movements

$\square$ Women's presence in public space

a Personal

International politics

Figure 6. Thematic clusters of the videos of the White Wednesdays' campaign's Instagram account
The interconnections between the identified themes could be better illustrated by clustering the similar themes into larger categories (see Figure 6). Although hijab-related activism including videos of women strolling without hijab, their confrontation with police, and religious or pro-regime people, and news and updates about arrested activists constitutes the larger body of Instagram posts,

the specific coverage of other resistance movements - including workers' unions, teacher unions, religious minorities, etc - comprise a considerable percentage of all the Instagram posts. The interrelation between activism against compulsory hijab, political resistance and spatial justice are clearly demonstrated in the way this small data project links these concepts together. The immediate reference to larger political frameworks could also be observed in the way the campaign represents itself at an international level to not only draw support for its activities, but also to put more pressure on the Iranian government to change its practices of systematic discrimination against women.

\section{E. Discussion and Conclusions}

This paper has theorised data justice by using the theory of 'abnormal justice' (Fraser 2008) with the recognition that justice cannot be formulated when specific groups of people have no chance/right to participate in "authorized contests over justice" (Fraser 2008, 408). By applying the principle of 'parity of participation' (Fraser 2008, 407) in order to recognise a situation as potentially bearing the possibility of justice, the Fraserian conceptualisation instantaneously exposes its political nature. Therefore, I have argued that data justice, as an instance of justice, cannot be scrutinized without considering the political framework that encompasses it. Such understanding of justice challenges the current literature on data justice that mainly focuses on democratic power relations. As this paper series pinpoints the issue of data justice in the global South, it proves necessary to situate questions of data justice also in less- and un-democratic settings. Furthermore, a political understanding of data justice cannot be complete, if it is not situated in intersection with other instances of injustice. In this case study, the overlap between spatial and data justice is explored but other research can incorporate other axes of analysis.

After developing a theoretical framework for spatial |data justice, the paper has specifically examined the aforementioned concept in regards to a case study in Iran. The extreme implementation of compulsory hijab regulations against women is defined as a case of 
spatial justice, since it regulates, bars and controls women's access to public spaces. Hence, the usage of traffic camera footage to punish female drivers with improper veiling is treated as a mishandling of data - a data injustice - but also only meaningful in conjunction with another form of injustice: spatial injustice. This critical intersectional approach to data justice is fully reflected in two examples of resistance against spatial|data injustice. The first example, Gershad, is an application that uses collective mapping to locate moral police patrols and the second example is a campaign that encourages women to reclaim the public space by strolling without hijab and recording possible reactions and confrontations. A thematic analysis of the social media posts by both projects demonstrate not only a strong interconnection with other forms of activism but also a manifest stance against undemocratic political systems. Such references to political issues reveal an underlying interrelatedness of discourses of justice, including those on data justice.

Drawing from the case study of Iran, this paper develops an intersectional political approach to data justice that situates the issue in a matrix of injustice within a broad political framework. Although such a matrix of injustice might seem less chaotic in a democratic political framework, especially in countries of the global North, a closer look would reveal hidden intersections. Furthermore, as data justice cannot be limited to a specific platform's data polices, it also cannot be contained in a country's approach to data and privacy rights. This paper argues that an intersectional political approach to data justice, as an analytical tool, could be employed in variety of contexts. In the next section, some possible research projects are discussed that would apply analytical tools conceptualised based on this case study. Additionally, although here a small data vs. big data approach has been introduced as a possible resistance strategy against data injustice, each case of data injustice would necessitate a different analysis of resistance alternatives based on its situatedness in the matrix of injustices within a political framework.

\section{E1. Recommendations for Future Research}

Spatial |data justice as a concept with an intersectional approach to data justice could contribute to any research in this area that has a spatial component. For example, research on informal settlements that analyse the right to the city for marginalised groups of citizens in conjunction with data-related issues could apply spatial|data justice as an analytical tool. Such research could include surveillance of crime in slums, informal settlements' mapping failures, collective mapping of neighbourhoods and many other research areas that specifically investigate 'space'.

A political intersectional approach to data justice could also include other forms of injustice. This paper has taken space as an axis of analysis but other notions are immediately imaginable. Even in this paper's exact case, 'class' could be considered as an analytical dimension, when it comes to motorcycle messengers in Tehran, that earn their living by minimising the time of a journey between two points in a city stretching to $1748 \mathrm{~km}^{2}$ through constantly breaking traffic laws. These messengers fall prey to the extensive network of CCTV cameras while economic circumstances and the low quality of state delivery services gravely affects their observance of traffic rules. Other broader examples could be drawn in different levels of analysis. There is for example a massive amount of research on the treatment of undesirable bodies (homosexual, queer, transgender, Muslim, 
veiled, poor, etc.) in European immigration systems ${ }^{12}$. The biometric and immigration data that is being collected on such bodies cannot be considered in a sheer discourse of data justice, since in order for a body to be the subject of such gathering of data, one must first belong to an undesirable category. European passport holders that enter the UK for example, do not even pass through such strict regimes of control. Here, doing justice to data justice necessitates an intersectional approach; an approach that cannot be even contemplated without positioning the question in the wider political framework of European immigration policy and socio-historical dimensions of such policies.

This case study also aims to open the discussion to a more detailed and deeper level of analysis of intersections of data justice. Here, thematic analysis has been used to demonstrate the interconnections between different instances of injustice, but other qualitative methods might have provided the case study with other conceptions of how these links are formed and maintained. For example, a discursive analysis of the social media posts could have shed light on the diversity of apprehensions of justice. Exploring and coding the social media content without emphasising one specific form of injustice, here spatial injustice, might have also brought about other interesting intersections using grounded theory.

Other fundamental considerations on 'power' and 'social structure' could also change the analytic direction of this case study's question and might lead to disparate theoretical discussions of data justice. One example is not to dichotomise power to "power of agency "power to" - [...and] structural power - "power over" (Heeks and Renken 2018, 97) and rather treat power in a Foucauldian framework arguing that "power is everywhere" and "comes from everywhere" (Foucault 1998, 63). What would such an understanding of power mean for an intersectional analysis of data justice? Another thread of thought could be followed in theorising data systems (Kitchin and Lauriault 2018) or surveillance (Haggerty and Ericson 2000) as an assemblage containing a "multiplicity of heterogeneous objects, whose unity comes solely from the fact that these items function together, that they "work" together as a functional entity" (Patton 1994, 158). Using assemblage theory could also affect how resistance to intersectional data injustice is formulated, which includes not only the state as the hegemonic power in establishing surveillance discourses but also "a number of other agents, such as users, civil society, regional and international flows, technological advancements, things and code" (Akbari and Gabdulhakov 2019).

Finally, as claims to data justice cannot be addressed without referring to political dispositions, research on data justice is also not exempt from such political repercussions. As a feminist activist and academic, writing about compulsory hijab without strong feelings is a cumbersome exercise. It is also a fine political line to walk since the issue of hijab is by far not a local issue, but an international tool to criticise the political foundations of the Islamic Republic of Iran. The controversy caused by the meeting between Masih Alinejad, the founder of White Wednesdays' Campaign and Secretary of State Mike Pompeo (Radio Farda 2019) is a bitter reminder that losing the political perspective in alleviating one case of injustice, can bring about other forms of injustice, if not more violence, war and insecurity.

\footnotetext{
12 One almost comprehensive directory of such research could be found in a European Commission policy review titled, "Research on Migration: Facing Realities and Maximising Opportunities" (King and Lulle 2016)
} 


\section{References}

Akbari, Azadeh, and Rashid Gabdulhakov. 2019. Platform surveillance and resistance in Iran and Russia: The case of Telegram. Surveillance \& Society 17 (1/2): 223-231.

Azarpey, Majid. 2017. Twitter. https://twitter.com/majidazarpey/status/941914487635918849.

Ball, Kirstie, Nicola Green, Hille Koskela, and David J. Phillips. 2009. Editorial: Surveillance studies needs gender and sexuality. Surveillance \& Society 6 (4): 352-355.

Bayard de Volo, Lorraine 2003. Service and surveillance: Infrapolitics at work among casino cocktail waitresses. Social Politics 10: 347-376.

Bayat, Asef. 2010. Life as Politics: How Ordinary People Change the Middle East. Stanford: Stanford University Press.

Beauchamp, Toby. 2009. Artful concealment and strategic visibility: Transgender bodies and U.S. state surveillance after 9/11. Surveillance \& Society 6 (4): 356-366.

Ben Shahar, T. H. 2017. Educational justice and big data. Theory and Research in Education 15 (3): 306-320.

Bidarzani website. 2015. Women's Experience of Guidance Patrols. Bidarzani. http://bidarzani.com/20614.

Bidbarg Legal Consultancy. 2018. Improper Hijab Fine for Female Drivers. Bidbarg Legal Consultancy. https://bit.ly/2UFGDle.

Braun, Virginia, and Victoria Clarke. 2006. Using thematic analysis in psychology. Qualitative Research in Psychology 3 (2): 77-101.

Browne, Simone. 2015. Dark Matters: On the Surveillance of Blackness. Durham: Duke University Press.

Brunson, Rod K., and Jody Miller. 2006. Gender, race, and urban policing: The experience of African American youths. Gender \& Society 20 (4): 531-552.

Campbell, Jacquelyn C. 2000. Promise and perils of surveillance in addressing violence against women. Violence Against Women 6 (7): 705-727.

Cho, Sumi, Kimberle Williams Crenshaw, and Leslie McCall. 2013. Toward a field of intersectionality studies: Theory, applications, and praxis. Signs: Journal of Women in Culture and Society 38 (4): 785-810.

Cinnamon, Jonathan. 2017. Social injustice in surveillance capitalism. Surveillance \& Society 15 (5): 609-625.

Conrad, Kathryn. 2009. Surveillance, gender and the virtual body in the information age. Surveillance \& Society 6 (4): 380-387.

Dalton, Craig M., and Jim Thatcher. 2015. Inflated granularity: Spatial 'Big Data' and geodemographics. Big Data \& Society 2 (2): 1-15.

Dencik, Lina, Arne Hintz, and Jonathan Cable. 2016. Towards data justice? The ambiguity of anti-surveillance resistance in political activism. Big Data \& Society 3 (2): 1-12.

Dubrofsky, Rachel E., and Shohana Amielle Magnet (eds.). 2015. Feminist Surveillance Studies. Durham: Duke University Press.

Egan, R. Danielle. 2004. Eyeing the scene: The uses and (re)uses of surveillance cameras in an exotic dance club. Critical Sociology 30: 299-319.

Erdbrink, Thomas. 2014. When Freedom Is the Right to Stay Under Wraps. The New York Times. https://www.nytimes.com/2014/05/08/world/middleeast/when-freedom-is-theright-to-stay-under-wraps.html. 
Foucault, Michel. 1998. The History of Sexuality: The Will to Knowledge. London: Penguin. Fraser, Nancy. 2008. Abnormal justice. Critical Inquiry 34 (3): 393-422.

Gandy, Oscar H. 1993. The Panoptic Sort: A Political Economy of Personal Information. Boulder: Westview Press.

Gershad. n/a. About Us. Gershad. https://gershad.com/\#about.

Gordon, M. 2000. Definitional issues in violence against women: Surveillance and research from a violence research perspective. Violence Against Women 6 (7): 747-783.

Gould, Rebecca. 2014. Hijab as commodity form: Veiling, unveiling, and misveiling in contemporary Iran. Feminist Theory 15 (3): 221-40.

Haggerty, Kevin D., and Richard V. Ericson. 2000. The surveillant assemblage. British Journal of Sociology 51 (4): 605-622.

Harvey, David. 2003. The right to the city. International Journal of Urban and Regional Research 27 (4): 939-941.

Heeks, Richard, and Jaco Renken. 2018. Data justice for development: What would it mean? Information Development 34 (1): 90-102.

Heeks, Richard, and Satyarupa Shekhar. 2019. Datafication, development and marginalised urban communities: An applied data justice framework. Information, Communication \& Society 22 (7): 992-1011.

Jiwani, Yasmin. 2015. Violating in/visibilities: Honor killings and interlocking surveillance(s). In Feminist Surveillance Studies, edited by Rachel E. Dubrofsky and Shoshana Amielle Magnet, 79-92. Durham: Duke University Press.

Johnson, Jeffrey Alan. 2014. From open data to information justice. Ethics and Information Technology 16 (4): 263-274.

Justice for Iran. 2014. 35 Years of Hijab in Iran; Extensive Violation of Womens' Rights. Justice for Iran. https://justice4iran.org/wp-content/uploads/2014/03/Hijab-reportFinal-FA.pdf.

Kar, Mehrangiz. 2017. How We Were Veiled?. Shahrvand. https://shahrvand.com/archives/85738.

King, Russell, and Aija Lulle. 2016. Research on Migration: Facing Realities and Maximising Opportunities. Luxembourg: Publications Office of the European Union.

Kitchin, Rob, and Tracey P. Lauriault. 2018. Toward critical data studies: charting and unpacking data assemblages and their work. In Thinking Big Data in Geography: New Regimes, New Research, edited by Jim Thatcher, Josef Eckert and Andrew Shears, 3-20. Lincoln: University of Nebraska Press.

Koskela, Hille. 2002. Video surveillance, gender, and the safety of public urban space:

'Peeping Tom' goes high tech? Urban Geography 23 (3): 257-278.

Lefebvre, Henri. 1968. Le Droit à la Ville. Paris: Anthropos.

---. 1991. The Production of Space. Oxford: Blackwell.

Lyon, David (ed.). 2003. Surveillance as Social Sorting: Privacy, Risk, and Digital Discrimination. London: Routledge.

M, Maryam. 2015. A Day Spent with Guidance Patrol. Iran Wire. https://iranwire.com/fa/features/2266.

Marcuse, Peter. 2009. Spatial justice: Derivative but causal of social injustice. justice spatiale / spatial justice 1: 1-6.

Mason, Corrine, and Shoshana Magnet. 2012. Surveillance studies and violence against women. Surveillance \& Society 10 (2): 105-118. 
Mizan News Agency. 2017. Legal Cases for Improperly Veiled. Mizan News Agency. https://bit.ly/2Kz6168.

Mohyeddin, Samira. 2005. Personal Website. http://www.samiramohyeddin.com/2005/08/.

Monahan, Torin. 2009. Dreams of control at a distance: Gender, surveillance, and social control. Cultural Studies $\leftrightarrow$ Critical Methodologies 9 (2): 286-305.

Moore, Lisa Jean, and Paisely Currah. 2015. Legally sexed: Birth certificates and transgender citizens. In Feminist Surveillance Studies, edited by Rachel E. Dubrofsky and Shohana Amielle Magnet., 58-78. Durham: Duke University Press.

Newman, Nathan. 2015. Data Justice: Taking on Big Data as an Economic Justice Issue. Data Justice Organization.

Pardis, Sara. 2011. Report on Tehran's Guidance Patrols. Kalame. https://www.kaleme.com/1390/08/12/klm-79151/.

Patton, Paul. 1994. Metamorpho-logic: Bodies and powers in a thousand plateaus. Journal of the British Society for Phenomenology 25 (2): 157-169.

Puar, Jasbir K. 2007. Terrorist Assemblages: Homonationalism in Queer Times. Durham: Duke University Press.

Radio Farda. 2019. Pompeo Tells Iranian Rights Activist Of U.S. Support. Radio Farda. https://en.radiofarda.com/a/pompeo-meets-with-alinejad-and-voices-ussupport/29752266.html.

Reporters Without Borders. 2016. The 15 Enemies of the Internet and Other Countries to Watch. Reporters Without Borders. https://rsf.org/en/news/15-enemies-internet-andother-countries-watch.

Sa'di, Ahmad H. 2012. Colonialism and surveillance. In Routledge Handbook of Surveillance Studies, edited by Kirstie Ball, Kevin D. Haggerty and David Lyon, 151-158. London: Routledge.

Sadeghi, Fatemeh. 2010. Bypassing Islamism and feminism: Women's resistance and rebellion in post-revolutionary Iran. Revue Des Mondes Musulmans Et De La Mediterranee 128: 209-228.

Sedghi, Hamideh. 2007. Women and Politics in Iran: Veiling, Unveiling, and Reveiling. Cambridge: Cambridge University Press.

Shojaie, Mitra. 2014. How Hijab Became Compulsary After The Revolution?. Deutsche Welle Persian. https://p.dw.com/p/1B2j8.

Silva, Leiser. 2007. Epistemological and theoretical challenges for studying power and politics in information systems. Information Systems Journal 17: 165-183.

Smith, Andrea. 2015. Not-Seeing: State surveillance, settler colonialism, and gender violence. In Feminist Surveillance Studies, edited by Rachel E. Dubrofsky and Shohana Amielle Magnet., 21-38. Durham: Duke University Press.

Soja, Edward W. 2009. The city and spatial justice. justice spatiale / spatial justice 1: 1-5. ---. 2010. Seeking Spatial Justice. Minneapolis: University of Minnesota Press.

Spiegel Online. 2016. Neue App: So warnt Gershad die Iraner. Der Spiegel Online. https://www.spiegel.de/fotostrecke/gershad-app-fotostrecke-134500-4.html.

Tasnim News. 2017. The Head of Traffic Police Denied the Rumours on Improper Hijab Fines. Tasnim News. https://bit.ly/2v20Nab.

Taylor, Linnet. 2017. What is data justice? The case for connecting digital rights and freedoms globally. Big Data \& Society July-December: 1-14.

Van der Meulen, Emily, and Robert Heynen (eds.). 2016. Expanding the Gaze: Gender and the Politics of Surveillance. Toronto: University of Toronto Press. 
Veale, Michael, and Reuben Binns. 2017. Fairer machine learning in the real world:

Mitigating discrimination without collecting sensitive data. Big Data \& Society JulyDecember (1-17).

Voice of America Persian Service. 2015. Special Police Forces Have Access to CCTV Cameras. Voice of America Persian Service. http://m.ir.voanews.com/a/iran-policecamera/3115271.html.

Welles, Brooke Foucault. 2014. On minorities and outliers: The case for making Big Data small. Big Data \& Society April-June: 1-2.

Wesely, Jennifer, and Emily Gaardner. 2004. The gendered 'nature' of the urban outdoors: Women negotiating fear of violence. Gender \& Society 18: 645-663.

\section{Acknowledgements}

The "Urban Data, Inequality and Justice in the Global South" case studies form part of a Senior Research Fellowship funded by the University of Manchester's Sustainable Consumption Institute with additional financial support from Canada's International Development Research Centre.

\section{About the Author}

Azadeh Akbari is a PhD candidate at the Department of Human Geography, Heidelberg University. Her research uses Iran as a case study to investigate the links between surveillance and spatial justice in physical and virtual spaces in undemocratic contexts. Azadeh holds an MSc in Gender Research from the London School of Economics and has been a journalist and activist for many years. Her PhD project is funded by the Hans Böckler Foundation of the German Trade Unions. 


\title{
Case 4: Urban Slums in a Datafying Milieu Challenges for Data-Driven Research Practice
}

\author{
Bijal Brahmbhatt \\ Mahila Housing Trust \\ Neha Lal \\ Mahila Housing Trust
}

\author{
Siraz Hirani \\ Mahila Housing Trust \\ Bhumika Chauhan \\ Mahila Housing Trust
}

\begin{abstract}
With the ongoing trend of urban datafication and growing use of data/evidence to shape developmental initiatives by state as well as non-state actors, this exploratory case study engages with the complex and often contested domains of data use. This study uses on-theground experience of working with informal settlements in Indian cities to examine how information value chains work in practice and the contours of their power to intervene in building an agenda of social justice into governance regimes. Using illustrative examples from ongoing action-oriented projects of Mahila Housing Trust in India such as the Energy Audit Project, Slum Mapping Exercise and women-led climate resilience building under the Global Resilience Partnership, it raises questions about challenges of making effective linkages between data, knowledge and action in and for slum communities in the global South by focussing on two issues.
\end{abstract}

First, it reveals dilemmas of achieving data accuracy when working with slum communities in developing cities where populations are dynamically changing, and where digitisation and use of ICT has limited operational currency. The second issue focuses on data ownership. It foregrounds the need for complementary inputs and the heavy requirement for support systems in informal settlements in order to translate data-driven knowledge into actionable forms. Absence of these will blunt the edge of data-driven community participation in local politics. Through these intersecting streams, the study attempts to address how entanglements between southern urbanism, datafication, governance and social justice diversify the discourse on data justice. It highlights existing hurdles and structural hierarchies within a data-heavy developmental register emergent across multiple cities in the global South where data-driven governmental regimes interact with convoluted urban forms and realities. 


\section{A. Introduction}

Of late, governance regimes in the global South have been increasingly enamoured by the reach of data, digitisation and documentation in order for the state to see, regulate and govern its citizens (Scott 1999). In Benign Dataveillance - the New Kind of Democracy?, Payal Arora (2019) illustrates some of these rising impulses through the ongoing biometricallydriven and database-led Unique Identification Number (UID) project in India for citizen documentation; and the Social Credits system in China that crosslinks citizenry's online and offline activity to rewards or punitive action on the basis of their credit scores. While such reconfigurations within governance as a way of producing level playing fields and pushing the agenda of equity remain questionable, what continues to intrigue is the way in which the process of datafication is being made an indispensable precursor to the discourse on the future of governance.

As one of the biggest digital projects in India if not the world, UID, popularly called Aadhaar ${ }^{13}$ is hailed as a technological overhaul of welfare scheme targeting and direct benefit transfers. Scholars argue that "Aadhaar may not only enable efficient design, delivery, monitoring and evaluation of services...[..]...but may also offer the possibility of using modern data analytics and machine learning techniques for finding large-scale correlations in user data. This, in turn, may facilitate an improved design of social policy strategies, including targeting, and early detection and warning systems for anomalies" (Banerjee 2017). Yet at the same time, the scheme has courted both debate and protests on issues of privacy, security and exclusionary biases.

Likewise in specific relation to urban governance, the rally towards data-driven decision making is being pitched as a means to reform policy and better deliver on urban development goals. The Smart Cities Mission launched by India's central government in 2015 is one such initiative towards using big data for urban governance and administration, with ambitions spanning from rationalising traffic routes through GIS to predictive profiling for surveillance. Given that the world of big data is known to cast such long shadows, why does it continue to have such resonance with decision-making bodies? What hopes are we pinning on data for fairness of outcomes and the future of equity?

\section{Anticipating Risk? Thinking Data?}

We face unprecedented rates of urbanisation in the world, with cities across Africa, Central and Latin America, and most of Asia carrying the lion's share of this burden. This brings an urgent need for mitigation against risk susceptibility and for social equity, without which the sustainability of these cities will fall into question. India, China and Nigeria will cumulatively account for $35 \%$ of the projected growth in the world's urban population between 2018 and 2050. In absolute numbers, 2050 projections estimate that India will add another 416 million urban dwellers, while China will contribute 255 million and Nigeria 189 million (UN 2018). In addition to a rising urban population, demands for energy and water will also be

\footnotetext{
${ }^{13}$ Aadhaar is based on the etymological play on the word 'basis' or 'foundation' with Sanskrit origins. For citizens in India, it is a biometrically-tagged 12-digit number unique to each individual that is being designed as a way to identify and document persons.
} 
peaking and that too in much shorter time frames. By 2030, global demand for energy and water will see an expected growth of 40 and 50 per cent respectively (UN 2016).

While current estimates point out that 1 in 4 will live in a slum by 2030, this scenario is bleaker for developing countries where inadequacy of shelter will be a reality for every third urban resident. Hence the urban poor residing in informal settlements and slums in cities of the global South are highly vulnerable to resource scarcity and risk. Whether it may be incremental changes and stresses like heat stress, pollution, poverty, induced weather extremities or natural disasters, what makes the urban poor in slums particularly susceptible to risks is "lack of secure land tenure, lack of access to basic infrastructure and services, and overcrowding" (World Bank 2011:45).

For those on the veritable margins, data is being heralded as the tool that can give them visibility in discourses where they may have remained so far unaccounted. In the case of India with a population of 65 million slum residents, the potential for producing actionable data to reduce poverty and effect change is immense. After over six decades of tepid responses of centrally-funded welfare schemes and poverty reduction measures, countries like India are stepping into the domain of data with the hope and intent of catalysing new modalities of urban governance and of addressing the scarcity and risk that these vulnerable populations will increasingly face. While the promise of ICTs as a fast mover was first envisioned some decades ago, the current push for data-driven governance and 'marking' citizens has been galvanised by the promise of digitising platforms, services and records/archives. For 'invisible' slums, whose insecure tenure and non-networked nature may often keep them off official maps and city plans, this could provide the possibility of a crucial break.

We already know, though, that achieving the potential of urban data will not be all plain sailing. Ananya Roy (2009), for example, notes exception, informality and invisibility as not gaps within but modalities of planning itself. In cities of global South, these often come to be used as purposive instruments to manage the failure of planned developmentalism. To demand visibility is thus a political negotiation against exclusionary discourse of planning and policy. While invisibility may provide temporary tenure and allow life to go on under the nose of the state; to make oneself apparent, to demand or negotiate for visibility is a political move against being enumerated on terms in which one may have no say (Warner 2013). Thus slums confront the city and often remind it of many cities that live within it.

Creating and collating data about slums and grounding the origins of this data with the community can push the envelope by providing visibility and adding further granularity to what is known about these areas; an essential foundation to proofing them against a future of risk. Yet government and municipal authorities have been faced with the temptation to enumerate and mark residents of informal settlements in limited ways, and the challenge of going further than this. Linnet Taylor (2017) argues that in low-income environments accuracy and granularity of data capture remains a practical difficulty for government authorities and urban local bodies. This is very much a reality for Indian cities which have high density slums that are constantly under the process of incremental building and have a high rate of attrition (Ghertner 2016). 
So, while the promise of data-driven decision-making is real, what does this mean in everyday practice? First, as just noted, there are challenges in the very process of collecting and analysing data, such as the complexity of capturing the details of dense slums in Indian cities and the political implications of this process. But more importantly, even if such data can be gathered, there are real-time dilemmas and impediments in making use of it for evidence-based civic participation. Thus, analysing the issues that plague this practice especially for communities residing in informal settlements in the global South not only has potential to improve operational efficiency of processes but also to better deliver on goals of social equity and justice.

Mahila Housing Trust (MHT) is an Ahmedabad-based NGO that has been working with slum communities for over two decades in areas of habitat upgradation, improving livelihoods and productivity, and building climate resilience. Over the course of the last 25 years, MHT has attempted to create both broad-range and particularised data to understand the demographics and deliver on the needs of communities and households in informal settlements across eight states in India. With a deeply embedded community-based and community-led model, MHT's on-ground practice attempts to realise this process of moving from data to knowledge and subsequently to action not only 'in' but 'with' slum communities.

In partnering with communities, there is a deliberate push for obtaining data of high contextual accuracy but this simultaneously makes maintaining data quality increasingly complex. A similar dichotomy exists with using ICT in countries like India where urban slum areas and smaller towns are still developing the means to conquer digital divides and patchy telecommunication capacities. Tussles over data ownership and agenda-setting roadblocks continue to structure outcomes of data-driven decision making for slum communities on individual and collective scales.

Given these challenges, the central questions of this case study focus on two core issues within the larger spectrum of concerns for data justice. First, issues of accuracy, digitising data and the use of ICT; and second, issues of ownership and translating data-driven knowledge into actionable forms. Through these, this case study engages with the existing discourse on data justice and attempts to bring out real-time challenges of the process of data creation and the potential held in producing actionable data that communities may use in making governance and planning processes more accountable.

The subsequent section elaborates on the central analytical framework used in this study i.e. the 'information value chain' adapted from the work of Richard Heeks and Satyarupa Shekhar (Heeks and Shekhar 2019). Details on the methodology used for developing the study are presented in the following section. Findings detail how barriers and real-time challenges emerging from on-ground practice structure pro-equity development initiatives in order to reflect on the information value chain in practice from the context of developing cities in India. Reflections emerging from the case study analysis are presented in the concluding section with recommendations for a future agenda. 


\section{B. Background}

Scholars and policymakers have acknowledged that developmental agendas in the contemporary world have moved on from being merely informed to being driven by data (Taylor 2017). Despite this technological overhaul in structuring the governmental agenda, the domain of data and its potency can be circumscribed for many parts of the population. Cross linking, mining and deploying data carries risks of further exclusions and reinforcing inequalities especially for those on the margins. For instance, who gets framed as key perpetrators in the data on air quality in Delhi indicates not just the stakes but also the politics of data representation and speaks of the power inscribed within the collection and presentation of large-scale digital datasets. In the process of datafication, a farmer can be a data point divorced from issues of soil salinity, ground water shortage or crop failure, as s/he seems located within a system but divorced from its structural deprivations. In the process of assigning blame for air quality in the capital, does the responsibility of inner-city industries producing noxious fumes or private motorised vehicular traffic get subsumed in the larger narrative of pollution spikes due to stubble burning by farmers in North India? Who gets penalised in legal proceedings may often flow from the results of these representations; and in this case lead to hefty penalties on the middle- and small-scale farmers who supply Delhi with its grains (Mukerjee and Goswami 2016).

The ability of data to frame narratives or drive agendas speaks of a larger ecosystem and how it interacts with the core data processes of any initiative, project or information system. Those core data processes can be understood as an 'information value chain' (see Figure 1). The information value chain model used by Heeks and Shekhar (2019) visualises the process of datafication with its constituents at upstream, midstream and downstream stages.

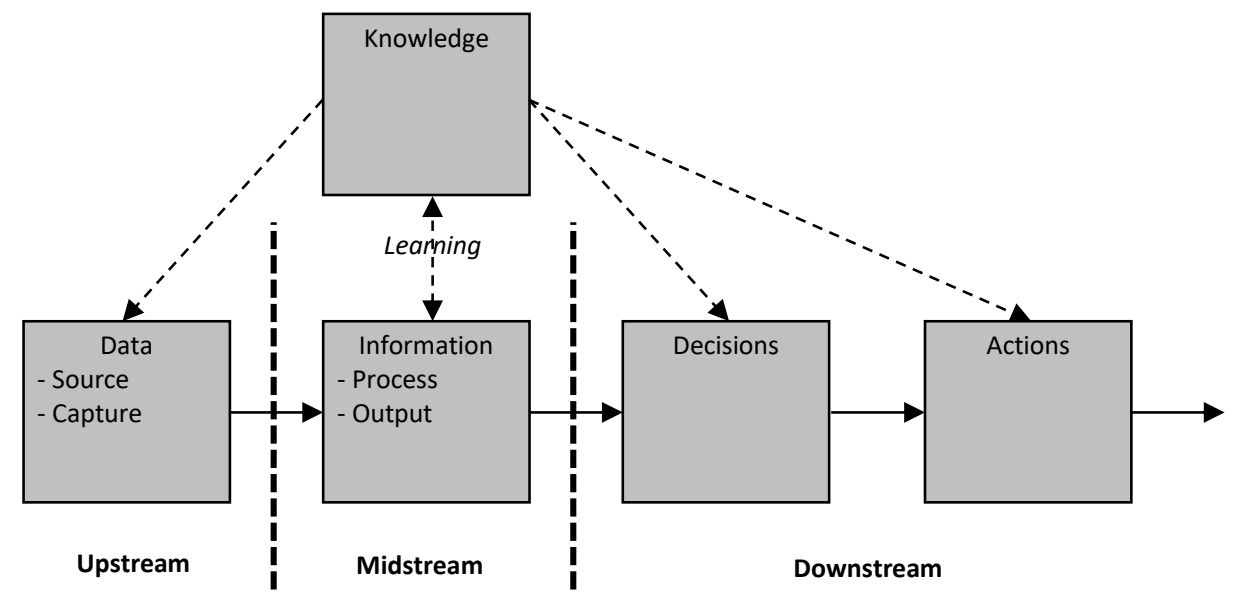

Figure 1. The information value chain (adapted from Heeks \& Shekhar 2019)

Larger structural realities and socio-economic vectors sit around these core data processes. They not merely influence information value chains but get consequently shaped by the results and outcomes of information produced through datafication. The entangled nature of data and broader contextual reality thus urges a deeper look into the upstream (e.g. needs, tools and collection processes), midstream (e.g. processing and analysis), and 
downstream (e.g. decision making, action plan dissemination and enactment) components of the information value chain. These can therefore be seen to either counter or reinforce discrimination, redress or perpetuate invisibility for those without social privileges, empower communities or sever their rights, etc.

What can data justice mean in such a scenario? Richard Heeks and Jaco Renken define data justice as "the primary ethical standard by which data-related resources, processes and structures are evaluated" (Heeks and Renken 2018:92). They break this down into different dimensions like instrumental data justice (fair use of data and its outcomes), procedural data justice (fair handling and management of data), distributive data justice (fair distribution of data). Threading Amartya Sen's capability approach within this idea imparts agency and emphasises the interlinkages of data/evidence and decision making to improve life opportunities (ibid.). An information value chain hence functions and thrives within an ecosystem of social action, interest groups and other external factors which all come to bear on the production, operation and outcome of the value chain.

While the information value chain model (Heeks and Shekhar 2019) provides a central framework for this study, the arguments presented here build upon how this might work in real-time practice and what that could mean when one speaks of data justice. It attempts to foreground the dynamics of heterogeneous experiences of ICT and digital reach, iterative datafication techniques, and limitations in human proficiency for turning data/evidence into action. These are issues that remain true for a wide majority of slum residents in Indian cities and hold an overarching influence in not just the data outcomes but the process of datafication itself. A capability or a choice to shape data outcomes may be highly varied across different locational and socio-economic contexts; not just for individuals but organisations like MHT itself which attempt to strike balances between pro-poor advocacy and producing unbiased data sets.

What this effectively suggests is the urgent need to ensure data use is open, accountable, effective and responsible especially when data intermediaries (organisations working in the zone between the state and the citizens) frame and actualise pro-data equity initiatives. Linnet Taylor notes that, "the framing of data justice ... operates at the highest level - where the social contract is shaped and negotiated - and at the most basic, in the practices of everyday ... life" (Taylor 2017:11). Given this all-encompassing influence in an increasingly datafying milieu, there remains a significant need and potential for building "ethical paths" (Taylor 2017:2) and embedding a social justice agenda within the larger ecosystem of datafying developmental regimes (Taylor 2017, Heeks and Renken 2018). In the case of action-oriented projects being run for and/or in slum communities, this takes on particular forms and challenges.

Given the digital divide and existing socio-structural hierarchies, data related issues - who collects the data, for what purpose, using what tools for collection, with what level of participation of the community and what availability and openness of data sets, how data is framed or harvested, and what balance exists between privacy and representation and between accuracy and manipulation - all shed light on the multiple intersecting streams of contestation that lie across the information value chain. While discussing Bowker and Star's idea of efficacious systems, Taylor extrapolates that a good, usable system becomes so 
convenient that it disappears and only its answers remain (Taylor 2017:6). Similarly, the 'work' in a data-driven world carries a messy underbelly of stakes, interests, costs and controls which catalyse processes even as they remain in the foreground; while the information they hold travels and is harnessed across different contexts or purposes.

While it remains impossible to eliminate the effects of all of these challenges, using a data justice framework allows for bringing self-reflexivity into working with/through data. Hence this study uses the information value chain as a starting point to analyse data-justice-inpractice by reflecting upon interventions and action-oriented projects. The two core issues it identifies attempt to highlight the complexities at two different stages within the information value chain from the perspective of slums and their residents in India (see Figure 2). The first issue is of data accuracy and digitisation of data that pertains to the upstream components of information value chains. The second - focussing on downstream issues - is that of linking data ownership to the community as well as the challenges faced and potential unlocked in harnessing data/evidence.

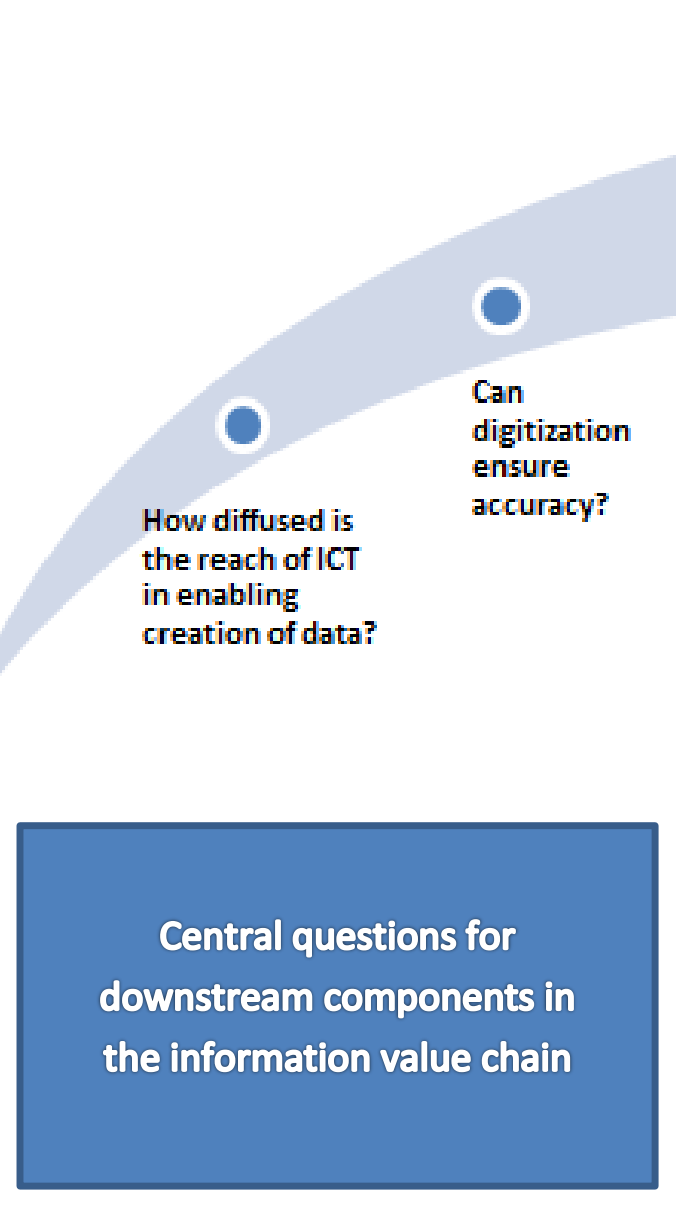

Central questions for downstream components in the information value chain
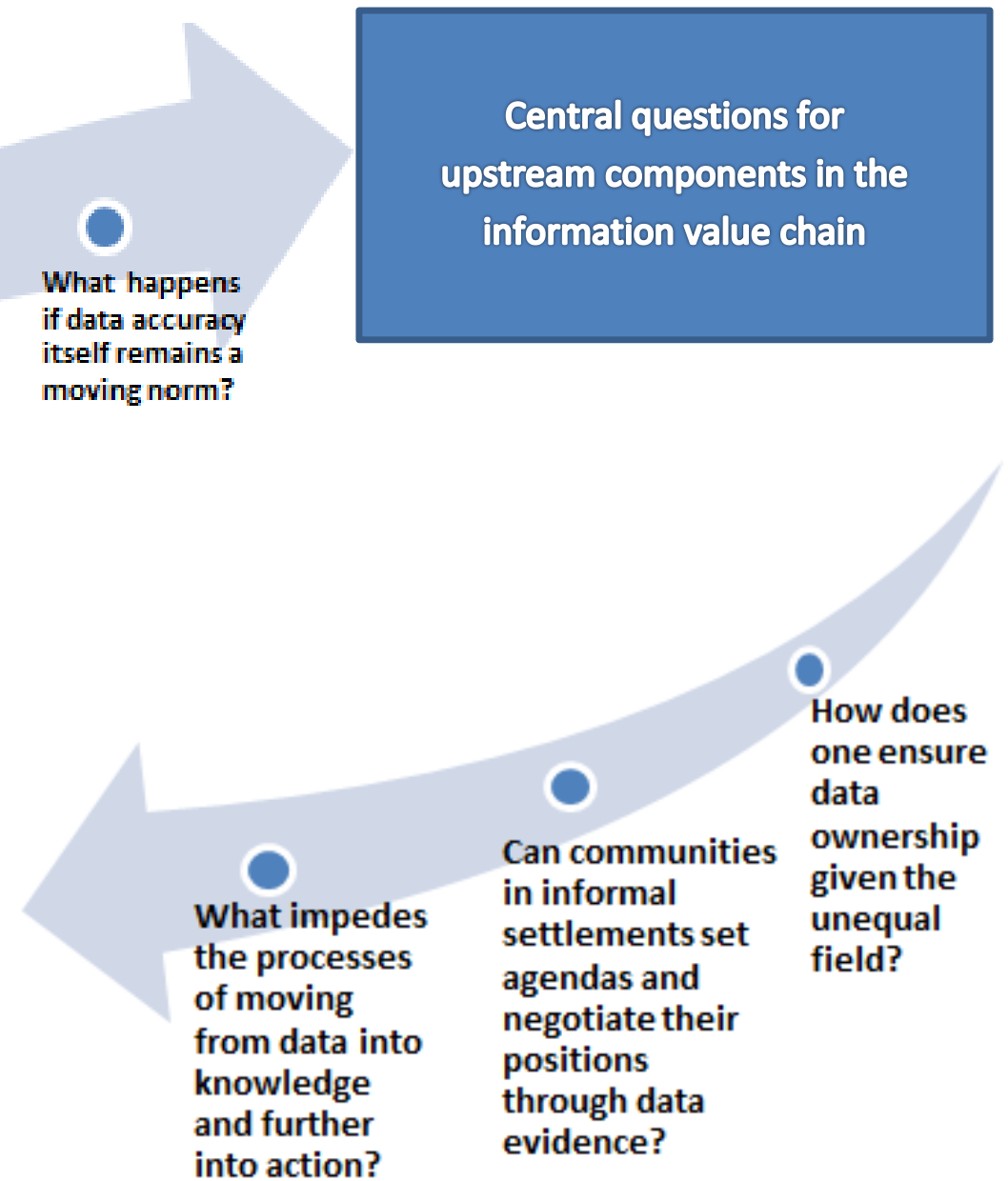

Figure 2. Central focus and key questions of the case study 


\section{C. Methods}

A combination of secondary and primary research is employed for the purposes of the study. The key framing issues and literature review is carried out through a secondary analysis of some key literature around data justice as a conceptual category and a modular form. In addition, the study is pivoted on a critical evaluation of Mahila Housing Trust's own experience of working with data through examining illustrative examples, experiences and on-ground learning from three key projects:

- Slum Mapping Exercise in Ranchi (ongoing): The project was a slum boundaries, infrastructure and service delivery indicator mapping exercise done via community participation in order to produce digitised, updated and geo-tagged maps for 20 informal settlements which have remained largely invisible to date within urban governance in the city. The process was based on translating paper maps made via community collaboration and household-level data collected via mobile apps by trained MHT personnel onto geo-referenced formats for community awareness and mobilisation as well as public advocacy.

- Energy Audits in Ahmedabad (ongoing): The Energy Audit project is a community-led energy mapping exercise where women leaders from the community (trained by MHT) in Ahmedabad collect household data about energy expenditure and requirements. Post-analysis, families from informal settlements were provided with customised solutions through microloans, energy-efficient products and suggestions based on their household layout, need and capacity to pay. The collection was carried out by community women through audit tools and paper-based surveys processed and analyzed at MHT with the onus of decision making and action plans on the community itself. The project aimed to ultimately develop the capacities of community-based organisations to monitor and maintain infrastructure involving them in meter reading and the supply and payment of bills.

- Global Resilience Partnership Challenge (GRP)-supported project building climate resilience for the urban poor (2015-17): The project titled "Women's Action towards Climate Resilience for Urban Poor" was run in seven cities of South Asia to co-create data and action plans on housing typologies, climate risk and current conditions at the household and slum level. Collected through mobile apps and shared with the community, it allowed for them to create community-level plans and mobilise towards ensuring public accountability.

Primary evidence on challenges and reflections on data justice in practice was collected through qualitative research tools such as unstructured interviews and focus group discussions (FGDs). All primary work was conducted between January-April 2019. The FGDs were targeted towards three different levels of data 'agents' or stakeholders within the organisation, each of whom play vital roles in shaping project design, what kinds of data we seek, what tools are used to handle and secure the data, but also shaping how data is circulated and used. 
These levels correspond to: on-ground field team, data management team, and senior management at MHT. The field team is the key data gathering unit and works closely with the community. For the purposes of this study, the field team from MHT's local office in Ranchi in Jharkhand was involved due to the challenging, diverse and wide-ranging project portfolio of ongoing projects at that location. The data management team not only design research tools and survey timelines but perform various upstream and downstream tasks like ensuring training of surveyors, aiming for maintenance of research ethics in the field, handling software and back-end processes, checking and cleaning data, and handling its analysis and presentation. They include a variety of consultants and outside experts as per the need of the project and mostly work out of the head office in Ahmedabad. The team has been moving towards centralising databases through an MIS system for ease of operations and higher consistency.

The third nodal point for FGDs was the senior management who set agendas and steer the work of our projects and organisation at large. These may include but are not limited to those who are in direct contact with donors, policy makers, sector experts, researchers, etc. This level includes those key members from MHT who decide what data may be needed, how the data reports may be presented and shared, and how knowledge that is produced through our work gets disseminated.

\section{D. Findings}

\section{D1. 'Fixing them on the maps'}

The moving parts of a machine often determine its collective function but to unpack the 'process' of datafication is to grapple with an emergent form whose life and creation remain inherently under flux. What happens if the idea of a norm is no longer static but shifting due to the realities in which it is achieved? How and where does one set a benchmark or fix data points? The question of defining data accuracy presents such dilemmas in the practice of creating data for slums in Indian cities where discontinuity and inconsistency often puncture the idea of achieving accuracy.

In many smaller Indian cities that are still transitioning from predominantly rural to urban forms, like their counterparts elsewhere in the global South, informal settlements due to the insecurity of their tenure and disrupted domesticity either fall off the map or remain hard to capture. They continually mutate or incrementally build in relationship with the externalities they encounter from eviction, heat stress, civil strife to disasters, etc (e.g. Chandran 2019). To capture these marginalised communities and aim for data accuracy through the use of ICT remains equal parts potential and challenge. To use community participation as a means of improving accuracy and create data from the ground up can provide added granularity to GIS maps or drone mapping that may rely solely on remote sensing or official survey maps. However the experience of immersive fieldwork and community involvement also raises concerns over local conflicts, exposure to induced errors, and technological hurdles in remote locations which posit accuracy as not an unattainable but a shifting norm. 
For instance, we can take MHT's experience in the ongoing slum mapping exercise in Ranchi undertaken through a complementary process of field-based studies and subsequent digitisation of slum surveys and service mapping via GIS. This illustrates some of the dilemmas in seeking to ensure data justice. Essentially the project was devised as an iterative process of following four stages (see Figure 3). The first stage involved immersive fieldwork and iterative processes to map slum boundaries and enumerate households. While the slum boundary mapping was a collaborative effort between field teams from MHT and community residents, the household-level data was collected by trained field surveyors from the organisation itself. The next stage involved digitising these into geo-tagged formats. To this another layer of data was overlaid by collecting information about household particulars and service levels within the community. In the fourth stage, this information was collated, verified and presented in the form of digitised slum maps for communities which have remained on the margins of state discourses and planning paradigms, in order to initiate public advocacy and to initiate community-led demands upon the state for civic entitlements in informal settlements.

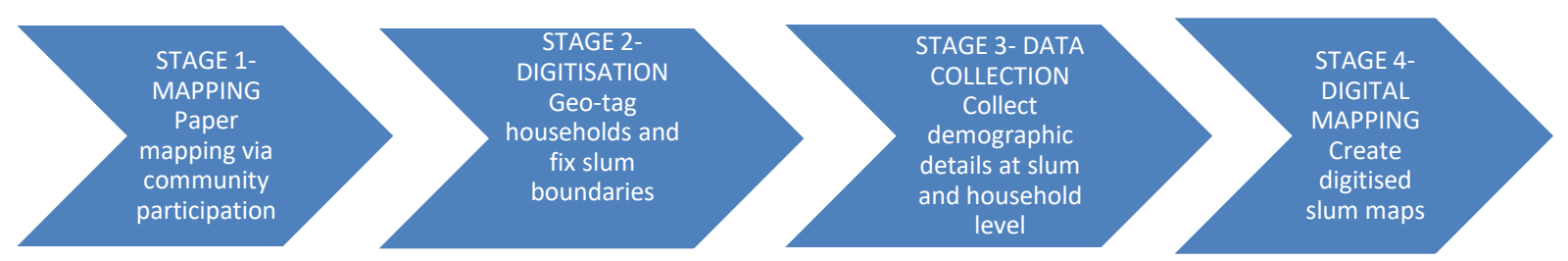

Figure 1. Steps for slum mapping in Ranchi in MHT's ongoing Slum Mapping project

The slum mapping exercise in Ranchi was highly dependent on community knowledge to establish settlement boundaries and service deficiencies in the settlements for enabling service provision and furthering advocacy. While a participatory exercise improved chances of community control over how their reality was captured, this came at a cost where higher chances of inducing manual error, the environment with slums, and attrition rates all shaped outcomes. MHT's Ranchi field team explained that problems arose from a range of issues. Illegal subdividing of houses for rental yields kept changing total numbers of houses for each slum as new doors and temporary partitions often sprang up in subsequent visits to the same slum. Locked houses due to seasonal migration or high incidence of daily wage labour left verification processes reliant on secondary and tertiary sources which often became the neighbours or village-level officers who had little idea about the on-ground situation. Topographical inaccessibility such as open drains and low-level areas which were flood-prone also made coverage of entire settlements and in-person investigation harder especially during monsoons. Organic street networks and fuzzy settlement boundaries due to constantly building and shifting within the settlement made fixing street segmentation and clear boundaries on digitised formats an inherently unfinished business.

In these cases triangulation of data gathering became necessary (for instance, asking respondents, cross-checking with neighbours and via personal observation). But surveyors were often put in decision-making dilemmas, whether their intervention towards achieving accuracy meant inducing bias as a corollary to reducing error. Illegal service connections were observed and often reported by field teams in cases where a true picture at the slum level would benefit from reporting the truth about the household-level picture. Field 
officers also noted higher accuracy in household-level data when slum residents perceived that they would be beneficiaries of targeted projects rather than participating in background exercises for advocacy such as the slum mapping exercise. The field teams stated that they operated on a 70-90\% confidence level in terms of data accuracy where micro details may only be gathered through using proxy indicators and/or attempting triangulation through asking the respondent, their neighbour and self-observation. 'Fixing them on the maps' and 'making the maps' were hurdles which were constantly being negotiated in the field.

As a data intermediary, working in local contexts also meant dealing with low technological proficiency and testing field conditions. The potential of digitising information about slums through ICT faced high barriers in Ranchi where network issues, limited literacy of field surveyors and respondents as well as geographical inaccessibility produced impediments to creation of data and to translating data into legible and actionable forms. Patchy mobile network connectivity and use of basic devices often led to time lags and poor records of locational accuracy during geo-tagging procedures. For instance household-level surveys were often backlogged due to unavailability of data services in informal settlements in the periphery of the city. It also resulted in delayed updating of survey forms and in extreme cases, mobile device operating system crashes or jumbling of back-end data.

Building staff capacity and maintaining trust with communities was and remains an ongoing challenge. For MHT, building community trust has been a core focus which entails a long drawn-out period of informal field visits, interacting with the community and understanding their needs as well as laying foundations for building community-based organisations in the informal settlements across Ranchi where MHT is working. This initial trust-building process takes around 3-6 months and usually precedes the project or other need-based collecting of data. If absent, it can lead to sources of bias and inaccuracy. From MHT's experience, it is increasingly apparent that data accuracy is directly proportional to levels of mutual trust and intended benefits. Field teams noted that residents of informal settlements shared more accurate data when they have familiarity with and trust the surveyors / organisation.

Women-led teams also encountered hostility and uncomfortable situations at times. Cases were reported of catcalling as well as questioning of women surveyors by male slum residents who were drunk and/or felt threatened by the presence of female surveyors in their settlement collecting data. This forced the organisation to have male members within the team in order to ensure safety. Such involuntary considerations as well as disruptions in the field not only increased the time lag in data collection but also bore financial consequences for the project. A detailed flowchart of the challenges faced at each step is presented in the Appendix.

Experiences from practice urge a rethinking of the idea of data accuracy: not as a static benchmark but a shifting norm structured by the on-ground realities including its emergent milieu and conflicting stakeholder interests especially in areas whose ontology is constantly under flux. While the community felt empowered in terms of participating in creating data and being visible, there still remained discomfort and hesitation in sharing household-level information due to the perceived illegality of their status. Use of ICT facilitated digitisation processes but led to entry level barriers and operational hindrances for local research teams 
and the community. Overcoming processual lags and ensuring validity was thus an incremental effort which was enabled through purposive decision making and multiple rounds of cleaning and re-verification. Inducing bias during datafication was wagered against presenting a real-time picture of informal settlements and their needs, while minimising their exposure to punitive action from state and non-state actors.

How context itself shapes the benchmark for data accuracy reveals the contested territory of fixing data while working with information value chains. It reveals that the structural data justice framework holds up a more destabilised and messy world of iterative processes and interactions within action-oriented projects in informal settlements where feedback loops, hierarchies of knowledge and technique, and constant shifts shape more than just the form that data takes.

\section{D2. Data ownership and translating data/evidence into action}

Another central focus for data justice discourse has been ensuring that ownership and control of the data created about individuals and communities remains accessible, understandable and actionable for them, in contrast to the intentions for big data. For Taylor (2017), who advocates building ethical paths in a datafying milieu, balancing between integrating the freedom to be seen and represented appropriately with the freedom to be unseen and free from intervention remains a central concern and in practice, a constant challenge. With the marketplace for data expanding drastically - making data one of the most precious and potent commodities in the world today - democratising its access and routes to its use for shaping outcomes has become even more indispensable. Data intermediaries, especially those working for developmental and pro-equity initiatives, need to push for ensuring that communities remain a vital stakeholder in not just generating but owning and using the data generated through them, even if translating data/evidence into actionable forms may prove to be a variegated experience. Community empowerment is pivotal in translating data/evidence into actionable form: merely making data/evidence available to a community does not necessarily translate into desired action.

What are the real possibilities of creating data ownership amongst communities? Additionally can we rethink slum residents as integral parts of information value chains at different stages: from upstream catalysts like research surveyors to data/evidence-driven action agents? Experiences from ongoing projects provide a highly diverse scenario in this regard with every project, location and context defining its own set of hierarchies, hurdles and possibilities.

The energy audit project run by $\mathrm{MHT}$ in cities like Ahmedabad provides an interesting example. As part of the project, MHT trains women leaders from slum communities to work as energy auditors in the households within their communities where they audit households on the basis of their energy usage by generating and collating data on electricity bills, consumption and family preferences. The auditing tool they use maps the existing layout of the interior of a dwelling and the light sources and spatial use given many dwellings also double as workspaces for their residents. This mapping helped the women leaders themselves and family members of the households in question to understand how they used their home spaces for different activities. Improvements are then suggested in the 
location of light points e.g. splitting the light points to give focused brightness but using lower wattage sources.

Up to this point, MHT has trained a group of nine women across Ahmedabad, who now work as energy auditors for their community. While on the one hand the training empowered community members in creating and analysing their own energy needs, the communities remain dependent on trained experts and architects on second-order issues such as devising layout-based solutions for each household. The process strengthened the community in domains of awareness and decision making at the household level as it prioritised the involvement and needs of the families it aimed to study and benefit. The initial gains on data/evidence-driven action were taking shape through decision making on energy consumption and shifts being made on the level of the household to tackle heat stress, ventilation and low lighting issues as well as improvement in storage capacity and spatial usage within the household unit. By keeping the process and solution localised and indicative rather than directive, the families and community had greater control over the data-driven solutions they wanted to experiment with and invest in. Most of the data collection was still done through paper and usage of electrical equipment such as voltmeters required significant external support. Local identities, politics and socioeconomic conditions still held a significant impact on what action could stem from the awareness that is generated.

Additionally these energy auditors also introduce low-cost, energy-efficient solutions and products manufactured by MHT through subsidised means. Through its network of women energy auditors, MHT has sold sustainable energy products such as LED lights, smokeless cook stoves, solar lanterns and solar lighting, and cooling systems to more than 27,500 slum families across 10 cities in India. Yet this network made the women in the community answerable and accountable to the organisation. The data being collected was held in a central repository at $\mathrm{MHT}$ which had the final say on its usage. The process of democratising all the way along the information value chain hence remains far from over and requires more work. Even while one domain may acquire more openness or robustness, others produced new hierarchies in terms of how data was processed or where it was sought to be deployed.

While the energy audit process trains community women to recognise and devise solutions for rationalising their energy needs at household and neighbourhood level, the umbrella project for women-led climate resilience building under the Global Resilience Partnership (2015-17) pushed the agenda of data/evidence-driven civic participation further along the road to achieving data justice. Based on evaluating, harnessing and improving community capacity in seven cities across South Asia ${ }^{14}$, the project, with its process methodology detailed in Figure 4, was designed to shift the sustainability quotient and driving gear of the datafication and action planning process into the hands of the community. The project was conceptualised to ensure:

\footnotetext{
${ }^{14}$ Ahmedabad, Bhopal, Bhubaneshwar, Jaipur and Ranchi in India, Kathmandu in Nepal, and Dhaka in Bangladesh.
} 
If the urban poor are provided with the requisite knowledge to undertake vulnerability and risk assessments and are equipped with accessible resilient technologies, they will be able to devise and implement locally relevant and pro-poor climate resilient solutions. If the poor are empowered to implement their own resilience plans, and the institutional mechanisms representing their voices are in place, they will be able to better influence city planning and governance on pro-poor adaptation and resilience action (MHT 2017:ii)

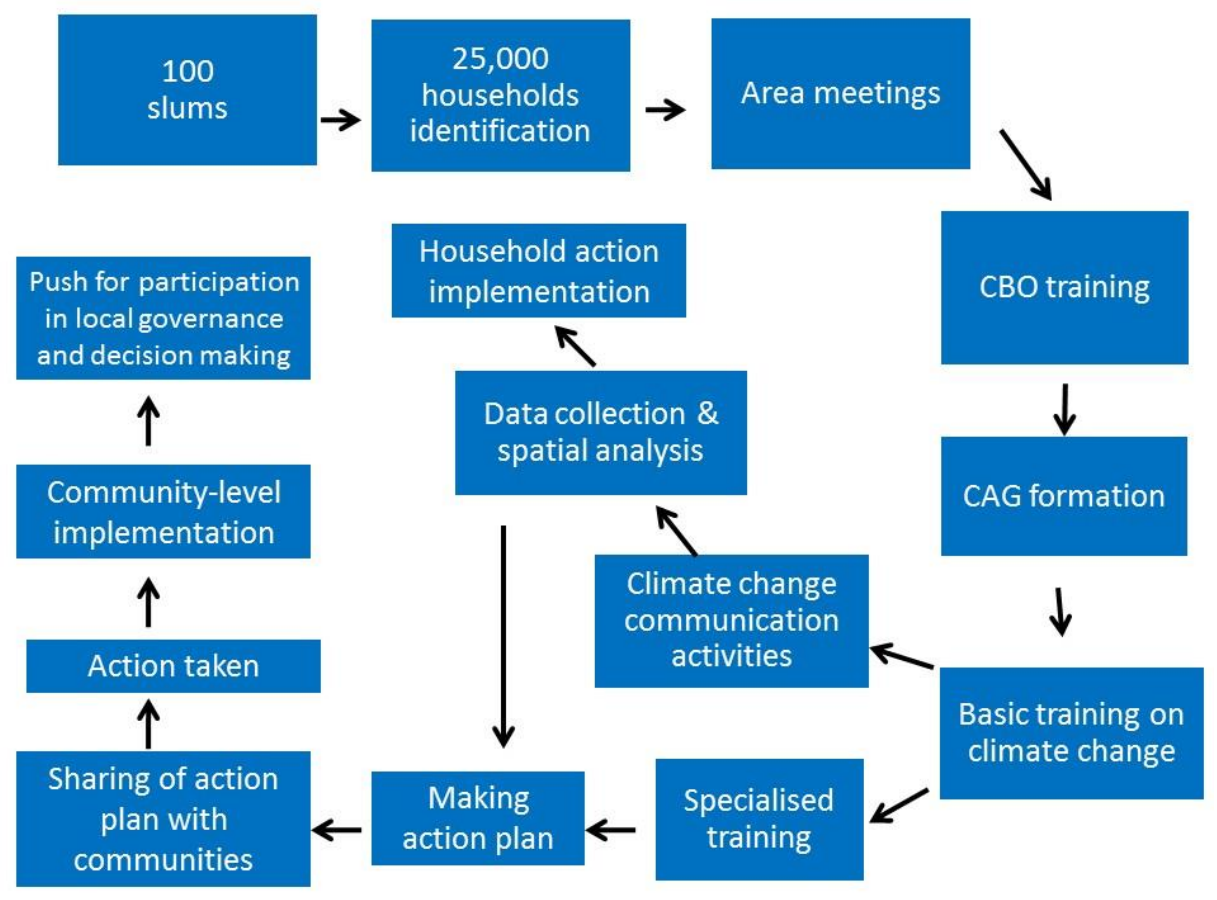

\section{Figure 4. Methodology for carrying out MHT's climate resilience building programme at community level under GRP}

Premised on building community-based organisations (CBOs) and their active proponents called community action groups (CAGs) at the slum level, community participation was central in each stage from collecting data to training to negotiation of action agendas by interacting with local municipal authorities. The GRP project allowed community action groups to form community-based action plans for each site according to their own priorities against the identified risks of water inundation, flooding, heat stress and vector-borne diseases. Use of data/evidence in setting priorities - not just for local decision making but for improving governance - pivoted on motivating and externally supporting community mobilisation based on data/evidence at the slum level which was being generated for the first time and pushing them to urge for inclusivity in local governance.

Some of the success towards this goal included community leaders from slums in Ahmedabad being made stakeholders in devising municipal authority Heat Action Plans; in Bhopal they were invited by the city municipality's Malaria Department to undertake vector surveillance in other slums; whereas in Ranchi community leaders managed to push for including rainwater harvesting incentives in local implementation of the national-level housing policy, Pradhan Mantri Awas Yojana. The women in the community were slowly trained to identify and understand technical terms and conceptual categories like climate 
change, risk, heat stress, vector-borne diseases, green roof - ideas that will permeate into the memory and vocabulary of the community over a longer, more sustained period of time. New initiatives such as climate saathis (partners) and child doctors were instituted to involve adolescents within the community.

Despite the positive response from the community and growing platforms for them to interact in local governance, many challenges still remain. The GRP programme provided the first push towards participatory processes where slum communities could interact with government to demand entitlements or better provisions but requires scaling for this effect to bring a significant change in how communication channels in local contexts are structured. The research design for a major portion of the household data collection exercise was undertaken by MHT's research teams who collected, collated and analysed the datasets produced cross multiple sites. A significant amount of training and external support remained necessary throughout and after the project in measuring and collating temperature variations, or maintenance of equipment for installed green roofs and modular roofs.

While the community members played a participatory role in producing data and deciding what forms it could take while translating evidence into community-level action plans as was envisioned in the initial project design, their role in taking it to the level of participation in local governance remained dependent on $\mathrm{MHT}^{\prime}$ s support, from organising women leaders to fixing meetings or creating platforms for engagement. On different occasions, interactions between stakeholders at meetings with local authorities had to be facilitated by MHT. Often the agenda setting and modes of intervening in local decision making were devised at the organisational level and diffused into community meetings, later being picked up by them and pursued depending on their feasibility.

Additionally while data collection and action plans still possessed an active component of co-creation at the community level, the downstream channel of data dissemination was narrower than desired due to logistical issues and privacy concerns. As a result, collated datasets were managed and remained with $\mathrm{MHT}$ itself even if their broad results were used by the community members. While data justice aims to close the loop on accessibility and dissemination of data/evidence for the communities who may be represented through it, deficits in terms of organisational planning about how this could be made available to them as well as prevalence of digital illiteracy amongst slum residents hampered the cause of open access and free use of post-analysis trends and evidence on risk and resilience capacity.

As illustrative examples, both the energy audit and GRP project present different scales and modes of how slum residents generated data/evidence and participated in decision making. For the energy audits, data creation and its concerted use was squarely at household and community level. This made the transition to action comparatively easier. The local dynamics and household considerations determined interactions and responses, where dependence on organisational support for technical proficiency and solutions remained considerable. In this case, the field surveyor, data analyst and decision maker are all from and within the community - a relatively rare scenario. This was enabled through empowering and training the community. While these required high $\mathrm{MHT}$ involvement in 
the primary stages, it eased community reach and closing of the loop from knowledge to action.

With GRP, the community's dependence on MHT for understanding issues, building and mobilising the community, and catalysing their interactions with city-level decision makers remained significant. Results for data analysis were shared with the community but the collated and analysed databases were held at the organisation level. Even while these remained accessible for community members, making them practically usable has remained challenging due their digitised form. Demonstrative results from the analysed data such as results from water testing or vector-eradication drives was what the community largely relied on to understand and prioritise their resilience strategies. As complexity of data collection, analysis and decision-making process increases, community participation and ownership becomes harder to ensure yet necessary for enabling free and fair use of data; i.e. necessary for data justice.

\section{E. Discussion and Conclusions}

The projects and experiences from the field provide insights on both upstream and downstream issues of information value chains. The slum mapping exercise in Ranchi brings in contextual learnings relevant to similar locations undergoing rural-urban transitions and seeing high rates of attrition and incremental building in informal settlements. Their location and topographical conditions produce challenges of access for fieldworkers and for fixing them in digitised and geo-tagged formats with cohesiveness and complete accuracy. In addition, high political stakes and tenure insecurity drive communities to make conflicting or inconsistent claims that push field researchers to triangulate data and make choices between correcting or inducing bias. The upstream stages of information value chains remain extremely entangled in practice i.e. moving back and forth due to procedural and ethical dilemmas of fixing accuracy. Further, digital divides and limited diffusion of ICT have meant that it often creates hurdles for both researchers and the community in implementing research as well as translating information into action. Hurdles such as low network connectivity, limited ICT diffusion and low digital literacy change the discursive domain of what can be achieved in the course of enumerating and mapping slums.

On the other hand, experiences from practice in the energy audit programme and GRP project help reflect on how issues of data ownership and challenges to data-driven civic engagement shape the downstream effects of information value chain operations. While the energy audit was at the settlement level and improved chances of keeping the information value chain operation grounded and community-led, on macro, multi-city scales like those in GRP this became harder. Slum communities in Ahmedabad needed support and handholding in enabling action through data/evidence-driven negotiations. Socio-economic conditions, gender biases, literacy levels, and digital illiteracy continue to be entry barriers in pushing for desired outcomes. Creating chances for data-driven civic engagement required ongoing organisational support and facilitation. Data ownership in the case of GRP at least remained circumscribed to the domains of intermediaries, research organisations or state actors. While this process of using data/evidence-driven action is getting 
democratised, representation of macro data sets, rules for access and maintenance of erepositories remains harder to decentralise.

Improving $\mathrm{MHT}^{\prime}$ s own data and project documentation has also been a challenge that the organisation continues to strive for. Building consistency in our data collection and handling will allow for better preparedness towards improving channels for access. In addition, another key learning from ensuring data justice in practice is to build the familiarity and capacity of working with digital formats for those within the organisation as well as the communities. Developing technical knowhow and capacity building by intermediaries like MHT which work at grassroots level may be a step towards improve the ability of slum communities to effectively understand, handle and yield their data in future. Another learning has been towards developing data collection tools that incorporate multiple formats suitable to support triangulation. For instance, survey questionnaires for respondents that incorporate input media such as audio and taking geo-tagged photographs of locations improve data cleaning processes and accuracy levels.

While the promise of data justice could restructure hierarchies, the new forms of dependencies being created also need attention. For informal settlements in the global South not just digital literacy but literacy more generally remain an unfinished goal; yet a basic foundation for data justice in a digitising world. ICTs can play a role to democratise and decentralise datafication processes but only if we move towards fairness of use and representation, and enable a rights-based discourse that balances the need to be seen with the right to determine how and the space to refuse. A contextually-grounded evaluation of the work of information value chains allows us to consider the domain of possibilities against contours of impediments, both of which remain inherent in the processes of a datadriven environment. The discussion on data justice in MHT's case study runs across multiple registers. First, the case study allows us to engage with logistical or ethical concerns that emerge in practice such as dealing with concerns regarding efficacy versus limits of ensuring accuracy, and working in technologically-deficient locations or with conflicting interests. Second, the analysis of the projects illustrating data/evidence-driven engagement highlights how data can intervene in the lives led by the urban poor and in the challenges that continue to plague them.

A future research agenda towards building data justice into practice needs to focus on better understanding of capacity-building interventions with communities; particularly identifying strategies for them to actively engage with and own the process of creating actionable data for change. This requires them to be not merely providers of data but stakeholders in the process of envisioning data-driven civic engagement. Another key focus for future research will be scaling decentralised data initiatives. In small-scale or community-based projects such as energy auditing, there was considerable evidence to suggest that the envelope on data ownership and subsequent decision making was being pushed. However, this remained a challenge for macro-projects like GRP. Building grounded frameworks and models for scaling interventions that aim for data justice in practice remains a necessary next step for a just and fair future. 


\section{References}

Arora, P. (2019) Benign Dataveillance - the New Kind of Democracy? Examining the Emerging Datafied Governance Systems in India and China, Communicative Figurations, Working Paper 24. ZeMKI, Centre for Media, Communication and Information Research, University of Bremen.

Banerjee, S. (2017) It's time to disentangle the complex Aadhaar Debate, The Wire, 20 Apr. https://thewire.in/government/aadhar-privacy-analysis

Chandran, R. (2019) More than 11 million face eviction, displacement as India booms, Reuters, 9 Jun. https://in.reuters.com/article/india-landrights-eviction/more-than-11million-face-eviction-displacement-as-india-booms-idINKCN1RL2VL

Ghertner, A. (2015) Rule by Aesthetics: World Class City Making in Millennial Delhi. OUP, New York.

Heeks, R. \& Renken, J. (2018) Data justice for development: what would it mean? Information Development, 34(1), 90-102.

Heeks, R. \& Shekhar, S. (2019) Datafication, development and marginalised urban communities: an applied data justice framework, Information, Communication \& Society, 22(7), 992-1011.

MHT (2017) Women's Action towards Climate Resilience for Urban Poor in South Asia, Mahila Housing Trust, Ahmedabad

Mukerjee, P. \& Goswami, S. (2016) Delhi air pollution: identifying perpetrators and fixing responsibility, DownToEarth, 7 Nov. https://www.downtoearth.org.in/news/air/delhiair-pollution-identifying-perpetrators-and-fixing-responsibility-56240

Roy, A. (2009) Why India cannot plan its cities: informality, insurgence and the idiom of urbanization. Planning Theory, 8(1), 76-87.

Scott, J. (1998) Seeing Like a State: How Certain Schemes to Improve the Human Condition have Failed. Yale University Press, New Haven, CT.

Taylor, L. ( 2017) What is data justice? The case for connecting digital rights and freedoms globally. Big Data \& Society, 1-14.

UN. (2016) Urbanization and Development: Emerging Futures, World Cities Report 2016. UNHABITAT, Nairobi.

UN. (2018) 2018 Revision of World Urbanization Prospects. UNDESA, New York.

Warner, G. (2013) In Kenya, using tech to put an 'invisible' slum on the map, Parallels, 17 Jul. https://www.npr.org/sections/parallels/2013/07/17/202656235/in-kenya-using-tech-toput-an-invisible-slum-on-the-map

World Bank. (2011) Guide to Climate Change Adaptation in Cities. World Bank, Washington, DC.

\section{Acknowledgements}

The "Urban Data, Inequality and Justice in the Global South" case studies form part of a Senior Research Fellowship funded by the University of Manchester's Sustainable Consumption Institute with additional financial support from Canada's International Development Research Centre. We wish to thank all the members from field teams and local offices who work towards improving our reach towards the community and ways of knowing them through data and relationships we create in improving the habitat of nonnetworked slums. But most of all, we remain grateful towards the residents, communities and women from informal settlements across India who continue to trust us and remain 
enthused about actively shaping the world they inhabit - through data, action and their unwavering resilience.

\section{About the Authors}

Bijal Brahmbhatt is currently the Director of Mahila Housing Sewa Trust (MHT). A civil engineer by training and having expertise in habitat improvement, community development, housing finance and urban climate change resilience, she oversees MHT's operations at the national level. She has proven experience in conceptualising, planning, managing and providing support for women-led climate resilience programmes across India. Her professional experience has focused on a range of poverty alleviation issues, particularly with women, entrepreneurship, slum upgradation, water and sanitation, housing and urban planning, housing finance, housing technology and renewable energy.

Siraz Hirani is presently working as Senior Programme Management Specialist at Gujarat Mahila Housing Sewa Trust. He is a senior professional with over 16 years of strategic and operational experience with international development organisations including 8 years in leadership positions at global and national level. He holds an MSc in Disaster Mitigation, MSc in Life Science and MBA with specialisation in Finance. He is an alumnus of the Harvard Kennedy School with work experience in multi-cultural and challenging countries like India, Bangladesh, Afghanistan, Tajikistan and Myanmar. He has proven capability in strategic planning, programme management, policy development, change management, fund raising, forging partnerships and talent management. His sectoral experience includes disaster risk management, humanitarian aid, habitat development, water and sanitation, health, and livelihoods and governance.

Neha Lal is Senior Research Associate at Gujarat Mahila Housing Sewa Housing Trust and works on research, documentation and capacity building at MHT. She holds a Masters and MPhil in Sociology from Delhi School of Economics, University of Delhi and works on the intersections of issues of housing, citizenship, urban governance and planning. Her MPhil thesis looked at the changing terms of citizenship and rights of belonging for urban poor in millennial Delhi. She was also an Urban Fellow at the Indian Institute of Human Settlements, Bangalore. Neha has lived in multiple Indian cities, working on issues of housing rights, governance, water and sanitation and urban infrastructure, contemporary history and urban ecology.

Bhumika Chauhan is a postgraduate in ICT, Agriculture and Rural Development from Dhirubhai Ambani Institute of Information Communication Technology, Gandhinagar, India. At $\mathrm{MHT}$, she has been working on developing research and documentation tools, GIS portals, a vulnerability calculator and community kiosk, and automated indoor hydroponics systems that focus on providing technological solutions to poor communities. With multiple years of experience in IT project management, GIS and programming languages, Bhumika's work focuses on designing and promoting innovative technological solutions for poor communities living in informal settlements in order to mitigate their exposure risk, enable knowledge transfer and push for political advocacy. 


\section{Appendix: Slum Mapping Steps and Challenges}

$\begin{array}{llll}\text { Stage } 01 & \text { Stage } 02 & \text { Stage } 03 & \text { Stage } 04 \\ \text { MAPPING } & \text { DIGITISATION } & \text { DATA COLLCTION } & \text { DIGITAL MAPPING } \\ \begin{array}{l}\text { Paper mapping via } \\ \text { community }\end{array} & \text { Geo-tag households and } & \text { Collect demographic details } & \text { Create digitised slum } \\ \text { participation } & \text { fix slum boundaries } & \text { at slum and household level } & \text { maps }\end{array}$

\section{MAPPING}

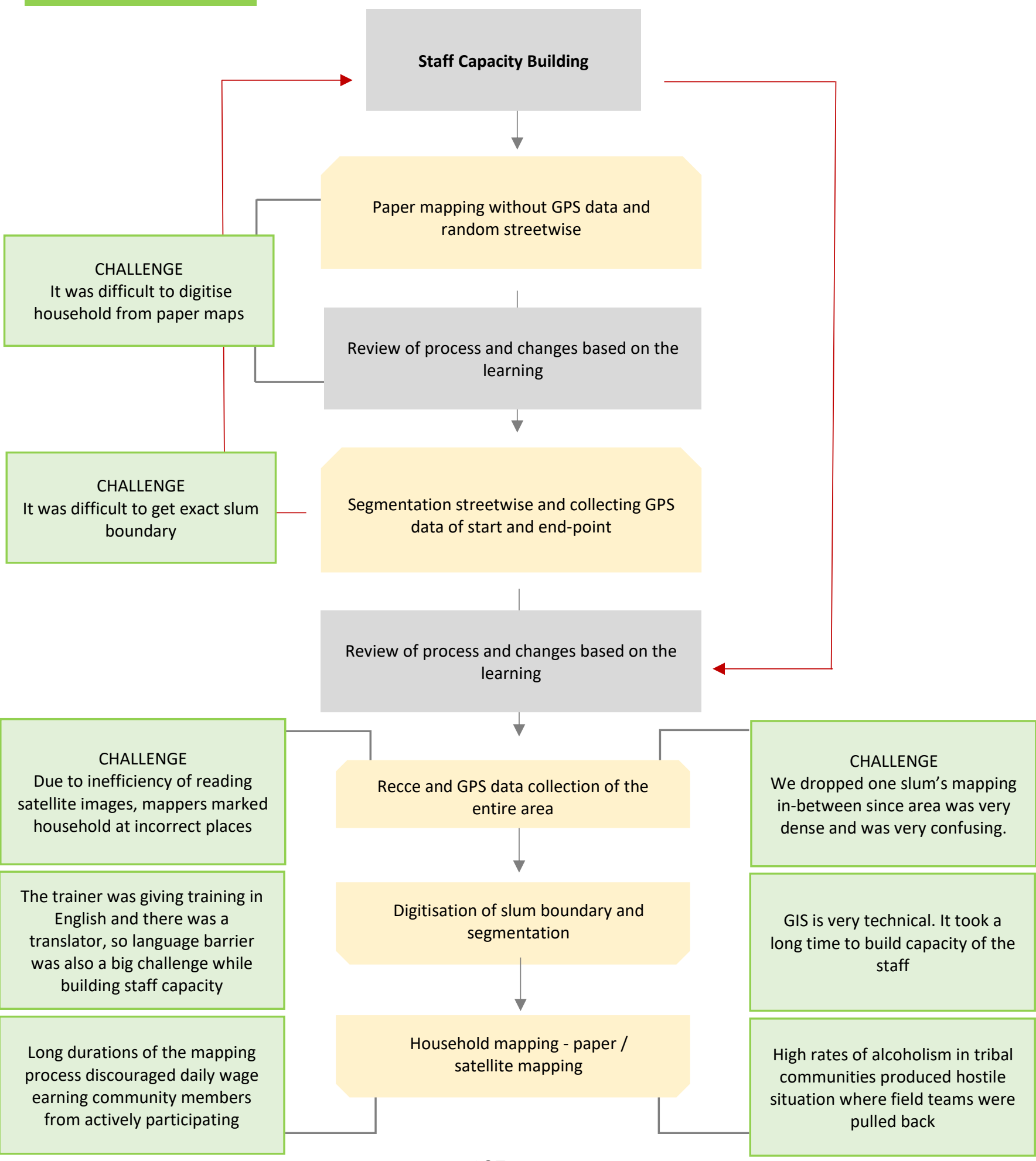




\section{DIGITISATION}

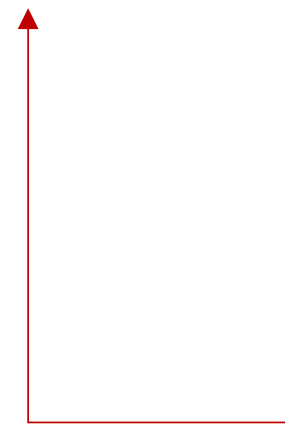

Geo-referencing of the satellite image or paper maps

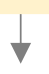

Review of process and changes in mapping process based on the learning

Geo-referencing of the satellite image or paper maps

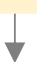

Creating household polygon on the geo-reference image with the help of CAD plugin of QGIS

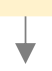

Map sharing with field team for data collection
CHALLENGE

Geo-referencing was very difficult in the initial stage, when we were not collecting GIS data 


\section{MAPPING}

\section{DIGITISATION}

\section{DATA COLLECTION}

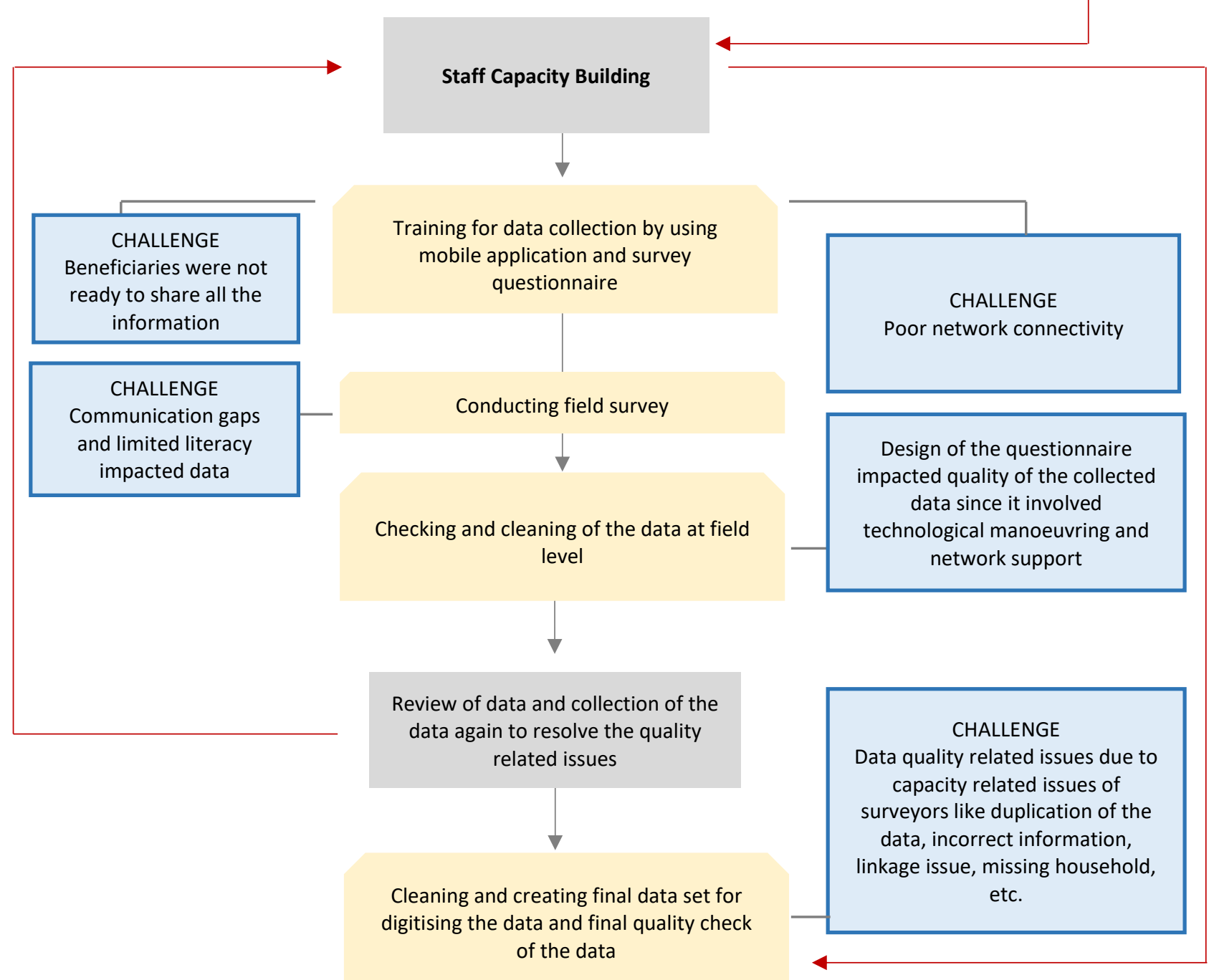




\section{DIGITAL MAPPING}

Superimpose actual GIS map slum boundary (created during recce and segmentation time) and household polygons

Creating attribute table and creating final map with respect to land-title (ownership), water accessibility, toilet availability, solid waste collection, type of house, electricity connection, etc. based on the data collected during the survey 


\title{
Case 5: Data Justice through the Prism of Information Politics and Resource Injustice A Case Study from Hyderabad's Urban Frontier
}

\author{
Loraine Kennedy \\ CNRS-CEIAS, EHESS, Paris \\ Debdatta Chakraborty \\ Indian School of Business, \\ Hyderabad
}

\author{
Ashima Sood \\ Indian School of Business, \\ Hyderabad \\ Ram Mohan Chitta \\ Indian School of Business, \\ Hyderabad
}

\begin{abstract}
How does data visibility affect vulnerable communities that face uncertainty over occupational rights? Or in other words, can data justice be realized in settings of acute resource injustice? These are the overarching questions that our case study interrogates by opening up the black box of the community in the volatile and fast-transforming context of occupation rights on the peri-urban frontier. We examine the unfolding of data and information processes through the lens of enumeration and community mapping exercises conducted in a low-income neighbourhood or basti located in the fast-transforming periurban fringe of Hyderabad, India. We argue that the realization of data justice is mediated by 'information politics', i.e., the ways in which informational resources, as well as the risks and rewards associated with them, are distributed across individual actors and identity groups within the community. In so doing, our case study underlines the importance of a structural understanding of data justice and also suggests directions for embedding justice in data processes.
\end{abstract}




\section{A. Introduction}

How does data visibility affect vulnerable communities in cities of the global South? Does the increasing prevalence of digital technologies help realize data justice in settings of resource injustice? Or does it thwart it? While recent scholarship has examined data processes in low-income communities in the global South (Heeks \& Shekhar 2019), this literature has often focused on issues of justice surrounding data processes in the relationship between the community and external actors. Our aim here is to open up the black box of the community to understand information flows within it, in order to understand attitudes about, and receptivity to, data collection exercises.

The location of our study on the volatile peri-urban frontier of Hyderabad, in an area with little presence or activity of non-governmental organizations (NGOs) or community-based organizations ( $\mathrm{CBOs}$ ), allows a reckoning with the role of 'leaders' in mediating these information flows. Thus, we take as our variable of interest not simply data, which is in some forms inaccessible to the innumerate and the illiterate, but the larger landscape of information. The assumption is that our empirically grounded approach will generate insights into a range of questions at the heart of research on data justice in relation to access, receptivity and visibility.

We focus on two adjacent but discrete communities: a basti (slum) we call 'Gachi Basti' and a recently constructed 'transit' housing complex, designated here as the Provisional Housing Complex (PHC). ${ }^{15}$ Together they accommodate approximately 1,800 residents, although lack of basic data about these communities, including population, motivated our decision to undertake an enumeration survey (see below). Both families from the basti and current residents of the $\mathrm{PHC}$ have faced housing evictions in the last year. The trauma of these evictions, experienced by the evicted families but felt across the settlement, therefore provide the most immediate prism through which we engage with the questions of data and information justice. Our conceptual framework draws closely from the specificity of this setting, and we subscribe to Heeks and Renken's (2018) position that a structural approach offers an appropriate foundation for understanding data justice in a development context.

In particular, our study demonstrates the need to embed the data justice framework within a broader understanding of the politics of information and resource access. From the perspective of distributive or rights-based justice, we focus on the right of the marginalized communities to continue to reside in their self-built settlement and their right to basic amenities provided by the state. In this way, our conceptualization of distributive justice echoes the notion of a right to the city (Lefebvre 1996, Harvey 2003, Zérah et al 2011).

Millions of India's urban residents live in informal/illegal settlements. Although these areas cover a wide range of legal and material situations, they are invariably under-serviced areas

\footnotetext{
15 The name of the basti and surrounding place names have been anonymized in light of the precarious circumstances of the basti dwellers.
} 
and home to the most socially and economically underprivileged urban residents. ${ }^{16}$ These citizens are increasingly integrated, voluntarily and involuntarily, into large-scale digitization exercises and databases. In some cases, such as India's unique identification system Aadhaar, which is based on an individual's biometric and demographic data, the ostensible aim is to improve access to public services and welfare schemes (Drèze et al 2017, Krishna 2019). Likewise, their exposure to video surveillance is justified in terms of greater safety and security (Rathi \& Tandon 2019).

In other cases, for which there is no solid body of evidence yet, these settlements, often in strategically located areas of the city with rising property values, become coveted objects of spatial mapping on the part of government planners, private property developers and land mafias. Our study is a first attempt to assess how local communities perceive their engagement in these different types of exercises in terms of risks and benefits. We show how knowledge/data about a community's physical occupation of space articulates with justice and rights in a local context. We argue that the residents' lack of occupation rights in conjunction with their lack of reliable information greatly intensifies their sense of insecurity and powerlessness. As Johnson (2014) and others have noted, land records digitization, upon which officially recognized land rights are based, is accompanied by significant hazards for people without secure tenure.

The context for this analysis is the western Hyderabad landscape also known as Cyberabad, a fast-transforming economic frontier for digital technologies. Expected to reach 10 million residents in the next decade, Hyderabad is one of India's IT services boomtowns. The city's development into an IT services powerhouse has been led by state government initiatives since the 1990s when the Chief Minister Chandrababu Naidu promoted the iconic HITEC City ${ }^{17}$ enclave on the western periphery of the city to house IT and financial services majors. In the ensuing growth push, large tracts of land have been assigned to multinational and national IT-enabled services companies for campuses and Special Economic Zones. Existing farming and pastoral communities have found themselves pushed to the margins of these 'world-class landscapes' as older livelihoods and ways of living have been rendered unviable. At the same time, newer populations of migrants from neighbouring states have arrived to participate both in high skill professional jobs and in low skill services activities such as construction work, housekeeping, driving and domestic help to service the IT economy.

Against this backdrop, the questions raised by our case study about the relationship of new digital and data technologies to issues of distributive justice assume special piquancy. Our primary conceptual frame is one of 'information politics', i.e., the way information is used to wield power and to perpetuate information inequalities.

Our case study offers a grounded empirical examination of these questions through the lens of community mapping exercises in low-income communities located at the fringes of the information technology-led economy of western Hyderabad. Our major comparison is

\footnotetext{
${ }^{16}$ According to 2011 Census of India and National Sample Survey 69th Round, 2012, 65.49 million slum inhabitants live in 13.92 million households. The slum population is $5.4 \%$ of the country's total population and $17.4 \%$ of the total urban population (MHUPC 2015).

${ }^{17}$ Acronym for Hyderabad Information Technology and Engineering Consultancy City.
} 
between an enumeration exercise conducted by our research team and a community survey conducted by the local anganwadi or government-supported natal and childcare facility for the Integrated Child Development Services (ICDS). The first exercise, carried out by our team, consists of a household enumeration of the basti, including geospatial coordinates of individual dwellings. This exercise ran into concerted hostility from some basti leaders, making it difficult to complete the enumeration. Although incomplete, it nonetheless offered considerable insight into the informational landscape of the basti. This contrasts with the second, more formalized data generation exercise carried out by the ICDS, which was digitized for the first time this year via a smartphone app that included geotagging. Although the ICDS surveyors faced relatively little resistance in previous rounds, this year's exercise did elicit some resistance, indicating the larger sentiment of mistrust around digital technologies. Residents complained that both forms of data collection could expose them to eviction.

Among the key questions we seek to answer: What are the main structural and contingent factors that shape information politics in local communities? How are the broader information landscapes related to attitudes/perceptions about digitalization and about the risks and benefits of data collection exercises in particular? Our analysis has a two-fold scalar focus: first, the locality of Gachi Basti and the PHC as social units, with their internal divisions (based on political factions, class, gender, status as migrants or non-migrants). Second, we take into account the basti's relationship to the outside, whether as marginalized 'clients' in larger patronage networks, as low-income residents in an increasingly upscale area, or as citizens vis-à-vis state agencies.

Our findings suggest an arena of stark informational disparities between these vulnerable, indigent populations and the increasingly sophisticated digital data apparatuses used to encode them. Although the availability of digital audio-video technologies through cheap mobile networks among basti residents is rendering traditional hierarchies somewhat more volatile, it has not in any meaningful way disrupted the regulation of information flows by socially, economically and politically powerful actors. As we argue, the democratizing potential of emerging digital technologies is severely constrained by structural inequities across gender, caste, class, political and even linguistic lines. Therefore, data processes must take explicit cognizance of these disparities and fragmentation to ensure that data justice is realized. Our case study thus offers a cautionary note about 'naïve' data collection exercises that fail to recognize the internal structural differentiation of vulnerable communities. We argue for an explicit mapping of the information flows and associated information politics that characterize such settings.

In the next section, we outline the conceptual framework we employ to understand these findings. The following section gives an account of the methods employed during data collection and comments on the research design developed for this study. In the section on findings, we present the observations from the various methods of data collection, focusing on three key themes - the effects of information politics in datafication, receptivity to upstream datafication processes, and the use of technology in everyday lives. The fifth section ties together the evidence collected and concludes by highlighting the implications for future research on data justice themes in cities of the global South. 


\section{B. Background}

While the emerging literature on data justice has largely relied on theories developed or conceived in the global North (Taylor 2017, Heeks \& Renken 2018), a promising new strand of work evaluates how issues of data justice play out in the cities of the global South. Work in this vein has introduced a valuable element of empirical engagement with themes that animate wider urban governance modalities at the interface of the formal and the informal in these settings (Donovan 2012, Heeks \& Shekhar 2019). Our case study, although located in a larger literature on datafication in informal settlements in cities of the global South, nonetheless departs from it in several respects. Key to the contribution of our study is its setting on the peri-urban frontier of one of India's premier IT hubs. First, it allows us an opportunity to assess the existence of channels for the diffusion of digital technologies across physically adjacent spaces. Second, it represents an uncharted terrain as far as NGOs and CBOs are concerned. For the vast majority of existing studies (Lundine et al 2012, Shekhar 2012, Panek \& Sobotova 2015, Hagen 2017 and others cited in Heeks \& Shekhar 2019 as well as in Patel \& Baptist 2012), reliance on a variety of such intermediaries and/or leaders tends to obscure internal differentiation within the 'community'.

Our case study thus opens up the black box of the community to reveal the internal fissures and fragmentation that mark the information landscape in settings without active civil society intervention, the default in most peri-urban sites. Given the unique features of our case, our approach has been inductive. The aim has not been primarily to test hypotheses suggested by the data justice literature but to understand and derive a picture of information flows within and beyond the communities under study. As indicated, our variable of interest is not simply data, but the larger landscape of information.

Figure 1 maps out the internal divisions that mark our sites and the potential interfaces with the outside world. These interfaces also represent possible opportunities for information outflow.

\section{Figure 1: Internal Divisions and Potential Information Flows outside the Community}

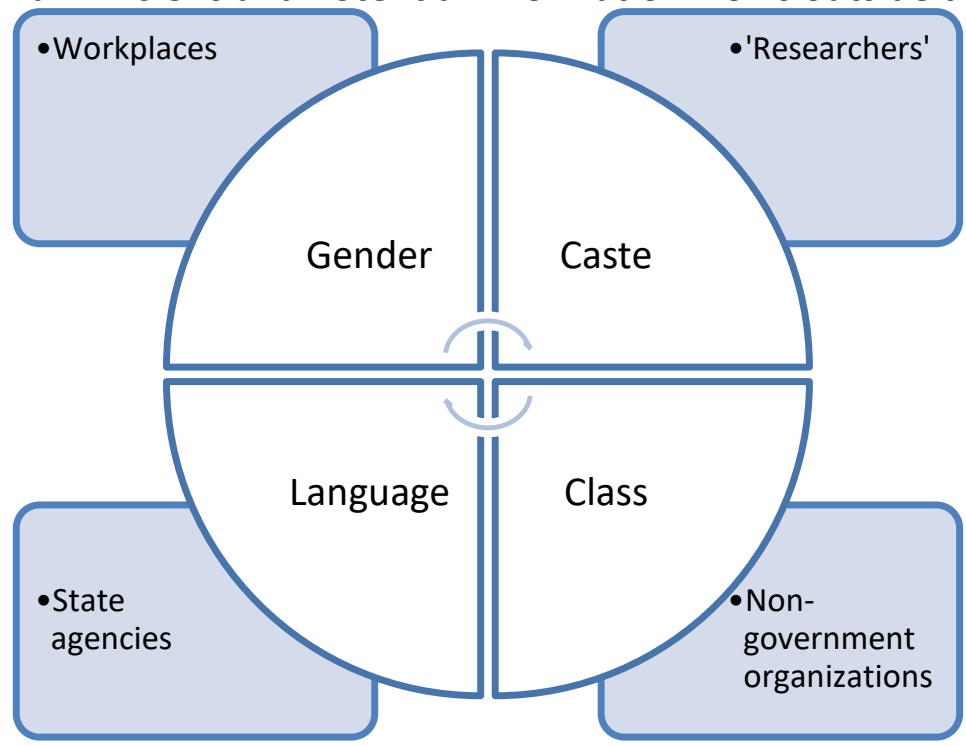


Our setting thus leads us to adopt a critical approach, recognizing that structural conditions, including institutions that embody those conditions, shape both the distribution of data resources and the patterns of benefits that derive from them (Johnson 2014, Heeks 2017, Heeks \& Renken 2018). This approach involves examining how social, political and institutional structures condition access to information as well as services and/or resources. Our focus on how conflicting interests underpin the generation and sharing of data/information and on how issues of access to data/information intersect with larger power relationships underlines the political economy of information in this setting.

Nonetheless, our analysis allows for individual agency within the broader structural approach. Our case will contribute to a reflection on how to expand on a structural framework to encompass the empirical realities of the field. We draw on Heeks and Renken (2018) to examine various dimensions of data justice. Our conceptual frame for understanding the role of structural factors is the idea of information politics.

Although instrumental concerns have been shown to shape data processes in this type of setting (Heeks \& Renken 2018), our analysis suggests the need to qualify this understanding in specific contexts. For example, from the perspective of the residents, "downstream"18 processes of execution would appear to matter significantly. As our interviewees repeatedly told us, they believe that previous attempts by government agencies to collect data led to disastrous consequences in terms of demolition and eviction. Thus, our findings would suggest that an instrumental perspective should apply both to risks and rewards that accrue from information sharing.

However, in fact, the ostensible salience of instrumental concerns is mediated by issues of distributive justice and undercut by the real structural imbalances in access to data and information across the state agencies and the residents. This is because the distribution of rewards from information exchange depends critically on the individual's location within the landscape of information politics. As many of our Dalit ${ }^{19}$ and female respondents reminded us, they were the ones to bear the brunt of the risks of sharing information with outsiders. In contrast, basti leaders were often able to capitalize their strategic position within community information flows to consolidate the rewards they accrued for transmitting information to elected representatives at various levels. Thus, structural data injustices both configured and were reconfigured by the broader information politics of this setting.

\footnotetext{
18 "Downstream" here refers to later activities in the "information value chain" (Heeks \& Shekhar 2019): the use of processed data in the form of information, for decisions and actions about or by basti residents. "Upstream" refers to earlier activities: the gathering, processing and visualization of data about low-income settlements.

${ }^{19}$ Dalit ('oppressed') is the term used to designate various groups who have suffered institutionalized discrimination because of their position at the bottom of the ritual hierarchy under Brahmanical Hinduism.
} 


\section{B1. Occupancy as a structural factor}

The vast majority of the basti inhabitants have no legal rights but only a tenuous form of occupancy rights over the place they live. ${ }^{20}$ Yet their continuous occupation over several decades has given them a sense of entitlement to this place; their settlement long preceded the arrival of Cyberabad and the high-rise gated communities.

In particular, the issue of illegality is central to an understanding of this case and its theoretical significance. The lack of a legally sanctioned presence in this place leaves its residents at the mercy of distant bureaucrats, elected officials and members of the community with ambitions. At the same time that residents are distrustful of becoming part of a database, they are desperate to establish their right to stay. To do so, they call upon a collective shared history, which is often implicit, community-based knowledge to corroborate their claims and position themselves in relation to more recent arrivals. Likewise, they make paper claims (formal, bureaucratic knowledge) such as electricity or water bills as proof of residency (see also Ranganathan 2013). Several respondents whose houses were demolished believe those latter forms of proof should have provided protection. Many told us, "we built our homes and nobody said anything". ${ }^{21}$ In other words, a lack of punitive action on the part of the state was interpreted as consent. Far from irrational, this is emblematic of the way the urban poor navigate in their 'negotiated', never fully secured, right to the city (Benjamin \& Raman 2001, Zérah et al 2011).

This case underscores the necessity to recognize how seemingly antagonistic regimes coexist simultaneously: for instance, one based on private property rights and one based on occupation rights. Occupation rights are de facto recognized in India in specific settings at specific points in time (Benjamin 2008), although they must be constantly renegotiated. A key question is whether data-intensive development practices can co-exist with the informal 'management' of populations by the state (Chatterjee 2004, Roy 2009), based on the implicit recognition of the rights of vulnerable communities to the commons (property or resources). Thus, our notion of information politics resonates with structural approaches to data justice.

\section{B2. A frontier setting?}

Our study can contribute to wider debates on data/information justice. In many respects, it is an extreme case, focused on people with multiple vulnerabilities: social (illiterate, low caste), legal (without legal tenure, squatters) and spatial (located at the urban frontier, in the interstices of rapidly transforming high-value land). Yet although extreme, it is not marginal in the sense that it is emblematic of many situations in India, involving millions of citizens. Two important features of our setting particularly deserve notice.

\footnotetext{
20 The Basti Development Committee president claimed that the basti land was allotted to them by a previous chief minister but he had no knowledge of any document officially recognizing the same. Interview, 25 February 2019.

${ }^{21}$ Recorded during the focus group discussion with evicted residents at the PHC on 24 February 2019.
} 
First, unlike several of the case studies discussed in Heeks and Shekhar (2019), Gachi Basti is a frontier setting which has seen little intervention by community-based organizations or civil society groups. As a result, residents have little experience with instrumentally 'fair' data processes mediated by such groups.

Second and equally important, the information landscape of the basti is highly fractured on lines of caste, ethnicity, language, gender. The basti leaders occupy important nodes of power, largely by proxy, by virtue of their links to politicians. These include, but are not limited to, the elected corporator of Greater Hyderabad municipality and the local Member of Legislative Assembly (MLA). As we document below, this differential access to information by different groups within the basti and the tight regulation of information to and from the basti by the leaders have serious consequences for shaping the information inhabitants have about their entitlements.

In other words, the achievement of procedural, instrumental or distributive data justice ${ }^{22}$ is fundamentally determined not only by the larger structures of power in terms of statecitizen relationships, which have received attention in the existing literature (Heeks \& Renken 2018), but also by the power asymmetries at the micro-level of the basti. The slum's dominant social structures affect data processes, as well as their outcomes. This is the essence of our focus on information politics. As we document in our findings below, the choices available to individuals and their capability to exercise control over their lives are enabled and constrained by broader social structures.

\section{C. Methods}

As indicated above, our field site comprises Gachi Basti, a locality classified as a slum as per municipal surveys in Greater Hyderabad, and its neighbouring PHC blocks. The background and rationale for our choice of the site come from the housing vulnerability that shapes the experience of communities such as these. In August 2018, authorities demolished 56 houses in Gachi Basti in an early morning raid, leaving the residents deeply shaken and rendering numerous families homeless. These families were allotted housing in the PHC at the other end of the basti. Shortly before that, in April 2018, some 200 families were also shifted to the PHC from another demolition site, nearly 10 kilometres away. Those families had lost their houses to a slum-wide demolition drive that occurred after a fire accident. Before developing our research methods in more detail, a brief description of the field site provides important context.

Gradually built-up through self-construction starting in the 1980s, the core community of Gachi Basti belongs to a so-called "backward" caste and members of this group worked until recently as stone crushers in the nearby quarries. They migrated over time from northern Telangana (the Indian state of which Hyderabad is the capital) and the border area with the

\footnotetext{
22 These are three dimensions of data justice (alongside rights-based and structural): procedural refers to "fairness in the way in which data is handled"; instrumental to "fairness in the results of data being used"; and distributive to "the (in)equality of data-related outcomes" (Heeks \& Shekhar 2019:995). For further details, readers are referred to Heeks and Shekhar (2019).
} 
neighbouring state of Karnataka. Telugu is the native language spoken by the majority of the population. Some of the families who once spoke Kannada (native to Karnataka), adopted Telugu as their first spoken language. The area started rapidly transforming from the late 2000s. The privately-operated quarries were shut down in 2009 and the land became increasingly occupied by the rapidly expanding IT cluster, which is characterized by largescale housing compounds and office complexes that accommodate globally-connected firms employing highly educated professionals. Some people from the local communities found jobs in the cluster in "housekeeping" (cleaning and maintenance), security services, etc., although many lack the minimum qualifications and skills required.

Since a large proportion of the residents of Gachi Basti belongs to a single caste, there is a sense of connection among people, even when they are not directly related. However, our investigation also indicates deep internal divisions, although the nature of the fracture lines - political, ideological, class or ethnicity - is not entirely clear. Basti leaders, all men, are aligned to more powerful politicians or movements and individuals appear to be loosely affiliated to one or the other faction, although there is fluidity and overlap. In addition to the more established third-generation residents, our incomplete enumeration exercise revealed a significant number of non-Telugu-speaking migrants, from outside Telangana, renting accommodation in the basti. They are engaged in largely unskilled service activities such as construction work, housekeeping, driving and domestic help.

The approach to empirical research adopted for this study was case study strategy, based on mixed qualitative and quantitative research methods. These included observation during frequent visits to the locality, interviews with key informants, and focus group discussions with residents. Within the community, our informants included basti leaders, a leader of a women's self-help group as well as government functionaries such as anganwadi workers, water board employees or education inspectors. Informants outside the community included elected officials and municipal officers. In addition to questions on information flows, we investigated the impacts of new technologies, smartphones and various datafication processes, with the aim to assess how increased access to digital data is shaping social dynamics in the slum, such as access to employment, information about government schemes and knowledge about rights (to public services and property). Although not initially a focus of our research design, the PHC on the edge of the basti took on significance in light of the fact that evicted residents of Gachi Basti were resettled there.

\section{C1. Enumeration exercise}

We initially planned an enumeration exercise in order to allow us to develop a stratified sample survey of residents who could be further interviewed individually. In our interviews with leaders of the basti and the focus group session with the residents at the PHC blocks, we discussed our upcoming fieldwork at the basti. The leaders and other residents were open to sharing information about Gachi Basti and offered to introduce us to other residents. ${ }^{23}$

\footnotetext{
${ }^{23}$ Interviews, 22 February 2019.
} 
After obtaining consent from residents, we used smartphones to collect data about their family size and house, geo-tagging each residence (Table 1). Despite giving consent, it soon became clear that many residents had doubts about the aims of our study.

Members of our team were asked about the intentions and end-use of our data collection. The digital mapping through GPS, in particular, was seen as risky. As we were employing, in parallel, a numbering system on printed Google Maps, residents expressed worry about the need for a geographical survey. As the news/misinformation spread in the basti about our enumeration exercise, households refused to share data unless the basti leaders intervened. Hostility to the enumeration process was ostensibly demonstrated most vocally and persistently from one basti leader, who instructed residents not to cooperate with us. This man insisted that we stop visiting the basti and threatened our collaborators with physical harm if we continued. ${ }^{24}$ Although several of the leaders were individually open to our presence and survey, their multiple political affiliations had fragmented into discrete spheres of influence, making it difficult to bring them to common ground.

As we sought to understand the apprehensions of the residents, we learned that a similar exercise had been linked in the residents' minds with the eviction drive conducted by the Mandal Revenue Office (MRO). ${ }^{25}$ As one resident put it,

Even before the eviction, people like you came in to the basti and took our information posing as government servants and bank officers. Then the result of it was the eviction as you see it. Now we feel afraid to share information with anyone. ${ }^{26}$

As this suggests, and as we elaborate below, what people believe happened in previous data collection processes, and its link to eviction, colours their views on subsequent exercises. The findings from the partially completed enumeration are presented in Table $1 .{ }^{27}$

Table 1: Enumeration Exercise Results

\begin{tabular}{|l|l|l|l|}
\hline $\begin{array}{l}\text { No. of households } \\
\text { (also no. of } \\
\text { responses) }\end{array}$ & $\begin{array}{l}\text { No. of families } \\
\text { renting out a } \\
\text { house/a room (out } \\
\text { of 125 responses) }\end{array}$ & $\begin{array}{l}\text { Reported no. of } \\
\text { residents in the } \\
\text { surveyed } \\
\text { households }\end{array}$ & $\begin{array}{l}\text { No. of households } \\
\text { with at least one } \\
\text { mobile phone }\end{array}$ \\
\hline 181 & 31 & 770 & 171 \\
\hline
\end{tabular}

Source: Author's calculation based on primary data.

Note: We recorded a unit of household based on the Census of India definition, i.e., a group of individuals living together and sharing a common kitchen. In the second column, we were able to collect only 125 responses; in the absence of legal rights over the land on which they have constructed their houses, many families were not willing to reveal to us whether they lease out a part of their house to others.

It is worth noting that the survey was conducted in almost half of Gachi Basti. Among the households surveyed, $74 \%$ (134 households) were one-room structures. We observed that as the survey approached the part of the basti where the eviction had taken place,

\footnotetext{
${ }^{24}$ Interaction, 4 March 2019.

${ }^{25}$ A local government office responsible for a variety of state functions within a local area.

${ }^{26}$ Interview with a daily wage worker staying at Gachi Basti on 23 February 2019.

${ }^{27}$ In our enumeration exercise, several respondents asked what tangible benefits they would receive if they answered our survey. See further discussion in the section on Findings.
} 
resistance from residents to our enumeration became more pronounced. People brought up the recent eviction drive as a lesson to avoid sharing information with 'outsiders'.

In addition, we also spoke to the families who were recently evicted from the basti and placed in the PHC in two focus group discussions. This access has given us important insights into the politics of information, and data justice more broadly. It is interesting to note that the respondents were more open to sharing opinions and information in open-ended interviews. One woman even commented,

... people like you [researchers] should come to the basti and observe our living conditions. But today we do not know who represents what or who to believe; we are scared because we have been betrayed. ${ }^{28}$

Our methodology and the main sources of our primary data are summarized in Table 2.

Table 2: Methods and Coverage

\begin{tabular}{|c|c|c|}
\hline Method & Site & Number / size \\
\hline Interviews & $\begin{array}{l}\text { Residents and } \\
\text { representatives in PHC } \\
\text { and Gachi Basti }\end{array}$ & 23 in-depth interviews \\
\hline Media reports & $\begin{array}{l}\text { Reports on eviction in } \\
\text { print and television news } \\
\text { (TV news uploaded to } \\
\text { YouTube) }\end{array}$ & $\begin{array}{l}5 \text { print news reports (in English) } \\
\text { and } 12 \text { TV news coverage } \\
\text { reports (on YouTube) }\end{array}$ \\
\hline Focus group discussions & Gachi Basti and PHC & $\begin{array}{l}\text { Two; one each with evicted } \\
\text { family members of Gachi Basti } \\
\text { (five participants) and the } \\
\text { evicted residents of the basti } \\
\text { where the fire occurred (six } \\
\text { participants) }\end{array}$ \\
\hline Household enumeration & Gachi Basti & 181 households \\
\hline Ethnography (observation) & $\begin{array}{l}\text { Basti community meeting } \\
\text { for caste association/ } \\
\text { HMWS\&SB office, } \\
\text { Anganwadi centre, basti } \\
\text { house construction site }\end{array}$ & 3 situations \\
\hline $\begin{array}{l}\text { Administrative data } \\
\text { collection }\end{array}$ & $\begin{array}{l}\text { Telangana Housing Board, } \\
\text { HMWS\&SB, MRO, ICDS } \\
\text { (Anganwadi), Municipal } \\
\text { Corporators office, } \\
\text { Mandal Education Office } \\
\text { and GHMC office }\end{array}$ & $\begin{array}{l}\text { Multiple visits to each: data } \\
\text { collection (public land records), } \\
\text { interviews with key informants }\end{array}$ \\
\hline
\end{tabular}

Source: Compiled by the authors.

Notes: HMWS\&SB is the Hyderabad Municipal Water Supply and Sewerage Board, ICDS stands for Integrated Child Development Services, GHMC stands for Greater Hyderabad Municipal Corporation.

${ }^{28}$ Focus group discussion with evicted residents at the PHC on 24 February 2019. 


\section{C2. Comparing with the ICDS survey}

The anganwadi survey conducted by the state government's ICDS was used as a comparative benchmark for our team's enumeration. In its prior iterations, the anganwadi survey was conducted on paper to calculate the population and family sizes in the basti. The survey recorded data based on the Aadhaar identity number of residents to provide prenatal and post-natal services to pregnant women and their children (see, for example, Table 3 ). The data was recorded on registers to keep track of the population in order to deliver adequate services.

Table 3: Consolidated Data from the 2018 Anganwadi Survey

\begin{tabular}{|l|l|l|l|l|l|l|l|}
\hline $\begin{array}{l}\text { Number } \\
\text { of Males } \\
\text { (Above }\end{array}$ & $\begin{array}{l}\text { Number } \\
\text { of } \\
\text { Females 6) }\end{array}$ & $\begin{array}{l}\text { Number of } \\
\text { (Above } \\
\text { Age 6) }\end{array}$ & $\begin{array}{l}\text { Number of } \\
\text { Women }\end{array}$ & $\begin{array}{l}\text { Mothers } \\
\text { with } \\
\text { (Age } \\
\text { Newborn } \\
\text { Children }\end{array}$ & $\begin{array}{l}\text { Girls } \\
\text { (Age } \\
0-6)\end{array}$ & $\begin{array}{l}\text { Total } \\
\text { Number } \\
\text { of } \\
\text { Families }\end{array}$ & $\begin{array}{l}\text { Total } \\
\text { Population }\end{array}$ \\
\hline 772 & 734 & 8 & 11 & 10 & 15 & 253 & 1541 \\
\hline
\end{tabular}

Source: Based on data collected by the State Government under the annual ICDS survey conducted in 2018. Note: Unlike the household definition used in our enumeration exercise (see Note, Table 1), the anganwadi data considers families related to each other, and living next to each other, as a single household. The anganwadi survey encountered technical problems in recording data in the PHC, hence the above data does not cover most residents in the PHC.

The anganwadi digitized the survey for 2019 using an app developed by the ICDS. The digitized survey records data about the family members along with the geographical coordinates (geotagging) of each household. We interviewed the anganwadi surveyors while the digitized survey was ongoing, to understand the reception of the basti residents to the new survey method. The surveyors reported that some residents who had recently moved into the basti expressed fear over the use of digital technology and hence, refused to share their data. These specific families were afraid that digitally recording their presence in the basti would make them more vulnerable to eviction. The surveyors were reminded of the eviction that took place last year and were told by those families that recording such data posed a threat to their homes. ${ }^{29}$

${ }^{29}$ Interview with the surveyor, 4 June 2019. 


\section{D. Findings}

Our case study analysis yielded three main findings corresponding to our research questions outlined at the outset. First, issues of data justice are embedded in informational politics i.e., the ways in which informational resources, as well as the risks and rewards associated with them, are distributed across individual actors and identity groups. This information landscape is shaped by structural factors. Secondly, instrumental concerns shape data processes in this setting to a degree, and in some contexts, downstream processes appear to matter. However, the internal disparities in the community mean that structural factors dominate more than instrumental concerns. Third, residents in the basti have differential access, capabilities and attitudes to digital technology. These findings are further developed below.

\section{D1. Datafication processes are influenced by wider structures of power, which mediate information politics}

We argue that issues of data justice are embedded in informational politics, i.e., the ways in which informational resources, as well as the risks and rewards associated with them, are distributed across individual actors and identity groups. Widespread illiteracy and innumeracy are underlying contextual factors that inhibit growing datafication from having a 'liberating' effect in the form of access to independent sources of information. The social hierarchy of the community is also a major impediment to the free flow of information, and the community's internal power structure, therefore, becomes crucial to the analysis.

As Figure 2 shows, basti leaders centralize information flows. This convergence is facilitated by the fact that the slum is fragmented in terms of caste, language, gender, ethnicity and political affiliations. This also leads to informational disparities among various groups with implications for their participation in political processes. In addition, the gatekeepers of the slum exercise tight control over the information value chain, by controlling both the inflow and outflow of information (see Figure 3 ). 
Figure 2: Information Flows within the Community

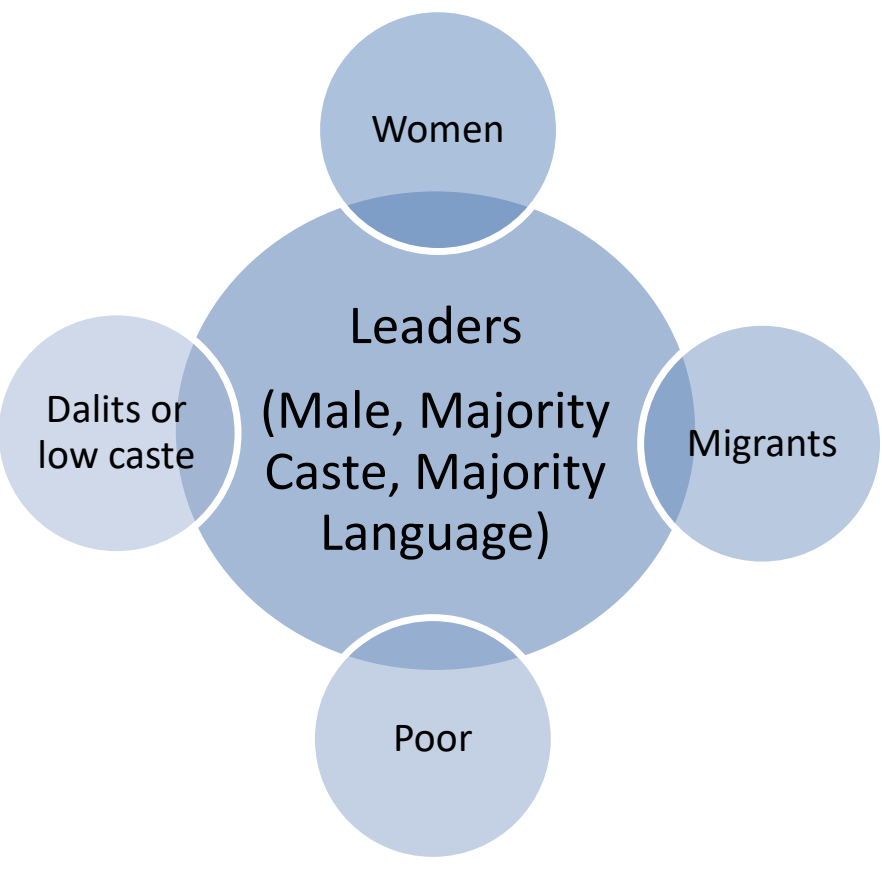

Figure 3: Upstream and Downstream Activities Work within the Information Politics of the Community

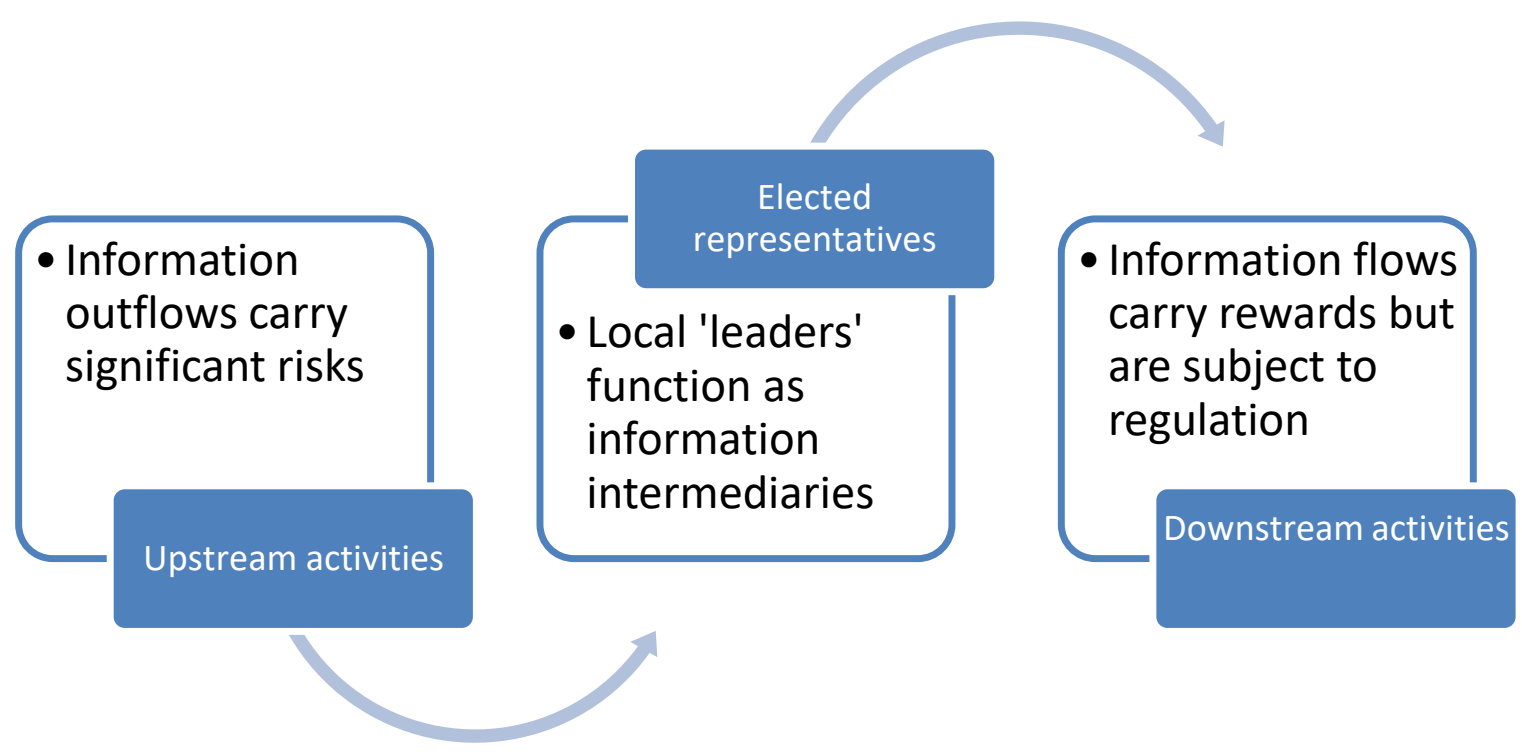


In terms of social structure, it is significant that neither of these settings (Gachi Basti or PHC) has active formal CBOs or non-partisan NGOs. While the resettled families in the PHC are supported by a church headed by a local pastor, the Hindu nationalist organization, the Rashtriya Swayamsevak Sangh (RSS), has an active presence in Gachi Basti. The overtly political agenda of the RSS, articulated through the electoral politics of the ascendant Bharatiya Janata Party (BJP), lends a strong 'political society' orientation to collective action in the community (Chatterjee 2004).

Party politics is a significant mode through which community grievances and demands find expression. The major political parties install local 'leaders' who play a key role in transmitting information from elected party officials higher up in the chain and in turn communicating community issues to elected representatives. For example, immediately following the demolition at the basti, local BJP cadres organized vehicles to bring people to the administrative office and led the protest. The protesters were taken into police custody and court cases were initiated against them. Several of the women who had been arrested admitted to being completely unaware of the grounds of their conviction or the litigation process.

In our focus group discussions, respondents reported that only leaders remained in contact with municipal officials and elected representatives. This forced community reliance on the leaders for all issues pertaining the basti, including housing and development work. One of the women who lost her house in the eviction drive and got arrested in a subsequent clash with the police remarked about the leaders:

[T] hey are all hungry for power. I went to their doors over ten times after my release to ask about our home, but none of them helped me. (...). These leaders even mediate our talks with the MLA and do not allow us to question him directly. Our family has been living here for three generations now, but we still do not have a place in our own basti. ${ }^{30}$

The evictees from the basti at the PHC said that when they tried to meet the elected representatives on their own, they were turned away and told to "behave themselves" and communicate through their leaders. ${ }^{31}$

The people in the PHC have little idea about what the government has planned for their future accommodation; they were promised individual apartments by their political representatives, but there has been little further news about that. Almost without exception, respondents lacked certainty about the title deeds or patta on the land they occupied. Some claimed they possessed patta, but that the municipality is holding their legal documents as a form of collateral. These claims could not be cross-checked.

If information is power, the political profoundly shapes information flows in these settings. Thus, the politics of information become salient and even central both to spatial resource and data justice agendas. However, collective action is made difficult by the sheer fragmentation of the terrain. Thus, although they live adjacent to each other and share

\footnotetext{
${ }^{30}$ Focus group discussion with evicted residents at the PHC on 24 February 2019.

${ }^{31}$ Focus group discussion with evicted residents at the PHC on 24 February 2019.
} 
common issues, the people belonging to the main caste group of Gachi Basti do not speak to the Dalit evictees from the fire who live in the PHC. Similarly, although they occupy the same physical space, language barriers divide the migrant renters from outside the state from local Telugu-speaking communities.

These constraints further reinforce the politics of information. Information transmission for vulnerable groups, in particular, women, the evicted, and Dalits, carries considerable risks. In both our field sites, our interactions with local community actors were often subject to approval and redirection by the 'leaders' and occasionally self-appointed gatekeepers who attempted to determine the topics of discussion.

To summarize, the internal structure of power in the slum is a crucial dimension of the analysis. We found that the slum was fragmented in terms of caste, language, gender, ethnicity and political affiliations. This leads to informational disparities among various groups along with implications for their participation in politicized informational processes (see Figure 4).

Figure 4: Information Intermediation in the Community

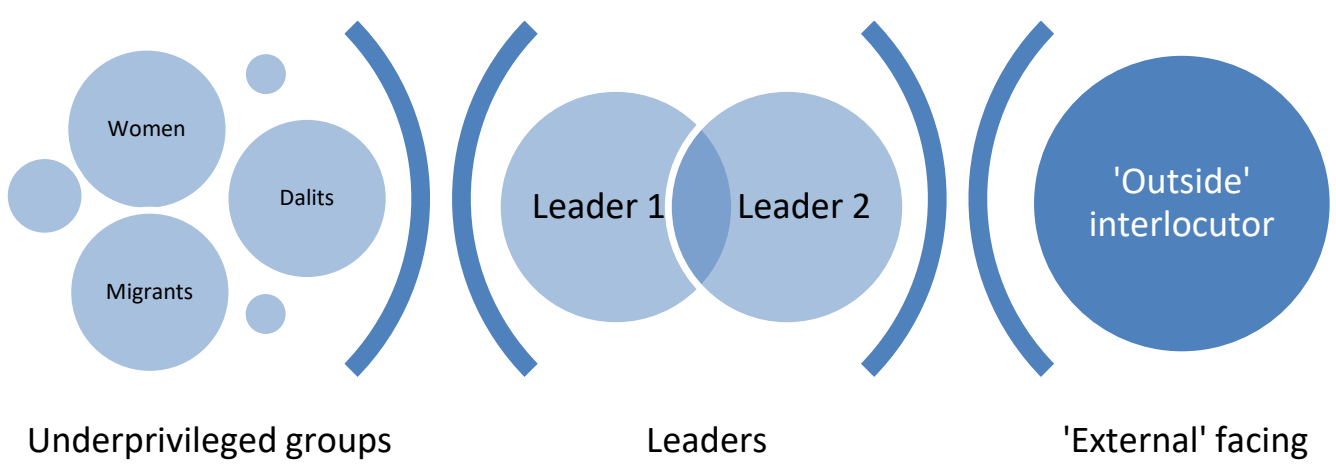

\section{D2. The assessment of downstream effects shapes receptivity to upstream activities, but only to a degree}

Our information politics framework pays careful attention to distributive issues of the risks and rewards of information flows. Instrumental concerns, i.e., the perspective of gaining benefits downstream, do appear to shape data processes in this setting. However, this needs to be qualified as expectations about outcomes can lead to cooperation or resistance depending on whether they are perceived positively (benefits) or negatively (risks). Previous experiences certainly condition whether residents will cooperate or resist attempts at data collection. If residents were reluctant or refused to participate in our enumeration exercise, it is probably because there were no tangible benefits they could anticipate.

Moreover, as we explained above, in the sheer informational miasma that characterized residents' understanding of the outcome of the data they had shared with government 
agencies, many were convinced it had led to their eviction. This explained heightened anxiety and resistance from them to further attempts at datafication, both our enumeration and the digitalized ICDS survey. However, not only is the receptivity to the ICDS survey hardening somewhat in the aftermath of the demolition, it is worth noting that there may be some grounds to the widespread perception that the pre-demolition survey was intended to support the eviction. There is considerable evidence available, both from our interviews with residents, as well as the spatial characteristics of the demolition site that the authorities had spatial information on the basti. ${ }^{32}$ We were not able to confirm this in our interviews with officials because of the politically sensitive nature of the eviction. Moreover, the responsible officers in the MRO that were directly involved with the demolition were transferred in the weeks following the incident and were hence not available. ${ }^{33}$ More importantly, the local Member of the Legislative Assembly, the most important elected representative at the state level explicitly linked the demolition to the spread of 'encroachment' on land designated for a housing scheme by the central government. ${ }^{34}$

In an interesting contrast, we observe there is greater openness to sharing information when residents perceive tangible benefits. The water board and the electricity board have information about the basti (names, house number, location, phone number), which the residents shared in order to receive services. ${ }^{35}$ The anganwadi survey generally met with little resistance due to the physical presence of the anganwadi centre in the basti for the past seven years, and the familiarity of the residents with the anganwadi facilitators (teacher, helper), unlike our own team of enumerators.

Corroborating findings from other studies (e.g. Heeks \& Shekhar 2019), we observed an ambivalence between the desire to remain invisible and the desire to be recognized as legitimate citizens, with occupancy rights. For instance, renting rooms to migrants is an important source of livelihood for the basti residents, which they want to hide from the authorities. Their current anxiety, exacerbated by the recent demolition and eviction, has made them wary and suspicious of data collection exercises.

\footnotetext{
32 Using Google Maps, we could see that the polygon of the evicted site measures exactly the area that officials had claimed was encroached or illegally occupied prior to the eviction.

33 Interview at the Mandal Revenue Office, 26 February 2019.

34 This statement was recorded in interviews in the press after the eviction. We are not referencing these reports so as to not divulge the name of our field site.

35 Information collected from the Water Board, Hyderabad, 31 March 2019.
} 


\section{D3. Digital audio-video technologies are increasingly available in the basti, but they have not disrupted the regulation of information flows by powerful actors}

Regarding the role of digital technology in the basti, our field investigations examined exposure to digitalization at various scales, starting with access to the internet. We collected data on the types of information people access through technology. We found that people in the basti have differential access, capabilities and attitudes to digital technology.

Out of the 181 households covered by our incomplete enumeration exercise, 171 or $94.5 \%$ owned at least one mobile phone. Of these 171, 67 households (37\%) owned one mobile phone each, while 72 households (40\%) owned two and $32(18 \%)$ of those surveyed possessed more than two mobile phones. ${ }^{36}$

The use of technology is deeply gendered. In most instances, the man of the household owned a mobile phone which was shared by his spouse. Several respondents (men and women) said that women are not educated enough to handle mobile phones, or that women do not need mobile phones because they would stay at home most of the time. ${ }^{37}$ The idea of women's safety was also invoked to discourage women from using digital technology. It was claimed that the use of smartphones by women and their presence on social media can attract unwarranted male attention in the form of stalking. ${ }^{38}$

Digital technology puts the inhabitants of the basti into big data systems like Aadhaar, Google Maps or open data sources like YouTube. YouTube videos played important roles in our interaction with the basti and PHC inhabitants. Videos of both the Gachi Basti eviction and the fire that brought evacuees from further afield to the PHC are available on YouTube. Several respondents showed us such videos of the demolition and the fire respectively to substantiate their claims. While talking to people outside the basti about their precarity, they use the videos as evidence to testify the claims they make.

We did not find evidence that digital technology is being used for accessing information pertaining to employment opportunities or government schemes. One exception was security personnel working for a global firm staying in the basti, who claimed to have a WhatsApp group with colleagues where they share work-related information. Migrant workers, residing in the basti, working in housekeeping or security services in the surrounding IT hub used mobile phones to keep in touch with their families, irrespective of

\footnotetext{
${ }^{36}$ We did not record data on smartphone (as opposed to basic mobile phone) possession because of concerns residents expressed before the beginning of the survey. As one respondent said, "I bought this [showing his smartphone] with my hard-earned money. You cannot question what I have." Recorded during our enumeration survey on 3 March 2019.

${ }^{37}$ Respondents expressed such opinions during interviews and focus group discussions at the PHC when questioned about their use of mobile phones.

${ }^{38}$ Interviews with the migrants residing in the basti and the focus group with the fire victim families in the PHC, 24 February 2019, 9 March 2019.
} 
gender. ${ }^{39}$ While smartphones seemed to be primarily used for entertainment purposes and local news, inhabitants of the PHC had a WhatsApp group.

Under such circumstances, does differential access to technology-enabled information create new divisions among the residents of the slum? Rather than subverting the existing power structures in the basti, e.g., by easing access to various types of information among the residents, digital technologies may, on the contrary, strengthen them. Basti leaders may use technology as a means of increasing their control over the inhabitants. An example is the RSS youth leader circulating images of our team through WhatsApp to the people in the slum so that they would not share any information with us. Similarly, we found that elected representatives and other politicians used digital means such as WhatsApp to exclusively communicate with the leaders, rather than the community at large. ${ }^{40}$

At the same time, being part of the Aadhaar digital database has become central to gain access to all kinds of government services like admission to a school, water supply, bank accounts, etc. It is symptomatic that some families in the PHC have pasted their Aadhaar cards on their doors. In response to our questions, we were told it is to establish proof of their identity so that no one can question their stay in the $\mathrm{PHC} .{ }^{41}$ It is noteworthy that people working as domestic servants at the gated communities in the neighbourhood have to present their Aadhaar card each time they enter their workplace.

In summary, while making these communities more visible to state apparatuses, there is little evidence that digital technologies have empowered them in meaningful ways or subverted the internal power structures in the community.

\footnotetext{
${ }^{39}$ While most of the interviewed migrant women did not have smartphones, they did possess basic mobile phones that they would use to communicate with their distant families. Interviews conducted with migrants working in housekeeping, Gachi Basti, 10 March 2019.

${ }^{40}$ Interview with local corporator and staff, Khajaguda, 26 February 2019.

${ }^{41}$ Field visit, 24 February 2019.
} 


\section{E. Discussion and Conclusions}

Following from, but also nuancing Heeks and Renken (2018), our findings highlight the centrality of structural issues in shaping the relevance of other approaches to data justice. As Figure 5 shows, this is a key component of the information politics framework that we propose. The internal power dynamics as well as the relationship of the basti with the larger institutions of power - i.e., information politics - determine the data-information-decisionaction processes (who knows what and to what ends). It conditions the procedural, distributive, institutional and rights-based dimensions leading to information justice.

Figure 5: Information Politics - Instrumental, Distributive and Procedural Approaches to Data Justice are Mediated by Structural Dimensions

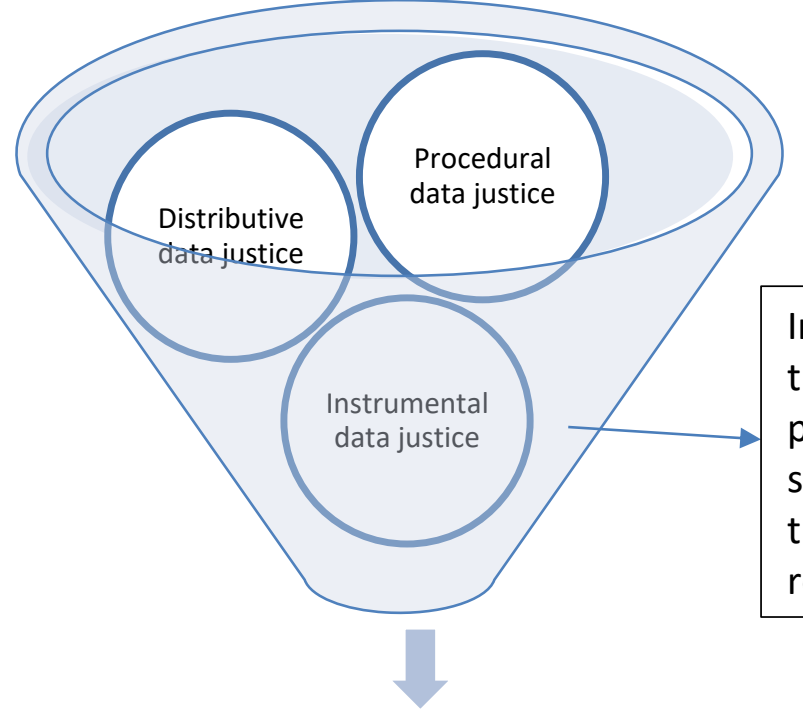

Internal power structure of the slum along with larger power structures of society manifested through state-citizen relations

\section{Information justice $\Longrightarrow$ Resource justice}

In terms of information justice, we share the concern that datafication processes and open data policies that render such communities more visible can exacerbate injustice, with potentially high costs for vulnerable groups (Raman \& Denis 2013, Johnson 2014). Once basti residents are counted and form part of a system of information, they may become more vulnerable. With eviction a very real threat, remaining invisible is often perceived as the best form of protection. As Heeks and Renken (2018) remind us, there is also a "right to be forgotten". In this context, we advocate a pragmatic as opposed to a normative stance with regard to promoting data collection activities, one that takes account of specific settings (cf. Recommendations below).

This takes on particular importance in light of the fact that the quest for invisibility is undermined by the structural nature of information and/or data justice. As Taylor argues, "the greatest burden of dataveillance (surveillance using digital methods) has always been borne by the poor" (2017: 2). We have noted the presence of surveillance cameras in the basti, near the PHC. This engenders the "ambivalence of legibility", noted by Heeks and 
Shekhar (2019:1006) -- marginalized populations want to stay hidden to avoid eviction and yet simultaneously want to be visible in order to access security, resources and services.

Despite the absence of formal property rights, we have observed a thriving informal rent economy. Residents lease out a room or two in their house to others, often migrants from other states. This rental income is a critical source of livelihood for these families, many of whom earn subsistence-level wages. There was a strong reluctance to reveal this rental economy to the gaze not only of the state but also to the putatively neutral gaze of the researcher. In fact, the most vociferous opponent of our enumeration admitted his suspicion that we would report his numerous rental premises. This somewhat more strategic, rather than survival, motive for the ambivalence of legibility may serve to nuance Heeks and Shekhar's (2019) analysis.

By drawing attention to the structural dimensions of data justice, our study contributes to a critique of mainstream views of data justice. Going beyond "justice as a set of theoretical principles" to "justice-in-practice" (Heeks \& Renken 2018:96), our case study speaks directly to the issues raised by these authors:

Why is access to data maldistributed in the global South? Why is participation in data processes unequally distributed? Why do the benefits of data systems in developing countries include some and exclude others?

We argue that broader forms of resource and distributive injustice also limit the scope for the creation of new datasets about slum communities, with potential implications for improving assets, as Heeks and Shekhar (2019) suggest. In our comparative assessment of data collection, we find that the promise of downstream impacts shapes receptivity to upstream activities to a degree but that instrumental or procedural justice approaches only go so far in allaying legitimate concerns and pervasive distrust of data collection in the presence of significant structural injustices. This is because information processes for such vulnerable populations carry material risks and are subject to significant regulation by sometimes self-styled leaders.

Our findings have ethical and methodological implications both for state and non-state data collection processes, including for researchers in such settings. Dealing with non-literate communities in a setting where structural factors shape or hinder the realization of data justice requires special precautions. It cannot be assumed that such communities will have the capabilities needed to assess the fallout of data processes. Deep mistrust, especially where previous state-condoned violence has taken place, is to be expected. Engaging community organizations or resource providers, where they exist, rather than relying on traditional leaders, may help bypass the more intractable aspects of information politics.

Our findings suggest some concrete repercussions for community mapping and data collection exercises, outlined below. 


\section{E1. Recommendations}

- Before undertaking upstream data collection activities, data collectors must map out risks and rewards for different interest groups, remaining cognizant of the ways the information landscape is splintered by caste, class, language and gender lines. In other words, understanding the interplay of information politics within the community is a key first step, especially in the absence of civil society gatekeepers/facilitators or CBOs.

- Qualitative approaches that allow for open-ended 'listening' are received better by vulnerable groups compared to quantitative surveys or more structured approaches that can often be perceived as 'extractive'. In our experience, spatialized data collection and spatial mapping, in particular, can be perceived as threatening and may lead to resistance from residents.

- State-led data collection with clearly identified downstream impact linkages such as surveys conducted by the ICDS may represent an exception to this resistance. It is still early to judge because most of these surveys were conducted before the eviction in August 2018. State-led surveyors (like those of the Indian Census) have a more direct approach and they inform the residents of the benefits of the survey upfront.

- More broadly, while demonstrating clear downstream linkages may be key to realizing the promise of the digital technology revolution for vulnerable urban populations in the global South, we argue that instrumental or procedural concerns only partially address the deeper structural factors that mediate the politics of information in these settings. Recent resistance to the digitized version of the ICDS survey highlights the ways in which mistrust is engendered by the way digital technologies are deployed in these settings. Digital data processes operate most often to make vulnerable populations visible, leaving them little scope to stake out claims to land or livelihood.

\section{E2. Future directions}

The role of socially prominent gatekeepers in the context of intra-community differentiation has received considerable interest in the methodological literature on ethnography (for example, Srinivas 1980). Employing the lens of information politics, our conceptual framework offers an approach to broaden these concerns to understand how hierarchy and disparity within the black box of the community may play out in the context of the datafication of vulnerable communities. In this paper, we have focused our attention on the ramifications of such information politics on community mapping and data collection exercises. However, our larger contention remains that information is a resource, access to which is regulated through structures of power within and outside vulnerable communities.

In future work, we aim to explore the ways in which power mediates the relationship of information access to resource access by looking at public services beyond occupational rights. In particular, access to water remains a deeply contested and potentially illuminating arena for the interplay of information/data processes with the right to the city (for the Indian context see Zérah et al 2011). Can communities expand information and resource access by adapting to the digitization agenda of the state?

In addition, while a large body of work has established the rise of spatial and institutional fragmentation in peri-urban settings, this case study suggests intriguing clues about 
emerging forms of informational fragmentation that follow and deepen socio-economic fissures in these spaces. Indeed, the salience of caste, language and gender disparities may also provide a link between informational and institutional fragmentation that underlie emerging forms of segregation in Indian cities. For example, the rise of gated communities consolidates both physical and informational barriers across caste-class divides. However, our study points to hitherto little understood forms of informational division - for example between local communities and low-skilled migrants along lines of language. Tracing the contours of these merging informational landscapes remains an important agenda for future work. 


\section{References}

Benjamin, S. (2008). Occupancy urbanism: radicalizing politics and economy beyond policy and programs. International Journal of Urban and Regional Research, 32(3), 719-729.

Benjamin, S.A. and Bhuvaneswari, R. (2001). Democracy, Inclusive Governance and Poverty in Bangalore. Birmingham, AL: University of Birmingham.

Chatterjee, P. (2004). The Politics of the Governed: Reflections on Popular Politics in Most of the World. New York, NY: Columbia University Press.

Donovan, K. (2012). Seeing like a slum: Towards open, deliberative development. Georgetown Journal of International Affairs, 13(1), 97-104.

Drèze, J., Khalid, N., Khera, R. and Somanchi, A. (2017). Aadhaar and food security in Jharkhand. Economic and Political Weekly, 52(50), 51.

Hagen, E. (2017). Open Mapping from the Ground Up: Learning from Map Kibera, Making All Voices Count Research Report. Brighton, UK: Institute of Development Studies.

Harvey, D. (2003). The right to the city. International Journal of Urban and Regional Research, 27(4), 939-941.

Heeks, R. (2017). A Structural Model and Manifesto for Data Justice for International Development, GDI Development Informatics Working Paper No.69. Manchester, UK: Centre for Development Informatics, University of Manchester.

Heeks, R. and Renken, J. (2018). Data justice for development: What would it mean? Information Development, 34(1), 90-102.

Heeks, R. and Shekhar, S. (2019). Datafication, development and marginalised urban communities: An applied data justice framework. Information, Communication and Society, 22(7), 992-1011.

Johnson, J.A. (2014). From open data to information justice. Ethics and Information Technology, 16(4), 263-274.

Krishna, S. (2019). Aadhaar-led Identification and Datafication among Informal Workers in South India: A Data Justice Perspective, Development Informatics Working Paper No. 79. Manchester, UK: Centre for Development Informatics, University of Manchester.

Lefebvre, H., 1996. Writings on Cities. Oxford, UK: Oxford University Press.

Lundine, J., Kovacic, P. and Poggiali, L. (2012). Youth and digital mapping in urban informal settlements: Lessons learned from participatory mapping processes in Mathare in Nairobi, Kenya. Children, Youth and Environments, 22(2), 214-233.

MHUPC (2015): Slums in India: A Statistical Compendium. New Delhi: Ministry of Housing and Urban Poverty Alleviation.

Panek, J. and Sobotova, L. (2015). Community mapping in urban informal settlements. Electronic Journal of Information Systems in Developing Countries, 68(1), 1-13.

Ranganathan, M. (2014). Paying for pipes, claiming citizenship: Political agency and water reforms at the urban periphery. International Journal of Urban and Regional Research, 38(2), 590-608.

Rathi, A. and Tandon, A. (2019) Capturing Gender and Class Inequities: The CCTVisation of Delhi, Development Informatics Working Paper No. 81. Manchester, UK: Centre for Development Informatics, University of Manchester.

Shekhar, S. (2012). The unequal access to municipal services and the role of local elected representatives, paper presented at N-AERIS XIII, Paris, 22-24 Nov.

Srinivas, M.N. (1980). The Remembered Village. Berkeley, CA: University of California Press. 
Taylor, L. (2017). What is data justice? The case for connecting digital rights and freedoms on the global level. Big Data and Society, 4(2), 1-14.

Zérah, M.-H., Dupont, V. and Tawa Lama-Rewal, S. (eds.). (2011). Urban Policies and the Right to the City in India. Rights, Responsibilities and Citizenship. New Delhi: UNESCO \& Centre de Sciences Humaines.

\title{
Acknowledgements
}

The "Urban Data, Inequality and Justice in the global South" case studies form part of a Senior Research Fellowship funded by the University of Manchester's Sustainable Consumption Institute with additional financial support from Canada's International Development Research Centre. The authors acknowledge their gratitude to Rajkumar Passedula and Ravi Teja Sangeetha, who assisted with the enumeration and interviews. Their deep knowledge of the field and sharp insights contributed in multiple ways to our understanding of this case. They also thank Richard Heeks for his detailed and constructive comments on previous versions of this document.

\begin{abstract}
About the Authors
Loraine Kennedy is CNRS Research Director at the Centre for South Asian Studies (CEIAS), EHESS, in Paris. Her current work, at the crossroads of political economy and political geography, examines sub-national state rescaling and metropolitan governance in India and in international comparison. Ashima Sood is Fellow at the Centre for Learning and Management Practice at the Indian School of Business, in Hyderabad. Her research lies at the intersection of institutional economics and urban and development studies. It combines qualitative and quantitative methodologies to examine the policy frameworks encouraging greenfield urban development and privatized forms of urban governance in India. Debdatta Chakraborty is a Research Editor for ISBInsight magazine at the Indian School of Business, in Hyderabad. She has completed her post-graduation in Sociology. Her research interests lie in informal labour in urban spaces. Ram Mohan Chitta is a Research Editor at the Centre for Learning and Management Practice at the Indian School of Business, in Hyderabad. His key interests are in urban sociology, digital media and critical theory.
\end{abstract}




\title{
Case 6: Aadhaar-Led Identification and Datafication Among Informal Workers in South India A Data-Justice Perspective
}

\author{
Shyam Krishna \\ Royal Holloway, University of London
}

\begin{abstract}
Aadhaar - India's national biometric digital identity programme through its unique 12-digit number for every Indian resident - has been intricately linked to daily aspects of living in recent years. The programme aims to enable digital linkage to governmental and nongovernmental services and through that achieve digital financial inclusion of groups like unbanked informal workers into the mainstream economy. This paper focuses on the Aadhaar experiences of two groups of informal workers in an Indian urban setting - cabdrivers and domestic workers. These informal workers access digital platforms like online recruitment portals and gig-economy apps which are aimed at employment of urban 'blue collar' workers, using Aadhaar as an identity for verification through its complex technological ecosystem.
\end{abstract}

Based on this evidence base, the paper provides two contributions. First, it presents a novel theoretical lens of social justice by operationalising 'abnormal justice' in a way that is synergistic with elements of surveillance and datafication inherent to digital identification. This results in a framework of data justice, enabling analysis along cultural, economic and political dimensions. Second, using this framework the paper deconstructs empirical evidence collected using semi-structured interviews and field observations. Ultimately it argues that while Aadhaar identity and the data-flow it enables has become critical in enabling digital participation of informal workers, digital identity is intimately related to inequality experienced by urban marginalised groups in three ways: current use of digital identities reifies extant cultural inequalities experienced by marginalised workers; unprotected datafication creates new economic inequalities that exploit new-found digital participation enabled by digital identities; and unfair barriers continue to exist for the marginalised under digital identity to voice 'informed consent' or to access redressal of security issues. 


\section{A. Introduction}

Strong identification systems, reliable databases, and the surveillant visibility of the citizen to the state have been presented as a prerequisite to build 'a social contract between governments and citizens' (Breckenridge 2014, Diop 2017). An acknowledged issue of the socio-economically disadvantaged population is that they fall into under what Gilman \& Green (2018) have called the 'surveillance gap' - the 'systemic invisibility' of certain classes within society. Based on this, particularly in the global South, identification programmes are seen as a necessity to enable hitherto disadvantaged groups to participate in socioeconomic transactions (Koops et al. 2009, Bennett \& Lyon 2013, Lyon 2013). Countries including India, Brazil, Ghana, Malaysia, Indonesia and China are in the active phase of implementing a digital identity infrastructure (Nanavati et al. 2002, Madanapalle 2017, Swearingen 2018).

Born out of a similar justification, Aadhaar - India's national biometric and digital identity programme - works using iris scans and fingerprints. These biometrics are used as the means of bodily verification of the individual specifically to prevent duplication of the individual's records across the national database of residents. This results in a random 12digit digital unique identity number for the individual. Personal information like demographic data, address, mobile phone numbers and email addresses of citizens are linked to this Aadhaar number. This information is also printed on paper documents for offline use, alongside the other option of using downloaded XML data-files and QR codes which encode personal information - shared using purpose-built mobile app or through USB thumb drives.

This positions Aadhaar such that while biometric data itself is not shared beyond Aadhaar's database, verification using Aadhaar enables sharing of personal information necessary to prove one's identity. Alongside this, advanced technical capabilities of Aadhaar's architecture espouse the 'big data' paradigms of 'openness' to interoperability and 'scalability' to achieve high volumes of data (Varma 2014), and using 'application programming interfaces' (APIs) that enable digital verification. Consequently, Aadhaar functions at the core of a complex ecosystem where the digital identity verification is used by both governmental and commercial systems. Ultimately, the personal information shared via the paper document or XML data-file can be confirmed as being genuine using the Unique Identity Authority of India (UIDAI) website directly or by software integration of governmental and commercial systems that consume the UIDAI API (Viswanathan 2019).

Given such capabilities, Aadhaar and its linkages create a need to understand the impact of 'datafication' and its relation to digital identity. Datafication, defined as the transformation of social actions or outcomes into data through online quantification (Mayer-Schoenberger \& Cukier 2013, Van Dijck 2014), carries the impact of identification forward in relation to the data-driven context of use of Aadhaar as digital identity. This means that despite the state not collecting vast quantities of data directly with a motive of surveillance, a move towards datafication creates data-flows that cause social impacts beyond the original intention for which data was collected (Nayar 2012). It is acknowledged that marginalised groups within India especially face a situation where their newly found digital participation makes them vulnerable to risks due to unethical practices of data use (The Wire 2017). Even when the 
state seeks to address such concerns, its benefits do not always apply to the disadvantaged population due to factors like data-literacy, absence of awareness, or lack of access to redressal (Abraham et al. 2017, ET 2018a). This presents a knowledge gap of understanding issues like ethics, fairness and inequality - encapsulated as the meta-issue of justice, in relation to the use of complex surveillance ecosystem of digital identity on those who are already marginalised and are seeking a means to participate in the wider society.

The focus of this paper is in understanding the impact of datafication through the study of two aspects. First, this paper places the use of digital identity within its complex ecosystem of use and its consequent impact. Secondly, this paper contextualises the use of digital identity and its surveillance capability among the experiences of the marginalised population. To achieve this the paper studies the daily-life experiences of informal workers in south India using the lens of social justice to understand how they navigate the effects of surveillant visibility and datafication. The research question that this paper ultimately answers can be presented as: What is the social justice impact of a digital identity and the datafication enabled by it?

The paper is structured to first discuss the relevant literature from which a conceptual framework of data justice is identified. Following a brief description of the case study background and the research methods, the empirical findings from the analysis of the case are presented. Finally, the wider implications of the paper and its findings are discussed before concluding with its specific recommendations.

\section{B. Literature}

This section will briefly introduce recent scholarship on datafication, and its relation to surveillance and social justice. Building further on this a conceptual framework is developed that is to be used for the analysis of the case study under focus.

\section{B1. Identification and Datafication}

'National identity' systems developed under electronic governance utilise digital technologies to deliver an open and multi-purpose identification infrastructure and enabling linkages to other systems, adding complexity to their social impacts (Whitley \& Hosein 2010). With the lack of data-protection frameworks in the global South (Arora 2016), there is a strong potential for data-led discrimination and breach of ethics in use of data where linkages of open surveillant-capable identification systems enable data-flow between the state and private entities. This has been acknowledged as an area of concern in recent scholarship calling for critical understanding of datafication and its context (Boyd \& Crawford 2012, Gangadharan 2012, Lyon 2014, Van Dijck 2014, Zuboff 2015, Dalton et al. 2016, Broeders et al. 2017, Roth \& Luczak-Roesch 2018). Research by Taylor \& Broeders (2015) has specifically called for a new ethical approach in understanding surveillant visibility and datafication specifically anchored in the global South. 
The growing corpus of work on 'data justice' - including by Johnson (2014), Dencik et al. (2016) and Heeks \& Renken (2018) - brings together the varying strands of theorisation related to datafication and surveillance, using a critical and an ethical lens. Mainly - as both Johnson (2014) and Dencik et al. (2016) present outright (Heeks \& Renken 2018 allude to it) - surveillance is centrally placed in theorising the 'justice' paradigm. Most relevantly Taylor (2017) has extended this to include theorisation of 'visibilities' in relation to data justice. This can also be read in the empirical works of Gangadharan (2012), who suggests the need to invoke 'social justice' as a means to understand inclusive participation predicated on digital technology and the 'complexity of what participation and incorporation into online worlds entail'. Echoing this, the section that follows conceptualises identification and datafication within surveillance theorisation.

\section{B2. Surveillance and Recognition}

Surveillance has been conceptualised by David Lyon (2010) as being 'liquid' - terming it 'liquid surveillance' - which in turn is rooted in readings of Zygmunt Bauman's (2000, 2013, and also Bauman \& Lyon, 2013) notion of 'liquid modernity'. Liquid surveillance presents an argument which helps conceptualise 'identification' within contemporary society as a means of individualisation and of seeking legitimate identity through digital technologies. These core ideas are to be engaged within the experiences of the surveilled individuals. Presenting surveillance as a concept of visibilities as Lyon (2010) summarises:

Liquid surveillance describes well today's regimes of in / visibility and is characterized by data-flows, mutating surveillance agencies and the targeting and sorting of everyone. (Lyon 2010: 325)

Surveillance is thus intricately connected to datafication enabled through technological artefacts like mobile phones, codes and passwords, digital identities and online profiles, working together to enable participation within the network (Bauman \& Lyon 2013).

Under such a theorisation the social function of surveillance can be probed further as 'recognition' (Taylor 1997, Brighenti 2010, Lyon 2016). Recognition here is the means of establishing one's identity and categorisation as a demonstration of one's position within society. This notion of recognition has been co-opted by Bauman \& Lyon (2013) (also see Bauman 2001, Lyon 2016) as the starting point of liquid surveillance. Legitimate identification sought by disadvantaged groups to be seen, to belong and to be counted by the state through programmes of welfare, of financial inclusion, and even of citizenship is subsumed in such a theorisation. Brighenti (2010) presents this as the need for 'individual recognition' sought by the previously disadvantaged and undocumented individual to be 'seen' by the state using regimes of identification including the use of identity cards, technological artefacts (like smart cards), and digital artefacts (like biometrics or identity numbers). This relation between identity and recognition thus presented as a socio-political notion is intertwined with issues of inclusion and marginalisation (Taylor 1997, Lister 2004) and also of visibilities and surveillance (Brighenti 2010, Boellstorff 2013, Lyon 2016).

Further, the most relevant theorisation that uses 'recognition' as a core notion in relation to social justice is of 'abnormal justice' by Fraser $(1998,2000,2009)$. The next section presents this as a framework within which the need for legal identity is conceptualised as 'recognition' and is a key dimension of justice alongside other contextual social factors. 


\section{B3. Abnormal Justice}

Bauman (2001) invoking Fraser (1998) argues that 'recognition' must be understood with its allied economic or distributive justice factors. Fraser $(2000,2009)$ presents the same argument to understand complex ideas of justice with underlying dimensions as 'abnormal justice'. Here justice is achieved by equitable participation in society or 'parity of participation' - which depends on achieving parity in specific intertwined dimensions of distributive justice and recognition, echoing Bauman (2001).

Since economic subordination in a society in many cases can cause cultural subordination and vice versa, Fraser (2000) deems that considering the social role of identity as the result of a freestanding 'cultural' component in society would miss the economic component of seeking fair 'redistribution' of resources - or 'distributive' justice. To further contextualise claims to justice, Fraser extended redistribution and recognition as dual dimensions of justice by adding a third dimension of 'representation' and positing further that we live in an era of 'abnormal justice' as opposed to normal justice. Here normal justice presupposes 'parity of participation' according to normative 'social arrangements that permit all to participate as peers in social life' (Fraser 2008: 405). The parity establishes clear common understanding of the critical nodes of justice: the 'what', the 'who', and the 'how' justice can be achieved in a society. While studying participation of an already disadvantaged population within a society, this parity is not present and is sought. Under abnormal justice the 'what' of the justice is then profoundly changed. It is not just the fair distribution of resources or recognition in society. Here the 'what' is a wider conceptualisation of that which needs to overcome three societal injustices (Fraser 2009):

- Misrecognition - injustice in the cultural domain of existence where respect or esteem is unequal due to embedded cultural hierarchies. Disparity here results in unequal social standing where some individuals or groups face barriers due to cultural markers such as gender or caste.

- Maldistribution - injustice in the economic domain where the distribution of resources is unequal. Disparity in aspects like lower income, wealth, or other intrinsically-economic value markers define an economic structure of inequality between actors in society.

- Misrepresentation - injustice in the political domain where rules of participation in politico-spatial society are unequal. Disparity here creates a political voice-lessness and unequal democratic and procedural access to participation.

Overcoming the 'subordination' across cultural recognition, economic redistribution and political representation dimensions, the core objective of justice, which is 'parity', would be achieved as per Fraser $(2000,2009)$. These three dimensions as discussed below are presented as central to probing the impacts of digital identity and their social justice impacts.

The first two dimensions of recognition and redistribution were proposed initially by Fraser (2000). Recognition specifically zeroes in on the impetus to seek digitally enabled participation within society through surveillance artefacts (Bauman 2001, Lyon 2016), and can be read in a way that is coherent with Fraser's (2000) argument. Here the provision of an individual identity helps overcome extant cultural subordination and attain social 
'recognition' (Brighenti 2010, Lyon 2016a). This understanding of identity and its role in recognition is synergistic with the role of surveillance as understood by Bauman \& Lyon (2013) and Brighenti (2010) (also see Lyon 2016). But, as noted above from Fraser's (2000) work, economic subordination in a society can cause cultural subordination and vice versa. This is presented as the inevitable entwinement of the cultural and economic mode of participation, that is of recognition and redistribution - the first two dimensions of parity in 'abnormal justice' theorisation.

This entwinement of recognition and redistribution has been acknowledged by other authors. For instance, in relation to surveillance, Cinnamon (2017) argues that economic value varies due to the differing status hierarchy or 'data-class' (Manovich 2012, Andrejevic 2014) one occupies in a data-driven society. The lower class that produces data relinquishes control of personal data and faces status inequality where direct economic value is derived from their data by higher classes in the status hierarchy - those who can collect and analyse, making data extractable for its economic value. Taking a cue from this, the dimensions of recognition and redistribution can be employed to understand status subordination leading to and resulting from use of digital identity, and possible inequalities in cultural and economic domain formed due to impacts of identification and consequent datafication.

The third dimension seeks out fair political representation and equal voice in processes that define rules and make decisions within society. Injustice is the lack of political 'voice' in being able to participate in determination of the rules of the society that individuals ultimately live under. Fairness in procedural aspects, especially in relation to data, falls under this dimension, particularly relating to those which determine control of an individual's data. For instance, the tenet of 'information disclosure' has been considered the means to provide 'voice' to users to be heard by decision makers (Bier 1993). In the more recent datafied condition a 'fair' means of giving voice and control of one's data has been presented in relation to procedures of 'informed consent' and options for 'opt-in' or 'optout' (Ashworth \& Free 2006, Fuchs 2011).

These three dimensions of participatory parity operate within the same politico-spatial 'frame', which is to say a typification of a societal setting not necessarily limited by geographical boundaries. The frame then defines the rules and in turn the boundary conditions of being accepted for participation, including in relation to a non-state or international entity. Any injustice in defining the boundary can exclude individuals from participation itself. In case of non-state participation like online services this can be understood as being defined by the 'terms and conditions' agreed. As the terms are dictated outside a 'normal' framework of justice there is potential for the frame to be set on 'exploitative terms of interaction [which] then exempt [service providers] from democratic control' (Fraser 2010). This complex political nature of justice particularly lends itself to study of surveillance and datafication run through private, non-state actors and also can help query the heavy involvement of private platforms and firms in technological infrastructures (Cinnamon 2017).

In summary, the conceptual framework (Figure 1) is used for analysis of the case study. The three aspects of 'abnormal justice' will in this view be used to query injustice in relation to digital identity. The dimensions will query: 'misrecognition' in the use of identity in seeking 
to overcome cultural aspects of subordination, 'maldistribution' due to resulting datafication and its relation to enabling to unequal economic value creation, and 'misrepresentation' will deal with the loss of voice of individuals under surveillance mechanisms.

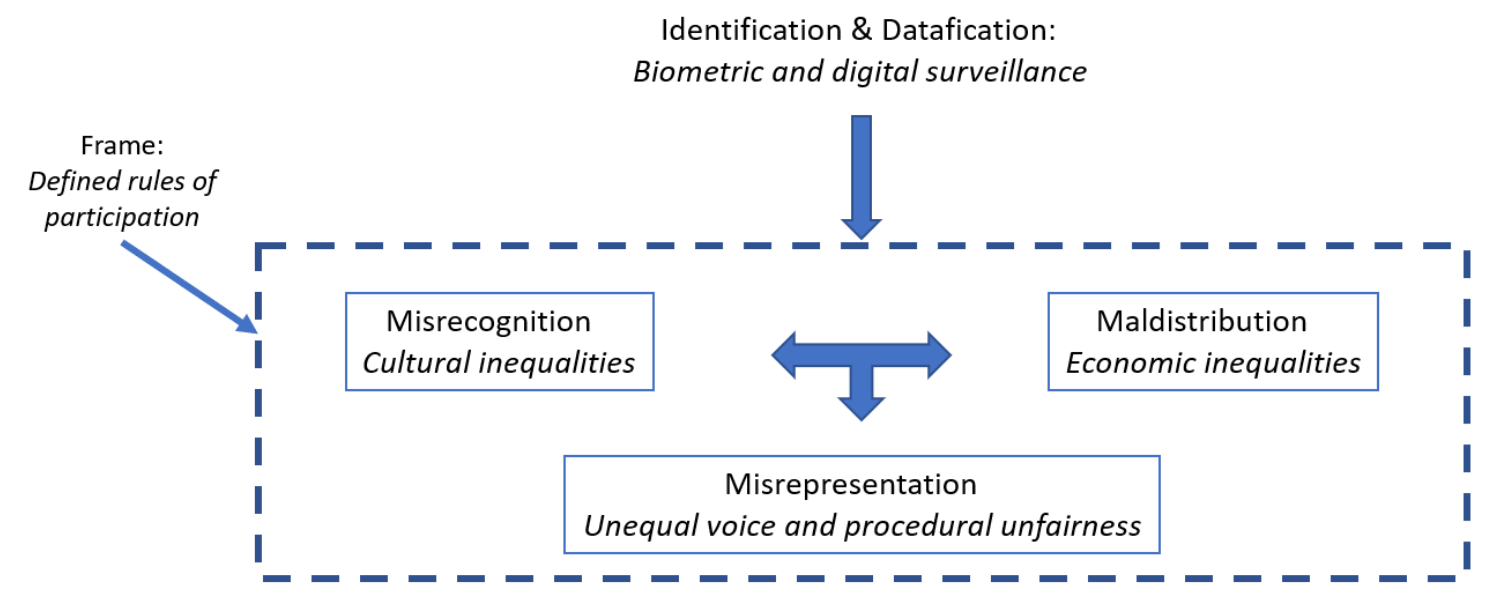

Figure 1: Data-Justice Framework - developed from Fraser $(2000,2008,2009)$

\section{C. Case Background and Methods}

Aadhaar, as undertaken by the Unique Identity Authority of India, works using biometric data - iris scans and fingerprints. These are linked to personal information like demographic data, address, mobile phone numbers and email addresses of citizens resulting in a random 12-digit digital unique identity number. Aadhaar then is used for a variety of services like opening bank accounts, receiving subsidies, or direct benefit transfer (Sarkar 2014, UIDAI 2014a, 2014b). Enrolment is 'non-mandatory' and is to be demand-driven (UIDAI 2014a). One of the key services enabled is 'Electronic Know Your Customer' (e-KYC). This offers electronic authentication and verification of individuals with its linkage to a bank account made mandatory for governmental subsidy, and mobile number linkage to Aadhaar made mandatory as the channel for communication of information by text messages in relation to subsidy by the state (MoF 2016). An 'open' architecture of digital infrastructure under Aadhaar was evangelised by proponents ${ }^{42}$ furthering adoption of Aadhaar across public and private sector services as the basis for digitally driven financial inclusion. Based on this there has been growth of Aadhaar-enabled digital payment services including mobile applications and digital payment gateways, with the services developed, delivered and consumed by multiple private sector players.

Using Aadhaar, the state focuses on the financial inclusion of the informal sector which accounts for $81 \%$ of India's working population with most of this informality concentrated in rural and agricultural jobs (The Wire 2018). Given this focus a case study has been chosen with the city of Chennai (the capital of the South Indian state of Tamil Nadu) as the urban setting to explore the experiences of two sets of informal workers - cab-drivers and

\footnotetext{
${ }^{42}$ India Stack - a non-state collective of technologists whose expertise and knowledge exchange furthered adoption of Aadhaar across public and private sector services: http://indiastack.org/aadhaar/
} 
domestic workers (CMDA 2008). The total working population in the Chennai Metropolitan Area (CMA) is estimated at 6.8 million in 2016 of which 1.2 million are deemed informal workers. In the state of Tamil Nadu - in which CMA is the largest urban area - urban inmigration has led to an increase in marginal settlements like slums and has driven the growth of urban informal labour in the last decade (TNGov 2014). Further, the choice to study domestic workers and cab-drivers was done due to their long-standing visible presence as traditional urban informal workers and the prominence of these jobs in the narratives of informality targeted by Aadhaar as a programme (UIDAI 2008).

An ecosystem of technologies (see Figure 2 below) provided by private sector companies and their eventual relation to Aadhaar are of interest for this case study.

- The first group of interest are the online recruitment portals that started catering specifically to 'blue-collar' workers in Indian cities. One of the earliest of the portals started in 2007 but with the bigger players joining after the advent of Aadhaar. These portals enabled job seekers to create online profiles detailing their skills and applying for jobs listed by potential employers as ads. Jobs listed include domestic workers, drivers, couriers and delivery personnel, 'handymen', restaurant workers etc. The focus of study here was of domestic workers who use these portals - e.g. Babajob, Quikr, Aasaanjobs - to seek employment.

- The second group of interest are mobile apps and platforms that cater to informal gig-based work specifically in urban areas. In recent years, these have grown with the advent of smartphones and location-based services. The focus here is on cabdrivers' use of ride-hailing apps which have supplemented and then fast replaced online recruitment portals as the source of employment opportunities. The drivers under study here use their own car, or leased cars via these apps, e.g. Ola, Uber.

In both recruitment portals and apps, the informal worker provides identity documents - in many cases a copy of Aadhaar as a paper document - to signal their legitimate identity as a potential worker.

Other than the above digital platforms there is the presence of digital trust platforms (e.g. BetterPlace, Yoti) which are used by recruitment portal and gig-work apps as a business-tobusiness service to 'verify' informal workers. This verification works by using their governmental identity information including photo and personal details cross-verified using digital scans against information provided by the informal workers on these digital platforms. With Aadhaar these work in two modes. First, online verification using Aadhaar e-KYC ${ }^{43}$ where the UIDAI API with its open, vendor-neutral architecture (UIDAI n.d.), helps to confirm validity of personal information. Second, offline verification using XML data-files and QR code images encoding Aadhaar-related personal data. As part of informal worker onboarding these digital trust platforms use these e-KYC, XML or QR codes to do faster and bulk validation of information provided by the workers. The role of these digital trust platforms within the ecosystem has not been probed in detail, but it is acknowledged here as they provide a basis for the faster scaling up of digital identity use among informal worker populations.

${ }^{43}$ This has been limited after a recent Supreme Court ruling disallowing private sector use. 


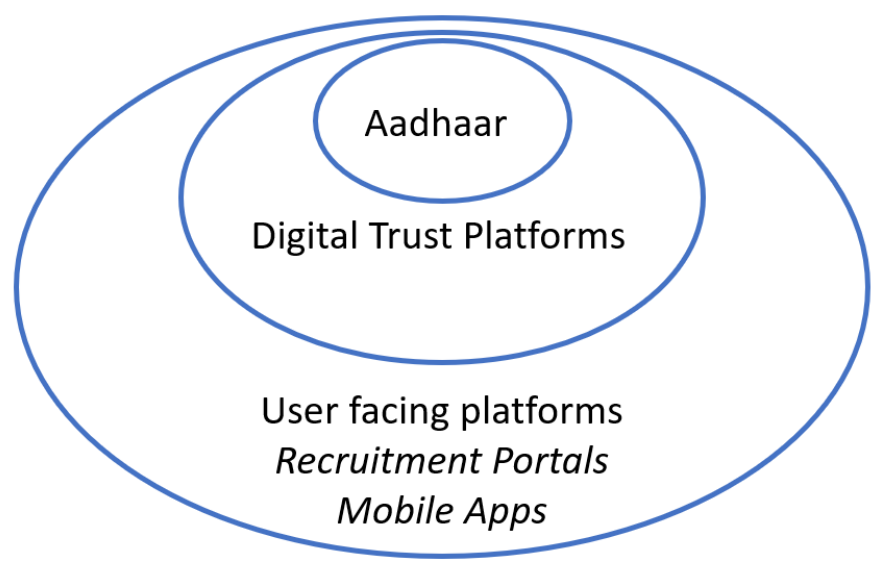

Figure 2: Ecosystem of Technologies

The case study is built by thematically analysing mainly interviews (see Table 1) using the data-justice framework described earlier (see Figure 1). Semi-structured interviews ${ }^{44}$ of informal workers and worker group leaders were done between January to March 2019 focused on the daily-life experience of using technologies of Aadhaar and its ecosystem. Additionally, interviews of digital platform creators (management of a leading 'blue-collar' recruitment portal interviewed as part of a pilot in Bangalore during April 2017) were used to contextualise the data. Data was further triangulated by field observations and interactions, and by the author's use of digital platforms as a customer on ride-haling apps and by the author signing-up as a prospective employee on a recruitment portal. Secondary sources used included mass media content, government white papers and policy reports, technical blogs and documents, and websites of the platforms under study. All these are cited where appropriate.

\begin{tabular}{|l|l|}
\hline Type (number of interviews/observation instances) & Anonymised reference \\
\hline Domestic workers without online recruitment engagement (8) & DWA1 to DWA8 \\
\hline Domestic workers with online recruitment engagement (8) & DWB1 to DWB8 \\
\hline Domestic workers group and NGO leaders (3) & DWL1, DWN1, DWN2 \\
\hline Domestic workers self-help group (2) & DWM1, DWM2 \\
\hline Cab-drivers using ride-hailing apps (15) & CDA 1 to CDA15 \\
\hline Cab-drivers union leaders (2) & CDL1, CDL2 \\
\hline $\begin{array}{l}\text { Digital platform creators - management-level employees from } \\
\text { one of the leading blue-collar recruitment portals (2) }\end{array}$ & DPL1, DPL2 \\
\hline Cab-drivers union meetings (1) & CDM1 \\
\hline Cab-drivers protest (2) & CDP1, CDP2 \\
\hline
\end{tabular}

Table 1: List of Interviews and Field Observations

\footnotetext{
${ }^{44}$ When this paper in the later parts refers to 'interviewees', this broadly means the informal workers interviewed, relating to a finding emerging across multiple interviews. Interviews of leaders and digital platform creators are specifically referenced where used.
} 


\section{D. Findings}

This section is structured based on the data-justice framework discussed in earlier sections. The injustices arising due to cultural, economic and political subordination are presented respectively as per the 'abnormal justice' dimensions.

\section{D1. Misrecognition}

\section{Asymmetry of Recognition}

Aadhaar opens new avenues for informal workers to seek employment on digital platforms as cab-drivers and domestic workers. Prominently the slogan that the programme is branded with, is 'My Aadhaar. My Identity/Recognition'45. It is reinforced by government advertisement strategies that project use of Aadhaar as the digital means to claim recognition for disadvantaged groups - particularly domestic workers. The narratives with which Aadhaar has been presented thus plays on the need for recognition in gaining employment as an informal worker (Aadhaar UIDAI 2018). Before the Supreme Court ruling in late 2018 disallowed private sector use of Aadhaar, digital recruitment and trust platforms partnered with UIDAI in enabling e-KYC-based authentication of job seekers, showing the 'Aadhaar verified' tag on profiles as a signal of trust to recruiters, and to incentivise verification through Aadhaar for other job seekers (DPL1, ILO 2017). But clients the private household employers on the recruitment portals and cab-riding customers on ride-hailing apps - who would employ the services of informal workers are not verified.

The digital verification here mainly works to signal trust by enabling the clients to gauge their risk in engaging services of a new employee. But a similar function is not available to the workers as the clients themselves are not verified digitally, resulting in an asymmetrical one-way formalisation of surveillance and recognition. Digital verification here replaces urban local-area informal referral networks which are traditionally used to seek employment (DWA8). There is a loss of these 'mutual trust' networks - sometimes in place for decades - which help informal workers recognise potential 'good' employers referred via word-of-mouth by their peers in both the cases of cab-drivers and domestic workers (DWL1, CDM1). Informal workers highlight this asymmetry as an issue of safety which hinders their easy recognition of potential employers and in not knowing their local work conditions, as the traditional peer networks provided a possibility to informally vet households of potential employers. Similarly, this asymmetry manifests again when cab-drivers highlight a need for assurance of their on the job safety. Citing recent crimes against cab-drivers by cab-riding customers (TOI 2017, HT 2018a, The Hindu 2019), the drivers suggest Aadhaar-based verification of cab-riding customers as a possible solution that mirrors their own verification on digital platforms (CDM1). Asymmetrical verification practices deem the informal workers only to be trusted after a formal mechanism of verification, even when they are provided no avenues for formal knowledge of their working conditions and employers.

\footnotetext{
${ }^{45}$ In Hindi - Mera Aadhaar, mera pehchaan - the word 'pehchaan' has a technical meaning of identity with recognition as the broader meaning.
} 


\section{Absence of Worker Legitimacy}

The drivers argue that the stringent identity verification using Aadhaar while joining a digital platform - made mandatory for all practical purposes - uses their verification only to signal safety to cab-riding customers and enable participation in digital payment. Operationally the digital identity does not help them gain recognition as legitimate drivers during their daily work on the road due to lack of institutional support from the digital platforms, irrespective of the driver's verification status. This is especially evident when issues of customer dispute arise or when drivers need to engage with the police (CDL2). Traffic or beat police, as reported by cab-drivers, use their prior disposition of domination against informal workers. As a result, instances are reported where police use their petty power to verbally abuse and intimidate cab-drivers, and in some cases seek bribes (Thozhilalar Koodam 2019). Cabdrivers protest this as 'police harassment' and seek a means to gain legitimacy of their role as a driver (CDP1). Ultimately while a digital identity helps the drivers gain work through digital platforms it does not lend itself to signal legitimacy for such purposes on the road.

The fragmented nature of work on digital platforms is also related to how such issues of identity affect the cab-drivers. Consider the case of the long-running transport option of auto-rickshaws (also known in other countries as tuk-tuks) where an organised and formal unionising of drivers and collective efforts has long existed through 'auto stands' (local area parking spaces that act also as meeting spots) (Transparent Chennai 2012). In many cases these organised efforts also have the advantage of strong political party patronage. Autorickshaw drivers resort to their union or auto-stands for institutional support when for example they gain negative attention from the police in claiming their legitimacy as drivers. Cabs on the other hand are a recent phenomenon in Chennai, with a strong dependence on digital platforms as a basis for atomised self-employment. While digital platforms have reduced the infamous ability of drivers (both auto and cab) to set exorbitant rates and engage in undue haggling, the atomised existence of platform-based work leaves drivers cab-drivers particularly - to their own devices to contend with the lack of recognition of their urban role as a driver. To get over this issue, fledgling efforts have begun on unionising. One cab-drivers' union now issues paper identity cards that they seek to use to signal their union membership. These collective efforts of the drivers are directed to claim their legitimacy given the lack of support on this front from the digital platforms, especially when stopped on the road by the police or when challenged by customers (CDM1, CDL1).

In summary, while Aadhaar provides increased employment opportunities, as a social impact the push for digital verification is seen to be based on the status subordination of informal workers, with their extant social subordination ostensibly extended into the digital realm. Here Aadhaar-based verification in its social role is directly used to assuage security anxieties of the clients of digital platforms who hail from middle and higher socio-economic classes. But as an identity Aadhaar and its uses on digital platforms is not set up to help claim legitimate recognition of the informal workers' role in their workplace and it does not address security and safety concerns of the informal workers. Ultimately Aadhaar works mainly as a tool of recognition asymmetrically through routine surveillance of the already culturally-subordinated groups - digitally reifying the socially extant inequity of recognition. 


\section{D2. Maldistribution}

\section{Limited Digital Financial Inclusion}

Aadhaar is directly related to two aspects of financial inclusion of informal workers into the wider economy - as verification for bank accounts and to enable digital payments. The easy opening of bank accounts for previously unbanked populations like the informal workers has been the main agenda of Aadhaar in driving financial inclusion. The interviewees' expected benefits and reasons why they signed up to Aadhaar are tied to narratives of seeking economic betterment. These include the possibility to participate in the wider economy through the opening of bank accounts, and through the ease of accessing government subsidies and getting cash benefit transfers directly to their accounts. Specifically, they also mention the possibilities to access loans from both public and private lenders (various interviewees, DWL1, DWN2). These ideas presented by the workers themselves are congruent with the governmental narrative of Aadhaar-enabled financial inclusion.

While such Aadhaar uses have driven an increase in number of bank accounts, it is acknowledged widely ${ }^{46}$ that in practice Aadhaar mainly acts as yet another paper document to prove individuals' identity, as was the case for most of the interviewed domestic workers. Such Aadhaar linkages are done mainly due to the state push to make these verified bank accounts a channel for receiving government subsidies. Digitally-enabled financial inclusion beyond this is limited as further formal economic participation using bank accounts does not occur easily. This echoes the World Bank finding (Demirgüç-Kunt et al. 2017) on financial inclusion where almost half of all accounts opened under the recent governmental efforts see them being inactive in the last year. This is true particularly for domestic workers whose wages are transacted in cash and their bank accounts only work to receive government subsidies. With the wider economy that the informal workers engage with being still cashoriented, cash is still king for their livelihood (various interviewees).

In this context Aadhaar also enables digital financial transactions - like mobile payments or digital wallets based on linked bank accounts. But there is not yet a widespread use among the informal workers to undertake daily economic transactions using digital means, beyond that which is imposed by digital platforms as in the case of cab-drivers. Even the digital financial transactions integrated on ride-hailing apps present some challenges. Digital payments are clearly presented as a convenience and attraction to cab-riding customers to increase demand of platform usage. To match this customer demand, during the initial marketing phase, digital platforms ramped up the supply of cab-drivers and focused on enabling them to accept digital payments from customers. Drivers were incentivised to join with full verification using Aadhaar which was required for their use of digital payments. The initial promise was one of a lower commission taken by the digital platforms with the drivers promised higher income (CDL1). Drivers' experiences in Chennai echo reports from other Indian cities where drivers expected and were promised an income around Rs.100,000 per month (c.US\$\%1,500). But they saw their income fall to $20 \%$ of this promised amount. As

\footnotetext{
${ }^{46}$ Both from interviewees and from a report 'State of Aadhaar' from the Omidyar Network based on a largescale survey for 2017-18 - see Abraham et al. (2018).
} 
the market matured there was increased competition for passengers but also an increased share of income taken as commission by the digital platforms (HT 2018c).

Further specific tactics across the board from major ride-hailing apps cut into driver's income. In 2015 the platforms started levying a fixed fee per week from the drivers over and above the per-ride commission. This was designed as a bid to discourage drivers from switching between apps and to lock them in - as the fixed costs are payable even if the driver logs in just once a week. So, a driver using two apps will be charged by both platforms and is better off using only one of them to avoid double fixed costs. Such factors have brought about a decreasing share of cab-driver share of booking revenue (in one report a decrease from $60 \%$ to $24 \%$ ) (ET 2018c). This lowering of income has also pushed some drivers into further financial difficulties, especially as some of the drivers purchase a car (and in some cases other items such as phones) via the platform financed through loans tied to their contract as a self-employed partner. Their income from the digital platforms then is deducted to the tune of the expected regular loan payment amounts, levied directly through the driver's bank account. All these factors lock such drivers to the platform for employment with declining earnings with them stuck with the major ongoing liability of a car loan with additional payment processing fees payable to digital payment providers which cut into the cab-driver's profit margin.

\section{Impacts of Digital Payment}

The adoption of Aadhaar is related to the increase in digital payments within the last few years which specifically has impacted informal workers. The Indian government, driven by Aadhaar as a core technology has pushed for a 'state-of-the-art' digital payment system (RBI 2019a). Digital identification plays the central role in the long-term strategy of the India central bank to ensure availability of 'aggregate data' about credit across the country and to drive formal economic participation (RBI 2019b). The culmination of these efforts was the demonetisation of currency notes that happened in 2016, which disproportionately affected those within the informal sector (Gupta \& Auerswald 2019). Nearly $80 \%$ of currency in use in the economy was taken out of circulation by the Government of India - citing control of corruption and 'black money', and as a bid to force formalisation of financial transactions within the sizable informal part of the Indian economy. Informal workers saw the immediate necessity to participate in the digital economy for their livelihoods and encountered rapid changes in employment and their income governed by the digital platforms. The cash crunch not only affected the livelihoods of cash-dependent informal workers, but also the informal part of the economy that they depend on, due to the inability of small businesses like micro traders who struggled to adapt to digital payments (Unni 2018).

Meanwhile, there has been an acceleration in the Indian economy with cashless and digital transaction becoming prevalent bringing in a near-exponential increase in the digital payments market. Cab-drivers are increasingly dependent on the digital platform's integrated payment solutions such as digital wallets or card payment interfaces. Though these solutions have been reported to have frequent operational delays in transferring customer fare payments into the bank accounts of the cab-drivers (various interviewees). Even as the Indian government pushed for the spread of digital payments and reduced the transaction costs of taking card payments - which were at 1 to $2 \%$ - the digital platforms 
have not passed on this reduction in costs to the driver. Due to these factors lowering their income, drivers sometimes see a situation of daily cash crunch. Most of them depend on the turnover of cash to manage their mostly cash-based daily living and working conditions including paying for petrol (CDL1, CDL2, various interviewees). To counter this effect of digital payments it has been observed that some drivers call potential riders, after accepting rides and ahead of pick-up, to agree on cash payments (CDL1, author observation). Though not all can undertake this workaround due to platform-imposed revenue targets.

Thus, the imposition of digital payments affects informal workers disproportionately compared to upper and middle socio-economic classes who have access to formal and regulated banking. This, as an increased benefit to the already formalised section of the economy, reinforces existing economic inequality driven by increasing dependence on digital payments. With the digital platforms and the gig-economy remaining largely unregulated, the workers face exploitative terms of work and uncertainties even when they do participate in digital payment transactions.

\section{Monetisation of Data}

At its core, digital verification is presented as a direct economic benefit to informal workers with them handing over their personal data and sometimes engaging with biometric surveillance in the process. This results in a direct loss of control of their personal data in the absence of actual legal data protection and defined privacy assurance on digital platforms. The platforms derive economic value through monetisation of this data which is available without any legitimate guidelines of data-use. An analysis of recruitment portals show that monetisation is sought by sale of premium services and subscriptions to both recruiters and job seekers alike. The recruiters are able to 'buy' contact information in tranches which includes personal information of the job-seeker. Additionally, data-driven marketing elements like advertisement revenue and cross-selling using data-analytics are made possible. The observed case was of 'special offers' for jobs seekers seemingly targeting 'verified' job-seekers using their profile data which advertised opening a bank account using 'easy' identity verification.

The accumulated data due to increasing datafication and new-found digital participation of informal workers is available to the platforms as a user-base and dataset which in turn forms an economic asset that makes up a core part of their business model (DPL1, DPL2). This is seen in the growing economic performance of the platforms - with ride-hailing app valuations driven by verified driver numbers (Traxcn 2016), and an ongoing consolidation in the recruitment portal market based on their 'blue-collar' worker user-base (Modgil 2017) . The state has also bolstered increasing datafication by policies like the National Career Service (NCS) government portal which makes Aadhaar mandatory (NCS n.d.) for registration for job search. The government portal includes listing of urban informal worker opportunities and works with direct integration to online recruitment portals and ridehailing apps.

Thus, Aadhaar-enabled verification of the previously digitally excluded population driven by existing economic inequality is the basis on which these business models see a direct increase in their user-base enabling extraction of economic value of user data through the 
monetisation practices on these platforms. This echoes arguments of 'informational capitalism' (Andrejevic 2015) - of parting with one's personal data not necessarily providing economic value to the individual but extracted for value in the aggregate by platforms. The main issue of equity arises due to the synergy of technology companies' business models and the state push for ostensible mandatory digital securitisation of society under Aadhaar. While the workers find new avenues for job-seeking via the digital technologies, enabling digital participation in this mode without due protection has helped platforms gain the most economic value with clients following next in gaining advantage due to digital provision of services. The state to a lesser extent gains the ability to enact digital surveillant control on the previously invisible informal workers. Ultimately informal workers themselves gain the least in such an environment where the absence of regulation and data protection directly places them in an emerging form of economic subordination.

\section{D3. Misrepresentation}

\section{Informed Consent Issues}

Aadhaar's procedures for 'informed consent' have been contested legally and in practice. This is especially because the law that ratified Aadhaar and its defined process of consent emerged in 2016 but biometric and other data had been collected since 2010 (ET 2018d). Mass collection of consent was done in what has been referred to as 'consent camps' (ET 2017) with a rather bureaucratic approach to getting consent by rote 'retroactively' after the wider roll-out. Echoing this the interviewed informal workers acknowledge routine signing and filling up of forms during enrolment and linkages; undertaken without time or capacity to fully understand what is being signed. Moreover, many of the online forms and printed terms which collect consent are in English, the dominant language of governance in India (author observation). This is true of commercial digital platforms as well. Yet Englishlanguage literacy among informal workers is low. These issues position the surveilled individuals facing a lack of information while giving consent, particularly so for informal workers who are disadvantaged in data-literacy and language (Kaur 2018); a systemic issue faced by marginalised groups. As one of the domestic workers puts it linkages are done as 'the government says so and we do it. We don't question it' (DWA7).

This has enabled seemingly 'mandatory' Aadhaar linkages pushed by private players like telecom companies. With the absence of clarity on whether Aadhaar was mandatory or voluntary, during the early months of 2018 banks and telecom companies sent continuous and officious notifications forcing customers to link Aadhaar to their bank accounts and mobile numbers (Manzar 2018). This practice continued until a clear direction on the disallowance of private use of Aadhaar authentication came in by September 2018. The 12digit Aadhaar numbers collected by such mechanisms still reside in the databases of the private sector agencies (HT 2018b). This and the pervasive linkages of Aadhaar numbers to multiple databases presents a possibility for cross profiling by the state and private entities; again without the explicit or valid informed consent of the individuals who have been recorded. 


\section{Disparity in Procedural Redressal}

Following the Supreme Court ruling in late 2018, the sharing of Aadhaar numbers and linkages to certain private sector services like telecom companies or mobile digital payment providers was deemed a security issue that needed to be addressed. In response, specific solutions were devised including Aadhaar de-linkage requests (Business Standard 2018) using online forms or emails directed to private sector providers, and a solution of a temporary 'Virtual Identity Number' generated online that would mask the actual Aadhaar number (ET 2018b, IE 2018). The identified issues of security were independent of the kind of users of Aadhaar and cut across all different classes of the society. However, since the redressal presented for these issues was mainly depended on online solutions and use of the internet. These solutions thus have an unequal reach putting vulnerable groups like informal workers at a disadvantage.

In fact, there has been a dearth of promotion and wide communication of the solutions to security issues, compared to how strongly and in an accessible manner the linkages were pushed in the first place using mobile text alerts. This too affects the vulnerable population disproportionately. Interviewees mentioned that while some aspects of the Supreme Court ruling and the media conversation around that are known to them, none of them have used a Virtual Identity Number or sought de-linking as they have not been informed authoritatively by telecom companies or the state about these things. Even the cab-drivers who are more data-literate relative to the domestic workers group, mention that while they use mobiles apps and services like Facebook (CDL1), the engagement with online governmental processes is limited and time consuming.

The inequity of these redressal processes being primarily online or smartphone-based is compounded by two other factors - kiosk-driven services and mobile-based 'one-timepasswords' (OTPs) for security. Firstly, government Aadhaar kiosks are expected to serve those who cannot access the internet directly. This creates a disparity for the marginalised groups who need to pay to access kiosk services as opposed to someone who can access these free services on the internet. Further, due to delays or higher demand at regulated governmental kiosks, the informal workers recount being forced to use unregulated and potentially corrupt private internet browsing centres which charge higher fees that are hard for these workers to afford.

Secondly, the safety of Aadhaar transactions is dependent mainly on a 'secret' mobile textbased OTPs (LiveMint 2018). These OTPs are routinely shared with others - especially due to absence of clear information about their usage and because of data-literacy challenges as experienced by informal workers, which directly affects their data security. Domestic workers - almost all of whom using feature phones rather than smartphones - reported it difficult to engage with the OTP process. They depend on an intermediary such as a family member or acquaintance to read text messages, with many such alerts reported by some as having been left unread for a long period of time. In one case it resulted in delay of subsidy reaching the domestic worker's bank account (DWL1). Further, In case of cab-drivers they report submitting Aadhaar paper copies at the time of signing up to be a ride-hailing app driver and receiving multiple OTPs on their mobile which were then asked for by customer care agents over the phone (CDL1, CDL2). These were effectively used to set up the cab- 
drivers with digital payment options related to the apps. The cab-drivers in their subordinated position find it obligatory to share the OTPS and without any opportunity for provision of informed consent. Loopholes like this have been highlighted as the basis for financial scams where impostors pretending to be officials call up asking for Aadhaar-related OTPs (Ganjoo 2018).

Thus, procedural aspects around Aadhaar present a subordination based on digital access and data-literacy to create undue disparity based on both information presented and of recourse to redressal. Marginalised communities under Aadhaar who are pushed to mandatorily use digital identity are unable to voice consent in practice due to an ineffectiveness or absence of information presented to them. This is further exacerbated when procedural solutions as corrective action also create disparity due to varying levels of digital access.

\section{E. Discussion}

Under abnormal justice Nancy Fraser presents a 'frame' as the rules of participation across the three dimensions of justice. Here the 'frame' is the basic societal rules of Aadhaar-led inclusive participation of informal workers driven by data and identity. This in practice is a heterogeneous assemblage of laws, processes and technologies, which have been queried in the above discussion. Taken as a whole the understanding of the 'what' of justice emerges as equitable participation overcoming subordination in attaining fair recognition, distribution and representation. This also presents a means to connect justice to the wider context of marginalisation, digital identification and the datafication of livelihood at large. This alongside a further discussion on the data-justice framework follows in this section.

\section{E1. Justice under Datafication}

Culturally, justice can be formulated as fair access to legitimacy, as sought by marginalised groups in their use of digital technology in a bid to overcome the existing social imbalance of recognition that acts against them. Additionally, data justice also needs to incorporate the impact of participation in the digital economy. Justice then can be queried; asking if technology helps overcome cultural subordination or in a negative sense technology acts exploitatively to cement existing inequities. Much as Cummings \& O'Neil (2015) commented, here technology is a 'mirror' of the society, in that it can replicate the extant class-based and cultural issues related to marginalisation. Going by the case evidence, data justice has to account for the risk that subordination - which existed in cultural and social practices experienced by marginalised groups - is digitally reified onto their datafied representation and the technological processes they engage with.

Economically, digital identity is intimately connected to economic development and poverty reduction programmes as evident in agendas such as 'identity for development' (ID4D 2016, Beduschi et al. 2017). But these programmes do not account for the impact of datafication that inevitably follows the provision of digital identity. Data in such a case has been seen to be intrinsically connected to economic value production for commercial players. Clearly, 
enough evidence exists that imperfect protection of an already marginalised community can further exacerbate their economic condition. But an additional distributive aspect of justice then emerges where technology helping fair participation of the economically subordinated can also enable unfair exploitation of the personal data of the marginalised. Injustice here as shown can lead to even further economic subordination based on the newfound digital participation of marginalised groups.

Finally, in the political domain, justice as an aspect of representation is intimately connected to the wider political voice-lessness of marginalised groups - the solution to which is devised through digital technologies and by datafication by recent governmental policies and programmes (Gurumurthy et al. 2016). Digital identity is clearly adopted globally under such a tenet. Two aspects of datafication form the focus of political justice. Unjust rules for consent under processes of datafication deny vulnerable communities a voice in participating equitably, putting them at further disadvantage. Redressal efforts to technological problems also can be procedurally unfair, aggravating existing marginalisation. Justice then is conceptualised as equal 'voice' through informed consent and as a fair procedural means to question any vulnerability arising due to digital technology.

\section{E2. Stakeholders of Data Justice}

The case study also provides insights into subordination through the 'who' of justice - the second node. As Fraser (2009) noted, cultural and economic subordination can feed off one another - with middle and higher socio-economic groups who already enjoy dominance reifying that position in the digital realm. People can be understood as disparate classes within society with digital technology clearly benefitting some over others. This presents an opportunity to theorise the role of those who are affected by technology and data under the data-justice lens. Existing discussion of inequalities related to data (Manovich 2012, Andrejevic 2014, Cinnamon 2017) presents the analytical category of users related to datafication based on personal data production. For instance, Manovich (2012) presents three divisions of the 'data-classes' - the ones who create data, who collect data, and who analyse data. But the 'who' of data justice based on the above discussion can extend analytical categories beyond data production. Especially to contextualise the impact of data after its production and use, one can propose a data-class based analysis of stakeholders to study effects of datafication and who it benefits. This will invoke the three dimensional cultural, economic or political subordination in categorising stakeholders. From the case study, we can ascertain that Aadhaar as a means of digital participation unjustly subordinates informal workers in relation to other entities:

- Culturally, informal workers continue to be subordinated to clients who engage services using digital platforms. These are the private household employers on the recruitment portals and cab-riding customers on apps. Additionally, the state through the actions of the police continues to exert local power on informal workers.

- Economically, data is accumulated by digital platforms for extraction of economic value, presenting an unjust distribution of economic value that is based on the newfound and unprotected datafied existence of informal workers.

- Politically, the state and private entities create disparities based on informed consent and recourse to procedural solutions that create further digital-led vulnerability for informal workers. 


\section{F. Conclusions and Recommendations}

The intricate entwinement of surveillance and datafication under digital identity has been explored in this paper with a case study of Aadhaar, India's biometric digital identity programme. The paper makes specific contributions in theorisation and through presentation of empirical analysis. The paper presents an adaptation of the social justice theorisation that works synergistically with notions of surveillance and datafication to present a data-justice framework. Using a rich empirical analysis, the paper has demonstrated the viability of such a framework derived from Nancy Fraser's (2009) work on 'abnormal justice' and its constituent dimensions - cultural recognition, economic distribution and political representation.

Empirically, by analysing the emerging surveillant technology of Aadhaar and its networked ecosystem, the paper sheds light on the social impact of such a programme. While surveillance using a digital identity is aimed at an agenda of inclusive participation of the disadvantaged in society, the use of a social justice lens points to the complex nature of its impacts. Via study of cab-drivers and domestic workers and their use of digital identity and platforms, this paper engages with digital identity and its complex networked ecosystem to understand consequent datafication, data-flows and their impacts.

Digital identities, it is found, do produce benefits to marginalised communities like informal workers in providing a legal identity both digitally and on paper - as a means of recognition, and in helping them participate in the mainstream economy through subsidy disbursement and by providing access to formal bank accounts. But there are downsides to these benefits across the three domains of justice. It is found that digital identity in its current form largely prioritises cultural and economic benefits for middle and higher socio-economic classes. Culturally, lower socio-economic classes do not see an improvement in their social standing as claimed by the wider identity agenda, while also being affected in the economic domain due to personal data being prone to extraction for value by commercial digital platforms. This is further impacted politically by inequity in voicing needs and due to unfair procedural aspects, both of which inordinately affect lower socio-economic classes.

These findings point to an exacerbation rather than narrowing of inherent inequalities between marginalised communities like informal workers and the more formal entities of Indian society: commercial businesses including digital platforms, and their middle-class clientele. Particularly it presents a complex synergy between governmental and private sectors: the data-flows between them and the impact on an already vulnerable population. Thus, the implication of the findings would be on both domains of data-subject rights and citizen rights. Although the discussion in the paper is based on the Indian case study, by engaging with the contestations for justice under surveillance and datafication, this paper has sought to more-widely contextualise the experience of marginalised communities under datafication. The paper also proposes understanding data-justice stakeholders using an extended 'data-class' notion incorporating the complex nature of cultural, economic and political interactions enabled by data.

The findings and the theorisation presented here contribute to the research agenda by addressing a specific knowledge gap. The social justice approach used here specifically 
answers the call to move away from the top-down technological approach prominently taken in presenting digital solutions that seek to enhance equitable participation in society (Eubanks 2014). In light of this, the paper has sought to understand everyday routines through which individuals use technology and data, and engage with digitally-delivered participation and its resultant social impacts. This argument has found favour with authors writing on data justice (Taylor 2017, Heeks \& Renken 2018). Thus, the theorisation presented subsumes aspects of marginalisation, inequality, datafication and surveillance all under a lens of justice. Building further on this the research also seeks to understand the wider impact of data and technology in the global South in a way that goes beyond the individualistic-centric paradigms of privacy and rights which have been acknowledged as a gap in research (Marwick 2018).

Building on this paper, a future research area that needs closer inspection would be the effects of ongoing platformisation of work and wider datafication on informal workers. This paper particularly has laid the groundwork to understand the global South context in two specific ways which need to be prioritised for future research, especially using the lens of social justice. First, this paper has briefly explored the ways in which digital technologies like identity and gig-work platforms are intricately connected to collective and individual rights of informal workers in a datafied employment landscape. A detailed study of this is warranted with focus on the role of formal labour unions and other informal entities, and their efforts such as protests, collective bargaining and membership drives. Second, this paper has discussed specific details of how daily practices of informal workers are affected due to newfound digital participation on platforms. A wider exploration of the existing informality and marginality of such global South workers is needed, with a possible longitudinal study of informal workers transitioning into gig work. This can shed light on the expectation and needs of marginalised users such as informal workers before they transition onto digital platforms and provide insights into the impact, both positive and negative, once they take up gig work.

Finally, the following recommendations for practice can be garnered from the analysis of this paper:

- There is a need to determine the boundaries of datafication - with particular focus on limits of open-architecture systems.

- Promoting advocacy of data rights among vulnerable populations is needed alongside data-literacy improvements.

- Transparency needs to be demanded from governmental data-sharing arrangements especially in the global South.

- Mechanisms of accountability for monetisation of personal data from governmental and private players alike need to be established including its impact on vulnerable populations.

- Advocacy is needed for hybrid-artefact solutions like smart cards, that can work stand-alone or when connected, and that can enable digital participation of vulnerable populations while mitigating risks of open architecture and multi-purpose digital identity.

These serve to engage with the rampant datafication in the global South in the absence of a data-protection law - an issue in a number of countries, including the case of India under study. 


\section{References}

Aadhaar UIDAI. (2018). Aadhaar - The Most Trusted ID in India. YouTube, 21 May. https://www.youtube.com/watch?v=nHUgnK68cUQ

Abraham, R., Bennett, E. S., Bhusal, R., Dubey, S., Li, Q., Pattanayak, A., \& Shah, N. B. (2018). State of Aadhaar Report 2017-18. New Delhi: IDinsight. http://stateofaadhaar.in

Abraham, R., Bennett, E. S., Sen, N., \& Shah, N. B. (2017). State of Aadhaar Report 2016-17. New Delhi: IDinsight. http://stateofaadhaar.in

Andrejevic, M. (2014). The Big Data Divide. International Journal of Communication, 8, 16731689.

Andrejevic, M. (2015). Personal Data: Blind Spot of the "Affective Law of Value"? The Information Society, 31(1), 5-12.

Arora, P. (2016). Bottom of the Data Pyramid: Big Data and The Global South. International Journal of Communication, 10, 1681-1699.

Ashworth, L., \& Free, C. (2006). Marketing Dataveillance and Digital Privacy: Using Theories of Justice to Understand Consumers' Online Privacy Concerns. Journal of Business Ethics, 67(2), 107-123.

Bauman, Z. (2000). Liquid Modernity. Cambridge: Polity Press.

Bauman, Z. (2013). Legis/ators and Interpreters: On Modernity, Post-Modernity and Intellectuals. Cambridge: Polity Press.

Bauman, Z., \& Lyon, D. (2013). Liquid Surveillance: A Conversation. Cambridge: Polity Press.

Beduschi, A., Cinnamon, J., Langford, J., Luo, C., \& Owen, D. (2017). Building Digital Identities: The Challenges, Risks and Opportunities of Collecting Behavioural Attributes for new Digital Identity Systems. Exeter: University of Exeter. https://ore.exeter.ac.uk/repository/bitstream/handle/10871/28297/Buiding\%20Digital \%20Identities\%20Report-FINAL.pdf

Bennett, C. J., \& Lyon, D. (2013). Playing the Identity Card: Surveillance, Security and Identification in Global Perspective. New York: Routledge.

BetterPlace. (2019). Blue Collar Jobs and Migration Trends Report. Bengaluru: BetterPlace. https://www.betterplace.co.in/betterplace-blue-collar-jobs-and-migration-trendsreport/

Bier, R. J. (1993). Privacy and Procedural Justice in Organizations. Social Justice Research, 6(1), 69-86.

Bloomberg Quint. (2018). UIDAI Restricts Digital Wallets from Accessing Aadhaar Database. Bloomberg Quint, 4 Jun. https://www.bloombergquint.com/aadhaar/uidai-restrictsdigital-wallets-from-accessing-aadhaar-database

Boellstorff, T. (2013). Making Big Data, in Theory. First Monday, 18(10).

Boyd, D., \& Crawford, K. (2012). Critical Questions for Big Data: Provocations for A Cultural, Technological, and Scholarly Phenomenon. Information, Communication \& Society, 15(5), 662-679.

Breckenridge, K. (2014). Biometric State. Cambridge: Cambridge University Press.

Brighenti, A. M. (2010). Visibility in Social Theory and Social Research. London: Palgrave Macmillan.

Broeders, D., Schrijvers, E., van der Sloot, B., van Brakel, R., de Hoog, J., \& Ballin, E. H. (2017). Big Data and Security Policies: Towards A Framework for Regulating the Phases of Analytics and Use of Big Data. Computer Law \& Security Review, 33(3), 309-323. 
Business Standard. (2018). Here's How to Delink Aadhaar from Digital Wallet, Bank: Step-ByStep Guide. Business Standard, 2 Oct. https://www.businessstandard.com/article/current-affairs/how-to-unlink-aadhaar-number-from-bankaccounts-paytm-mobile-sim-digital-wallets-118092600417 1.html

Cinnamon, J. (2017). Social Injustice in Surveillance Capitalism. Surveillance \& Society 15(5), 609-625.

CMDA. (2008). Second Master Plan for Chennai Metropolitan Area, 2026. Chennai: Chennai Metropolitan Development Authority. http://www.cmdachennai.gov.in/smp main.html

Cummings, C., \& O’Neil, T. (2015). Do Digital Information and Communications Technologies Increase the Voice and Influence of Women And Girls: A Rapid Review of the Evidence. London: Overseas Development Institute. https://www.odi.org/sites/odi.org.uk/files/odi-assets/publications-opinionfiles/9622.pdf

Dalton, C. M., Taylor, L., \& Thatcher, J. (2016). Critical Data Studies: A Dialog on Data and Space. Big Data \& Society, 3(1), 1-9.

Demirgüç-Kunt, A., Klapper, L., Singer, D., Ansar, S., \& Hess, J. (2017). The Global Findex Database 2017: Measuring Financial Inclusion and the Fintech Revolution. Washington, DC: World Bank. https://globalfindex.worldbank.org/

Dencik, L., Hintz, A., \& Cable, J. (2016). Towards Data Justice? The Ambiguity of AntiSurveillance Resistance in Political Activism. Big Data \& Society, 3(2), 1-12.

Diop, M. (2017). Making Everyone Count: How Identification Could Transform the Lives of Millions of Africans. Washington, DC: World Bank. http://www.worldbank.org/en/news/opinion/2017/05/24/making-everyone-counthow-identification-could-transform-the-lives-of-millions-of-africans

ET. (2017). Government Starts Mega Drive to Link NREGS Accounts with Aadhaar. The Economic Times, 26 Jul. https://economictimes.indiatimes.com/articleshow/59762569.cms

ET. (2018a). No Question of Deleting Aadhaar Data: UIDAI CEO Ajay Bhushan Pandey. The Economic Times, 1 Oct. https://economictimes.indiatimes.com/opinion/interviews/noquestion-of-deleting-aadhaar-data-uidai-ceo-ajay-bhushanpandey/articleshow/66027536.cms

ET. (2018b). DoT Asks TELCOs to Offer Aadhaar Number, Virtual IDs for New SIMs from July 1. The Economic Times, 12 Jun. https://economictimes.indiatimes.com/industry/telecom/telecom-news/dot-askstelcos-to-offer-aadhaar-number-virtual-ids-for-new-sims-from-july1 /articleshow/64561419.cms

ET. (2018c). Uber, Ola Strike Hits Delhi and Mumbai Riders. The Economic Times, 23 Oct. https://m.economictimes.com/small-biz/startups/newsbuzz/uber-ola-strike-hits-delhiand-mumbai-riders/articleshow/66325573.cms

ET. (2018d). Clause in Aadhaar Act Badly Drafted, Says Supreme Court. The Economic Times, 11 Apr. https://economictimes.indiatimes.com/articleshow/63706883.cms

Fraser, N. (1998). From Redistribution to Recognition? Dilemmas of Justice in a 'Post-

Socialist' Age. New Left Review, 212, 68-93.

Fraser, N. (2000). Rethinking Recognition. New Left Review, 3, 107-120.

Fraser, N. (2008). Abnormal Justice. Critical Inquiry, 34(3), 393-422.

Fraser, N. (2009). Scales of Justice: Reimagining Political Space in a Globalizing World (Vol.

31). New York: Columbia University Press. 
Fraser, N. (2010). Who Counts? Dilemmas of Justice in a Post-Westphalian World. Antipode, 41, 281-297.

Gangadharan, SP. (2012). Digital inclusion and data profiling. First Monday, 17(5).

Ganjoo, S. (2018). Ex-Banker Warns About Growing Aadhaar Scams, Here's How You Can Save Yourself from Being Tricked. India Today, 25 Dec.

https://www.indiatoday.in/technology/news/story/how-to-save-yourself-from-aadhaarscams-1416910-2018-12-25

Gilman, M., \& Green, R. (2018). The Surveillance Gap: The Harms of Extreme Privacy and Data Marginalization. NYU Review of Law \& Social Change, 42, 253-307.

Gupta, A., \& Auerswald, P. (2019). The Ups and Downs of India's Digital Transformation. Harvard Business Review, 6 May. https://hbr.org/2019/05/the-ups-and-downs-of-indiasdigital-transformation

Gurumurthy, A., Chami, N., \& Bharthur, D. (2016). Democratic Accountability in The Digital Age. Brighton: Institute of Development Studies.

https://opendocs.ids.ac.uk/opendocs/bitstream/handle/123456789/13010/ResearchBrief-India-1.pdf

Heeks, R., \& Renken, J. (2018). Data justice for development: What would it mean? Information Development, 34(1), 90-102.

HT. (2018a). Ola, Uber Drivers Continue to Strike in Mumbai Over Fares. The Hindustan Times, 23 Oct. https://www.hindustantimes.com/mumbai-news/ola-uber-driverscontinue-to-strike-in-mumbai-over-fares/story-RCBy1DgkVgaPDJ55/g99HN.html

HT. (2018b). After Supreme Court Order, Confusion Over Telecom Service Providers Deleting Aadhaar Data. The Hindustan Times, 23 Oct. https://www.hindustantimes.com/indianews/after-supreme-court-order-confusion-over-telecom-service-providers-deletingaadhaar-data/story-FwTSDdiZRdBfBmpSAPNvGK.html

HT. (2018c). High Margins Vs Driver Incentives: The Ola, Uber Business Model. The Hindustan Times, 21 Mar. https://www.hindustantimes.com/business-news/highmargins-vs-driver-incentives-the-ola-uber-business-model/storygCKPwKHQcBqCcvvg3Ftjcl.html

ID4D. (2016). Identification for Development: Strategic Framework. Washington, DC: World Bank. http://pubdocs.worldbank.orgen/179901454620206363/Jan-2016-ID4D-StrategicRoadmap.pdf

IE. (2018). Submit Plan to Delink Aadhaar in 15 Days: UIDAI to Mobile Firms. Indian Express, 2 Oct. https://indianexpress.com/article/india/submit-plan-to-delink-aadhaar-in-15days-uidai-to-mobile-firms-5381885/

ILO. (2017). Employment Policy Department - Employment Working Paper No. 233. Geneva: International Labour Organisation. https://www.ilo.org/wcmsp5/groups/public/--ed emp/documents/publication/wcms 614389.pdf

Johnson, J. A. (2014). From Open Data to Information Justice. Ethics and Information Technology, 16(4), 263-274.

Kaur, N. (2018). Right to Privacy. The Leaflet, 28 May. https://theleaflet.in/specialissues/none-of-the-problems-in-the-implementation-ofnrega-can-be-fixed-by-aadhaar-on-the-contrary-aadhaar-is-the-source-of-someproblems-says-reetika-khera/

Koops, B-J., Leenes, R., Meints, M., van der Meulen, N., \& Jaquet-Chiffelle, D-O. (2009). A Typology of Identity-Related Crime: Conceptual, Technical, and Legal Issues. Information, Communication \& Society, 12(1), 1-24. 
Lister, R. (2004). A Politics of Recognition and Respect: Involving People with Experience of Poverty in Decision-Making That Affects Their Lives. In: The Politics of Inclusion and Empowerment, J. Andersen \& B. Siim (eds), 116-138. London: Palgrave Macmillan.

LiveMint. (2018). You Must Not Share Aadhaar and its OTP with Anybody. LiveMint, 27 Mar. https://www.livemint.com/Money/wwxe6Mw4V8uR0kdAld2CpN/You-must-not-shareAadhaar-and-its-OTP-with-anybody.html

Lyon, D. (2010). Liquid Surveillance: The Contribution of Zygmunt Bauman to Surveillance Studies. International Political Sociology, 4(4), 325-338.

Lyon, D. (2014). Surveillance, Snowden, and Big Data: Capacities, Consequences, Critique. Big Data \& Society, 1(2), 1-13.

Lyon, D. (2016). Surveillance, Liquidity and The Ethics of Visibility. Revue Internationale de Philosophie, 277(3), 365-379.

Madanapalle, A. (2017). How Aadhaar compares to Other Biometric National Identification Systems Around the World. First Post, 5 Apr. https://www.firstpost.com/tech/newsanalysis/how-aadhaar-compares-to-other-biometric-national-identification-systemsaround-the-world-3700543.html

Manovich, L. (2012). Trending: The Promises and the Challenges of Big Social Data. In: Debates in the Digital Humanities, M.K. Gold (ed), 460-475. Minneapolis: University of Minnesota Press.

Manzar, O. (2018). Aadhaar: Issues and Implications. New Delhi: Speaker's Research Initiative. http://sri.nic.in/workshop-aadhar-issues-and-challenges

Marwick, A. E. (2018). Privacy at the Margins | Understanding Privacy at the MarginsIntroduction. International Journal of Communication, 12, 9.

Mayer-Schoenberger, V., \& Cukier, K. (2013). The Rise of Big Data: How It's Changing the Way We Think About the World. Foreign Affairs, 92, 28.

Modgil, S. (2017). Quikr Acquires Babajob To Cement Position In Blue Collar Jobs Segment. Inc42, 21 Jun. https://inc42.com/buzz/quikr-babajob-acquisition/

MoF. (2016). Spreading Jam Across India's Economy. Economic Survey 2015-16 Vol. I. New Delhi: Ministry of Finance. https://www.indiabudget.gov.in/budget2016-2017/es201516/echapvol1-03.pdf

Nanavati, S., Thieme, M., \& Nanavati, R. (2002). Biometrics: Identity Verification in a Networked World (Vol. 20). New York: John Wiley \& Sons.

Nayar, P. K. (2015). Citizenship and Identity in the Age of Surveillance. Cambridge: Cambridge University Press.

NCS. (n.d.). National Career Service Portal: Local Services. New Delhi: National Career Services, Government of India.

https://www.ncs.gov.in/User\%20Manuals/Local\%20Service\%20Provider\%203.0.pdf

OECD. (2014). India Policy Brief. Paris: OECD. https://www.oecd.org/policy-briefs/IndiaImproving-Quality-of-Education-and-Skills-Development.pdf

RBI. (2019a). Payment and Settlement Systems in India: Vision - 2019-2021. Mumbai: Reserve Bank of India. https://www.rbi.org.in/Scripts/PublicationVisionDocuments.aspx?ld=921

RBI. (2019b). Public Credit Registry and Goods and Services Tax Network: Giant Strides to Democratise and Formalise Credit in India. Mumbai: Reserve Bank of India. https://rbi.org.in/SCRIPTs/BS ViewBulletin.aspx?ld=17758 
Roth, S., \& Luczak-Roesch, M. (2018). Deconstructing the Data Life-Cycle in Digital Humanitarianism. Information, Communication \& Society, advance online publication, 117.

Sarkar, S. (2014). The Unique Identity (UID) Project, Biometrics and Re-Imagining Governance In India. Oxford Development Studies, 42(4), 516-533.

Swearingen, S. (2018). The Role of Biometric Authentication in The Pursuit of Global Financial Inclusion. Biometric Update, 26 Oct.

https://www.biometricupdate.com/201810/the-role-of-biometric-authentication-in-thepursuit-of-global-financial-inclusion

Taylor, C. (1997). The Politics of Recognition. New Contexts of Canadian Criticism, 98, 25-73.

Taylor, L. (2017). What is Data Justice? The Case for Connecting Digital Rights and Freedoms Globally. Big Data \& Society, 4(2), 1-14.

Taylor, L., \& Broeders, D. (2015). In the Name of Development: Power, Profit and the Datafication of the Global South. Geoforum, 64, 229-237.

The Hindu. (2019). Taxi driver's death: probe on. The Hindu, 2 Feb. https://www.thehindu.com/news/cities/chennai/taxi-drivers-death-probeon/article26156784.ece

The Wire. (2017). It's Time to Disentangle the Complex Aadhaar Debate. The Wire. https://thewire.in/government/aadhar-privacy-analysis

The Wire. (2018). Nearly $81 \%$ of the Employed in India Are in the Informal Sector: ILO. The Wire, $20 \mathrm{Apr}$. https://thewire.in/labour/nearly-81-of-the-employed-in-india-are-in-theinformal-sector-ilo

Thozhilalar Koodam. (2019). Who Killed Rajesh? - Taxi Driver's Death Raises Important Concerns on Working Conditions and Police Harassment. Thozhilalar Koodam, 8 Feb. https://tnlabour.in/news/7959

TNGov. (2014). Employment - Chapter XI. Tamil Nadu - An Economic Appraisal 2011-12 to 2013-14. Chennai: Department of Evaluation and Applied Research, Government of Tamil Nadu. http://www.tn.gov.in/dear/Employment.pdf

TOI. (2017). Cab driver kidnapped and murdered. Times of India, 4 Aug. http://timesofindia.indiatimes.com/articleshow/59905530.cms?utm source=contentofi nterest\&utm medium=text\&utm campaign=cppst

Transparent Chennai. (2012). Fight for Fair Fare: A Study of Autorickshaws in Chennai. Chennai: Transparent Chennai. http://www.transparentchennai.com/wpcontent/uploads/downloads/2013/07/Fight\%20for\%20a\%20Fair\%20Fare.pdf

Traxcn. (2016). Research on Transport Tech Startup Valuations. Bengaluru: Traxcn. https://tracxnblog.s3.amazonaws.com/wp-content/uploads/2016/03/Tracxn-StartupResearch-Transport-Tech-India-Landscape-March-2016.pdf

UIDAI. (2014a). Aadhaar Technology and Architecture: Principles, Design, Best Practices and Key Lessons. New Delhi: Unique Identification Authority of India. https://uidai.gov.in/images/AadhaarTechnologyArchitecture March2014.pdf UIDAI. (2014b). Aadhaar Technology Strategy: Ecosystem, Technology and Governance. New Delhi: Unique Identification Authority of India. https://uidai.gov.in/images/AadhaarTechnologyStrategy March2014.pdf UIDAI. (2018). Aadhaar: Frequently Asked Questions. New Delhi: Unique Identification Authority of India. https://uidai.gov.in/images/recently asked ques 13012018.pdf UIDAI. (n.d.). Features of Aadhaar. New Delhi: Unique Identification Authority of India. https://uidai.gov.in/my-aadhaar/about-your-aadhaar/features-of-aadhaar.html 
Unni, J. (2018). Formalization of the Informal Economy: Perspectives of Capital and Labour. The Indian Journal of Labour Economics, 61(1), 87-103.

Van Dijck, J. (2014). Datafication, Dataism and Dataveillance: Big Data Between Scientific Paradigm and Ideology. Surveillance \& Society, 12(2), 197-208.

Varma, P. (2014). Architecting World's Largest Biometric Identity System - Aadhaar Experience. Strata + Hadoop World, New York, 15-17 Oct. https://cdn.oreillystatic.com/en/assets/1/event/119/Architecting\%20World s\%20Large st\%20Biometric\%20Identity\%20System\%20\%20Aadhaar\%20Experience\%20Presentation.pdf

Viswanathan, V. (2019). How to Integrate Aadhaar Auth API? Bengaluru: Veri5digital. https://veri5digital.com/veri5-blog/how-to-integrate-aadhaar-auth-api/

Whitley, EA., and Hosein, G. (2010) Global Identity Policies and Technology: Do We Understand The Question? Global Policy, 1(2), 209-215.

Zuboff, S. (2015). Big Other: Surveillance Capitalism and The Prospects of An Information Civilization. Journal of Information Technology, 30(1), 75-89.

\section{Acknowledgements}

The "Urban Data, Inequality and Justice in the Global South" case studies form part of a Senior Research Fellowship funded by the University of Manchester's Sustainable Consumption Institute with additional financial support from Canada's International Development Research Centre. The author would like to thank the School of Management, Royal Holloway, University of London and particularly Dr Yingqin Zheng and Dr Philip Wu for their support in developing this paper as part of his $\mathrm{PhD}$ research project.

\section{About the Author}

Shyam Krishna is a doctoral candidate in the School of Management, Royal Holloway, University of London. 


\title{
Case 7: Data Gathering and Justice in the Urban Informal Sector Views from the Frontline
}

\author{
Terry Gibson \\ Inventing-futures.org
}

\begin{abstract}
This case considers the challenges faced by civil society organisations (CSOs) in gathering and applying data in urban informal contexts. Given that one billion people are estimated to live in such contexts globally and that the number continues to grow it is clearly important to build understanding of these localities; understanding which CSOs have found difficult to acquire. The specific case is the development of participatory data gathering and knowledge creation programmes - 'Views from the Frontline' (VFL), 'Action at the Frontline' (AFL) and 'Frontline' - by the Global Network for Disaster Reduction and application of that knowledge to influence practice in informal urban contexts.

It challenges tactical approaches which assume that knowledge will necessarily lead to effective action, highlighting the barriers faced in the VFL, AFL and Frontline programmes. It therefore investigates structural, distributive and instrumental aspects of data justice, highlighting the necessity for a nuanced and strategic understanding which takes account of power structures, if knowledge is to support effective social transformation. The discussion and findings contribute to the developing understanding of data justice and apply this specifically to the activity of CSOs in attempting to engage in informal urban contexts. They highlight the role of 'small data' gathering and application as having both process benefits through the engagement of participants, and impact benefits through increased visibility and voice for informal urban populations.
\end{abstract}




\section{A. Introduction}

The focus of this study is the challenges for civil society organisations (CSOs) - both large international and small local - in acquiring data and acting in urban informal contexts. David Satterthwaite sets the scene:

"Consider the difficulties facing any international agency wanting to improve conditions in informal settlements. There is usually no data on who lives there and on the deficiencies in provision for water, sanitation, health care, schools, emergency services and much else besides. Most residents have no title to the land they occupy and their right to be there is often contested. Official household surveys do not provide data on informal settlements; they only collect data for a national sample. Census data, if collected in informal settlements, is not available at ward, sub-ward or street level so does not fill the information gap. There are usually no maps and often no street names. Professionals may worry about their safety - or in large informal settlements about getting lost" (Satterthwaite, 2018)

Oxfam GB recognised these challenges in their 'Getting Ready for The Century Of The City: 2013-2016 Urban Framework Report' which noted a 'bias against urban' within the organisation. It acknowledged limited investment in urban programming:

"urbanisation of poverty and suffering is a missing story within Oxfam. It is very optimistically estimated that $10 \%$ of Oxfam GB's non-emergency funds are directed towards urban programmes" (Oxfam, 2012, p1)

A workshop of 40 senior international non-governmental organisation (INGO) representatives noted:

"Many INGOs, more comfortable in rural settings, have not begun to adapt their poverty reduction strategies to the rural-urban demographic shift underway in developing countries, much less integrate a response to these new developments. This is another leading edge for the work ahead" (Moser et al, 2007, p20)

Several initiatives have addressed the need for data from urban informal contexts. For example Desinventar gathers risk knowledge from mixed sources including newspaper and other media reports published locally (Desinventar, undated). Slum/Shack Dwellers International (SDI) operates in over 7000 informal slum areas in 200 cities, using local enumerators to gather data populating its 'Know Your City' database (SDI, undated).

This paper's study focuses on the 'Views from the Frontline' (VFL). 'Action at the Frontline' (AFL) and 'Frontline' data gathering programmes conducted by the Global Network for Disaster Reduction (GNDR), which also engaged local enumerators, gathering data from local respondents (Views from the Frontline, 2019). GNDR emerged in 2007 as a network of local level civil society organisations collaborating on data gathering and campaigning in relation to disaster risk reduction. Its data gathering programmes, established in 2009, recorded perceptions of risk at community level across communities in 48 low and lowmiddle income countries; with the ability to disaggregate data, for example as here to focus on urban informal contexts. As discussed within the paper, during iterations of the programme, data gathering shaped to external frameworks and priorities gave way to data gathering framed by respondents' own priorities, which enhanced its ability to develop 
understanding of dynamic informal urban contexts by reducing the filtering of presuppositions about such localities.

The programmes assume that acquiring knowledge of these formerly opaque contexts will provide a basis for appropriate action, directly by civil society organisations and indirectly through advocacy addressed at other relevant institutions. The case demonstrates instrumental benefits of the programmes through a dual impact at local, wider subnational and national levels and also reflects critically on limitations of tactical approaches based on the maxim 'sunshine is the best disinfectant' (Fox, 2015). It foregrounds questions of power and its ability to bar or refashion knowledge. In terms of the data justice model this case study considers ways that gathering and application of data in urban informal contexts may be undertaken justly or unjustly in relation to those contributing the data. In particular the focus is on structural (do interests and power in wider society support fair outcomes) and distributive (who gets what) data justice (Heeks and Shekhar, 2019). Its findings also discover instrumental data justice effects - in other words fair use of data, resulting in positive impacts for those who contribute data - as a notable aspect of these programmes is the initially undervalued role of small data looped back at local level, which was seen to lead to enhanced social agency in urban contexts such as Delhi, India; Limbe City, Cameroon and Kathmandu, Nepal, whereas the big data aspect directed at institutional contexts proved more problematic.

The paper proceeds through the background, which considers earlier means of applying data in social development and outlines a framework for considering the effects of different forms of knowledge and power on such applications. It continues with discussion of the qualitative methods used to gather and analyse the data forming the case study, and explores findings from this data, considering the effects of the VFL, AFL and Frontline methods at local and other scales. The discussion and conclusions explore the contribution of this case study to understanding the role of data gathering methods in informing CSO roles in informal urban contexts and consider these through a data justice lens.

\section{B. Background}

This case focuses on the data justice implications of gathering data locally to support advocacy for social development, focusing on urban informal contexts. These are areas of cities fed by inward economic migration and other forms of internal displacement and characterised by lack of registration, lack of rights to accommodation, informal economic activity, rapid unmanaged growth, poverty and consequent vulnerability. These characteristics mean data and actionable knowledge are difficult to secure. Yet, at present, we understand relatively little about methods for CSOs to acquire actionable data concerning urban informal contexts. There has also been limited analysis of data gathering methods in such contexts and limited work on considering such actions through the lens of data justice, asking whether data which is gathered is used sensitively and ethically to the benefit of its contributors. This case study seeks to address some of these lacunae.

Data, in the broadest sense, has been gathered locally to support social development in many ways, predating digital and social media technologies. Much of this work was 
considered under the umbrella of 'Communications for Development' where media included print, audio, radio, photography, film and video. Taking as an example the application of film and video, groundbreaking work was conducted between 1968 and 1970 by Donald Snowden and colleagues with the Fogo Islanders of Newfoundland (becoming known as the 'Fogo Process') to document and share experiences of individuals' lives and bring this material before government to advocate for change and support (Quarry and Ramirez, 2009, p72-78). What drew attention to the project was the intention to bring, with relative transparency, local knowledge to other scales.

Many other projects drew on this initiative, capitalising on increasingly accessible technology so that whereas Snowden's project used $16 \mathrm{~mm}$ film with associated costs and complexities of processing, editing etc, a participative project undertaken by Braden (2003) on behalf of ActionAid using mini digital cameras and laptops was able to bring the medium closer to the participants. The process was similar to Snowden's in that the local conditions of villagers in rural Malawi were documented and then presented regionally to political leaders. As with the Fogo process this work raised questions concerning the participation of those contributing knowledge. Braden (2003, p36) reflected that:

"Methodologies of participation (RRA, $\left.P R A, P L A^{47}\right)$ are routinely used but the outputs are seldom debated and analysed by either participating communities or facilitating development workers. Rather they play a token role in the credo of participatory development, or, at best they offer fieldworkers some background information, and, in the case of ranking, some way of offering a semblance of democratic choice and decision-making."

A wide range of participatory methods of the types referred to by Braden are deployed by CSOs at local level (see for example the collection of community risk assessment methodologies (Provention, undated)). Typically results are held locally and not aggregated. Braden's concern about the application of data gathered in this way echoed an increasing groundswell of concern about the nature of participation in development, highlighting the tendency for supposed participation to become a performance to validate pre-programmed interventions. The conference and associated collection 'Participation: the New Tyranny?' (Cooke and Kothari, 2001) explored this problem in some detail, predating questions of data justice in relation to handling of digital data gathered from local participants.

A large scale approach to participatory data collection aggregated into a global report foregrounded further questions about the acquisition and application of local level data. 'Voices of the Poor' (Narayan, 2000) was a large scale study which looked through the local end of the telescope, aggregating 78 participatory assessments from 47 countries to combine a total of 40,000 voices, analysed qualitatively to inform policy via the platform of the World Development Report 2000/2001. Two research studies were conducted on this project, McGee and Brock (2001) consider the Voices of the Poor case, comparing it with an Oxfam initiative, and finding in both that policy is formulated on the basis of the agency of policy actors, only peripherally informed by the technical data gathered. Brock et al (2001) move on to consider power, knowledge and the nature of political spaces in the framing of

\footnotetext{
${ }^{47}$ Three widely used appraisal methods: RRA is rapid rural appraisal, PRA is participatory rural appraisal, and PLA is participatory learning and action.
} 
poverty policy. The study focuses in on the nature of political spaces in which dominant narratives are either reinforced or disputed, drawing on earlier work by Gaventa to suggest that 'invited spaces' opened by powerful institutions are able to reinforce dominant narratives, reflecting McGee and Brock's finding that political rather than technical perspectives shape poverty reduction policy. They also identify more 'autonomous spaces' created from below where experiential narratives such as those gathered participatively may be heard and may shape policy and action. The overall message is that simply gathering and analysing data is not sufficient to influence and shape policy. Such data can only achieve influence where they run in synchrony with the dynamics of power or, if not, where those dynamics of power are addressed.

Analysis of the effects of participative processes and their application in gathering and aggregating local data has highlighted similar issues to those emerging from more recent analyses of data gathering initiatives drawing on the data justice framework; for example in Heeks and Shekhar (2019), which discussed four pro-equity data initiatives gathering data from marginalised urban contexts. Issues include barriers to 'instrumental data justice', 'distributive data justice' and 'structural data justice' ${ }^{48}$ resulting from the exercise of power in political spaces. This therefore sets the scene for consideration of the case of 'Views from the Frontline' and the other GNDR programmes that were intended to gather and aggregate local data in order to influence national and international policy. The case will demonstrate a range of challenges to CSOs in achieving policy influence at different scales. It highlights that tactical approaches reflected in the 'sunshine is the best disinfectant' maxim are insufficient. The case study aims to investigate a gap in understanding of the role of data in informing policy and action in urban informal contexts, considering more strategic approaches to its application and in doing so identifying the role of 'small data'.

The framework used as a basis for analysis is a power/knowledge matrix (Gibson, 2019) (Figure 1), which draws on Gaventa's idea of political spaces articulated in Brock et al (2001) and in his 'power cube' (Gaventa, 2005). This forms the basis of the 'power' axis of the cube:

- Closed spaces are easily understood as functioning behind closed doors, where those holding political power are able to make decisions without reference to other stakeholders.

- Invited spaces are those in which a range of stakeholders are able to participate. However in such places the powerful host still has control of who speaks and who is silent, what weight is put on different contributions and what conclusions are drawn from the process, so the power of the invited participants is often extremely limited.

- Created spaces are those not constrained or controlled by powerful actors but established by a range of stakeholders through drawing together partnerships and collaborations, therefore allowing them to make significant contributions and to shape outcomes.

The knowledge axis reflects findings from McGee and Brock's (2001) study and investigation of the nature and relevance of situated, scientific and political knowledge (Gibson, 2019).

\footnotetext{
${ }^{48}$ Defined, respectively, as "fairness in the results of data being used" (instrumental), "the (in)equality of datarelated outcomes" (distributive) and "the degree to which the interests and power in wider society support fair outcomes" of handling, use and impacts of data (structural) (Heeks and Shekhar, 2019, p995).
} 
- Situated/Local knowledge is that which is held by individuals and socially, based on experience. Such knowledge is contextual and specific, and often not formalised but shared verbally.

- Scientific/Technical knowledge is the result of formal knowledge production methods in educational, scientific and technical institutions. It is often regarded as having greater weight than situated/local knowledge.

- Political/Institutional knowledge is actionable knowledge often informing policy and action which results from the political interpretation of scientific/technical knowledge and to a much lesser extent situated/local knowledge. In many contexts this has greater weight and influence than other forms of knowledge.

The matrix identifies two extremes:

- At top left, knowledge is defined institutionally, through interpretation of scientific/technical and situated/local knowledge in line with institutional priorities, and this is applied in closed spaces to impose preferred political priorities. Local actors therefore make very limited contributions of knowledge and are shut out of decision-making processes.

- At bottom right, socially created and applied knowledge is that which is derived primarily from situated/local sources and which is applied in created spaces in which a range of stakeholders have power and influence. They are therefore able to bring such knowledge to bear to shape outcomes in line with their concerns and priorities. These two extremes contrast the institutional imposition of power and manipulation of knowledge with social creation and application of knowledge. The shading of the matrix implies a spectrum of applications of knowledge and power in different contexts.

The framework is employed to investigate barriers within the CSO community to achieving the different forms of data justice, particularly in the poorly understood arena of informal urban communities. 


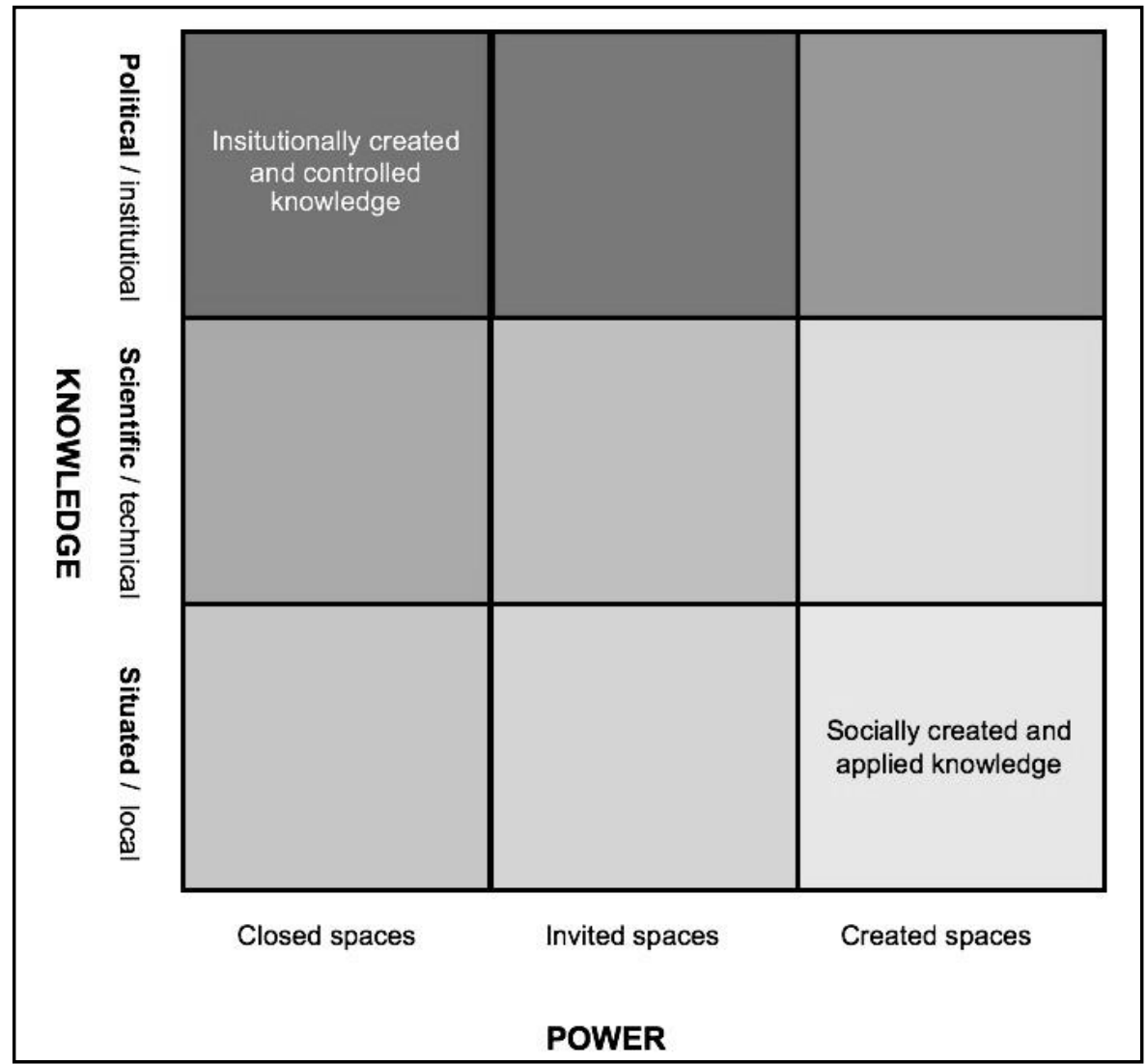

Figure 1: Power/knowledge matrix

The matrix identifies different kinds of space where knowledge and action interface, with differing power relations. Concerning the power axis invited spaces are more seductive to social actors than are closed, as they offer the appearance of participation, though as the framework highlights this appearance is typically illusory as the powerful hosts shape involvement and outcomes. Gaventa suggests that engaging with formal politics by invitation into spaces controlled by institutions does not confer power but co-opts the participants within the existing system. He therefore suggests that power relationships are only disrupted in 'created spaces' which step outside current structures and confer agency on participants. The knowledge axis acknowledges the privileging of political/institutional knowledge over situated/local knowledge which, though undervalued, is critical given the increasing recognition - for example in the capabilities approach (Sen, 1999) - that development depends on context-specific and multi-dimensional understanding.

The dimensions in the power/knowledge matrix can be related to those highlighted by Heeks and Renken (2018) in their discussion of structural data justice (Figure 2):

\begin{tabular}{|l|l|l|}
\hline Framework & Knowledge/Data & Spaces/Structures \\
\hline Power/Knowledge Matrix & Political $\Leftrightarrow$ Situated & Closed $\Leftrightarrow$ Created \\
\hline Structural Data Justice & Big data $\Leftrightarrow$ Small data & Structure $\Leftrightarrow$ Agency \\
\hline
\end{tabular}

Figure 2: Comparing power/knowledge matrix and structural data justice

Attempts to affect structural and distributive aspects of data justice are seen, according to this schema, as requiring shifts in the matrix between the upper left and lower right zones, 
which signify transition from large institutionally controlled datasets and analyses controlled by those power structures to 'small data' 49 accessed locally and supporting agency (agency = power to, structure = power over) (see Figure 3).

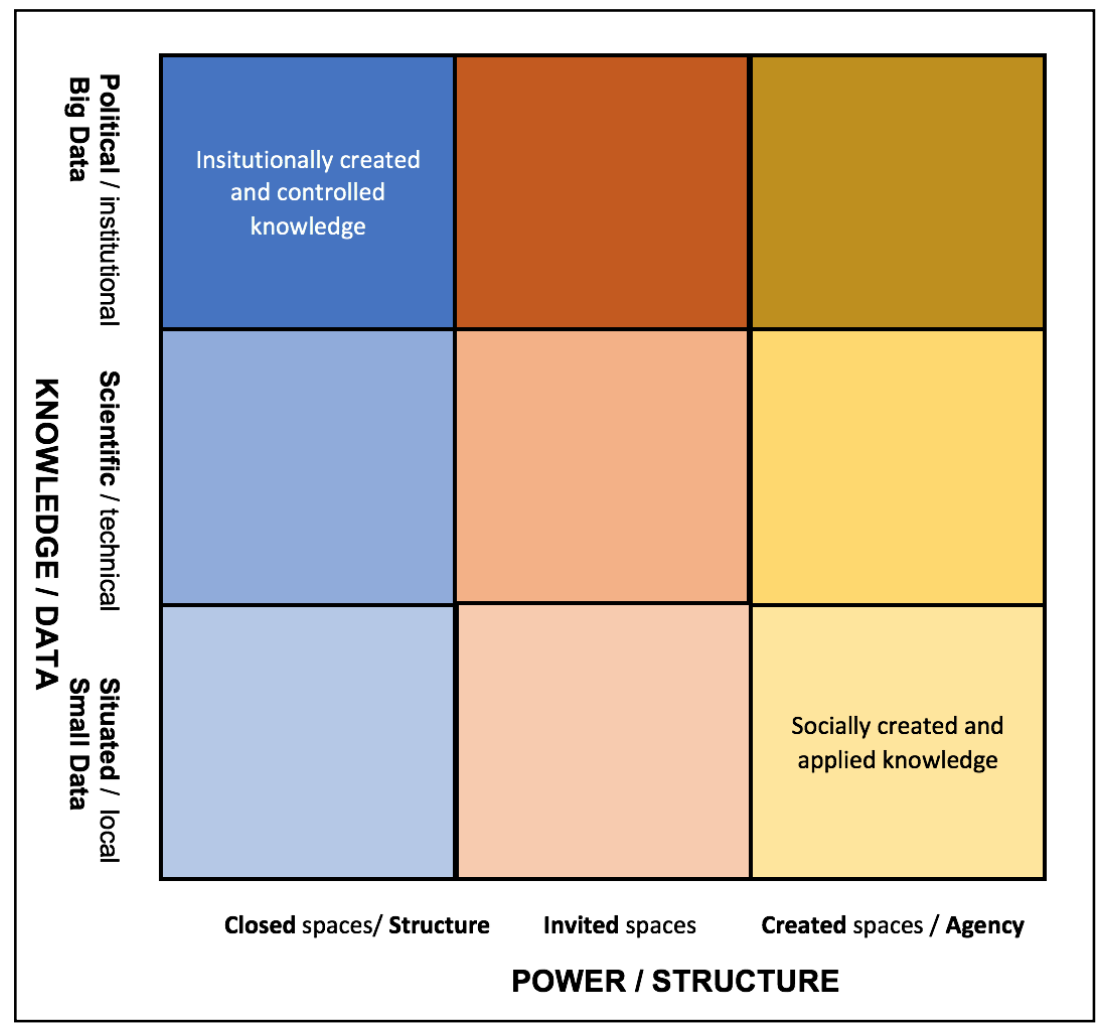

Figure 3: Power/knowledge matrix including structural data justice dimensions

\section{C. Methods}

The method adopted in analysing the case is action research, from a participant observer perspective. The author was a co-director of GNDR and the project leader from 2008-2016 (with continuing ad hoc involvements) on development and deployment of the three programmes mentioned earlier and considered in this case study:

- 'Views from the Frontline' used a questionnaire method to gather local perceptions of progress in disaster risk reduction. It was initially conducted three times: in 2009, 2011 and 2013. Another VFL was then undertaken in 2019.

- 'Action at the Frontline' added a local level participatory process for communities to interpret data, identify and undertake actions, and was undertaken between 2011 and 2015.

- 'Frontline' was a further development which strengthened local level knowledge gathering and application of data for local action; from 2013 to 2017.

The author conducted doctoral research 2008-2011 (Gibson, 2012) on the network and its programmes concurrently with his tenure, creating a space for formalised critical reflection

\footnotetext{
${ }^{49}$ Small data is used here to describe datasets gathered locally which are unlikely to be sufficient in scale for quantitative statistical analysis but are sufficient in either quantitative or qualitative terms to be drivers for local usage through dialogue and negotiation.
} 
on action. His approach is rooted in the thinking of Freire, whose 'participative action research' was based on social participation in action and reflection:

". . reflection - true reflection - leads to action. On the other hand, when the situation calls for action, that action will constitute an authentic praxis only if its consequences become the object of critical reflection." (Freire, 1970, p48)

Related approaches include 'action science' (Argyris and Schon, 1989) and 'co-operative inquiry' (Heron, 1996). All have at their heart close engagement with the action scene allied to individual and corporate critical reflection on action. Therefore they are likely to lead to informed adaptation of the action, following the principle of the Kolb (1984) cycle of experiential learning, as well as generating research outputs. This was the case as will be seen in the evolution of the programmes under consideration.

GNDR, established in 2007, had a very small secretariat of two staff, including the author. Lacking accumulated bureaucracy it had considerable flexibility to perform real collaborative experiments in pursuing its goals. The research interests of the author were understood by the network secretariat and membership, creating opportunities for 'member check' (Yin, 2003) on provisional conclusions reached by the researcher. Management of the role therefore applied an integrated 'reflective practitioner' approach (Schon, 1983), while collaboration with other members of GNDR reflected the principle of Heron's co-operative enquiry (Heron, 1996).

The case draws on six types of data gathered through the action research:

1. Background and context: archive and historical sources primarily from the network and from the UN agency responsible for implementing the International Strategy for Disaster Reduction (UNISDR, now the UN office for Disaster Risk Reduction: UNDRR).

2. Qualitative data on network interactions: email correspondence; online discussions; surveys and questionnaires; GNDR reports and presentations.

3. Network praxis: data from the three VFLs conducted in 2009, 2011 and 2013, the AFLs from 2011-2015 and Frontline 2013-2017; learning reviews undertaken on VFL in 2009 and 2011; records of GNDR global workshops held in 2009 and 2013.

4. Observational data and reflection: personal records and narrative; research doctorate and subsequent research papers.

5. Structured collaboration: through co-production and critical discussion with a group of small NGO leaders, creation of case studies of local knowledge gathering and action, compiled in a journal special issue (Gibson and Norton, 2019) and a dedicated website (www.drr2dev.com).

6. Fieldwork: in the Philippines, meeting with CSO representatives and CSO networks (2019) who had been involved with the GNDR programmes, in order to provide insights and updates on the Philippines material considered in this case study. 


\section{D. Findings}

In this section, several phases of implementation of VFL, AFL and Frontline are examined and related to the power/knowledge matrix as a means of investigating the contribution of the case to understanding the application of data by CSOs in urban informal contexts through a data justice lens. The initial implementation of the VFL programme is described, showing the challenges in applying data for desired impact and in line with local expectations which led to the further development of AFL and Frontline. Applications of Frontline in three specific urban informal contexts are discussed, along with more general outcomes locally, nationally and internationally. Further structural challenges are considered, leading to another revision of the programme in 2019.

\section{D1. Implementation and Development of the 'Views from the Frontline' Programme}

GNDR was established with a goal of influencing disaster risk reduction frameworks established by UNISDR. The Hyogo Framework for Action (HFA) spanned 2005-2015, followed by the Sendai Framework for Action (SFA). GNDR had a stated intention to roll out a local level assessment of progress focussed on implementation of the HFA. This bottom up assessment would complement the top down attempt by the UN to monitor implementation of the HFA (Gibson and Wisner, 2016). GNDR's method employed a questionnaire with approximately 40 questions related to the five priorities of the HFA, with responses scored on a five point Likert scale.

Versions were created for community, CSO and local government respondents. GNDR member organisations organised, mobilised and conducted the surveys in 2009 based on training by the network. 5290 responses were gathered from the respondent groups and a further 2035 from women's and children's groups. 48 countries in Africa, Asia and the Americas were covered. Data were analysed to produce a range of summary charts which were included in a report presented to the UNISDR biennial conference monitoring progress of the framework. The purpose of doing so was advocacy, so the focus was on key messages drawn from the data. 


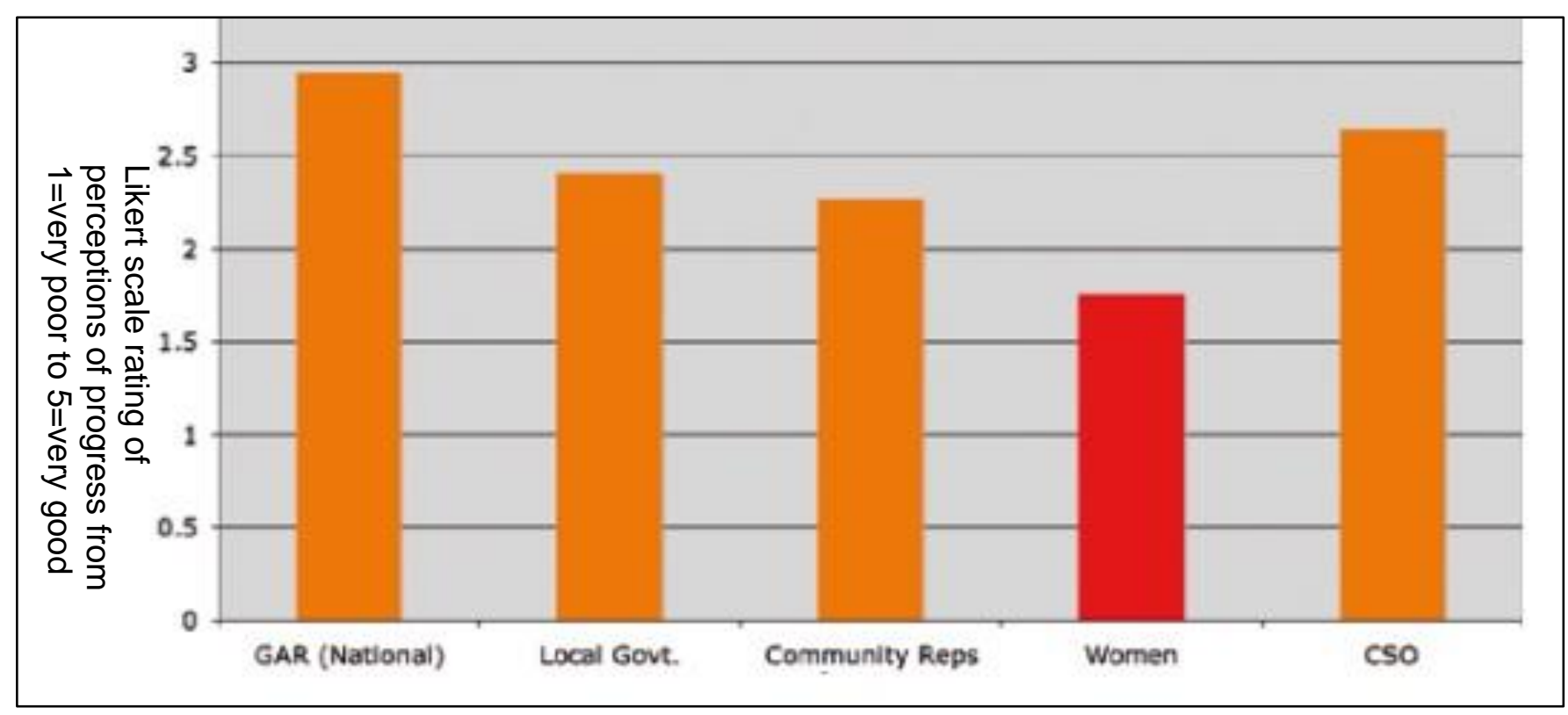

Figure 4: A breakdown of different responses to HFA progress showing 'fading-out' of perceptions of progress from national level to communities 'at-risk' 50

For example, Figure 4 was used to support the contention that experience of the impact of the disaster reduction framework was greatly reduced at local level compared with national level reporting. It also specifically emphasised the particularly negative perception of women, highlighted in red. The report attracted a lot of attention and coverage, effectively presenting a body of data to underpin the key messages. The then head of UNISDR said of it:

"Thanks to that report there is now a face, a recognition and an understanding of what you represent. Not because you are NGOs or civil society but through what you have done. The work you have done and you've put that forward. My feeling is that you have done something quite remarkable through that work." (Margareta Wahlstrom: UN Assistant Secretary for Disaster Risk Reduction, speaking at Global Workshop 27 January 2010. In Gibson, 2012, p157)

However it became clear that the messages and language put forward by the network, including the terms 'Views from the Frontline' and 'Local Action' were rapidly appropriated by UNISDR, who in the preparatory material for the following progress conference said:

"The Global Assessment Report 2011 recognizes local perspectives and incorporates "Views from the Frontline" from civil society organizations. But, to what extent do our interventions lead to improved conditions in the places where the vulnerable live and work? Are all our programs and policies targeted enough at supporting local action and building on local assets? How can we accelerate finance and increase investment in local action? What do we need to do to make this happen?" (Extract from second announcement of UN Global Platform for Disaster Risk Reduction, 17 November 2010. UNISDR, 2011. In Gibson, 2012, p177. Emphasis added.)

\footnotetext{
${ }^{50} \mathrm{GAR}$ is the Global Assessment Report of progress in implementation of the UN Disaster Risk Reduction frameworks, which is published biennially. The assessment of progress in the chart associated with GAR is based on self-assessment by responsible ministries within national governments.
} 
This appropriation might have been regarded a success if it led to demonstrable change in policy and practice. However, the chair's statement at the conclusion of the 2011 conference did not indicate any such change in policy; the messages appeared, rather, to have been absorbed within the established policy formulations.

Views from the Frontline was conducted using a similar format and methodology in 2011, with increased participation of 20,000 respondents in 69 countries, and in 2013, with 21,500 respondents in 57 countries. However learning reviews conducted with participating member organisations revealed disquiet about the value of the process (GNDR, 2012). The term "extractive" was used, and one organisation asked how the circle of returning the information for use by the people who provided it (what would later be seen as a 'small data' approach) could be completed. These responses highlighted a practical concern about the direct usefulness of the exercise to the respondents. Responses to the VFL surveys were markedly homogeneous leading to the suggestion that respondents did not have access to information to assess the questions being posed. It was recognised in discussions within GNDR that the method elicited local views on the HFA framework, but did not allow local articulation of experience and knowledge. A local level respondent said of similar surveys that they asked "what do you think about our framework?" rather than "what do you think?". This and other feedback prompted an assessment and redesign of the programme, based on local participative risk mapping, with the intention of emphasising local knowledge and creating outputs which would also have local relevance.

The Views from the Frontline programme had aimed to engage in closed and invited spaces such as UN conferences, offering in relative terms 'big' data related to the institutional knowledge contained in the UN frameworks, created through political negotiation by signatory countries. It is thus located in the top left of the power/knowledge matrix (see Figure 5). 


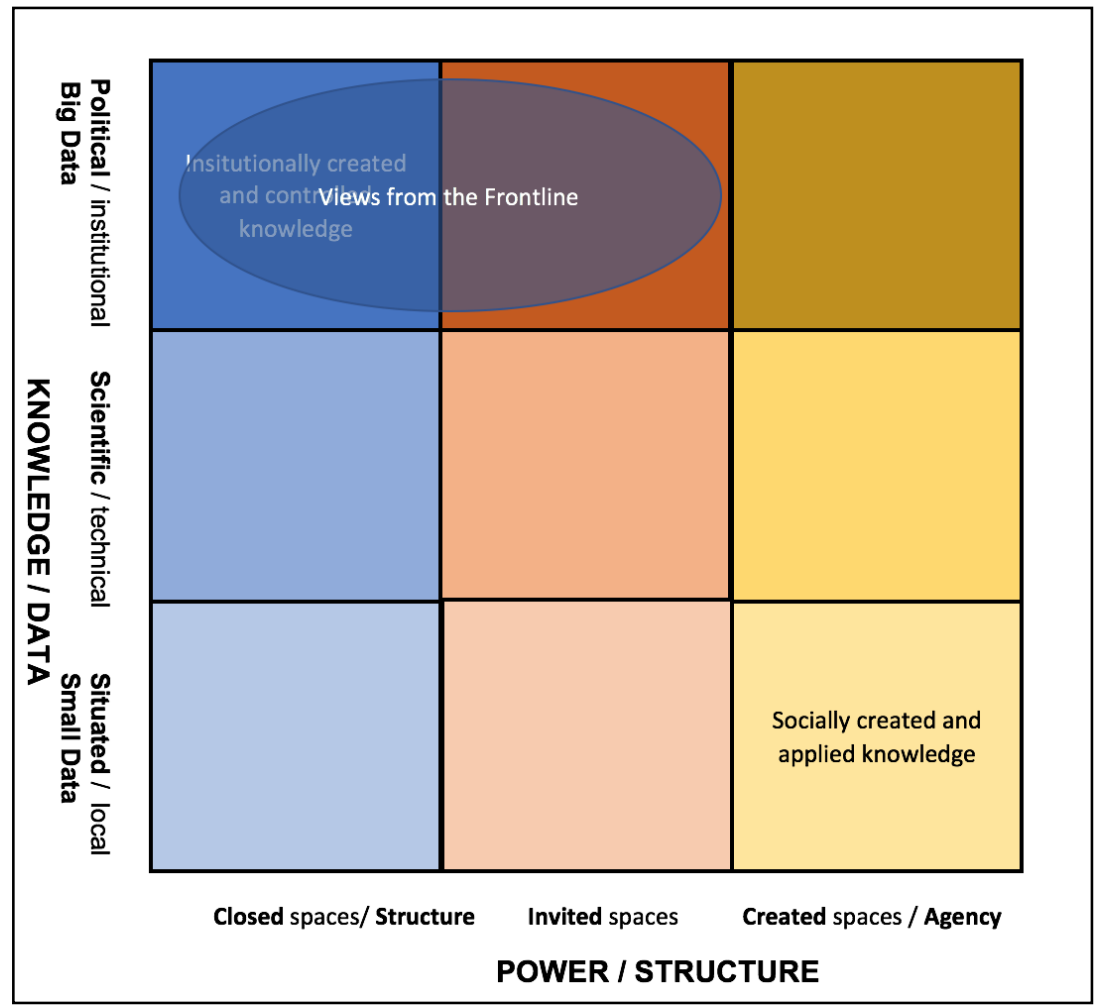

Figure 5: Views from the Frontline positioning in power/knowledge matrix

As with the assessment of uptake of knowledge from the 'Voices of the Poor' survey (McGee and Brock, 2001), political priorities were overlaid on the findings and as a consequence their influence on policy and implementation was slight. Structural data (in)justice was at play here as the system within which GNDR attempted to secure influence was structurally unreceptive to challenges to its policy orthodoxy, and was able to utilise aspects of its assemblage such a control of spaces for discourse and control of language to maintain stasis. Alongside the structural challenge there was an internal challenge as the membership questioned the distributive and instrumental data justice of the programme, complaining that it was extractive and did not have direct local benefits.

External and internal challenges to the programme prompted assessment and redesign. The secretariat suggested this should be based on local participative risk mapping, an activity with a long pedigree in supporting community participation and action. It would have the intention of emphasising local knowledge and creating outputs which would also have local relevance.

\section{D2. Development of the Frontline Programme}

The format, titled 'Frontline', which emerged from development work by the network secretariat and initial piloting of the programme in Peru in 2013 was conceptually related to local level participatory assessments discussed earlier. It differed in three ways. Firstly it was highly simplified, reducing the scale of training of the enumerators to enable it to be widely deployed. Secondly the consultation, based on a structured conversation leading to the respondent nominating their highest priority threats, consequences, actions and barriers, 
allowed free text responses so that respondents could express their own insights rather than responding to a questionnaire. Qualitative analysis coded the free text responses in order to aggregate them. Thirdly the prioritisation process allowed data to be aggregated at local level (for local application) and also at subnational, national and international level. These design aspects met the requirements identified in learning reviews for a process which allowed local knowledge to be gathered, allowed that knowledge to be used locally, but which also provided a larger-scale analysis to be used in national and international advocacy.

Figure 6, below, contrasts the epistemic focus of the Frontline programme with that of Views from the Frontline, showing that Views from the Frontline (blue) is driven by an external framing, whereas Frontline (orange) is driven by local perceptions and knowledge.

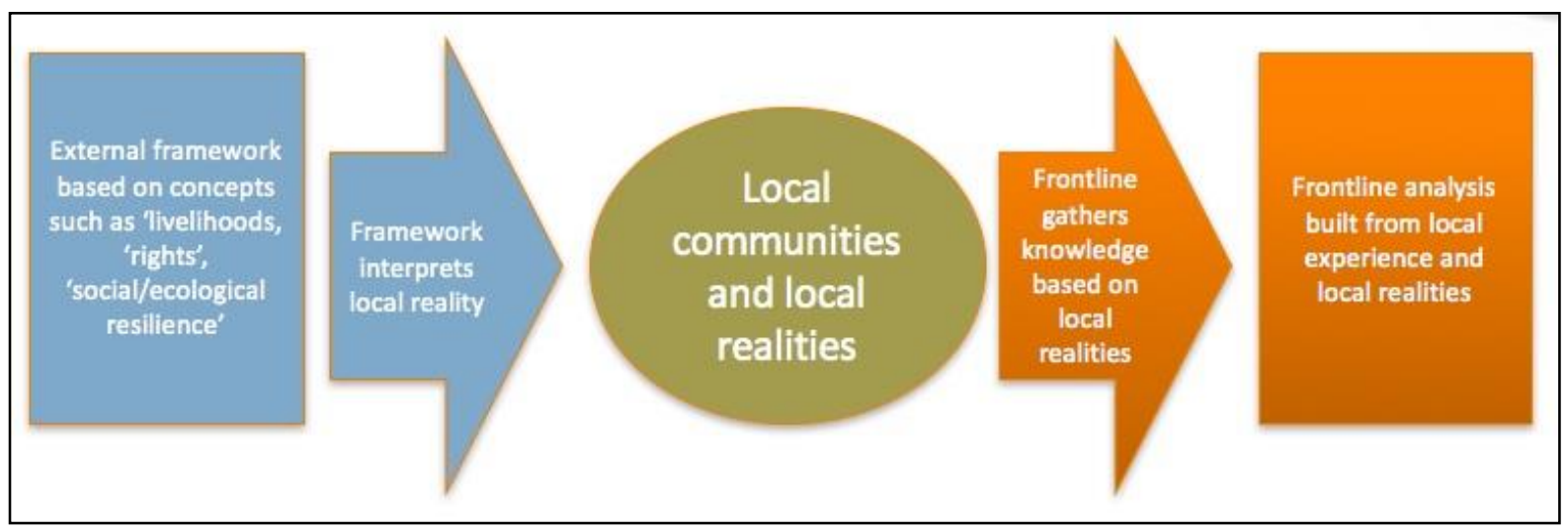

Figure 6: Contrasting the epistemic focus of 'Views from the Frontline' and 'Frontline'

As a further effort to ensure local relevance of the Frontline programme, a companion programme, 'Action at the Frontline' provided a framework for community consultations, action planning and implementation based on the locally analysed Frontline data. At other scales the data was analysed and then visualised using a 'Tableau' interactive online visualisation platform (Figure 7) which allowed the data to be sliced and diced by locality, risk zones, and by particular threats, consequences, actions and barriers ${ }^{51}$.

\footnotetext{
${ }^{51}$ The Frontline tableau interactive data platform can be accessed at https://gndr.org/tableau.
} 


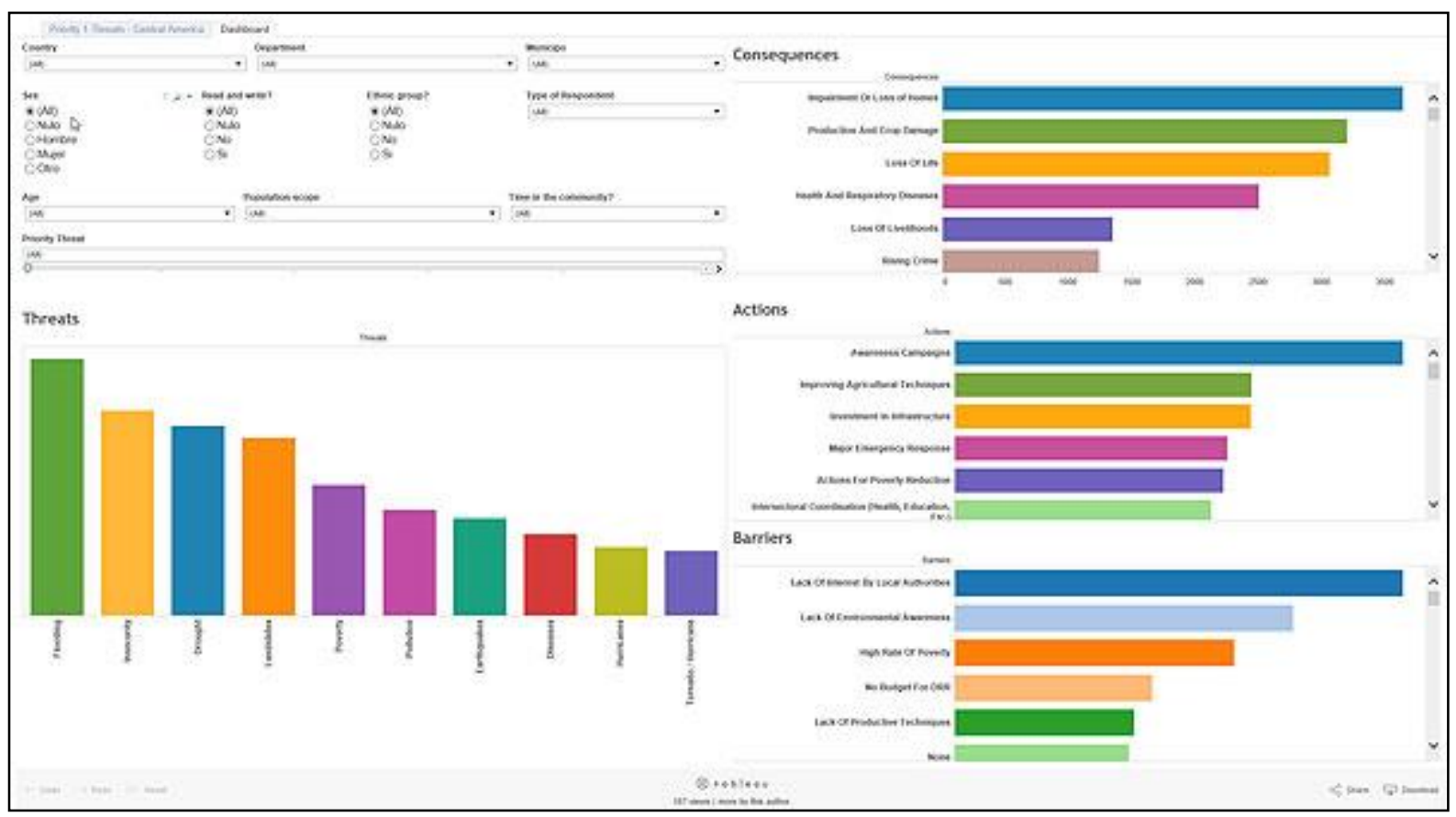

Figure 7: The Frontline tableau interactive data platform

\section{D3. Applications and Impact of Frontline}

\section{Data gathering and application in informal urban contexts in East Delhi, India}

Case studies and anecdotal evidence indicate that the application of data locally through community consultation and action were valued by the local NGOs involved in the programme. The implementation of the programme in India is used to illustrate this. It was focused on Assam, Bihar, East Delhi, Odisha, Tamil Nadu and Uttarakhand; localities selected to represent a range of risk zones. The analysis and report (SEEDS, 2016) aggregated data to indicate priorities in different risk zones. Figure 8 contrasts the threats prioritised by respondents in rural and urban risk zones:
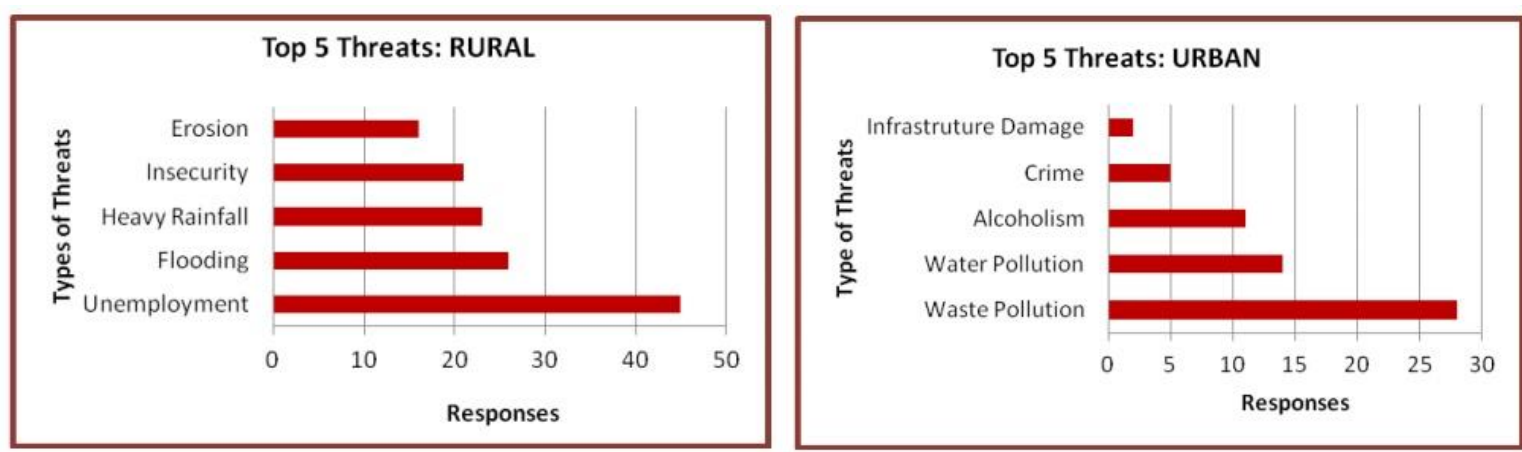

Figure 8: Urban and rural priority threats according to Frontline India

In line with findings from the 21 countries involved in the programme, risk profiles were found to be very context specific, which in itself underscored an important message addressed to institutional actors above moving from large scale towards local, context 
specific actions in implementing disaster reduction policy. The report provided further detail on each zone. Findings for East Delhi stated:

"Waste and water pollution, alcoholism, crime (again mainly women respondents) and infrastructural damage were identified as the greatest threats. Violence (physical, domestic, sexual, child abuse); blocked roads from garbage and rain; psychosocial impacts; and lack of clean drinking water were some of the direct consequences adding to the threats. The primary barriers perceived were lack of community's commitment; followed by the fear of reprisals (both within the community and with concerned authorities), unplanned urbanization: clustered shacks next to highways or on the streets without clear drainage system and highly limited spatial scope, poor sanitation and hygiene and poverty" (SEEDS, 2016, p21)

Data gathering and analysis in East Delhi underpinned and reinforced local action which included establishing community associations, one of whose actions was local level data gathering using a mobile phone app to document and report local hazards such as garbage accumulations and unsafe electric cabling (Gupta et al, 2019). Generation and application of data in this way addressed a particular political challenge experienced in informal urban communities, where the lack of registration and voting rights amongst such populations makes them a low priority in the eyes of local political leaders. The campaigning and advocacy leverage created by making the limited services provided in urban informal areas more clearly visible in the public eye through gathering and aggregating data - naming and shaming - provoked greater action on the part of the local government (pers.comm. Gupta, 2017)

\section{Data gathering and application in informal urban contexts in Limbe City, Cameroon}

Frontline's focus on accessing local knowledge and experience directly, rather than consulting respondents in relation to an external framework enabled it to provide specific contextual understandings of complex social contexts in urban informal settlements. The Frontline data gathering and analysis process was applied in Limbe City, Cameroon. A coastal city exposed to climate related disasters and also vulnerable to eruptions from nearby Mount Cameroon, the levels of poverty in informal areas of the city led to a range of other more pressing disaster impacts. These were revealed in the responses gathered through structured interviews.

Aggregated responses revealed the highest priority threats faced by the local population: seasonal flooding, coastal erosion, fire, landslide and poverty. In one low-lying area, Lower Motowoh, discussion of these findings led to agreed community actions to address clogging of the main watercourse because of poorly managed waste. Actions combined clearing the watercourse and promoting better waste management. Initial disinterest from local government and resistance from some community members were influenced by the visible actions and the resulting reclamation of low-lying land which was now habitable and led eventually to greater community participation and government support. The process of data gathering and presentation therefore triggered an iterative process engaging both community and government (Wong and Aka, 2019) 


\section{Data gathering and application in informal urban contexts in Metro Manila, the Philippines}

One of the world's mega-cities, Metro Manila has a population of over 21 million and is growing rapidly. Within sight of the city's skyscrapers many settlers have moved in to urban informal areas along the city's waterways, living in cramped, hazardous, often temporary accommodation. Due to their informality, estimates of the scale of this population are approximate, ranging from 104,000 families (CDP, 2015a) to one million people (pers. comm. Lorna Victoria, CDP, 2019) ${ }^{52}$.

The city government put forward mass relocation of populations as a resolution of the problems faced by these residents. However the proposed locations are relatively remote from the city, dislocating people from their communities and creating huge problems in either commuting back into their workplaces or securing other livelihoods. Residents have therefore resisted this strategy.

The Action at the Frontline local level data gathering process identified a range of threats faced by residents and also highlighted their interlocking nature (CDP, 2015a):

- Disaster: flood, fire, earthquake, garbage

- Economic: lack of jobs, difficulty in finding a job, vices due to lack of economic activities

- Peace and order: youth riot, use and selling of illegal drugs

- Social cohesion: gossip, fights

- Housing and relocation: landlessness

These findings were played back to meetings which included community members and also representatives of local organisations and local government. These meetings were the starting point for developing a community plan to effectively and efficiently reduce the threats. A field visit by the author in 2019 including meetings with CDP revealed that progress is slow, suggesting further iterations of such data gathering and dialogue processes are needed.

\section{Overall impacts of the pilot programme}

Frontline implementation and associated local 'Action at the Frontline' case studies during three pilot phases of Frontline were conducted in 30 countries in Latin America, Asia, Africa and the Caribbean. The last of these phases, spanning 15 countries, was linked with local 'Action at the Frontline' in 11 countries. Outcomes at local and national level are summarised below:

Locally the case studies of action based on the local analysis of Frontline data indicate that this locally co-created knowledge was applied to inform and motivate local action. Cases in India, Cameroon and the Philippines have been detailed above. In Indonesia local priorities for action contrasted with institutional perceptions leading to a focus on livelihoods based on strengthening tourism as a means of reducing illegal activity which created risk. In

${ }^{52}$ CDP is the Centre for Disaster Preparedness, a national NGO based in Manila, the Philippines. 
Kiribati the activity led to establishment of multi-stakeholder partnerships capable of organising mangrove restoration and other risk reduction activities. In Malawi a respondent cited the benefits of action focused on local priorities as a contrast to the more usual project-based activities defined by external funders. The overall assessment of the cases was that they stimulated local level collaborations based on local priorities.

Regionally the Frontline report in India (SEEDS, 2016) was used as a basis for multistakeholder consultations. In the Philippines the programme produced detailed reports in six regions which were presented nationally (CDP, 2015) and also triggered regional collaborations for action, notably in Carles region where a substantial multi-stakeholder collaboration was developed to drive development in the region (Molina, 2019).

Nationally some evidence was recorded of impacts of the data. During these pilot phases respondents reported using aggregated data to influence government policy for risk reduction in Chile, Columbia, Kiribati and Paraguay (Gibson and Wisner, 2016). In Indonesia the participating CSOs reported that presentation of Frontline data and reports at the national platform (PLANAS) and the National Disaster Management Agency had led to inputs to the national and regional disaster risk reduction policy (YEU, 2015).

Assessing this phase of the programme in relation to the power/knowledge matrix suggests that focus had shifted to the bottom right hand corner, where situated knowledge was engaging in created spaces (see Figure 9).

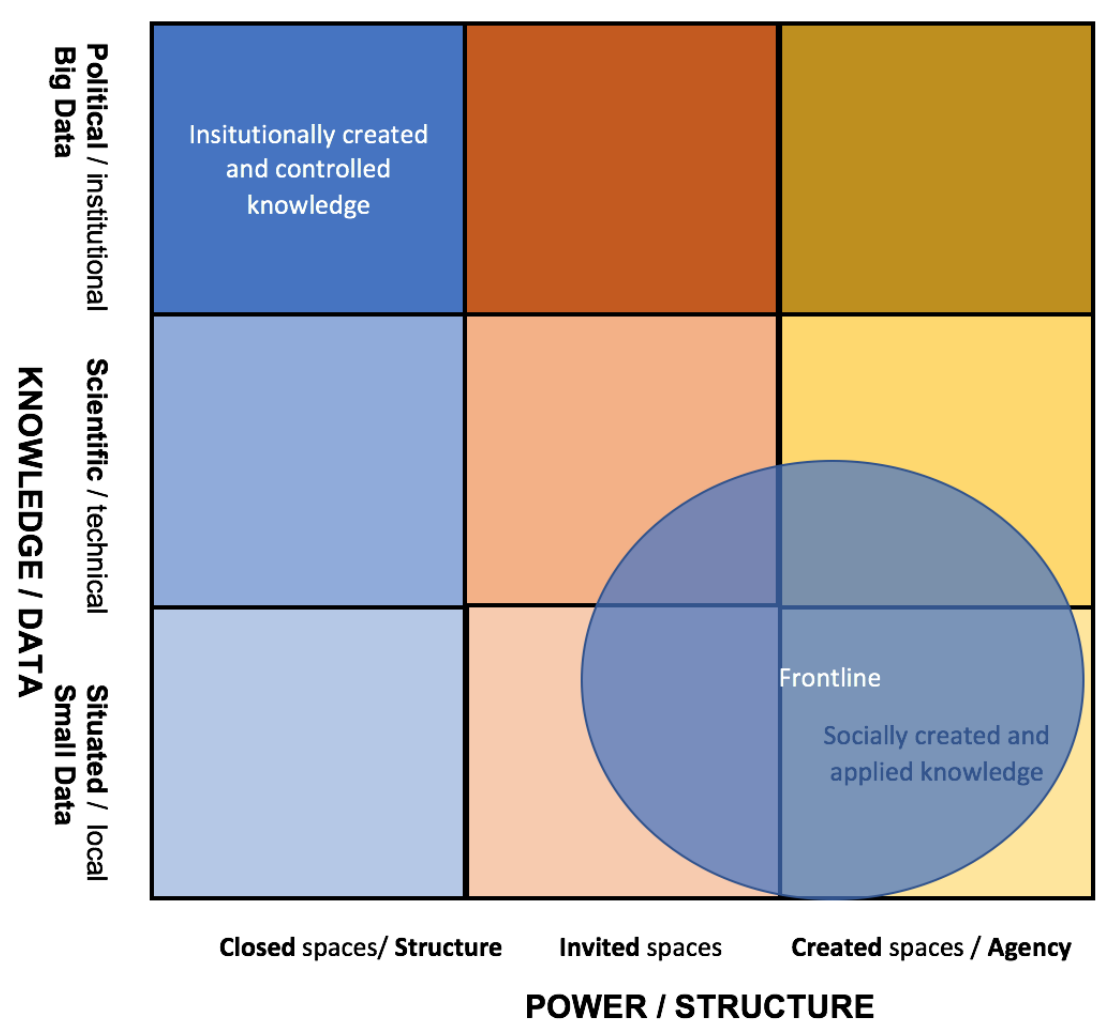

Figure 9: Frontline positioning in power/knowledge matrix 
This was 'small' data gathered, analysed and used locally (though also aggregated into larger databases for national/international use) and its local application was in contexts where participants had some agency, and indeed sometimes increased their agency through cycles of action. In some case studies the uptake of data drove a cycle of increasing local participation and emerging engagement with other actors such as local and national government, engaging in invited spaces - those where the hosts normally exerted control over proceedings and outcomes - and in scientific/technical discourse - where situated/local knowledge is often discounted, as illustrated in Figure 9. Engagement in these spaces appeared to occur disruptively, through 'legitimate subversion' rather than within accepted institutional framings as capabilities and confidence of local consortia grew iteratively (Gibson et al 2019). Thus this local level application of small data appeared to achieve a higher degree of structural data justice than the previous programme, through cocreating a space or structure in line with local interests and priorities. It met the network members' requests for distributive data justice by providing greater resources for marginalised groups. And the case studies during the pilot implementation offer examples of instrumental data justice, with data stimulating actions and hence impacts in line with local priorities.

\section{D4. Return to Views from the Frontline}

Evidence of the pilot phases of the Frontline programme were therefore that it met the network members' request for a data gathering exercise that had local level application, and there was some evidence that it was also used at national scale to influence policy. The programme was intended to be implemented more widely after the pilot phases. However this phase stalled. Although the GNDR Board and CEO had requested its development, they struggled to understand the approach, feeling more comfortable with the questionnaire based survey. Thus, after internal deliberations GNDR set out to design a new programme, taking the original name Views from the Frontline (GNDR, 2019).

This reflected the desire within the secretariat to be directly assessing the UN Sendai Framework for Action, as the earlier Views from the Frontline programmes had done, and the desire of potential funders to support such an action. However demand from the network's membership led to the new programme retaining the local level component. Therefore this programme, being initially deployed at large scale in 50 countries over a three-year period, has at its heart the earlier questionnaire style exercise, aimed at conducting a complementary assessment of the UN Disaster Reduction framework, and also in this iteration the Sustainable Development Goals and the Paris Agreement on Climate Change. Alongside this assessment it includes the Frontline-style local level prioritisation exercise, aimed at capturing local knowledge and using it as a basis for local action.

A pilot exercise for this new approach conducted in the Philippines with 2535 respondents analysed findings from the two elements of the survey (CDP, 2018). It showed that distinct risk priorities were identified in different localities and risk zones, and linked these to options for local action and to particular barriers to be considered. As with the earlier Frontline programmes the data gathered locally was actionable. The main finding of the questionnaire style assessment was of a consistent gulf between local community and local government perceptions of progress on all issues considered, with local government 
consistently positive and communities consistently negative about progress. This reiterated findings from earlier Views from the Frontline surveys, but raised the question of the utility of this finding, due to the barrier of institutional resistance experienced previously.

The intention in the new programme appears to be to locate the project within two zones in the power/knowledge matrix (see Figure 10).

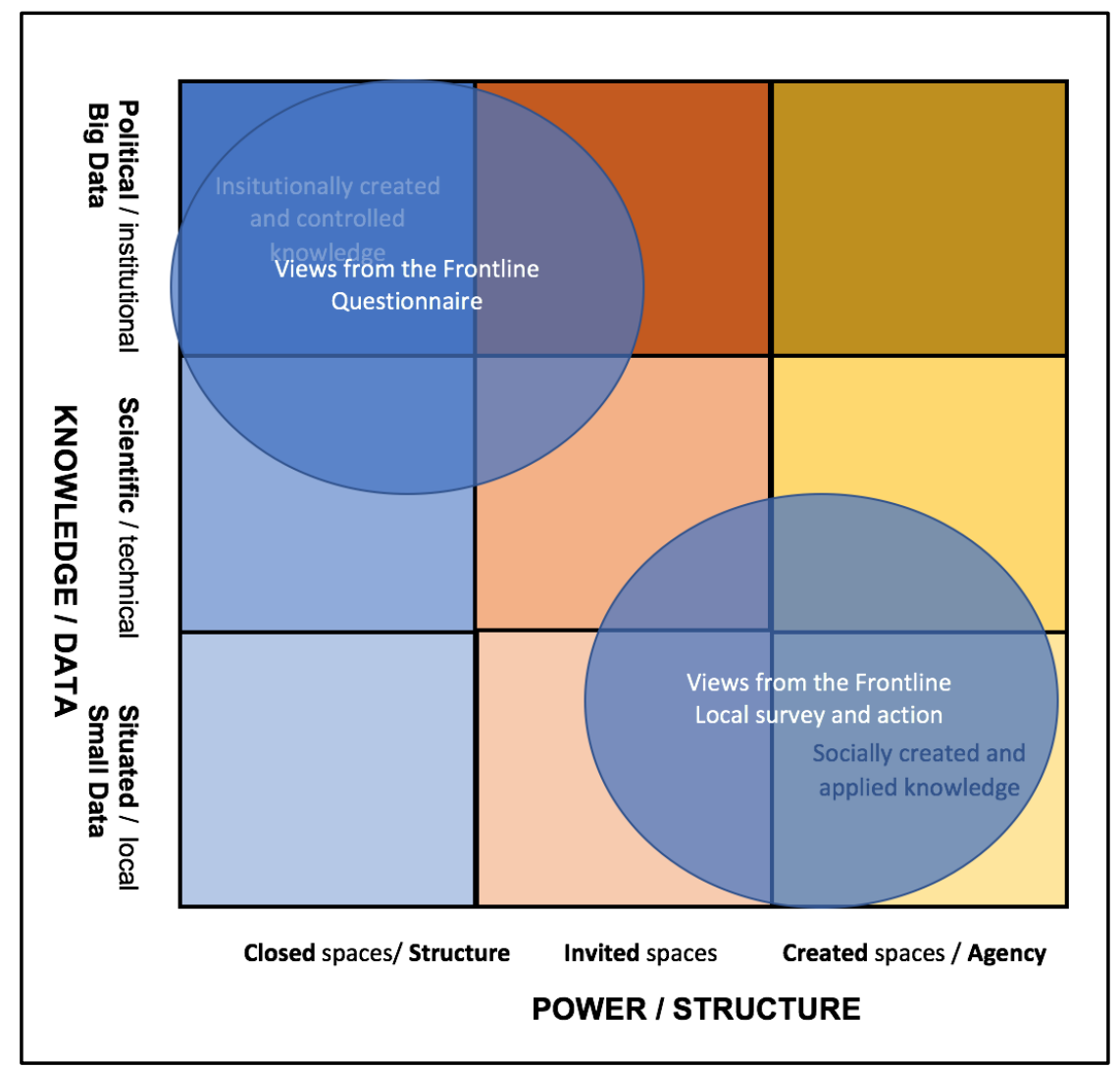

Figure 10: Locating Views from the Frontline 2019 in the power/knowledge matrix

The inclusion of the local level consultations, local knowledge generation and action (similarly to Frontline) is located at bottom right, in created spaces where agency can be exercised on the basis of situated knowledge. The questionnaire element, intended to assess the UN Disaster Reduction framework and also the Sustainable Development Goals and Paris Agreement on Climate Change, does not have any design elements addressing the challenges faced by the earlier and similar Views from the Frontline project. However while the programme may not achieve impact at international/national level it may be strategically necessary to include this element to maintain organisational credibility and funding. It may be that such a pragmatic approach recognises the limitations of structural data justice, therefore including an element previously found ineffective but which is nevertheless necessary to allow the other elements of the programme to proceed, in order to secure distributive and instrumental data justice. 


\section{E. Discussion and Conclusions}

This case focuses attention on civil society organisations as creators and users of data, and directs attention specifically to urban informal contexts, which it is suggested have been poorly understood by civil society organisations as well as by other institutional actors. Whilst the programmes considered in this study are not exclusively devoted to urban informal contexts it shows that the local level methodology, 'Frontline', is able to gather data explicating very specific contexts, including urban informal, through its open-ended qualitative method, contrasting with a framework-driven questionnaire approach such as that used in Views from the Frontline. There was a transition during the course of the programme from an international to a local focus in the application of data. In the first iteration the destination was international and institutional. In the second iteration the destination was local, the data looped back to its contributors as per the tenets of the small data approach. The contrast is illustrated in Figure 11.

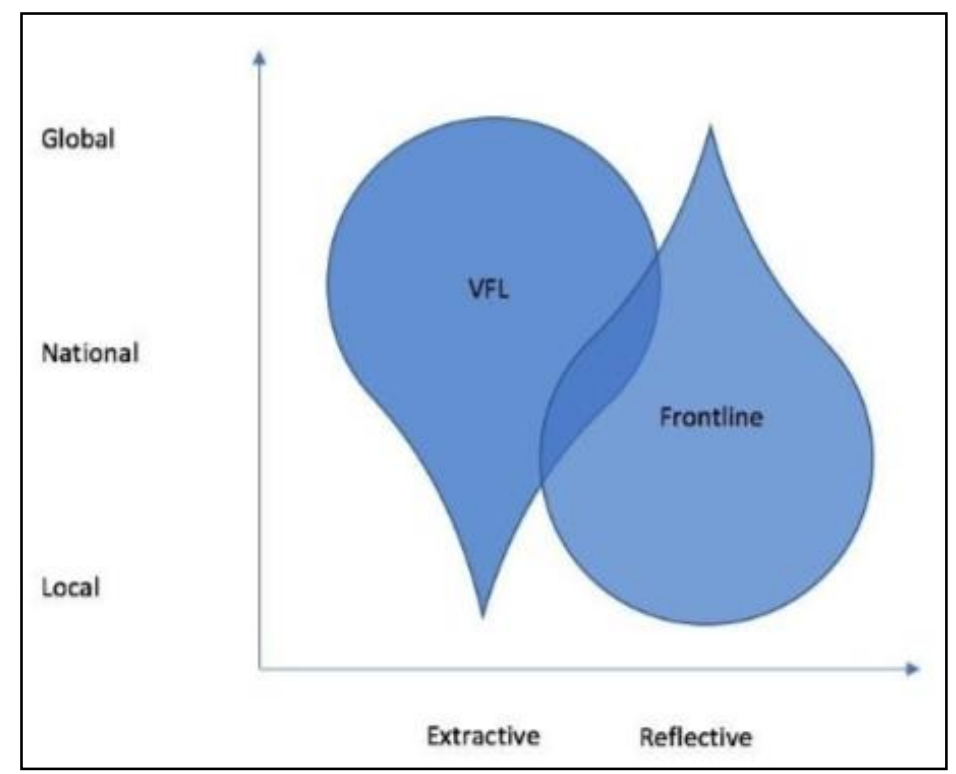

Figure 11: Contrasting emphasis of Frontline and Views from the Frontline

The third iteration, as discussed, includes both local and global elements.

The challenges in achieving institutional influence in the Views from the Frontline programme echo those highlighted by McGee and Brock (2001) and by Brock et al (2001) in their assessments of the large scale 'Voices of the Poor' programme. In both cases structural data justice - 'power over' - is in play. As Fox (2015) discusses, tactical approaches are insufficient to achieve influence in these closed institutional spaces. The power/knowledge matrix reflects the dominance of 'political knowledge' over technical and scientific considerations and over the even less privileged place of situated knowledge created locally. In both cases attempts to insert local perspectives and knowledge into the institutional discourse have proved ineffective.

In terms of the disaster reduction discourse Gaillard (2019) challenges an institutional hegemony which imposes an orientalist view of disasters in the prevailing institutional discourse on the topic, therefore failing to hear voices or views from the frontline. He 
argues for the importance of local researchers analysing local disasters using local epistemologies, suggesting therefore that it is impossible to bridge a dominant western epistemological perspective with that prevailing locally. This is an extreme position but it does echo the disjunction between community and government perceptions reported by Views from the Frontline (Figure 4) and in the later Views from the Frontline pilot (CDP, 2018). Therefore more strategic applications of data gathering and application must be considered, as Fox also argues.

GNDR's work in piloting the Frontline programme, dealing with small data in created spaces, is located by the power/knowledge matrix in contexts where greater agency is available and/or can be accumulated in the sequence represented below:

\section{Small data $\rightarrow$ local social visibility $\rightarrow$ stimulus for social action $\rightarrow$ social agency}

As such this reveals a strategic approach to application of data for development. However this initiative reveals an organisational challenge which can also attach to Gaillard's critique of institutional hegemony, as GNDR has faced pressure internally and externally - related to organisational credibility and funding - to return to the former survey format. This has led to pragmatic trade-offs in which the questionnaire assessment of several global frameworks has been reinstated, now complemented by the local level data gathering and application process. It remains to be seen whether the increased complexity of the resulting programme can be sustained. Piloting has demonstrated that the complexity of the dual approach creates an additional workload. App-based data recording is being developed to reduce this load, so accommodating the politically pragmatic dual approach has come at a cost (pers.comm. VFL project manager, June 2019).

\section{Conclusions: CSOs}

The case offers several messages to CSOs considering data gathering and application:

1. The challenges of engaging in institutional spaces, where political considerations outweigh technical and scientific, must be understood.

2. Tactical approaches - sunshine is the best disinfectant - are likely to fail and more strategic approaches should be considered.

3. Application of small data in local contexts creates significant opportunities to contribute to change processes as this data can inform understanding of complex contexts such as urban informal settlements and form a valuable part of iterative processes of action and reflection, incrementally increasing ability to influence local institutions through strategies such as 'legitimate subversion'.

4. Working strategically may entail, as in the case of the Views from the Frontline 2019 iteration, undertaking activities to maintain organisational stature even though these may not be intrinsically effective. That this is the case reflects a reality of structural data justice in systems with dominant and powerful actors. 


\section{Conclusions: Data justice model}

\section{Structural data justice}

The case has highlighted aspects of structural data justice and injustice regarding the application of data gathered through the VFL, AFL and Frontline programmes. It suggests that the imposition of power on knowledge, limiting the impact of data and analysis on policy, necessitates a pragmatically strategic approach which has resulted, in the final iteration of VFL in 2019, in parallel approaches intended to engage in the two extremities reflected in the power/knowledge matrix - institutionally created and controlled knowledge and socially created and applied knowledge. The case can further be seen to suggest that managing structural data justice is a dynamic rather than a static process, requiring iteratively strategic approaches to ensuring structural data justice.

\section{Distributive data justice}

The case has shown that even in socially and ethically motivated applications of social data, distributive data justice can be neglected. In the case under consideration it was feedback from network members that highlighted this issue, demonstrating a need to act critically and reflectively in the handling of data, rather than assuming an 'end justifies the means' approach.

\section{Instrumental data justice}

Iterative learning by GNDR during the implementation period of VFL, AFL and Frontline highlights unanticipated instrumental benefits of these programmes. The call from CSOs, representing communities, for direct local application of the programme led to the 'small data' aspect being emphasised, and this in turn led to both 'process' and 'outcome' benefits from this small data aspect of the programme. Illustrated in the cases from East Delhi, Limbe City and Metro Manila, the process led to instrumental benefits of local engagement, dialogue and collaboration which in turn strengthened local action. There were outcome benefits of influence on local government. 


\section{E1. Recommendations}

This case study, focusing on gathering data locally and applying it both locally and remotely, highlights the dominance of structural data justice issues and the need to work strategically rather than tactically:

\section{Data to influence institutional discourse}

As regards practice it focuses on such activities undertaken by civil society actors and recommends caution in conducting data gathering activities designed to influence institutional policy, recognising the ability of institutions to subjugate such data to their preexisting discourses.

\section{Data to support local collaboration and action}

It highlights the potential of small data gathering activities integrating with local uptake and action, not only in local community mobilisation but in incremental engagement with institutions at local level.

\section{Data to enhance understanding of complex urban informal contexts}

It shows that in complex contexts such as urban informal settlements such local knowledge creation is valuable in achieving local contextual understanding, addressing the deficit in such understanding felt by organisations such as INGOs.

\section{Pragmatic organisational strategies to address structural data (in)justice}

It also highlights, given the challenges of structural data justice, the necessity to consider such activities within a wider framing which pragmatically considers organisational sustainability given the low value placed institutionally on local, situated knowledge.

\section{Further research}

As regards research the case suggests that the dynamics of data justice and injustice in local data gathering and application are of interest. The case tangentially mentioned another local data initiative in East Delhi based on a smartphone app. The expanding range of technologies able to support local data gathering, analysis and application should also be considered, situated within the nuanced understanding of structural data justice emphasised by the power/knowledge matrix. Finally the role of that model in enhancing the understanding of the structural data justice element of the data justice model may be considered, investigating whether it illuminates Heeks and Renken's emphasis on the importance of structural data justice. 


\section{References}

Argyris, C. \& Schon, D. (1989) Participatory action research and action science compared, a commentary. American Behavioural Scientist, 32.5, 612-623

Braden, S. (2003) Participation - A Promise Unfulfilled? Building Alliance between People and Government: Action Research for Participatory Representation. Chronic Poverty Research Centre (CPRC), Manchester, UK. http://www.chronicpoverty.org/uploads/publication files/CP 2003 Braden.pdf

Brock, K., Cornwall, A. \& Gaventa, J. (2001) Power, Knowledge And Political Spaces In The Framing Of Poverty Policy, Working Paper 143. IDS. Brighton, UK. https://www.ids.ac.uk/publications/power-knowledge-and-political-spaces-in-theframing-of-poverty-policy/

Cooke, B. \& Kothari, U. (eds) (2001) Participation: the new Tyranny? Zed Books, London, UK. CDP. (2015) Frontline: Turning Community Views Into Action 2015 National Report. Philippines. CDP, Manila, The Philippines. https://www.dropbox.com/sh/s7doh7gx3cy7eo3/AADsRtb0mXp78WMLpS7mONIGa/Fro ntline/OFDA/FL2015-16\%20Philippines\%20National\%20Report.pdf?dl=1

CDP. (2015a) Everyday Risk: Action at the Frontline in Metro Manila, The Philippines. CDP, Manila, The Philippines. https://www.dropbox.com/sh/s7doh7gx3cy7eo3/AABLRsPQ0p-tg5PkMJBug4a/AFL/PHILIPPINES\%20AFL\%20Case\%20Study\%20 \%20Final\%20Urban.pdf?dl=0

CDP. (2018) Presentations of Findings: Views from the Frontline Pilot. CDP, Manila, The Philippines.

Desinventar (undated) What is Desinventar? Desinventar, Cali, Colombia. https://www.desinventar.org/en/

Fox, J.A. (2015). Social accountability. World Development, 72, 346-361

Freire, P. (1970) Pedagogy of the Oppressed. Penguin, London.

Gaillard, J. (2019), Disaster studies inside out. Disasters, 43, S7-S17

Gaventa, J. (2005) Reflections On The Use Of The Power Cube Approach For Analysing The Spaces, Places And Dynamics Of Civil Society Participation And Engagement. MFP Breed Network, the Netherlands. http://www.partos.nl/uploaded files/13-CSP-Gaventapaper.pdf

Gibson, T. (2012) Horizontal Learning and Social Media in an International Development Network. Doctoral Thesis, University of Manchester, UK.

Gibson, T. (2019) Making Aid Agencies Work: Reconnecting INGOs with the People They Serve. Emerald Publishing, Bingley, UK

Gibson, T., \& Wisner, B. (2016). "Let's talk about you ...": Opening space for local experience, action and learning in disaster risk reduction. Disaster Prevention and Management, 25.5, 664-684

Gibson, T., Aka, F., Aretaake, R., Bari, S., Chantry, G., Gupta, M., Molina, J., Norton, J., Parajuli, B., Rahmawati, H. \& Shresha, N. (2019) Local voices and action: concluding discussion. Disaster Prevention and Management, 28.1, 126-142

Gibson, T \& Norton, N. (2019) Disaster prevention: doing it differently by rethinking the nature of knowledge and learning, Special Issue. Disaster Prevention and Management, 28.1

GNDR. (2012) Learning Review, internal document. Global Network for Disaster Reduction, London, UK. 
GNDR. (2019) Views from the Frontline 2019 Global Network for Disaster Reduction, London, UK. https://www.gndr.org/programmes/vfl.html

Gupta, M., Talankar, P. \& Chavda, S. (2019) Citizens of Delhi lead resilience action. Disaster Prevention and Management, 28.1, 69-75

Heeks, R. \& Renken, J. (2018). Data justice for development. Information Development, 34.1, 90-102

Heeks, R. \& Shekhar, S. (2019) Datafication, development and marginalised urban communities: an applied data justice framework. Information, Communication \& Society, 22.7, 992-1011

Heron, J. (1996) Co-Operative Inquiry: Research Into The Human Condition. Sage, London, UK.

Kolb, D. (1984) Experiential Learning: Experience as the Source of Learning and Development. Prentice-Hall, Upper Saddle River, NJ.

McGee, R. \& Brock, K. (2001) From Poverty Assessment To Policy Change: Processes, Actors And Data, Working Paper 133. IDS, Brighton, UK. https://opendocs.ids.ac.uk/opendocs/handle/123456789/

Molina, J.G. (2019) Advancing small island resilience and inclusive development through a convergence strategy in Carles, Philippines. Disaster Prevention and Management, 28.1, 33-41

Moser, C., Sparr, P. \& Pickett, J. (2007) Cutting-Edge Development Issues for INGOs. Applications of an Asset Accumulation Approach, Asset Debate Paper 1. Brookings Institute, Washington, DC.

https://www.brookings.edu/wpcontent/uploads/2016/06/200707INGO moser.pdf

Narayan, D. (2000) Voices Of The Poor: Can Anyone Hear Us? Oxford University Press for the World Bank, Oxford, UK. http://documents.worldbank.org/curated/en/131441468779067441/pdf/multiOpage.pd f

Oxfam. (2012) Getting Ready for The Century Of The City: 2013-2016 Urban Framework Report. Oxfam. Oxford, UK. https://policy-practice.oxfam.org.uk/publications/gettingready-for-the-century-of-the-city-oxfam-gbs-urban-framework-20132016-337115

Provention. (undated) Community Risk Assessment Methodologies and Case Studies. Provention Consortium. http://www.proventionconsortium.net/?pageid=43

Quarry, W. \& Ramirez, R. (2009) Communications For Another Development. Zed Books. London, UK.

Satterthwaite, D. (2018) Is urban development too complicated for us?. IIED Blog, 17 May. https://www.iied.org/urban-development-too-complicated-for-us

Schon, D. (1983) The Reflective Practitioner. Basic Books, New York, NY.

SDI. (undated) The Know Your City Campaign. SDI, Cape Town, South Africa. http://knowyourcity.info/explore-our-data/

SEEDS. (2016) India Country Report: Frontline Year 1. Global Network for Disaster Reduction, London, UK. https://www.gndr.org/images/newsite/events-documents/2016-frontlinenational-workshops/FRONTLINE INDIA COUNTRY REPORT 2015-16.pdf

Sen, A. (1999) Development as Freedom. Oxford University Press, Oxford, UK.

UNISDR. (2011) Preparatory Statement For GPDRR 2011. United Nations Office for Disaster Risk Reduction, Geneva, Switzerland. 
Views from the Frontline. (2019) Last Phases of the VFL Pilot Implementation. Global Network for Disaster Reduction, London, UK. https://www.gndr.org/news/item/1906last-phases-of-the-vfl-pilot-implementation.html

Wong, G. \& Aka, F. (2019) Enhancing resilience against floods in the Lower Motowoh community, Limbe, Southwest Cameroon. Disaster Prevention and Management, 28.1, $76-83$

YEU. (2015) Understanding Disasters Risks from the Local Perspective. Country report: Indonesia. Survey from the Frontline Report 2015. Global Network for Disaster Reduction, London, UK.

https://www.dropbox.com/sh/s7doh7gx3cy7eo3/AACO4OPzspVe3iXEqYaR0xTBa/Frontli ne/OFDA/FL2015-16\%20Indonesia\%20National\%20Report.pdf?dl=1

Yin, R. (2003). Case Study Research Design and Methods, 3rd edn. Sage, Thousand Oaks. CA.

\section{Acknowledgements}

The "Urban Data, Inequality and Justice in the Global South" case studies form part of a Senior Research Fellowship funded by the University of Manchester's Sustainable Consumption Institute with additional financial support from Canada's International Development Research Centre.

\section{About the Author}

Terry Gibson travelled extensively filming aid and humanitarian work in villages, towns and cities around the world before becoming Operations Director of an international network of over 800 small NGOs. He developed and led a major research programme at the network, which consulted over 100,000 people facing everyday disasters, and combined this with research at the University of Manchester. He continues to research and write on these topics as an independent researcher. 


\title{
Case 8: Capturing Gender and Class Inequities The CCTVisation of Delhi
}

\author{
Aayush Rathi \& Ambika Tandon ${ }^{53}$ \\ The Centre for Internet and Society (India)
}

\begin{abstract}
Cityscapes across the global South, following historical trends in the North, are increasingly being littered by closed-circuit television (CCTV) cameras. In this paper, we study the wholesale implementation of CCTV in New Delhi, a city notorious for incredibly high rates of crime against women. The push for CCTV, then, became one of many approaches explored by the state in making the city safer for women.

In this paper, we deconstruct this narrative of greater surveillance equating to greater safety by using empirical evidence to understand the subjective experience of surveilling and being surveilled. By focussing on gender and utilising work from feminist thought, we find that the experience of surveillance is intersectionally mediated along the axes of class and gender. The gaze of CCTV is cast upon those already marginalised to arrive at normative encumbrances placed by private, neoliberal interests on the urban public space. The politicisation of CCTV has happened in this context, and continues unabated in the absence of any concerted policy apparatus regulating it. We frame our findings utilising an analytical data justice framework put forth by Heeks and Shekhar (2019). This comprehensively sets out a social justice agenda that situates CCTV within the socio-political contexts that are intertwined in the development and implementation of the technology itself.
\end{abstract}

\footnotetext{
${ }^{53}$ Authors are listed in alphabetical order.
} 


\section{A. Introduction}

The past decade has seen monumental growth in video-based surveillance systems across cities in the global South. Governments have invested in such systems for a variety of reasons, including anti-terrorism initiatives, general safety and security, and law and order (Firmino and Duarte, 2015). Surveillance of public spaces is also directed at providing security to women from harassment and violence, as can be seen in cities such as New Delhi that are grappling with high incidence of crime against women. Accordingly, the location for this research is New Delhi.

Over the past decade, Delhi has developed a dense network of cameras. These are implemented and controlled by a complex network of both private and public actors, who share management, resources, and control over closed-circuit television (CCTV) spread throughout the city. Private actors controlling the system include property-owning individuals, commercial establishments, and Resident Welfare Associations (RWAs) and Market Welfare Associations (MWAs) ${ }^{54}$. Public stakeholders include the Delhi government, which is currently in the process of fulfilling its election promise of providing each electoral constituency in the city with extensive CCTV coverage, the central government, the Delhi Police, the Public Works Department, the Delhi Metro Railway Corporation and three municipal corporations.

This paper contributes to the discussion on CCTV surveillance from the perspective of data justice, which assesses the ability of a data system to provide social justice to those it impacts. We interrogate the extent to which CCTV cameras support the achievement of justice, particularly from the perspective of women using public spaces. To do so, we adopt Heeks and Shekhar's (2019) model of data justice which provides various dimensions to analyse datafication initiatives.

We also borrow concepts from feminist surveillance studies, which has been overtly political in critiquing the "heterosexual, heteronormative, and sexist male gaze" of surveillance of women and sexual minorities (Walby, 2005). In generating empirical evidence, we employ a feminist qualitative approach to question intersectional power dynamics and centre the embodiedness of data, safety, and privacy in the city. We align this with the framework of urban data justice to understand datafication as being embedded within the social contexts in which the data systems are operationalised. Existing literature on feminist surveillance has underrepresented the experiences of women in the global South, while data justice has, so far, not directly engaged with feminist thought.

One of the key research aims of the project, then, is to critically deconstruct this narrative of greater surveillance and visibility equating to greater safety by using empirical evidence to understand the subjective experience of being surveilled. This allows us to position CCTV cameras within the broader understanding of gendered access to geographical space as well as rights and justice systems. These feed into interrogating the extent to which CCTV in

\footnotetext{
${ }^{54}$ Resident Welfare Associations and Market Welfare Associations, as the names indicate, are elected nongovernmental bodies that respectively represent the interests of residents or businesses operating out of particular residential or commercial areas.
} 
Delhi is designed to enable accomplishment of the stated objectives of safety to women, especially those from informal settlements.

The paper is structured as follows. The first section provides a background of the existing literature that the study will draw upon or challenge, largely within the fields of urban data justice, surveillance studies, and feminist surveillance studies. After briefly discussing the methodology, the findings from the research are presented using the five dimensional analytical framework developed by Heeks and Shekhar (2019). Finally, we conclude with some further discussion, and propose recommendations and future research questions that arise out of the present study.

\section{B. Background}

\section{B1. Feminist Surveillance Studies}

A crucial aspect of this paper is to advance an understanding of how, taken-for-granted as benign, surveillance technologies such as CCTV systems end up impacting already disenfranchised bodies. The dominant rationality of neutrality and objectivity that lend support to these technological tools could be borne out of historical inequalities, or morph and challenge them. For instance, Ruha Benjamin has shown that new technologies are often thrust upon populations that have historically had to resist their imposition (Benjamin, 2016). Browne $(2010,2015)$ draws nuanced linkages between the historical modalities of policing slaves and contemporary technologies of surveillance such as biometrics.

Questioning the supposed neutrality of these technologies allows for an exposition of the power relations that give rise to and govern the use of these technologies.

While not having been originally articulated in the context of 'datafication', a key theme utilised in feminist responses to surveillance borrows from feminist scholarship focusing on the intersectional, not additive, ways in which power differentials are wedded into the social relations of domination and resistance (Crenshaw, 1989). Using a critical intersectional feminist approach allows for the unravelling of "what constitutes surveillance, who is scrutinised, why and at what cost" (Dubrofsky and Magnet, 2015).

Monahan's (2009) conceptualisation of the overlapping gendered dimensions of surveillance is a useful analytical framework to draw from as well. Monahan conceptualises technology to mediate the reproduction and reinforcement of unequal power structures through: (a) body discrimination i.e. by privileging a certain type of person and rendering others as deviant, (b) context or use discrimination by reproducing already unequal social structures, and (c) discrimination by abstraction i.e. by the reduction to data points that facilitates the control from distance (ibid.). In other words, a feminist approach to surveillance allows for the interrogation of what the mythologies are that lend meaning to the technology in the first place.

That being said, most studies assessing CCTV along the axis of gender indicate general support for CCTV among women as a measure of providing the experience of safety and 
security (Koskela, 2002; Huey, 2010). This can be found in studies such as Hasija and Nagpal's (2018), who in their survey of 250 young women in Delhi and their responses to CCTV found overwhelming support despite awareness of the risk of stalking and abuse and lack of clarity about the identity of the surveiller or objectives of surveillance.

Previous research assessing CCTV surveillance from a feminist lens has also highlighted the impact of subjectivities and power relations on the experience of video-based and other surveillance systems. For instance, Wright et al. (2014), in their study on video-based surveillance within apartment buildings in Toronto, found that women tended to identify as the objects of surveillance rather than agents conducting the surveillance, even in private settings where residents have a certain level of control over surveillant infrastructure. They further found that women were more likely to express trust in the surveillance system if their objectives aligned with that of the surveillant authority.

\section{B2. Privacy and the Gaze through a Critical Feminist Lens}

In addition to state and private surveillance, feminist scholars have also had a long engagement with the subject of privacy and its relation to the male gaze, expanding on the notion of differentiated rights. Adler-Bell (2018) argues that for marginalised communities, privacy in the form of "ungoverned" spaces has been historically inaccessible. The Fourth Amendment in the United States, for instance, defines privacy spatially - the "reasonable expectation of privacy" is largely within the private space of the home (ibid.). This then implies that privacy as a right is contingent on property rights rather than being a universal right; something available only to those who can afford it. This leads to a stratified access to privacy, with groups living in informal settlements and the homeless having the least access to privacy (Gellman and Adler-Bell, 2017). One of the possible consequences of differential access to the right to privacy for different groups is the enforcement of normative boundaries in public spaces.

This is also reflected in jurisprudence around privacy in the United States, where the Supreme Court has ruled that citizens should not expect privacy in public spaces, as the constitution does not prevent people from spying on each other in public (Firmino and Duarte, 2014). The conception of the right to privacy as only available in private spaces is contingent on the historical dichotomy between the two (public and private) kinds of spaces, which has been amply critiqued by feminist scholars. They critique the imposition of modesty and domestic isolation on middle and upper class women in India and other contexts as a result of the private/public divide, which has also led feminist writers to critique the notion of privacy itself (Allen, 2011). Feminists argue that framing the discourse of privacy as protectionist, including in the context of video-based surveillance, does not align with a rights-based approach that would aim to increase decisional autonomy among women (Thomasen, 2018).

In the context of India, Phadke et al. (2011) argue that the threat posed by public spaces to 'respectable' women is constructed within middle class discourse as arising from lower class or Muslim men. In a three year project on the use of urban public space in Mumbai, they find women internalised this discourse, identifying Muslim and lower class men as a source of anxiety and threat (ibid.). This then justifies placing the surveillant (protectionist) gaze on 
middle class women and the surveillant (suspicious) gaze on lower class men - mediating access to public space for both.

Khan (2018) argues that in urban Pakistan, women are put under the surveillant gazes of men and the paternalistic state as they enter public spaces, with the attempt to provide women security by "inverting the male gaze onto itself". This is a function of state surveillance also embodying characteristics of the male gaze, such that only particular types of "good women" are guaranteed protection - those who enter public space for legitimate purposes and have a character deemed "worthy of protection" (Khan, 2018).

However, rights-based framings of privacy have also been critiqued by feminists for starting from the perspective of an individualised subject with bargaining power (Allen, 2011). Individualisation has the potential to invisibilise the web of power and social relations which mediate decision-making for women across the global South, including about their own bodies (Weinberg, 2017).

Kovacs (2017), while critiquing surveillance through the lens of gender, invokes Lyon (2003) in arguing for a shift from the individual rights-based framing of privacy to that of social justice, since surveillance is a "structural" rather than "individual" problem. This aligns well with the theorisation of data justice, the starting point for which is embedding data systems in their social context and web of power relations (Taylor, 2017).

\section{B3. Data Justice}

Where the discourse around CCTV surveillance, as with other data-driven systems, has been framed around tradeoffs between efficient security, privacy, and data protection (Dencik et al.,2016), data justice allows for factoring in the politics of data by squarely situating these data-driven systems within the social contexts in which they are embedded (Taylor, 2017).

Recognising the shifts in the social contract that datafication is bringing about, Taylor (2017) utilises a 'capabilities' approach to bridge disparate conversations around data justice to carve out three pillars on which an international data justice approach could be premised: (in)visibility, (dis)engagement with technology and anti-discrimination. Taylor (2017) argues that these integrate the key negative and positive freedoms which are required by individuals for a fair engagement with data systems globally. For instance, along with the right to privacy, this would include the right to be represented, or to move out of the "surveillance gap" - which applies to individuals or groups who are excluded from databases depriving them of critical rights ranging from citizenship to welfare benefits (Gilman and Green, 2018).

Heeks and Shekhar (2019) provide an overarching analytical framework to think through the different dimensions of data justice. As mentioned earlier, we use their model to situate our case study of CCTV systems in Delhi. They define data justice as having five dimensions, relating to data flows and results of the data system. The first dimension, that of procedural data justice, relates to the processes of data handling within the "information value chain": the flow from data through information and decisions to actions and results. It indicates the level of inclusion across different points in the value chain, upstream (relating to data and 
information) and downstream (relating to decisions and actions), which in turn indicates the distribution of those contributing data and those who make decisions utilising that data. The second dimension relates to instrumental data justice, or fairness in the results of the data system. Rights-based data justice relates to the enforcement of the negative and positive rights outlined by Taylor's (2017) framework, including representation and antidiscrimination. Structural data justice pertains to the extent to which the 'structure', constituted by dominant actors and institutions, supports social justice in the functioning of data systems. Finally, distributive data justice encompasses all of the categories detailed above, and relates to broader concerns of justice and equity (or lack thereof) that underpin data systems. Put simply, it is "the concern for who gets what as a result of data systems" (Heeks and Shekhar, 2019).

\section{B4. Neoliberal Governance and Urban Planning}

Data justice - particularly the structural dimension - concerns itself with the political economy of the data system, and the extent to which it is dictated by, or challenges, power differentials. Recent work has noted the increasing privatisation of public spaces, reflected in practices of neoliberal governance and the discourse around data-driven 'smart cities' (Firmino and Duarte, 2015; Coletta et al., 2018). A critical imperative within this discourse is projecting efficiency to attract investment by global capital (Firmino and Duarte, 2015). Phadke et al. (2011) argue that this imperative inherently conflicts with the rights of marginalised groups to equally access public spaces, as they get sanitised and commercialised. They go so far as to say that private spaces of consumption then "masquerade" as public spaces, welcoming only those with the "capacity to buy" (ibid.).

This happens, in part, through privately funded surveillance systems that impose the normative boundaries on public spaces, set by private actors. Fyfe (2004) characterises public-private partnerships in the United Kingdom as a way of "justifying private control over public spaces". He argues that private surveillance excludes those individuals that are considered deviant by the private actors that control the surveillance system (ibid.). Minnaar (2012), in an empirical study on growth of CCTV in South Africa, demonstrates that such growth can be mapped onto the parallel growth of gated neighbourhood enclosures. Gated residential enclosures have also sprung up all over New Delhi, and have been illegally encroaching on public spaces through the city (Govindarajan, 2016). Video-based surveillance in semi-private spaces such as gated residential areas then distributes security unequally (Huey, 2010), and could even reinforce caste and class relations by policing workers (Alkazi, 2015).

Firmino and Duarte (2015) further argue that the public-private model of CCTV systems leads to "scattered networks of technologies and practices", as opposed to acting like a centralised control system as has been projected in the discourse of urban planning. These are then understood to be locally contextualised and mediated, rather than entirely topdown systems with perfect command-and-control centres. Despite such fragmentation, it has been argued that constant awareness as a risk management strategy has become an integral identifier of contemporary societies (Giddens, 1990; Beck, 1992). As video-based surveillance systems move towards greater integration, penology moves away from problem diagnosis towards risk management (ibid.). An "actuarial" approach to managing 
criminal activity at the aggregated level of entire populations is then seen to be taking hold (McCahill, 2002).

\section{C. Methodology}

The study takes a feminist approach to qualitative methods. Drawing on Wickramasinghe's (2009) conception of feminist epistemology of knowledge in the global South, we conducted semi-structured, in-depth interviews to bring out lived experiences of surveillance among different stakeholders, with a focus on women living in informal settlements in Delhi. Other stakeholders were interviewed to surface the social relations in which the surveillance system is embedded. We interviewed six categories of stakeholders, listed in Table 1. Interviews also allowed us to glean perspectives of different stakeholders to interrogate dominant, alternative, and counter narratives around video-based surveillance and privacy, and integrate these into a theoretical framework of urban data justice.

We employed purposive sampling, aiming to gather perspectives from across key stakeholders engaged in and affected by video-based surveillance of public spaces in New Delhi. We employed the snowballing technique within purposive sampling for law enforcement and government officials, and attempted to diversify civilian respondents by class.

In addition to the interviews, some observational and anecdotal evidence was also collected during the course of the fieldwork, by observing meetings between stakeholders. Finally, we also sent in Right to Information requests to the Delhi Police inquiring about budgetary allocations to cameras and drones under programmes that aim to ensure safety for women.

\begin{tabular}{|l|l|}
\hline Stakeholder Group & No. of Respondents \\
\hline Women using public spaces & 15 \\
\hline Delhi Police & 11 \\
\hline $\begin{array}{l}\text { Delhi Metro Railway Corporation/Central } \\
\text { Industrial Security Force }\end{array}$ & 4 \\
\hline Resident Welfare Association & 7 \\
\hline Commercial Establishments & 8 \\
\hline $\begin{array}{l}\text { Government Officials (Ministry of Women and } \\
\text { Child Development, Public Works Department, } \\
\text { New Delhi Municipal Council, civil servants) }\end{array}$ & 5 \\
\hline Total & $\mathbf{5 0}$ \\
\hline
\end{tabular}

Table 1: Stakeholders Interviewed 


\section{D. Findings}

\section{D1. Procedural Data Justice}

\section{Fragmentation and function creep}

Several differing motivations and functions behind investment into video-based surveillance by the police and state emerged during the course of our research. This has implications for the manner in which data flows are structured and data handling processes are designed. While it is unclear precisely when and what the motivations were behind the initial uptake of CCTV installation in Delhi, one of our respondents from law enforcement suggested that initial installations were rolled out in the course of preparations for New Delhi hosting the 2010 Commonwealth Games. ${ }^{55}$ This is in consonance with other efforts to commercialise the city and make it appear worthy of investment including slum demolition and the growth of surveillance systems with commercial interests (something seen in other cities in the global South (Minnaar, 2012)).

The well-publicised push for CCTV installation in Delhi commenced as a response to the country-wide protests following the multi-perpetrator rape of a young female in New Delhi in 2012. A sizeable corpus of INR 6.6 billion (c.USD 96.5 million) earmarked for this purpose the Nirbhaya Fund - was set up by the central government in the immediate aftermath of the rape. The installation of CCTV formed a part of technological solutions that were to play a key role in making cities safer for women (Ministry of Women and Child Development, n.d.). From 2010 until February 2018, about 5,000 CCTV cameras were installed by the Delhi Police. However, as indicated by the responses to our Right to Information application to the Delhi Police, none of them have been installed under the Nirbhaya Fund. Moreover, an interview with an official of the nodal ministry for the corpus indicated that the ministry's outlook now was that CCTV systems are not to be funded out of the corpus as they were ineffective in enhancing safety - at least in the ministry's articulation of safety - and were more effective for the purposes of investigation.

What has also emerged is a fragmented yet organised matrix of CCTV systems used to surveil over public spaces and perform undefined roles, as theorised by Firmino and Duarte (2015) previously. This then leads to the utilisation of CCTV for purposes that are determined on an ad hoc needs basis. For instance, while CCTV systems have been installed primarily to increase safety for women in public spaces, the police unit that is specifically designed to address crimes relating to women and children had no role to play in the implementation or monitoring of such systems. In a similar vein, the implementation of CCTV cameras by the metro corporation was initially meant to aid in operational and crowd control objectives, and the utilisation of CCTV cameras for security purposes then became a by-product. Meanwhile, the objectives behind installation of a CCTV camera system by the municipal council in its jurisdiction was intended for maintenance of public order, not criminal activity as such.

\footnotetext{
${ }^{55}$ The respondent also suggested that most of the cameras installed back in 2010 while preparing for the Commonwealth Games are probably dysfunctional now and need to be replaced.
} 
Another way in which contradicting purposes behind CCTV installations emerge is by observing the provisioning of signage, if any, designed to indicate ongoing surveillance. Simply put, law enforcement officials described two aims behind placing visible signage accompanying CCTV cameras, (a) crime deterrence, and (b) making those under the camera's gaze feel safer by knowing they are being watched. On the other hand, covert surveillance, i.e. CCTV installations without any indication of such installation, aims to watch without the knowledge of the person being watched, which then has detection of crime as its primary motive. The two sets of objectives come into conflict, and are often adopted on an ad hoc basis.

For example, in a busy marketplace in Delhi, widespread CCTV installations by the MWA in this public spot were accompanied by regular announcements on the public address system informing those in the marketplace of being under surveillance. A law enforcement official posted at the marketplace, then, also indicated that CCTV cameras were intended to deter crime and for post-facto investigation. Within the same marketplace, however, several commercial establishments that we spoke to indicated that while they had initially installed cameras as an "insurance" against crime, a key purpose that they served now was to monitor stock as well as employees - or managerial surveillance, in other words. These commercial establishments either did not have any signage or the few that did opined that the signage was a relic from when they had initially installed the cameras, and that it served "no real purpose". For the commercial establishments especially, the symbolic deterrent effect of CCTV cameras (Hempel and Töpfer, 2004), then, is significantly diluted owing to an array of reasons: irregular monitoring, informational overkill, and the inertia within law enforcement.

The selective use of signage could additionally contribute to an information asymmetry between the implementers of CCTV cameras and those being surveilled. This argument is substantiated further in the next subsection.

\section{Access to information}

We found that a number of women were unaware of the existence of cameras installed or governed by law enforcement, except in places where cameras are very visible, such as in metro stations. A few interviewees expressed discomfort with the topic of conversation due to their perception of low levels of knowledge regarding CCTV cameras, and some women who were approached even refused to interview, citing their lack of any knowledge. None of the interviewees were aware of the extent or locations of camera coverage, the identity of surveilling authorities, or the demarcation between private and public systems - even if they were aware of the general existence of CCTV cameras. This information asymmetry was explicitly endorsed by some of our respondents within the Delhi Police, as they understood the purpose of CCTV surveillance to primarily be of crime detection. This, according to them, then mandates the least level of information dispersion, as surveillance was understood to be a covert activity to be performed without the knowledge of the watched.

In most cases, however, this did not erode trust in the system, as the general awareness of cameras operated by law enforcement made women feel safer, especially in isolated areas. This is in contrast to Koskela's (2002) interviewees, whose trust in the system was 
significantly eroded by lack of knowledge regarding the identity and location of the surveillers. This could partly be attributed to the perceived lack of capacity and approachability of, and therefore trust in, the Delhi Police. Women across locations and classes, with a few exceptions, expressed the inadequacy of the Delhi Police in responding to crimes against women. By and large, women who expressed distrust in the police also expressed increased trust in technological systems, perceiving them as unbiased and dispassionate observers.

\section{To regulate or not to regulate}

Delhi's CCTV project has stemmed from a drive towards crime control that is governed through coalitions between locally situated police, retailers, private citizenry and hyper-local governing institutions. What is emergent then is "scattered networks" (Firmino and Duarte, 2015). This has significant repercussions for the manner in which data is handled and the kinds of voices that become dominant in decision-making processes. Over the last 2 years, there have been calls from voices, albeit solitary, within the state machinery to have standard operating procedures in place that govern the installation of CCTV cameras (Barman, 2018). In the absence of any governing legislation speaking to the installation of CCTV cameras specifically, or data protection broadly, untethered power is being granted to both state and non-state actors without any accountability mechanism in place.

It was in this backdrop that a draft version of the "Delhi Rules for Regulation of CCTV Camera Systems in NCT [National Capital Territory] of Delhi, 2018" (CCTV Rules hereafter) were released. While the CCTV Rules still do not have the force of law, members of one RWA that we interviewed stated that the CCTV Rules make the CCTV installations legal and are being utilised to support further installation drives. The CCTV Rules seek to regulate the installation and use of CCTV cameras in public spaces in Delhi. The CCTV Rules do have some useful stipulations, such as somewhat limiting the purposes for which the information recorded is used, mandating signage indicating ongoing surveillance, and also on the utilisation of open technical standards. However, they fall short on several counts. For one, they treat the information recorded as belonging to the owner of the system with the right to access the information provided only to "authorised persons". It is unclear who such authorised persons are. Further, they pay performative obeisance to incorporating privacy protections when they state that "the camera shall be located at such place so that it shall not collect information which invades the privacy of an individual" (Government of Delhi, 2018). These stipulations read together encode an understanding of privacy as a condition that individuals occupying public spaces do not have a claim to. It is evident that a primary objective here is of according significantly enhanced law enforcement control to, knowledge of, and access to all CCTV installations "collecting information from a public space" (ibid.).

\section{D2. Instrumental Data Justice}

\section{Security for whom?}

The Delhi Police had installed 5,000 cameras across the city as of February 2018. A majority of its network comes from a public-private model of collaboration, called the 'Nigehbaan' scheme. This allows the Delhi Police to access another 175,000 cameras across the city. This 
network includes cameras installed by private individuals or groups, including individual residents, businesses, wealthier RWAs and MWAs. An overwhelming majority of CCTV cameras in Delhi are thus implemented and controlled by private stakeholders. As has been pointed out in other cities across the global North and South, the privatisation of security in public spaces inevitably results in unequal access to security for different groups (Huey, 2010). This also brings into question data ownership, as it is very likely that the individuals being recorded would not even have ready access to the footage, or any procedures in place in order to do so.

Access to public space itself becomes unequal, as privately funded security systems privilege the interests of the landed class or those with commercial capital and discriminate against lower caste and class groups entering those spaces (Alkazi, 2015). The interests of those who own surveillance systems often come into conflict with interests of those without access to resources and capital to perform surveillance - posing challenges to rights to access and ownership of data and data systems. This surveillance system can then be seen as a concrete reproduction of the 'suspicious gaze', extending here to all workers entering gated residential areas and other privately surveilled public spaces (Phadke et al., 2011).

Such conflicts emerged during a meeting we observed between residents of a gated residential area with local police officials in the south of New Delhi. Residents raised several questions demanding the implementation of CCTV, which they were told has been taken care of by the RWA. Law enforcement and residents then discussed security issues in the area, largely seen as arising from the entry of workers such as private security personnel, cab drivers and domestic workers within the gated community. Both residents and law enforcement discursively positioned workers as potential criminals to be controlled through surveillance systems. It is in such a context that CCTV systems are being introduced into the gated area, including those being funded by the Delhi government. The privatisation of data and data systems then inevitably creates the conditions for distributive injustice, as data is extracted from lower class workers and benefits accrue to upper or middle class employers.

Simultaneously, we found that poorer sections of the urban landscape, such as slum camps even those that are legally recognised by the state - were found to be existing in the surveillance gap (Gilman and Green, 2018). With no CCTV installations provided either by law enforcement or the state, these areas were curiously outside of the growing ubiquitousness of CCTV-based surveillance systems. This was consistent with the nonrecognition of their requirement for basic amenities such as water drainage and potholefree lanes. Contrast this with the experience of affluent gated communities where not only is there a web of privately installed CCTV cameras, but also funding and infrastructural support by the state for further installations. This leads to the structural invisibilisation of vulnerable groups with very little political voice.

Akin to how surveillance is utilised to reproduce power dynamics, the surveillance gap can be similarly utilised as a tool to exert social control (ibid.). While the "gap" is not something that is de facto intended to be bridged, our respondents expressed a strong preference for the installation of at least some CCTV cameras at the entry and exit points as a crimedeterrent tool in the absence of a responsive and approachable law enforcement mechanism. This lends further credence to the feminist understanding of privacy as having a 
deeply contextual meaning, instead of implying the complete rejection of surveillance systems.

\section{Conflicting expectations and objectives}

This section deals with conflicting expectations within women respondents and law enforcement, which indicate different results of surveillance for different groups. There emerged several fault lines, along the lines of caste, region, and class, within women respondents using public spaces. A small subset of women respondents, largely those who identified as middle class, advocated for CCTV cameras covering residential areas in which they lived. They expressed the need to monitor entry and exit points into gated residential spaces, and to regulate the movement of outsiders into what were perceived as private zones. These outsiders mostly constituted other marginalised groups, including working class men, male migrant workers from other states or neighbouring countries, and sex workers. This corroborates Phadke et al.'s (2011) conception of the dominant narrative of working class men being constructed as one of the primary threats to middle class women as they use public spaces, justifying the use of surveillance mechanisms to police both groups. Further, as corroborated by Wright et al. (2014), groups such as sex workers and beggars are at greater risk of persecution as they regularly perform solicitation on the street which either (a) heightens visibility in public spaces or $(b)$ is criminalised when performed in public.

Fault lines between the objectives of civilian women respondents and surveilling authorities also emerged in several cases. Most women respondents argued that CCTV fulfilled either or both of two purposes - prevention and investigation. However, all our interviews with law enforcement indicated that there is little to no crime prevention, including sexual harassment and violence, that they have experienced or expect to experience in the future at least while systems continue to be fragmented. In addition, women respondents also expected constant real-time monitoring in places where cameras had been installed, which is not the case across state and privately controlled systems. The perceived trade off being made by respondents between security and privacy in urban public spaces is then made in the context of limited information dispersion. This then leads to expectations of constant surveillance from a system that is excessively fragmented.

Fault lines were also found in specific use cases. We found that tracking missing persons is a regular function of the Delhi Metro surveillance system, which includes women or men who have run away from home. Maintaining the autonomy of the "missing persons" then lies at the discretion of the officers handling their case - as one respondent told us, they don't do anything "unethical" and therefore turn back husbands who are stalking their wives, but do help with cases of runaway persons whose parents report them as missing. That these fault lines appear along the axis of gender very frequently can also be found in other cases - such as in Orissa, when a camera that was installed to protect women against violence had to be removed after protests from women who did not want to be watched while bathing (PTI, 2012). These cases illustrate that the objectives and zones of protection determined by those in authority and those of the beneficiaries do not always overlap. 
The conflicts then bring out contradictions in surveillance systems that are aimed at both control and care, demanding the balancing of the right to privacy against physical security (Taylor, 2017). Wright et al. (2014) describe this conflict as the extent to which "visibility threatens or provides safety". Reading the concept of the male gaze along with Monahan's (2009) understanding of context/use discrimination is relevant here. Read together, they speak to the masculinised and distanced monitoring of the feminine body and feminised spaces. As Monahan (ibid.) argues, "when social contexts are already marked by sexist relations, then surveillance (and other) technologies tend to amplify those tensions and inequalities". The case of the surveillant gaze and the voyeuristic gaze are, in this case, overlapping to disadvantage either particular groups across contexts (couples getting intimate), or all women in a particular zone of surveillance (on the beaches of Puri). The latter can be addressed through the principle of engagement with technology (ibid.) within the principles of data justice, which enables selective use of technology, and could then be mobilised to reject surveillance in certain public zones.

\section{D3. Rights-Based Data Justice}

\section{Privacy and the surveillant male gaze}

We found women respondents prioritising the right to be represented in video-based surveillance systems over their right to privacy, displaying very high levels of support for CCTV systems. This then implies that the CCTV system in the city provides rights-based data justice, in the trade-off between security and privacy. As in Hasija and Nagpal's (2018) study, women overwhelmingly chose the right to be represented in the surveillance systems with the perceived benefit of security. Unlike Hasija and Nagpal's study however, we did not find evidence of women feeling at risk of stalking or violations of privacy. We further found that respondents who supported video-based surveillance also felt that current levels of coverage in the city were low, advocating for further coverage of isolated or lonely roads in particular.

Respondents across the various stakeholders we interviewed indicated their understanding of privacy as confined to private spaces, which were amorphously defined. Individual police officials define the private zone based on their subjective understandings of privacy. One of our respondents from the Delhi Police, for instance, conceptualised private zones as any area inside one's home that is not visible from the street. It then appears that being constantly monitored and recorded is inevitable for those who do not have access to private property, limiting rights to disengage with technology. It was striking that it was only in the context in which privacy in public spaces was brought up by a law enforcement official in our interviews was when referring to areas that house senior government officials and those with political power, described as "VIPs". A senior Delhi Police official revealed that the provision of safety to VIPs could even be through the temporary installation of cameras on routes being used by such persons, which are then removed to protect the privacy of permanent residents in these areas which typically house a host of high-level politicians and government officials. The right to disengage from surveillance systems, a critical data right (Taylor, 2017), was only accessible to publicly elected officials and government officials at the very top of the hierarchy. 
Women using public spaces affirmed the dominant discourse of privacy and public spaces being in completely separate domains, with privacy only to be sought and protected in the spatial understanding of the private domain. The lack of a conception of privacy in public spaces reiterates the gradations in access to the right to privacy outlined by feminists, through its contingency on a strict dichotomy between private and public spaces (Allen, 2011; Adler-Bell, 2018). The publicness of a space then justified, and even demanded, the presence of the surveillant gaze of law enforcement. The gaze is then aimed at sanitising public spaces of potentially dangerous elements, who could cause disruption to public order (Walby, 2005).

When asked whether they considered the leaking of footage of couples getting intimate in metro trains as a harm of CCTV-based surveillance, most women civilian respondents, with the exception of two, did not perceive this to be a privacy violation and blamed the couples for getting intimate in a public space. In a similar vein, Phadke et al. (2011) finds in her study that the discourse of privacy has been used to persecute couples for acts such as holding hands in public spaces, through the discourse of obscenity. Obscenity then overwhelms the privacy violation in the public imagination, with several respondents arguing that being intimate in a public space such as a metro, which has families and children, is against cultural norms of propriety in public spaces. This also points to the notion that expectations of privacy are hyperlocal and specific to the norms of a particular space.

Video surveillance in this case is used to enforce cultural behavioural norms by punishing deviance with not only the violation of privacy, but the removal of the expectation of privacy at all. This manifestation of privacy is very similar to Allen's (2011) notion of unpopular privacy - as an argument against autonomy.

Contrary to this, two women raised distinct objections to the leaking of footage of couples on the metro. One argued that such incidents are "disgusting" and "amount to the misuse of the public", particularly because the official monitoring the footage is "watching porn and gaining entertainment...they make a video of it and upload". The respondent raises a specific concern about the voyeuristic gaze of the surveillant authority, which brings disproportionate attention on women in public - including particular categories of vulnerability such as "breastfeeding women".

The second argument against data leaks, made by a respondent who described herself as being a recent entrant into public spaces without male companionship, supported increased protections against leakage "especially because people don't have knowledge of these things, and are very often not educated or aware". Lack of awareness could stem from poor access to information, barriers such as signs indicating the presence of cameras being in an unfamiliar language, or general unfamiliarity with public spaces due to barriers to access. It can be seen that categories such as women with unequal access to public space, undereducated groups, and migrants then simultaneously face higher risks of privacy violation (Adler-Bell, 2018) and/or have fewer resources or awareness to deal with such violation. This could then pose a threat to rights-based data justice as certain groups are overrepresented in the leaked data, and procedural data justice, as those groups are left out of the value-chain of information flows. 


\section{Criminalisation and the panoptic gaze}

In our interviews with Delhi Police in Central Delhi, the part of the city with the maximum concentration of government offices and other state agencies, and also therefore of public demonstrations, we found protest gatherings to be one of the key sites of surveillance. Officials from control rooms that perform the surveillance revealed that some of the fisheye cameras have been recently acquired and are only deployed in key locations - which includes the locations where political protests and public demonstrations are organised. The heightened surveillance at sites of public demonstrations are in a context where protesters can be detained or arrested for performing demonstrations as it constitutes a breach of public order, among other concerns (Delhi Police, 2019). Targeted surveillance at sites that have been demarcated for public demonstrations by law enforcement are an additional measure of control, in addition to prior permissions from law enforcement to stage such demonstrations. Taken together with instances of illegal detention, heightened surveillance adds to a context of constraints placed upon the right to freedom of assembly in the city.

This can be seen as an instance of a larger shift in how risk assessment and criminalisation is increasingly being thought of by law enforcement, with the imagination of heightened surveillance technology. Respondents involved in the implementation of CCTV systems expressed intentions to integrate other technologies in the 'ideal' security solution. Technologies such as facial recognition and video analytics were frequently suggested. One proposed implementation of facial recognition was of metro users at station entry and exit points. Among other functions, this could be used to expedite entry and exit from metro stations of certain categories of individuals such as government employees. The data of these individuals would be stored in a database against which the facial recognition software would cross-check the legitimacy of those seeking to enter or exit through this system. Another proposed implementation was for images of 'suspects' at metro stations to be searched in real-time against a database that already had stored images. Such 'searchability' in CCTV footage is also being desired nationally (NCRB, n.d.).

What these imaginations bring forth is the objective of CCTV-based systems to provide more than the raw data observed, and move towards the actuarial approach to crime management (McCahill, 2002). If implemented, these will have a profound impact on how CCTV systems are utilised, given that the data justice implications of these newer technologies such as facial recognition and artificial intelligence are only just starting to be understood by civil society. CCTV in and of itself, then, is also seen as a weak surveillance tool, whose integration with computer-based systems with sophisticated data processing power is crucial to then exercise more intensive surveillance (Lyon, 2001).

\section{D4. Structural Data Justice}

\section{"At least then they will believe us"}

Most participants from lower socioeconomic backgrounds had direct or secondary experiences of the Delhi Police as unresponsive to their needs or even violent. Poor women expressed very low levels of trust, with statements such as "the police is not meant for poor people, it is only meant for the rich". Several instances of such unresponsiveness were 
detailed through interviews, including cases where the police took a response time of several days, delayed investigations, or even refused to investigate. One group of participants, selling goods close to a busy thoroughfare in Central Delhi, spoke about routinely facing violence from the police, and regularly getting taken to police stations for thefts that they did not commit. They believed themselves to be easy scapegoats during police investigations, due to their constant physical presence in public areas. Poor women felt a fear of unresponsiveness or violence in their interactions with law enforcement, in addition to their fear of harassment or violence from men in public spaces. They partly ascribed their persecution by law enforcement to their constant presence in public spaces, as they operated in public every day to earn their livelihoods.

Due to the historical experience of suspicion that the police displayed towards them, they felt that cameras in public spaces would allow them to provide incontrovertible evidence of either cases where they were complainants, or prove their innocence in cases where they have been falsely accused. One group of women also expressed that it might help them to carry investigations through, as the police personnel usually take four to five days to respond to complaints by which time witnesses may no longer be available. In all of these instances, the presence of a camera could provide or improve access to justice and legal recourse for citizens and communities who currently feel excluded from such systems.

However, several participants challenged this reading of the camera, and reiterated that it is merely an object embedded in the social context, rather than a free floating tool to be used for the benefit of the aggrieved. They were thus sceptical of the extent to which CCTV could enhance access to justice, without responsive officers carrying out investigations on the basis of that footage. This indicates that increased access to legal redressal through video surveillance is contingent on rights-based justice within broader social structures - it is critical for citizens to have access to legal systems and data flows for this potential to materialise.

\section{Turning the gaze inwards}

Several respondents from among law enforcement and government officials spoke about initiatives to provide CCTV coverage to public offices, such as police stations, civil servants' offices, and Public Works Department's offices. This is following a Supreme Court order in 2014 to install CCTV across police stations in the city, and has been explicitly identified as a move to prevent violence against women in police stations (Express News Service, 2019).

Three objectives emerged behind the coverage of police stations and other government offices in our interviews with law enforcement and government officials. One, providing officials protection from false complaints. In particular, police officials spoke about protecting themselves against false allegations of violence, while government officials spoke about false allegations of committing atrocities against Scheduled Castes and Tribes, or of sexual harassment in case of male officers. Two, increasing accountability to the public, by treating government offices as public spaces to be monitored and held accountable to citizens. Three, managerial surveillance, with monitoring of their own stations as well as through centralised monitoring of several stations in one control room. Each of these objectives could potentially contribute towards making policing systems and government 
functioning more transparent and accountable to citizens, as their actions are made visible to the public and to each other. This requires greater emphasis on procedural aspects of data flows, with the inclusion of police officials upstream, and the inclusion of citizens downstream in the information value chain.

The configuration of the infrastructure of the monitoring system determines its contribution towards enabling accountability and transparency and ultimately, structural justice in the results of surveillance systems. In police stations, screens could either be placed in public areas such as reception rooms and/or in the offices of senior officials. We found some stations where screens were monitored and controlled only by senior officials, which could exacerbate power inequalities. During a field visit, for instance, we found that public demonstrators were told by beat officers that they would have to appear harsh in their behaviour since they were under surveillance from another station. On the other hand, a senior bureaucrat said that she uses CCTV cameras to ensure that each officer across departments is treating visitors properly. CCTV could then act as a tool to alleviate power inequalities between citizens and government and law enforcement, by making each stakeholder visible to the other. This is not the case in monitoring systems that prioritise upstream data flows (from citizens to state) over downstream ones (from state to citizens), posing barriers to data-just systems (Heeks and Shekhar, 2019).

\section{E. Discussion and Conclusions}

The design of contemporary urban spaces has been dominated by increasing concerns around securitisation. Achieving and maintaining these imaginations requires the reinforcing of implicit hierarchies, and by extension, exclusions, in public space. One way in which these have manifested is through geo-spatial segregations that are privately controlled. Indeed, the idea of the public itself has been constructed to value some social groups over others, with access to public space being made differentially available. That the urban public space itself is the medium as well as the outcome of social practices is abundantly clear. Exclusion and intolerance, and their conflation with safety and security, get negotiated and coproduced with others occupying the public space.

CCTV systems have proliferated remarkably in Delhi in the last few years, and continue to grow at remarkable levels even as this paper is being published. While there is a care motif at play here, it also showcases how disciplining functions co-evolve (see Lyon, 1994). Our findings indicate that the panoptic gaze is not a homogenous power exercised only by the surveiller, but is multifarious and intermingling. For example, one finding in this research is that the gaze of the panopticon is turned on itself, as both public servants and the public are both now within the gaze.

The disciplining power of the gaze also manifests in the internalisation of modesty ideals by women themselves, as women respondents in our street interviews indicated having internalised the absence of rights such as privacy that may be reasonably afforded in public spaces. The equating of increasing CCTV with increasing women's safety then indicates a contradiction in the shifting of the gender ideologies in public spaces, with women now required to be making themselves hypervisible in exchange for security guarantees from the 
masculinised state. Visibility, then, is made to be a prerequisite to security. Moreover, women respondents in the study invariably identified as objects of surveillance rather than subjects, consistent with research on CCTV surveillance elsewhere (Wright et al., 2014). This is reflected in the lack of female representation among those planning and executing surveillance systems, even among those designed specifically to combat violence against women.

\section{E1. Conclusions}

The theoretical focus of work on CCTV systems has focussed on it at a post-installation stage, on its operation. Such a view leads to the dehumanising of video-based surveillance whereas the material realities unsurprisingly indicate the centrality of human engagement at every stage of implementation and operation. Re-centring the 'human element' allows for work around data justice to understand technological developments in light of larger, historical forms of structural and institutional oppression. We utilise this framework, particularly the model of data justice developed by Heeks and Shekhar (2019), to study the implementation of CCTV systems in New Delhi and the social context in which those systems are embedded. Further, explicitly attending to questions around gender, while incorporating methodological and epistemic innovations put forth in feminist thought, allows for the exposition of a social justice agenda. In doing so, we were able to centre the power relationships that underpin surveillance.

Within the dimension of procedural data justice, or justice in handling data systems, we interrogated the motivations and interests of those who control CCTV systems in Delhi. We found objectives devised by civilians, the state, and law enforcement to be mutable, and at times contradictory. The provision of signage, or lack thereof, was found to be indicative of different theories of change behind CCTV installation. Responses addressing the uses of CCTV were usually wide ranging: pre-emptive behavioural change, and/or post-facto evidence of crime, and/or performative security. The objective for the state, at times, was to protect commercial interests, also at odds with the propagated public narrative that makes CCTV crucial in enhancing women's safety in public spaces. This could arise from the lack of representation of marginalised interests at the procedural stage of the system, with implementation being largely controlled by private actors, law enforcement, or the state.

Results of the system, or instrumental data justice, were found to be critically dependent on the harms or benefits of visibility to the state. Thus, while most middle class women supported CCTV systems for enhancing their safety, most women from informal settlements found it useful to prove their innocence in cases of false accusations or when officials refused to believe their complaints. Women performing activities in public spaces that heightened visibility while also inviting public censure or disrupting public order, such as sex workers, were found to be accruing the harms of the voyeuristic and controlling gaze of the state and others using public spaces.

Within the dimension of rights-based data justice, a key right that we focus on is that of privacy within public spaces. Our findings indicate a deeply contextual articulation of privacy. Inherent in the articulation is an internalisation of a strict separation between what constitutes a public or private space with privacy only to be expected in the latter. This, 
along with belief in the efficacy of CCTV in aiding greater security and safety, also provides the fuel for the articulation of greater CCTV coverage by the supposed beneficiaries of CCTV installation. However, contradictions emerge as this trade-off between privacy and security is made in an information-scarce environment, often intentionally designed as such by surveillers. The other key right we assessed was the right to be represented, which was unfulfilled for Informal settlements as they were found to be in the 'surveillance gap' despite wanting CCTV systems to deal with unresponsive law enforcement officials.

Finally, structural data justice, or the extent to which powerful institutions and individuals support the interests of equality and justice within data systems. We found that regardless of objectives and expectations of different stakeholders, the actual usage of CCTV systems is hyperlocal and determined by power relations, social norms, and institutional structures in the particular space in which it operates. This is also applicable to CCTV cameras that are placed upon law enforcement and government officials, which aim at turning the gaze of the state onto itself but can only succeed in doing so if upstream and downstream data flows are given equal attention.

\section{E2. Recommendations}

Given the multiplicity of actors that are engaged in the unrolling of Delhi's CCTVisation, as well as the breadth of intended beneficiaries, several conflicts emerge in how these systems are designed, who they are designed for, and what benefits and harms subsequently emerge. Such conflicts can be addressed through wide public consultations with different stakeholders, including non-governmental and civil society organisations working on women's rights, gender, urban planning, and the right to privacy, in addition to RWAs and MWAs (Goswami, 2018).

A recommendation that holds true for all datafication programmes in India that are at various stages of implementation is for the crafting of policy that ensures robust transparency and accountability measures are institutionalised. This is especially critical in the absence of any comprehensive data protection law. At the same time, there is a dire need for processes that mandate mechanisms of appraisal regarding the utility and subsequent appraisal of these datafication initiatives. This is glaring in the present case of CCTV, where it is effectively the mythology of the technology that is garnering the political support for increased demarcation of public funds towards the CCTV project.

The lack of any concerted approach towards the roll out of the CCTV programme has also led to potentially debilitating consequences owing to the ad hoc determination of use-cases by departments within government and law enforcement tasked with the mandate to implement CCTV. The case of the police unit that has been carved out to address crimes relating to women and children having no engagement with CCTV is telling. This is especially curious given the equating of more CCTV with enhanced women's safety, as well as a scenario where uptake of CCTV is being ensured in every police station in the city. Whether any internal processes govern this inter-departmental work allocation vis-a-vis CCTV is unclear, and in any case, opaque. 


\section{Future research agenda}

An immediate research agenda is to better understand the implications of the 'newer' technologies creating big data systems such as facial recognition software and artificial intelligence applications for which use-cases are being cultivated in datafication programmes being spearheaded by the state. The political economy around these moves is as yet understudied, and urgent work is required to pre-empt some of the distinct ways in which the governance of society and the data justice potential of systems could be impacted. As these make their way into the delivery of welfare systems in the global South, what datafication programmes entail for contemporary understandings of the social contract, participation in a democratic society and for citizenship itself are more overarching questions that require urgent addressing.

Any data justice project explicitly occupies the realm of governance, making it a worthwhile bridge to inform any such project through disciplines that do not occupy the space. While this case study was one such attempt at doing feminist surveillance studies, a data justice project could, in some sense, bring together any disciplines more occupied with critical approaches such as urban studies, critical data studies and surveillance studies. 


\section{References}

Adler-Bell, S. (2018). Privacy for whom? The New Inquiry, 21 Feb. https://thenewinquiry.com/privacy-for-whom/

Alkazi, A. (2015). Gated Communities in Gurgaon: Caste and Class on the Urban Frontier. Senior Projects Paper 114. Annandale-On-Hudson, NY: Bard College. https://digitalcommons.bard.edu/cgi/viewcontent.cgi?article=1249\&context=senproj $\mathrm{s}$ $\underline{2015}$

Allen, A. L. (2011). Unpopular Privacy: What Must We Hide? Oxford: Oxford University Press. Barman, S. (2018). State of surveillance: Who controls the data collected from CCTVs in the capital? Indian Express, 21 May. https://indianexpress.com/article/cities/delhi/state-ofsurveillance-delhi-cctv-aap-anil-baijal-5184751/

Beck, U. (1992). Risk Society: Towards a New Modernity (first ed.). London: Sage Publications.

Benjamin, R. (2016). Informed refusal: Towards a justice-based bioethics. Science, Technology, \& Human Values, 41(6), 967-990. doi:10.1177/0162243916656059

Browne, S. (2010). Digital epidermalization: Race, identity and biometrics. Critical Sociology, 36(1), 131-150. doi:10.1177/0896920509347144

Browne, S. (2015). Dark Matters: On the Surveillance of Blackness. Durham, NC: Duke University Press.

Coletta, C., Evans, L., Heaphy, L., \& Kitchin, R. (2018). Creating Smart Cities. Abingdon, UK: Routledge.

Crenshaw, K. (1991). Mapping the margins: Intersectionality, identity politics, and violence against women of color. Stanford Law Review, 43(6), 1241-1299. doi:10.2307/1229039

Delhi Police. (2019). Order No. 1872-1996/SO-ACP/Pt.Street/NDD. Sub-Division of Parliament Street, Delhi: Delhi Police.

Dencik, L., Hintz, A., \& Cable, J. (2016). Towards data justice? The ambiguity of antisurveillance resistance in political activism. Big Data \& Society, 3(2), 1-12. doi:10.1177/2053951716679678

Dubrofsky, R. E., \& Magnet, S. A. (eds.). (2015). Feminist Surveillance Studies. Durham, NC: Duke University Press.

Express News Service. (2019). 145 out of 192 police stations got CCTV cover. The New Indian Express, 10 Jan. http://www.newindianexpress.com/cities/delhi/2019/jan/10/145police-stations-got-cctv-cover-1923216.html

Firmino, R., \& Duarte, F. (2015). Private video monitoring of public spaces: The construction of new invisible territories. Urban Studies, 53(4), 741-754. doi:10.1177/0042098014567064

Fyfe, N. (2004). Zero tolerance, maximum surveillance? Deviance, difference and crime control in the late modern city. In L. Lees (ed.), The Emancipatory City? Paradoxes and Possibilities (pp. 40-56). London: Sage.

Gellman, B., \& Adler-Bell, S. (2017). The disparate impact of surveillance, The Century Foundation, 21 Dec https://tcf.org/content/report/disparate-impact-surveillance/

Giddens, A. (1990). The Consequences of Modernity. Cambridge, UK: Polity Press.

Gilman, M. E., \& Green, R. (2018). The surveillance gap: The harms of extreme privacy and data marginalization. NYU Review of Law and Social Change, 42(253).

Goswami, S. (2018). 1.4 lakh CCTV cameras in Delhi's markets, residential areas by October. Hindustan Times, 8 Feb. https://www.hindustantimes.com/delhi-news/1-4lakh-cctv- 
cameras-in-delhi-s-markets-residential-areas-by-october/storyIXabiOPoXuyu1YFVJJU4LN.html

Government of Delhi. (2018). Delhi Rules for Regulation of CCTV Systems in NCT of Delhi. Delhi: Government of Delhi.

http://dceast.delhigovt.nic.in/wps/wcm/connect/b4db69004622dcdbb778b7c8da9eb17 e/CCTV.pdf?MOD=AJPERES\& $/ \bmod =1855201116 \& C A C H E I D=b 4 d b 69004622 \mathrm{dcdbb778b7c}$ 8da9eb17e

Govindarajan, V. (2016). Should Delhi's (illegally) gated enclaves be thrown open to reduce traffic congestion? Scroll.in, 30 Jun.

https://web.archive.org/web/20190708123735/https://scroll.in/article/809558/shoulddelhis-illegal-gated-enclaves-be-thrown-open-to-reduce-traffic-congestion

Hasija, S., \& Nagpal, S. (2018). CCTV surveillance in public spaces of Delhi: Exploring the perspectives of youth visiting malls and Delhi Metro. IOSR Journal of Humanities and Social Science, 23(12), 2nd ser.

Heeks, R., \& Shekhar, S. (2019) Datafication, development and marginalised urban communities: an applied data justice framework. Information, Communication \& Society, 22(7), 992-1011.

Hempel, L., \& Töpfer, E. (2004). Final Report: CCTV in Europe, Working Paper no. 15. Berlin: Centre for Technology and Society, Technical University of Berlin. http://www.urbaneye.net/results/ue wp15.pdf

Huey, L. (2010). False security or greater social inclusion? Exploring perceptions of CCTV use in public and private spaces accessed by the homeless. The British Journal of Sociology, 61(1), 63-82. doi:10.1111/j.1468-4446.2009.01302.x

Khan, S. (2018). Punjab Government's Safe Cities Project, (Safer City) or Over Policing? Lahore: Digital Rights Foundation. https://privacyinternational.org/newsanalysis/2228/punjab-governments-safe-cities-project-safer-city-or-over-policing

Koskela, H. (2002). Video surveillance, gender, and the safety of public urban space: "Peeping Tom" goes high tech? Urban Geography, 23(3), 257-278. doi:10.2747/02723638.23.3.257

Kovacs, A. (2017). Reading surveillance through a gendered lens: Some theory. Gender Surveillance, February. https://genderingsurveillance.internetdemocracy.in/theory/ Lyon, D. (1994). The Electronic Eye: The Rise of Surveillance Society. Cambridge: Polity Press. Lyon, D. (2001). Surveillance Society. Monitoring Everyday Life. Buckingham: Open University Press.

Lyon, D. (ed.). (2003). Introduction. In Surveillance as Social Sorting: Privacy, Risk and Digital Discrimination. Abingdon, UK: Routledge.

McCahill, M. (2002). The Surveillance Web: The Rise of Visual Surveillance in an English City. Cullompton, UK: Willan Publishing.

Ministry of Women and Child Development. (n.d.). Framework for Nirbhaya Fund. New Delhi: Ministry of Women and Child Development. https://wcd.nic.in/sites/default/files/Approved\%20framework\%20for\%20Nirbhaya\%20F und $0 . p d f$

Minnaar, A. (2012). Private security companies, neighbourhood watches and the use of CCTV surveillance in residential neighbourhoods: The case of Pretoria-East. Acta Criminologica: South African Journal of Criminology, Special Edition 1, 103-116. 
Monahan, T. (2008). Dreams of control at a distance: Gender, surveillance, and social control. Cultural Studies <-> Critical Methodologies, 9(2), 286-305. doi:10.1177/1532708608321481

National Crime Records Bureau (NCRB). (n.d.). Request for Proposal to Procure National Automated Facial Recognition System (AFRS). New Delhi: Ministry of Home Affairs. http://ncrb.gov.in/TENDERS/AFRS/RFP NAFRS.pdf

Phadke, S., Khan, S., \& Ranade, S. (2011). Why Loiter?: Women and Risk on Mumbai Streets. New Delhi: Penguin Books.

Press Trust of India (PTI). (2012). CCTV cameras removed from Puri beach after protests by women. The New Indian Express, 7 Dec. http://www.newindianexpress.com/states/odisha/2012/dec/07/cctv-cameras-removedfrom-puri-beach-after-protests-by-women-431766.html

Taylor, L. (2017). What is data justice? The case for connecting digital rights and freedoms globally. Big Data \& Society, 4(2), 1-14. doi:10.1177/2053951717736335

Thomasen, K. (2017). Beyond airspace safety: A feminist perspective on drone privacy regulation. SSRN Electronic Journal. doi:10.2139/ssrn.3143655

Walby, K. (2005). How closed-circuit television surveillance organizes the social: An institutional ethnography. Canadian Journal of Sociology, 30(2), 189-214. doi:10.2307/4146130

Weinberg, L. (2017). Rethinking privacy: A feminist approach to privacy rights after Snowden. Westminster Papers in Culture and Communication, 12(3), 5-20.

Wickramasinghe, M. (2014). Feminist Research Methodology: Making Meanings of Meaning-Making. New Delhi: Zubaan.

Wright, J., Glasbeek, A., \& Meulen, E. V. (2014). Securing the home: Gender, CCTV and the hybridized space of apartment buildings. Theoretical Criminology, 19(1), 95-111. doi:10.1177/1362480614544210

\section{Acknowledgements}

The "Urban Data, Inequality and Justice in the Global South" case studies form part of a Senior Research Fellowship funded by the University of Manchester's Sustainable Consumption Institute with additional financial support from Canada's International Development Research Centre (IDRC). This case study was also partially funded by the "Big Data for Development Network", established and supported by IDRC. More information about the network and work produced by it can be found here: http://bd4d.net/. The authors express their gratitude to Richard Heeks and Linnet Taylor for being extremely generous with their time in providing prompt and insightful feedback.

\section{About the Authors}

Aayush Rathi is a researcher at the Centre for Internet and Society, India. A lawyer by training, he produces interdisciplinary research at CIS working at the intersections of feminist theory, surveillance studies and labour.

Ambika Tandon is a researcher at the Centre for Internet and Society, India. She works at the intersection of gender and technology through interdisciplinary research on areas such as surveillance, reproductive health, and labour. Before CIS, she was pursuing a Master's in Media, Communications and Development from the London School of Economics and Political Science. 


\title{
Case 9: Community-Based Data Justice A Model for Data Collection in Informal Urban Settlements
}

\author{
Denisse Albornoz \\ Hiperderecho
}

\&

\author{
Katherine Reilly \\ Simon Fraser University
}

\author{
$\&$ \\ Marieliv Flores \\ Hiperderecho
}

\begin{abstract}
Non-governmental organizations (NGOs) have become important curators of data from informal urban settlements. Given the absence of these communities in public datasets, they work to take informal settlements from a state of invisibility and injustice to one of visibility and justice, in and through data. The working premise of these NGOs is that by producing data about informal settlements, data can act as a "currency" through which individuals can access different forms of justice. However, the literature that studies datafication in marginalized urban communities shows this is not always the case. Data scholars have pointed out that datafication implies a series of risks, as well as new forms of exclusion and inequality for vulnerable populations and minorities. This paper studies, through the analysis of interviews of residents of informal settlements in Lima, Peru, whether intensive data collection in informal settlements is considered a process to access justice by vulnerable communities.
\end{abstract}

The study concludes that in the short term, datafication does not give access to justice to vulnerable communities but in fact, deepens or reproduces instances of oppression by reinforcing the perception of their lack of knowledge, lack of capabilities or lack of authority to use data to lead their own development. However, participating in the process of datafication sparked an interest among community leaders about the different ways in which data could be used to further their capabilities, mobilize collective action and address their development needs. Community leaders are interested and willing to use data in constructive ways to collaborate with diverse actors and transform their conditions. However, this interest, power and potential needs to be activated through capability development and the cooperation of data partners willing to invest their resources to provide this training. The paper closes with a list of recommendations, suggested by community leaders from informal settlements, on how to build a community-based data collection model that redresses harms and individual forms of injustice from previous experiences. 


\section{A. Introduction}

"As a society we have learned to perpetuate inequality by building walls, gates and divisions that go beyond the physical and reinforce the idea that the city is only for a few people" (TECHO-Perú, 2018)

In Peru, and most parts of Latin America and the wider global South, the state does not collect basic data about the living conditions of informal settlements. Their absence results in a two-tiered system of citizenship. Those who live in informal settlements and their needs remain invisible in public data and as a result are not considered as part of the urban reality of the city (Canales and Maulen, 2011). This new form of invisibility reinforces a historical inequality that Peruvian anthropologist José Matos Mar has described as the existence of two Perus: the "official Peru" made up of formal institutions and the "marginalized Peru" made up of urban masses that operate in clandestinity (see also Plöger, 2012).

In response to this situation, non-governmental organizations (NGOs) have become important curators of data from informal urban settlements in Peru. In particular, the NGO TECHO-Perú, the Peruvian branch of TECHO - an organization with over 15 years of experience working on social development and affordable housing projects in contexts of urban poverty - is producing datasets about life in local informal settlements through a cadastral survey or Relevamiento ${ }^{56}$ in Spanish. Through this data-intensive work, TECHOPerú is attempting to integrate the "marginalized Peru" into a "datafied official Peru" and improve the representation of the former's needs in public policies (TECHO-Perú, 2018). In other words, the aim of their work is to take informal settlements from a state of invisibility and injustice to one of visibility and justice in and through data.

This study takes a closer look at this assumption: that intensive data collection in informal settlements can be a process to access justice for vulnerable communities. The working premise of the Relevamiento is that the "the violation of rights in informal settlements is furthered by the absence of data" (TECHO-Perú, 2018). By producing data about informal settlements, TECHO-Perú implies data can act as a "currency" through which individuals can exercise their rights and access different forms of justice. However, the literature that studies datafication in marginalized urban communities shows this is not always the case. Data scholars have pointed out that datafication implies a series of risks, as well as new forms of exclusion and inequality for vulnerable populations and minorities (Donovan, 2012; Heeks and Renken, 2018). Data gathering is increasingly being theorized as a form of dispossession (Thatcher et al., 2016) that benefits external actors who have the resources to use the information, more than community members who provide their data (Heeks and Shekhar, 2019). This study explores these issues from the perspective of the residents of informal settlements: What does this data-intensive process mean for them? Do they consider that gaining "visibility" through data is a means to access justice? Or do they believe it will deepen their risk of further exclusion or deprivation?

\footnotetext{
56 The Relevamiento is an adaptation of a traditional cadastral survey. The cadastral survey focuses on collecting information about land property in informal settlements. The Relevamiento collected this information, as is explained in Section 9B, but it also collected socio-cultural information about life in these spaces.
} 
The paper will first provide context to the Relevamiento conducted by TECHO-Perú. It then provides an overview of Iris Marion Young's approach to justice $(1990,2006)$ and explains how we used her understanding of oppression to think about access to justice in datarelated activities in informal settlements. The Methods section describes our process to collect testimonies from community members who live in one particular informal settlement of Lima - San Juan de Miraflores (SJM) - and the methodological tools we used to interpret their participation as well as their refusal to participate in our study. The Findings section describes the common themes that emerged in testimonies regarding datarelated activities in informal settlements, analyzed using Young's concepts. And the Discussion section elaborates on how these findings and the experience of SJM can inform a community-based data justice model.

This work aims to contribute to a broader understanding of the concept of "data justice" as theorized in early works by Heeks \& Renken (2018) and Taylor (2017). The communitybased data justice model can also be a useful tool for data intermediaries like TECHO-Perú that are working overtime with limited resources to bring justice and equity to communities fraught by urban poverty. But above all, this paper hopes to be a platform from which the voices of community members of SJM can inform the design and reduce the harm of future data practices implemented by development practitioners in vulnerable communities. 


\section{B. Background}

\section{B1. Datafying Informal Settlements in Lima}

Over the past few years, attention has been placed on the importance of creating datasets from developing countries and marginalized urban communities as a means to improve their representation in the production of knowledge and information (Graham et al., 2012). The open data movement in particular, as part of its mission to promote access to knowledge, advocates for bottom-up production of urban datasets in rapidly transforming urban societies (Liu et al., 2015). According to data scholars, the production of data about marginalized communities can contribute to more diverse knowledge production, as it opens up new research opportunities in urban studies and planning (Crooks et al., 2015), as well as contributing to the inclusion of these communities in urban planning and management (Chakraborty et al., 2015). Others have argued, from a more critical standpoint, that the datafication of informal settlements can be tied to efforts of policy makers to reduce complexity in governance. Kevin Donovan (2012) draws from James Scott's Seeing like a State (1998) to reflect on how the turn to datafication is part of a larger effort of state-led "simplification" and "standardization" that enables powerful entities to maintain political control over diverse communities ${ }^{57}$. In all cases, data is conceived as a means to activate political will and mobilize policy makers to include informal settlements in public policy.

This rationale has been picked up in Latin America. Tamara Canales and Andrea Maulen (2011) who studied "invisibilization" of informal settlements in Chile argue the absence of data about informal settlements in "official figures" makes it impossible for these spaces to be "quantified, intervened and considered" in public policy and urban planning. Similar to other initiatives around the world that open up data of informal settlements such as Map Kibera or Map Mathare from Kenya, TECHO-Perú's work is a response to "the urgency to make visible the conditions of poverty and vulnerability in which informal settlers live" in Latin America (TECHO-Perú, 2018).

In the specific case of Lima, TECHO-Perú (2018) suggests that the invisibility of informal settlements in public policy disqualifies the sector as a potential area of public investment, leaving its communities in a situation of precarious access to services and territorial segregation. Furthermore, they argue that collecting this data can also stimulate citizen action. As in the case of Map Kibera, the absence of an open, up-to-date dataset about informal settlements, "leaves their [residents] disempowered and unable to use information to solve problems", excluding them from debates that influence policy and from the possibility of using this information to drive their own development (Hagen, 2011).

With these objectives in mind, TECHO designed the Relevamiento project: a large-scale regional effort to generate information to locate, quantify and develop a socio-territorial characterization (who lives there, types of organizations, needs, etc.) of informal

\footnotetext{
${ }^{57}$ Both Scott and Donovan warn that this over-simplification is against the interest of the public. It threatens to reduce the public's political autonomy and their ability to participate in decision making. In the words of Donovan: "What changes through state simplification is that information becomes accessible on a larger scale, one where community ties are less influential." (Donovan, 2012).
} 
settlements in Latin America. The data collection methodology was designed by the Centre for Social Research (CSR) of TECHO in Chile and mainstreamed across local branches of TECHO in Latin America. So far the cadaster or Relevamiento has been done in Argentina, Chile, Costa Rica, Nicaragua and Uruguay at the national level, and in Guatemala City, Bogotá, Asunción, Turgua and Lima at the city level. In Peru, the Relevamiento was conducted in the district of San Juan de Miraflores (see Figure 1), one of the five areas with the highest concentrations of urban poverty in Lima, according to the Ministry of Development and Social Inclusion ${ }^{58}$. This district has a total population of 432,282 people and is also considered the $8^{\text {th }}$ most populated district in Lima hosting approximately $5 \%$ of the total population (TECHO-Perú, 2018).

\section{¿POR OUE SAN JUAN DE MIRA- FLORES?}
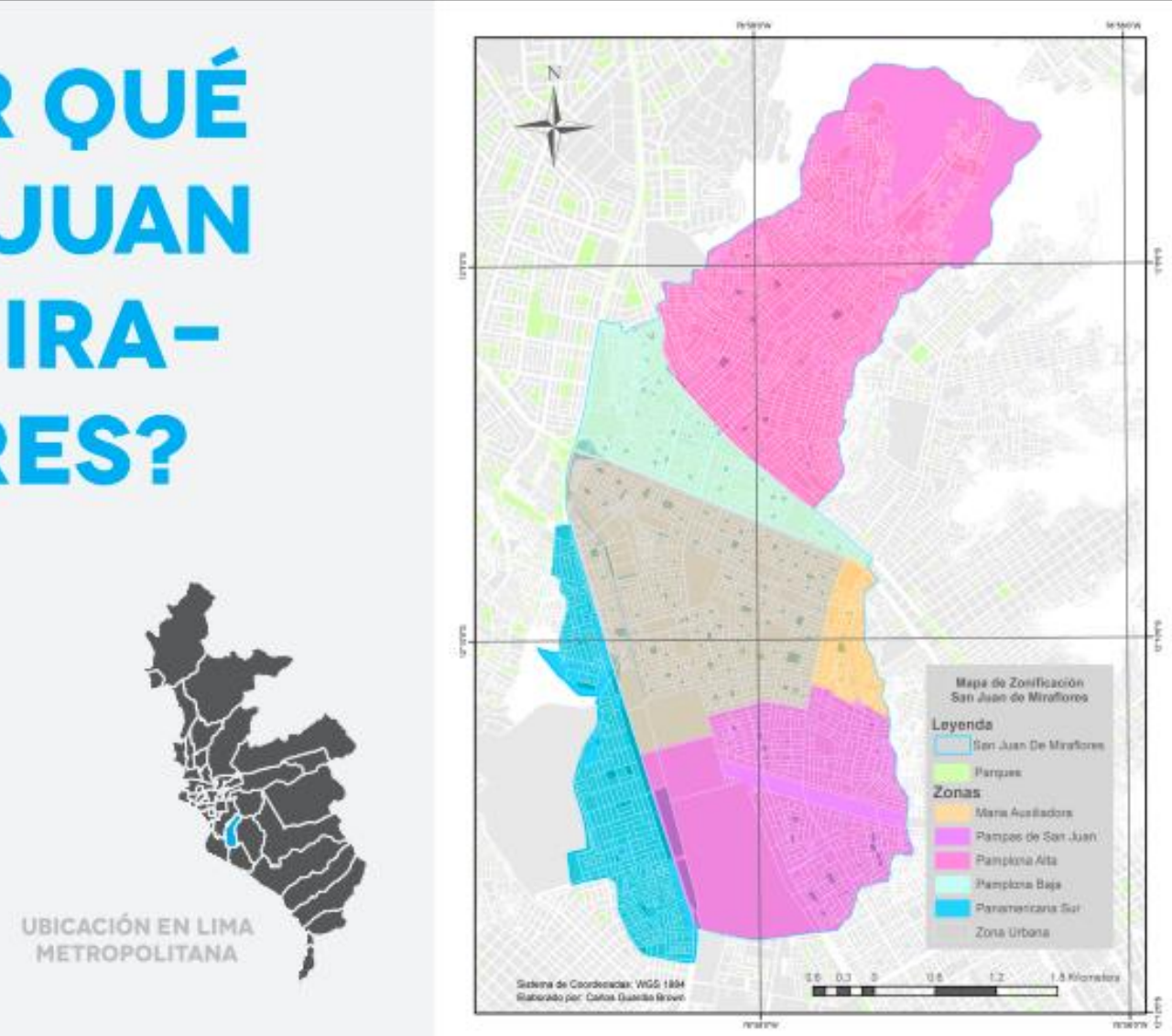

Figure 1: Map of the districts of SJM. Retrieved from the Relevamiento report (TECHO-Perú, 2018)

The main data collection instrument was a survey designed by TECHO's CSR to collect socioterritorial and geo-referenced data of the settlements in a standardized manner. Before deploying the questions, TECHO-Perú adapted the survey to the local context. They held a meeting with diverse actors that included state representatives, academics, community leaders from SJM, civil society organizations and private sector entities. The feedback

\footnotetext{
58 In Lima, 3.6 million people - from a total population of 9.3 million - live in urban poverty (Redacción Gestión, 2017). Most of the urban poor live in "urban marginal cities", areas characterized by the total or partial absence of infrastructure and basic services such as water network, electric energy or drainage system (Dede, 2018; Ministerio de Vivienda, 2017). Informal settlements are sub-sets of urban marginal cities where more than half of the population do not have a property title (TECHO-Perú, 2018).
} 
provided in this meeting was incorporated into the survey. The survey was then conducted in SJM by 10 staff members and 300 volunteers (see Figure 2 ) who were trained to collect data and survey every household in SJM between October 2017 and June $2018^{59}$. The data collection was conducted using Kobo Toolbox, an open source digital app developed by the Harvard Humanitarian Initiative, designed for non-governmental organizations that conduct research in the midst of humanitarian crises. According to TECHO-Perú (2018), Kobo Toolbox allowed them to work more efficiently, since it automatically generated an online database, aggregated the data and mapped the geo-referenced coordinates of the informal settlements.

The results of the Relevamiento were published in 2018 and it made available unprecedented data about SJM. It identified 138 informal settlements within SJM and estimated that at least 46,755 families live in a situation of informality, which represents $10.8 \%$ of the total population. It collected information regarding their lack of access to services: finding that $91 \%$ of informal settlements do not have access to the public water network, $92 \%$ do not have a drainage system, and $97 \%$ of settlements do not have property titles. It also collected information about community governance and social relations between SJM residents. It found that $80 \%$ of residents appreciate community solidarity and that $95 \%$ of settlements have a community board ${ }^{60}$ recognized by the local municipality. It concluded that informal settlements are predominantly political spaces where "governance is characterized by self-management of their territories and the struggle for their rights" (TECHO-Perú, 2018).

The data was published in an open data portal and presented to Congress representatives, SJM community leaders and civil society organizations. So far, its publication has inspired a working group in the Peruvian Congress to address the main problems affecting informal settlements and has also been picked up by local media. According to the Executive Director of TECHO-Perú, it has not impacted public policy at a large scale, but they have been successful at initiating a public conversation. It is still unclear whether community members consider this data-intensive process has created new opportunities to access justice for them or not.

\footnotetext{
59 TECHO-PERÚ staff mentioned that about five informal settlements within SJM refused to participate in the Relevamiento.

60 Community boards are groups of "neighbors" or individuals who mobilize and lead community governance. They are democratically elected and are chosen to lead social development programs to improve community infrastructure (TECHO-Perú, 2018).
} 


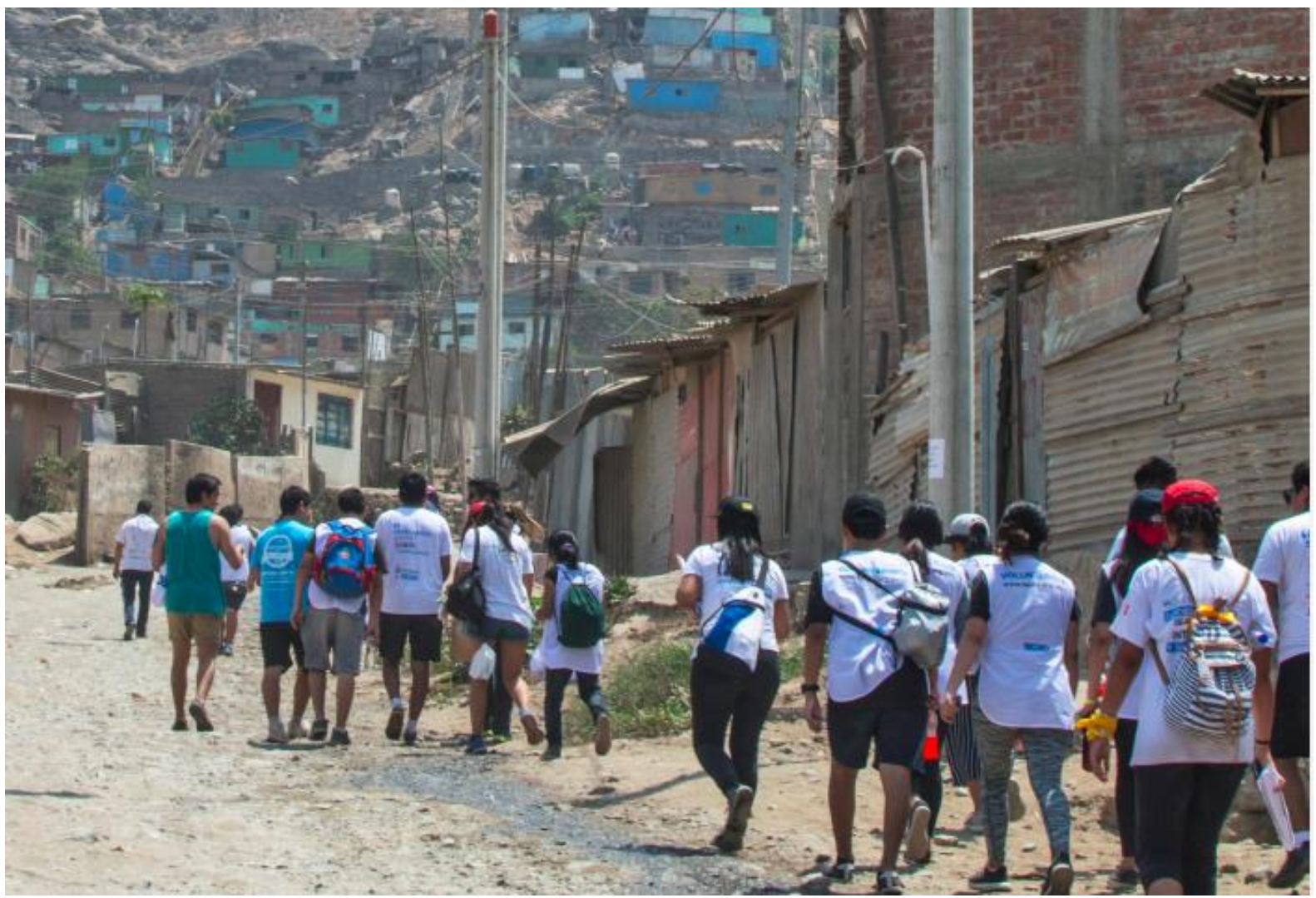

Figure 2: Volunteers heading to conduct surveys in SJM. Retrieved from Relevamiento report (TECHO-Perú, 2018)

\section{B2. Investigating Data Justice using Concepts Developed by Iris Marion Young}

To investigate access to justice through data we turn to the work of Iris Marion Young (1990, 2006); specifically her conceptualization of structural injustice and how it can be challenged. Young defines social justice as "the elimination of institutionalized domination and oppression" (1990, p 15); where domination and oppression refer to institutional constraints that prevent individuals from developing their capacities, expressing their needs, thoughts and feelings, and participating in discussions related to decisions that directly or indirectly influence their lives (Young, 1990; Uhde, 2010). This conception of injustice and oppression is structural. Young argues justice is not the result of a specific choice, policy or program (1990, p 5), but that these power dynamics are sustained by the norms, rules and practices present in the social, economic and political structures in which we participate. In our case study, this prods us to look beyond the effects of the Relevamiento itself, and to consider if this initiative is contributing to larger social and cultural dynamics that produce injustice.

According to Young, structural domination and oppression constrain the self-determination and self-development of social groups ${ }^{61}$ in different ways, affecting the power and capabilities they have to make decisions about their own lives.

\footnotetext{
${ }^{61}$ Young defines a social group as a collective of persons differentiated from at least one other group by cultural forms, practices, or way of life. Members of a group have a specific affinity with one another because
} 
"Structural injustice exists when social processes put large categories of persons under a systematic threat of domination or deprivation of the means to develop and exercise their capacities, at the same time as these processes enable others to dominate or have a wide range of opportunities for developing and exercising their capacities." (Young, 2006, p 114)

To determine if a social group is oppressed, Young describes five forms of oppression, from which we draw three: exploitation, marginalization and powerlessness (see Table 1$)^{62}$. These concepts are grouped into a sub-category of injustices that lead to the work and social contribution of individuals not being recognized in society (Uhde, 2010). These concepts are useful to understand if those who participated in the data collection process led by TECHOPerú perceive datafication as a process that sustains or challenges former or current experiences of oppression.

\begin{tabular}{|l|l|l|}
\hline Concept & Definition & Pathway to justice \\
\hline Exploitation & $\begin{array}{l}\text { The social process by which the } \\
\text { results of work performed by one } \\
\text { social group are appropriated to } \\
\text { benefit another }\end{array}$ & $\begin{array}{l}\text { Reorganization of institutions and } \\
\text { practices of decision making and } \\
\text { alteration of the division of labor }\end{array}$ \\
\hline Marginalization & $\begin{array}{l}\text { A social group is expelled from } \\
\text { useful participation in social life, } \\
\text { and experiences uselessness, } \\
\text { boredom, and lack of self-respect }\end{array}$ & $\begin{array}{l}\text { Establishing cultural, practical, and } \\
\text { institutionalized conditions for } \\
\text { exercising capacities in a context of } \\
\text { recognition and interaction }\end{array}$ \\
\hline Powerlessness & $\begin{array}{l}\text { A social group experiences lack of } \\
\text { authority, lack of decision making } \\
\text { power and exposure to } \\
\text { disrespectful treatment }\end{array}$ & $\begin{array}{l}\text { Capability development and creating } \\
\text { conditions in which those who hold } \\
\text { power recognize the authority, } \\
\text { expertise and influence of the social } \\
\text { group }\end{array}$ \\
\hline
\end{tabular}

Table 1: Summary of analytical framework concepts retrieved from Young (2012)

Young also sheds light on how oppressed social groups can take action to access justice. In the social connection model of responsibility ${ }^{63}$ she develops in Responsibility and Global Justice (2006), she explains that every individual who participates in economic, social or cultural processes, including those who experience oppression, bears a degree of responsibility for the unjust outcomes they produce (Young, 2006). Even though this may sound counter-intuitive, this definition recognizes that groups who are usually perceived as the victims of injustice have the power to change their conditions through collective action. They not only have a greater interest in structural transformation, but also have unique insights into the sources of structural injustice. In this sense, remedying injustice involves creating the institutional conditions in which oppressed groups can harness their power to change their conditions. While identifying what these conditions should be was out of the

of their similar experience or way of life, which prompts them to associate with one another more than with those not identified with the group, or in a different way (Young, 1990).

62 The other two concepts are violence and cultural imperialism (Young, 1990).

${ }^{63}$ For more detail, see features of the Social Connection Model of Responsibility in the Annex. 
scope of this study, we sought to recognize these unique insights by documenting the recommendations of community members on how datafication could create new opportunities for capability development and collective action.

Overall, Young's approach to social justice is useful to evaluate how the global turn to datafication is impacting local communities, and in particular, how the social processes that arise from datafication may put vulnerable communities at risk of further domination or deprivation. At the same time, there is an instrumental value to investigating data-related dynamics from the perspective of community members. Through the concepts developed by Young, we could assess if community members consider datafication furthers relations of oppression, or if it activates their agency and affords them opportunities to engage in collective action to transform their conditions through data. A summary of our approach is presented in Table 2.

\begin{tabular}{|l|l|l|}
\hline Research question & $\begin{array}{l}\text { Research concepts } \\
\text { developed by Marion Young } \\
\mathbf{( 1 9 9 0 , 2 0 0 6 )}\end{array}$ & $\begin{array}{l}\text { Insight these concepts } \\
\text { provide regarding justice and } \\
\text { data }\end{array}$ \\
\hline $\begin{array}{l}\text { Do community members } \\
\text { consider the } \\
\text { Relevamiento offers a } \\
\text { means to access justice? }\end{array}$ & $\begin{array}{l}\text { Conceptualization of injustice } \\
\text { and five faces of oppression }\end{array}$ & $\begin{array}{l}\text { Understand how data } \\
\text { collection processes can } \\
\text { sustain or challenge structural } \\
\text { injustice from the community } \\
\text { perspective }\end{array}$ \\
\hline $\begin{array}{l}\text { Do community members } \\
\text { consider the } \\
\begin{array}{l}\text { Relevamiento enabled } \\
\text { them to take action to } \\
\text { remedy injustice? }\end{array}\end{array}$ & $\begin{array}{l}\text { Parameters social groups can } \\
\text { use for thinking about their } \\
\text { own action in relation to } \\
\text { structural injustice }\end{array}$ & $\begin{array}{l}\text { Understand if data collection } \\
\text { practices enable or constrain } \\
\text { vulnerable populations to take } \\
\text { action to remedy injustice }\end{array}$ \\
\hline
\end{tabular}

Table 2: Applying Young's concepts to assess community perspectives on access to justice through data 


\section{C. Methods}

To learn about community perspectives, we conducted four in-depth unstructured interviews with SJM community leaders (or dirigentes) that mobilize social development programs within SJM and who are the point of contact for TECHO-Perú. For the interview itself, we used open-ended interview schedules that guided the conversation along the lines of the aforementioned themes. The interviews were then analyzed by the research team to identify common themes that capture the perspectives of SJM community members regarding the collection and use of their data in urban planning processes such as the Relevamiento. This approach was inspired by the work of Tawana Petty, Mariella Saba, Tamika Lewis, Seeta Peña Gangadharan and Kim M. Reynolds in Our Data Bodies Project (Petty et al., 2018). This report collected testimonies of individuals who are targeted for intensive data collection "as they confront data collection and data-driven systems in the process of meeting their basic human needs" in order to "identify commonalities and differences" between those testimonies while honoring the diverse histories and contexts of interviewees (2018, p 2). Drawing from their methodology, we analyzed the perceptions that inform the decisions SJM community members are making regarding data-related activities and sought to emphasize how these emerge in a particular context of structural injustice.

We also consulted ethnographic methods designed to negate extractive forms of knowledge production that privilege our research interests over those of the community we were interviewing. Max Liboiron (2018) and her team at the Civic Laboratory for Environmental Action Research in Newfoundland have been exploring what community peer review might look like and how to iteratively check in with researched communities to ensure consent over time. In this spirit, we created opportunities to obtain input and reiterative consent both from TECHO-Perú and the SJM community. For six months, we held several meetings with TECHO-Perú and collaborated with their staff to design the research process. This involved requesting their input regarding research deliverables, such as the funding proposal and the study write-up, requesting their consent whenever there was a change in research scope and making a commitment to work together at the completion of the study to translate research findings into actionable data collection strategies. The relationship with the SJM community was mediated by TECHO-Perú (e.g., see Figure 3). All of the interviews with community leaders were coordinated by the Research Director of TECHOPerú, conducted along with a TECHO-Perú volunteer and held in SJM around the availability of community leaders. We took these measures to ensure the research did not harm the relationship of trust that has been built between SJM and TECHO-Perú over the past 15 years.

In spite of these efforts, many community members refused to participate in our study. We initially hoped to conduct at least ten interviews with community leaders. The process of contacting them, setting a time to visit the informal settlements and securing their availability took three months, and only four interviews were secured. Eight community members refused or were unavailable to participate. 


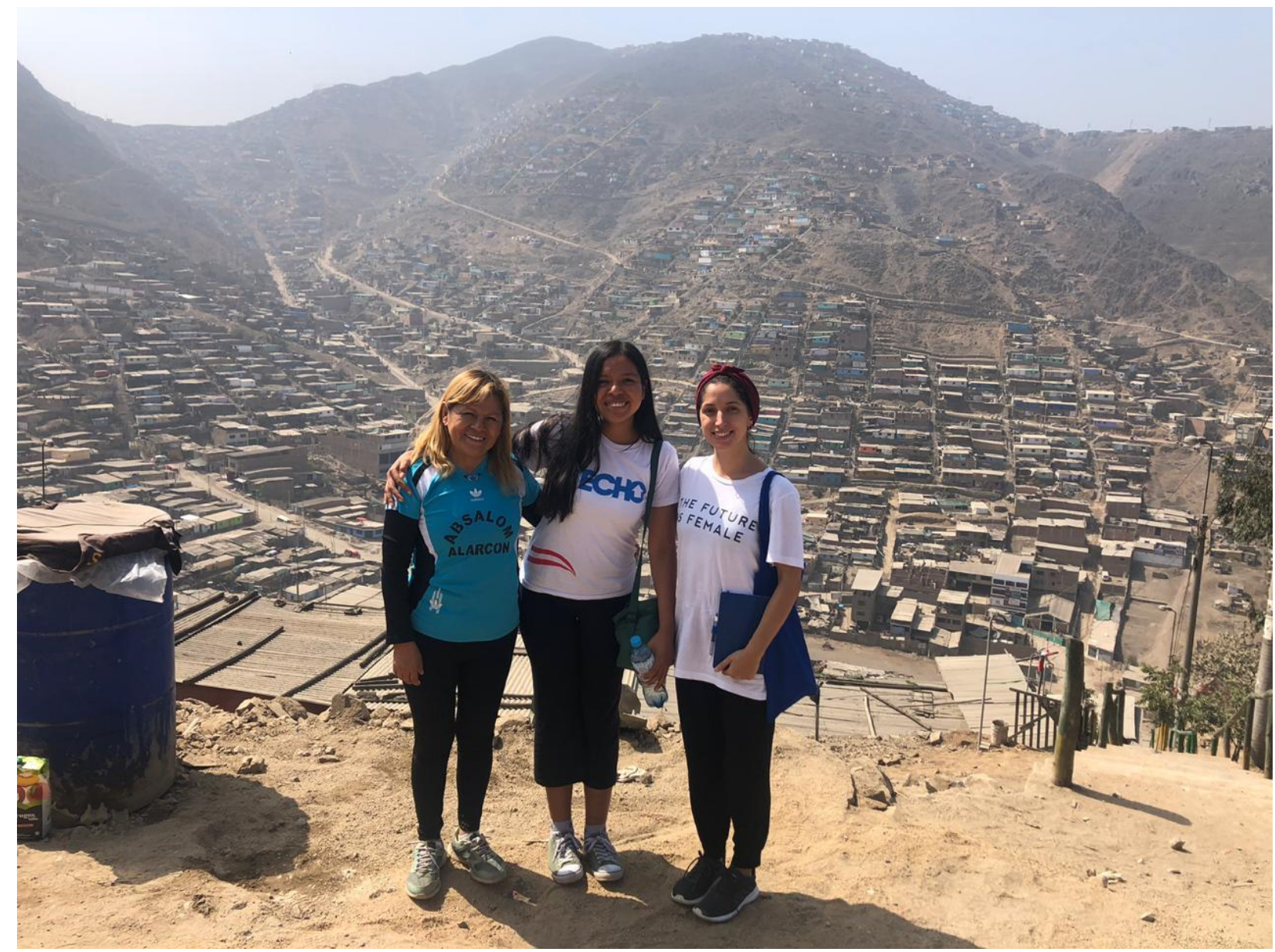

Figure 3: Maria Falcone, community leader; Brennda Huarcaya, TECHO-Perú volunteer; and Denisse Albornoz, author. Photo requested by Ms. Falcone, taken and used with her consent; May 2019

Ruha Benjamin (2016) has worked on the concept of "informed refusal" and how expressing refusal creates new, more equitable relationships between researchers and researched communities. Indigenous scholar Audra Simpson (2007) also describes the choice of refusal as an articulation "to ourselves and to outsiders" of "who we are, who you are and these are my rights". We interpret their refusal as an intention to set boundaries with TECHOPerú and our organization regarding the use of their time and their information. Kim Tall Bear (2013) also prods us to consider these silences "as productive and supportive" of the self-determination of social groups (Benjamin, 2016). Future data justice research that seeks to involve the perspectives of communities who are constantly the target of data collection must be aware of these constraints and allow for refusal and silence to inform and adapt the research timeline in constructive ways.

Finally, to complement the interviews, we also conducted desktop research about informal settlements in Peru and TECHO-Perú's research methodologies, and undertook two interviews with TECHO-Perú staff who participated in the design or implementation of the Relevamiento. With this information, we sought to contextualize the information provided by community members regarding the involvement of TECHO-Perú in SJM and learn more about community partnerships with the organization. 


\section{D. Findings}

This section summarizes our findings to address our two research questions, that address: a) if community members of SJM consider datafication - or acquiring visibility through data - a process through which they can access justice as operationalized by Young; and b) if community members of SIM consider datafication a process through which they can develop capabilities and activate collective action to remedy injustice.

\section{D1. Datafication as a Process to Access Justice}

Through the interviews, we found that community members spoke favorably about the intention to systematize and standardize the problems of SIM with the Relevamiento. However, interviewees also provided examples of how the data collection process and its aftermath is sustaining experiences of Young's three forms of oppression - powerlessness, exploitation and marginalization - that already exist within the community of SJM.

\section{Datafication and powerlessness ${ }^{64}$}

We found that participating in the Relevamiento impacted the community's perceptions regarding their own power in three ways. First, SJM community leaders believe the Relevamiento and the production of a data-based report about SJM, could empower them to make more objective and effective diagnosis of their development problems.

"The Relevamiento is very important. Our work needs to be based on a diagnosis. Imagine if we start working without knowing anything and we do everything based on our opinion. Suddenly we will leave aside the highest priority for the community. If you do not work with a diagnosis, you do not have a good result. Thanks to TECHOPerú we have been able to identify our priorities."

"We have worked with data [before]. We [used it to make] a short and medium-term schedule. This is how we built our stepped pathways and obtained street lighting. That schedule was done with TECHO-Perú and with their orientation."

The turn towards data-driven planning is not only in demand at the policy level, but is now becoming increasingly valued at the community level as well, most likely as a result of exposure to datafication processes. This also implies that other ways of knowing based on intuition, opinions or lived experiences are perceived as less valid or useful to plan and execute community programming than data-intensive approaches. In the long run, the growing pervasiveness of data collection exercises in the community may impact the forms of knowledge the community welcomes, values and desires to describe their context.

Second, the data produced through the Relevamiento was thought of as a tool they could use to challenge their own sense of powerlessness in front of more powerful actors. In particular, community members who considered data to be a source of legitimacy and authority, thought the Relevamiento could enable them to communicate on more equitable terms with three individuals and institutions. First, the municipal government authorities:

\footnotetext{
64 This section summarizes findings that speak to whether datafication furthers powerlessness - be it by furthering a sense of lack of authority, a feeling of incapability, or exposure to disrespectful treatment.
} 
who have most power and political interest to improve the living conditions of SJM. Second, central government authorities such as Congress representatives and policy makers who can steer political will and public narratives surrounding informal settlements. And third, research and civil society organizations who regularly visit informal settlements and request up-to-date data to understand the needs of the community and plan the scope of their work.

"When the survey began, municipality authorities said: "we are going to support and listen to everyone". The municipality was very willing to support the Relevamiento and use the data to support the needs that we have in the future. And who better than the municipality, to implement and make the most of the results of the Relevamiento?"

"There are several [civil society] organizations that come in to work and require information. Such as how many women currently live in the community, or what are the occupations of our neighbors. It would be important for me to be able to use the data collected by the Relevamiento to provide them this information."

However, most community members mentioned having the data in and of itself is not enough to use it effectively to enable collaboration. They emphasized the crucial role played by TECHO-Perú as an intermediary that should not only collect and share this data, but should also provide advice on how to use it strategically to mobilize power and resources. The expectation to continue working with TECHO-Perú is grounded in the trust the SJM community has placed in the organization, however it also threatens to generate dependency on the organization and further the notion that the community is incapable of using data to obtain support from powerful actors without their mediation.

And third, community leaders consider the Relevamiento is an opportunity to challenge misleading discourses about informal settlements and what life is like in these spaces. Culturally, those who live in informal settlements are subject to racism, classism and other forms of oppressive discourses that portray the members of settlements as informal, illegal and invisible outsiders, and are used to delegitimize their perspectives and expectations of development (Sakay et al., 2011). Community members believe that these discourses are not only held by the general public, but also by decision makers such as policy makers or public service providers. In their view, becoming visible through data is an opportunity to speak to these actors, tell their stories in their complexity and mostly, to be heard with empathy. However, some community leaders felt the questions asked in the survey of the Relevamiento did not give them this opportunity:

"There were a lot of questions missing in the questionnaire ${ }^{65}$. Sometimes I thought: I want you to ask me this' but it was not in the questionnaire. The questions lacked...empathy. They did not ask: Why is the community like this? Why have you not progressed? I would have liked to be asked questions about why we do not have

\footnotetext{
65 TECHO-Perú staff explained that even though they sought to include more qualitative questions in the questionnaire, they were constrained by the standardized survey designed by the Centre for Social Research from TECHO in Chile. The regional branch from Chile had encouraged them to use the same questions to make comparative analyses across the region.
} 
property titles until now. I have plenty of stories. Stories about terrorism, crime in the area. There are a lot of topics to be heard about."

They expressed discomfort about how the data produced by the Relevamiento will now shape what people know about SJM without providing the context or a more comprehensive explanation that humanizes informal settlers. As a result, one of their fears is that the final diagnosis produced by the Relevamiento misrepresents their reality, and does not get to the deeper structural factors that facilitate or constrain their development. Furthermore, if community members cannot verify what story is being told by the data, they will not be able to identify whether this narrative is harmful to their community and if so, make informed decisions regarding the impact of future data collection activities:

"The fear is that the information is not real, that it does not reflect our needs and that only some [people] have been represented [in the data]. That the final results don't reflect what we really want. The intentions behind this work have been really good but we worry that we will look at the information and think: what is this good for? We do not know if this is the case, because we have not seen it. Only after seeing the results, we will know if the job is well done. If it reflects the real needs. Only then we can talk about solutions."

This problem was also evident in an anecdote told by the Executive Director of TECHO-Perú. When a local newspaper shared the results of the Relevamiento (Rosas, 2018), it emphasized the unsafe living conditions of SJM. While TECHO-Perú thought this was a great opportunity to raise awareness about urban poverty in Lima, community leaders were disappointed with the coverage. They felt that the report oversimplified the problem and did not highlight the community-led initiatives to reduce the risks. This discomfort suggests that the data collection and dissemination process, as it is currently designed, is not determined by how community members choose to tell their stories, but is rather ruled by what intermediaries such as TECHO-Perú believe will be most effective approach to obtain institutional attention and support. In this sense the interests, priorities and decisions of the intermediary prevail over those of the community.

\section{Datafication and exploitation ${ }^{66}$}

We found that exploitation manifested in two ways. First, there is a general perception that community leaders who participated in the Relevamiento have not benefited from having participated. Two years have passed since the Relevamiento was conducted and to this date, many remain uncertain about how this data is being used, who is using it and what they have gained due to this process. The interviews show community leaders are still unsure about whether their expectations were taken into consideration:

"The neighbors asked TECHO-Perú: In what way will this be useful or beneficial for us? What are we going to obtain from participating? The TECHO-Perú representative explained that the survey would tell us the most urgent problems we have, and we told him that [we already knew] that our most urgent problem was lack of access to

\footnotetext{
${ }^{66}$ This section summarizes findings that speak to whether the Relevamiento created conditions of exploitation for community leaders in which more powerful groups benefitted from their work.
} 
clean water. It has been almost two years since the Relevamiento and nothing has improved. Things are still the same. We wanted progress, but [our district] has the least clean and most expensive water in all of Lima. And the Relevamiento is not attacking this problem. Maybe it is attacking other problems. We did not want this Relevamiento to be just a study, a paper. We want it to translate to 'obras' - to tangible outcomes."

Even though consent was obtained to conduct the research, it is not clear whether TECHOPerú was aware of why community members chose to participate in this process and provide their data. Were community leaders expecting an outcome in particular? Did they explicitly delegate the decisions regarding data use to the data intermediary, in this case TECHO-Perú? Did they create a system to demand accountability from the intermediary? By asking community members why they want to participate, data intermediaries can learn about the value communities ascribe to their raw data and thoughtfully incorporate these expectations into the design of their criteria for consent, use of data and the process of data collection.

Second, the reluctance to demand results from the Relevamiento is tied to the technical, capability and knowledge constraints faced by community members. Currently, they lack a general understanding about where to find the data and how they can use this data to generate action. These constraints also limit the decisions communities can make regarding their data and how they would like to use it to address their development needs.

Interviewees suggested TECHO-Perú should host regular assemblies every year to present the results of the Relevamiento and ensure there is continuity in the action plans that have been devised based on the results.

"The Relevamiento should be presented in front of the recently elected community leaders who are preparing their work plan. The new leaders do not know anything. It would be good to have a meeting every year and tell them: this is what we collected and learned from the Relevamiento."

Even though the final report of the Relevamiento has been published in an open data portal, most community members do not have access to the digital devices, infrastructure or knowhow to find it. As a result, many have not been able to use the data or request updates about the state of the study. The lack of access to it creates a situation in which the data can ultimately only be used for the purpose, benefits or interests of those who can access it and creates conditions of exploitation in which community members participate in a data collection process to produce an output they are not able to enjoy or use.

\section{Datafication and marginalization ${ }^{67}$}

We found that while the Relevamiento is creating a space in which voices and needs of historically marginalized communities can be represented, it is also amplifying social divisions and political struggles that already existed within SJM. The conflicts interviewees mentioned are diverse and complex, spanning from political tensions between community

\footnotetext{
${ }^{67}$ This section summarizes findings that speak to whether the Relevamiento led community members to feel excluded from useful participation in social life.
} 
leaders, accusations of corruption, and ethnic tensions between immigrants from different regions of Peru. Community leaders talked about how the data collection process contributed to these tensions. Even though TECHO-Perú made an effort to include as many community groups in the process as possible, ultimately, coordination meetings were most frequent with the groups that had the most political leverage and who were more effective at building partnerships with civil society organizations. The process ultimately became politicized and was perceived by some as biased:

"When the survey came around, I felt it became biased little by little. I felt that it only considered some people and left other people aside. There are communities with whom progress has been made, while with us, the communication slowed down. We feel like we are not being listened to. As a resident, you think to yourself: ¿ya para qué? - What is the point of participating?"

This sent the message to those who already felt marginalized by the data collection process that only the needs of the most powerful groups of the community would be represented in the Relevamiento and that as a result, only their concerns would be integrated into the public agenda. In other words, that only those who actively participated in the Relevamiento process would be able to access justice, while the rest would be excluded from the debates and programs designed after this data. This belief has been strengthened by the difficulties some community members are having to work with the municipal government:

"The municipality closes many doors for us. If you do not agree with them, they marginalize you. If you do not agree with their thoughts, they marginalize you. Why should I go and negotiate [with them] if I am not going to be listened to?"

Data is not sufficient to enable collaboration between different actors and ensure the equitable participation of the least powerful groups. Be it between municipal government authorities and SJM residents, or between community leaders, inclusion and collaboration is ultimately more contingent on community relations than on availability of information or data. Recognizing the political conflicts and social divisions of the community and how they will affect the access and use of information, is a precondition to using this data effectively as a political and social tool to redress power imbalances. This also places more responsibility on civil society organizations that collect data in historically neglected populations to develop mechanisms that identify pre-existing community conflicts and mitigate possible risks or harms brought about by the intervention. 


\section{Summary}

A summary of these findings is presented in Table 3.

\begin{tabular}{|c|c|c|}
\hline $\begin{array}{l}\text { Form of } \\
\text { Injustice }\end{array}$ & $\begin{array}{l}\text { Instances in which Injustice can be } \\
\text { Challenged Through Datafication }\end{array}$ & $\begin{array}{l}\text { Instances in which Injustice can be } \\
\text { Sustained Through Datafication }\end{array}$ \\
\hline Powerlessness & $\begin{array}{l}\text { - The data collection process has led to } \\
\text { an appreciation of data and data- } \\
\text { based planning by the community. } \\
\text { Data is perceived as a valuable asset } \\
\text { that ought to be used, managed and } \\
\text { applied by the community to } \\
\text { transform their living conditions. } \\
\text { - Communicating the problems of the } \\
\text { community using data is perceived as } \\
\text { an opportunity to demonstrate the } \\
\text { urgency of the problems faced by } \\
\text { informal settlers and highlight the } \\
\text { most pressing needs. } \\
\text { Some community members believe } \\
\text { the use of data grants legitimacy, } \\
\text { authority and objectivity to } \\
\text { community knowledge. } \\
\text { Data allows community members to } \\
\text { communicate and cooperate on more } \\
\text { equitable terms with powerful actors } \\
\text { who consider data-based knowledge } \\
\text { a more accurate and trustworthy } \\
\text { source of knowledge. }\end{array}$ & $\begin{array}{l}\text { - The data collection and dissemination } \\
\text { process is not determined by the } \\
\text { priorities of community members but } \\
\text { is rather ruled by what intermediaries } \\
\text { such as TECHO-Perú, believe will be } \\
\text { most effective approach to obtain } \\
\text { institutional attention and support. } \\
\text { The turn to datafication is making data } \\
\text { more valuable. Data is considered } \\
\text { more legitimate and useful than other } \\
\text { ways of knowing such as intuition, } \\
\text { opinions or lived experiences that are } \\
\text { also present in the community. } \\
\text { The role of an intermediary that } \\
\text { advises communities on how to use } \\
\text { the data effectively could generate } \\
\text { dependency and further the notion } \\
\text { that the community is incapable of } \\
\text { using this data without their } \\
\text { mediation. } \\
\text { Community members fear a data- } \\
\text { based narrative about the realities of } \\
\text { the informal settlement that lacks } \\
\text { context portrays them in harmful, } \\
\text { undesirable or dehumanizing ways. }\end{array}$ \\
\hline Exploitation & $\begin{array}{l}\text { - Community members are demanding } \\
\text { accountability from the data } \\
\text { intermediary; TECHO-Perú. They wish } \\
\text { to know how their data has been } \\
\text { used and who is benefitting from it. } \\
\text { Criteria for obtaining consent in data } \\
\text { collection processes can incorporate } \\
\text { the decisions made by community } \\
\text { members regarding their data: such } \\
\text { as why they are providing it and what } \\
\text { they are expecting in return. }\end{array}$ & $\begin{array}{l}\text { - Communities remain uncertain about } \\
\text { how the data has been used, who is } \\
\text { using it and what they have gained due } \\
\text { to this process. } \\
\text { Data is published in open data portals } \\
\text { community members cannot access } \\
\text { due to technical, capability and } \\
\text { knowledge constraints. } \\
\text { These constraints also limit the } \\
\text { decisions communities can make } \\
\text { regarding their data and how they } \\
\text { would like to use it to address their } \\
\text { development needs. }\end{array}$ \\
\hline Marginalization & $\begin{array}{l}\text { Datafication creates a space in which } \\
\text { voices and needs of historically } \\
\text { marginalized communities can be } \\
\text { represented. } \\
\text { Data can be used to capture attention } \\
\text { of powerful actors such as elected } \\
\text { government officials, international } \\
\text { development organizations and policy } \\
\text { makers. }\end{array}$ & $\begin{array}{l}\text { - If the data collection process does not } \\
\text { include every community, it risks } \\
\text { amplifying the voices of the most } \\
\text { powerful groups within the } \\
\text { community. } \\
\text { Data is not enough to spark the } \\
\text { interest of political actors. Political will } \\
\text { is more contingent on community } \\
\text { relations than on availability of } \\
\text { information or data. }\end{array}$ \\
\hline
\end{tabular}

Table 3: Summary of findings on powerlessness, exploitation and marginalization 


\section{D2. Datafication as a Process to Develop Capabilities and Take Action}

A more strategic use of community data could enable community leaders to challenge oppressive relations and take action to transform their conditions. Iris Marion Young argues in the social connection model of responsibility $(2006, p 123)$ that "structural processes can be altered only if many actors in diverse social positions work together to intervene in these processes to produce different outcomes". SJM community leaders identified three ways in which they can participate on more equitable terms in data-based initiatives and decisions. These ideas contemplate data capability development and are oriented towards improving conditions for decision making regarding the use of data in community development.

Datafication has generated interest in the community towards developing data capabilities The data-intensive process facilitated by TECHO-Perú has sparked a strong interest in the community to develop data capabilities. The frustration of not being able to access the data has led community leaders to reflect upon the value data has for their community and how they could use it in strategic ways to improve their livelihoods and collaborate with diverse actors. Even though the community of SJM already collects its own data through community-based initiatives, community leaders seem interested in learning to conduct large-scale, systematic processes such as the Relevamiento. Among the examples they provided, they wish to be able to access the data generated by the Relevamiento, crossreference it with community data, and use it to inform ongoing community development programs and to improve management and planning of the community resources.

\section{Community leaders want to transition from being data providers to data owners}

After the Relevamiento, community leaders think of data as a source of power and as a valuable asset. However, they currently lack the technical resources, knowledge and infrastructure to engage with it in a meaningful way and to set the terms for its use. A community leader used a powerful metaphor to explain how data could contribute to selfdetermination by comparing it to a "multi-purpose knife" or a "first-aid backpack", in that their utility depends on the readiness and sophistication of the user.

"The results of the Relevamiento should be like a first-aid backpack or a multipurpose knife. These knives have scissors, a bottle opener, a screwdriver, even a little hammer. Everything that could help me in an emergency. That is what the Relevamiento should do. It is a tool for us and also for the authorities. But you have to know how to use it. You need to know where to find it.".

\section{"If you give us the results on paper, [...] we will not understand what that report} means. If someone comes and explains it to us: 'now you have this benefit, or you can achieve this, and this. Or we have achieved this and this with the survey.' If it benefits us, we are going to do something with it."

To address this gap, community leaders suggest the development of training materials and learning modules that build data literacy, digital literacy and digital rights with an antioppressive lens. Their idea is to bridge the gap between data and the community through the use of creative tools, such as animated cartoons, dynamic videos or short movies, "that you can watch with the whole family", and that seek to situate and humanize data as part of "the reality" of the SJM community. 


\section{Community-based data infrastructure is key for community data management}

Finally, interviewees also expressed an interest in the creation of community-based data infrastructures where communities who provided their data can access it, manage it and set terms over how it is used. In practical terms, they suggested the creation of a digital repository or platform designed specifically for community leaders, where they can access and update their own data.

"All the community leaders of SJM should be able to use and manage that data. [I would like to] have a transparency portal with our data. We need a platform designed with the specific needs of SJM in mind. The data is currently available in a link, but they have not designed it with a [community] approach. A community leader should be able to access the data and feed the platform with new information. For example, if we know that there are more children being born or that there are new members in the community, we should be able to add it. I'm currently trying to use Excel. We need this information to be up-to-date to plan accordingly."

This suggests that SJM residents aspire to create conditions where they can see themselves as the experts and "owners" of their data, and create a system in which they have the power to decide what data to use and for what purpose. This is not to say that communities will use the data in an intrinsically positive or neutral way, but eliminating constraints on self-determination and self-development can possibly afford communities more agency to make decisions regarding data and also place more responsibility on them for how their decisions affect the overall system.

\section{Box 1: List of recommendations to build a community-based data collection model}

1. Collect information about expectations and aspirations of community members around data

2. Collect multiple forms of data that reflect how communities wish to be portrayed publicly

3. Co-design creative ways in which community members can share their own stories and perspectives beyond the use of quantitative data

4. Explain the value of different forms of data to community members and how each form of data can be used to achieve different purposes

5. Ask for consent both when collecting data, and again when using it. Ask for consent not just to collect data, but also about types of data use

6. Create strategies to cross-reference and integrate community data and data collected at a larger scale by external organizations

7. Build community capacities to use data for program and resource management

8. Develop digital and non-digital mechanisms to share data with the community aimed at reaching diverse publics

9. Design advocacy roadmaps that outline how data will be used to achieve communitydefined objectives

10. Design a community-based data infrastructure where communities who provided their data can access it, manage it and set terms over how it is used 


\section{E. Discussion and Conclusions}

Datafication is not only a technical process, but an activity that is deeply influenced by the power dynamics and the social, cultural and political tensions that operate within a given context. While in this study we mostly focused on identifying instances of oppression and the reproduction of inequality in data-intensive practices, Young's work prodded us to consider how residents of historically marginalized communities hold responsibility and agency to transform their conditions. Broadly speaking, datafication as it is being implemented now does not create justice for vulnerable communities. In fact, its process deepens or reproduces instances of oppression by reinforcing community perceptions regarding their lack of knowledge, lack of capabilities or lack of authority to use data to lead their own development.

However, participating in a process of datafication along with a trusted partner such as TECHO-Perú, sparked an interest in community leaders about the different ways in which they could use data to further their capabilities, mobilize collective action and address their development needs. Community leaders perceive themselves as capable and willing to use data in constructive ways to transform their conditions. This interest and power needs to be activated through capability development. The themes that emerged in the case study also led to the following four reflections:

First, the case illustrates how the cultural meanings given to data in historically marginalized communities are as important as the processes and practices we put in place to use it. In the case of Peru and SJM, we learned that datafication had a much stronger political and cultural significance than anticipated. For many, data was an objective form of expression that conferred authority to community leaders and was able to systematize the chaotic, complex and misunderstood reality of informal settlements. It also represented the opportunity to speak a lingua franca that bridged the gap between powerful decision makers from the "official Peru" and communities from the "marginalized Peru". However, to other community leaders, data embodied institutional power. It represented the imposition of a new set of rules, unmet expectations and the burden to learn new skills to stay relevant in the system. All in all, these perceptions highlight how datafication can simultaneously represent hope and oppression for vulnerable communities, and how these perspectives are not homogenous. The approach of each individual and each community group to data will be situated in their lived experiences and the power relations they are a part of. However, this case illustrates how these expectations, concerns, motivations, among others, are seldom considered in the design or the aftermath of the data collection process, leading to new forms of cultural marginalization, exploitation and powerlessness in which the perceptions of data producers and their contributions are ultimately marginalized or deemed irrelevant for the final output of the project.

Second, datafication also proved to be a process through which different actors acquire power, while others feel powerless or incapable of participating. Institutional actors or individuals who feel comfortable with the use of data will resort to datafication as a tool to boost their legitimacy and solve their problems, as is the case of local authorities who demand the use of data in evidence-based policy making or civil society organizations who 
require data to legitimize the work they do with vulnerable communities. However, we learned that individuals who lack the capabilities necessary to handle data, or the opportunities to develop these capabilities, feel they cannot use the data they provided and once owned in order to make informed decisions to address their development needs. In other words, not developing data capabilities creates conditions of exploitation in which individuals are providing their data to meet the purposes and benefits of external actors, while not being equipped to proactively reap benefits for their own community. A process of datafication that is not coupled with data capability building, limits the choices individuals from marginalized communities can make regarding their own data.

Third, the case of SJM suggests that NGOs and civil society organizations that act as data intermediaries can play a fundamental role in developing these capabilities and in enabling what Michael Gurstein calls "effective data use" (2011). We learned that the path towards becoming an effective intermediary involves understanding how to navigate communityresearcher-practitioner relations in an equitable way. If data intermediaries have the social and cultural capital to build relationships of trust with community members, they can also create the conditions to develop relevant data capabilities in the community and boost community-based datafication. We consider this should be the ultimate goal of organizations that undertake data-intensive practices in vulnerable communities: to create the conditions in which datafied systems are built and sustained by the community under norms, rules and practices set by the community. This is a particularly timely approach. As the trend towards datafication grows, every citizen will need these skills to uphold their rights and participate in society. Residents from informal settlements, along with other vulnerable communities will most likely be neglected by this process and will not have access to the opportunities to develop these skills in the same measure as other groups in society. Data skills and data justice principles could position them to assert their agency not only in datafication but in their ability to exercise their citizenship in the city.

And finally, the path towards a community-based data justice model involves imagining socio-technical practices and infrastructures that enable community data stewardship. The case of SJM illustrated how the Relevamiento was not designed to achieve structural change in and of itself, but to create tools SJM residents could use to exist and interact on more equitable terms within system. In this sense, the idea of a community-oriented data infrastructure is promising. Community members in SJM did not reject the process of datafication, but imagined a datafied system in which they would be able to access the data, and manage it continuously improve it. This introduces a different way to think about data that is built on the basis of community - as opposed to individual - ownership and stewardship. Many questions remain about the benefits or risks of this model: what data rights do they hold as a community? How can they establish boundaries for external, more powerful actors, that wish to access and use their data? Would this model reproduce the hierarchies of the current model by establishing gatekeepers and limited users of information? However, we believe it is a step forward to reduce the power of those who are currently leading datafication initiatives, and enable communities to define new rules for what datafication in development should do, in what way and for whom. 


\section{E1. Recommendations}

Practical recommendations were outlined above in Box 1. From an academic standpoint, future studies should attempt to use Young's framework to understand data-related injustice. Her concepts were very useful to identify specific ways in which datafication could mitigate or further an individual sense of injustice. However, more in-depth research is required to understand how larger, institutional forms of injustice are challenged or sustained by datafication. It is also key to continue investigating how relations of domination-oppression can translate into and affect other areas of life with wider implications for livelihood and survival over time. Some questions include: in what ways do powerlessness, exploitation and marginalization constrain access to social, economic or political participation? How do perceptions of these affect the decisions oppressed communities make in their personal, family and community life? How does injustice experienced in datafication intersect with other forms of powerlessness, exploitation and marginalization experienced on the basis of gender, race, socio-economic status, etc.?

To continue developing a community-based data justice model, future studies should explore community data management. On this occasion we found that community management is organized around collective action; yet this ideal is constrained by the political and ethnic conflicts that exist between the diverse social groups that exist in spaces like informal settlements. Many questions remain about what socio-technical systems need to be in place to enable effective community data governance: how will their cultural and social divisions translate into mechanisms for community data management? Who will have the power to manage community data? What checks and balances will need to be in place to ensure representation and accountability? As these questions are tackled, studies should continue to center the voices of those who live in marginalized communities and portray the diversity, complexity and power imbalances they navigate. 


\section{References}

Benjamin, R. (2016) Informed refusal: Toward a justice-based bioethics. Science, Technology, \& Human Values, 41(6), 967-990.

Canales, T., \& Maulen, A. (2011) Microcampamentos y su invisibilidad en la macrohistoria. Revista CIS, 9(14), 117-125.

Chakraborty, A., Wilson, B., Sarraf, S., \& Jana, A. (2015) Open data for informal settlements: Toward a user's guide for urban managers and planners. Journal of Urban Management, 4(2), 74-91.

Crooks, A., Pfoser, D., Jenkins, A., Croitoru, A., Stefanidis, A., Smith, D., ... \& Lamprianidis, G. (2015) Crowdsourcing urban form and function. International Journal of Geographical Information Science, 29(5), 720-741.

Dede, A. F. (2018) Ciudad Ilegal. Lima: El Comercio. https://elcomercio.pe/opinion/colaboradores/urbanizacion-lima-callao-ciudad-ilegalaldo-facho-noticia-497386

Donovan, K. (2012) Seeing like a slum. Georgetown Journal of International Affairs, Winter/Spring, 97-104.

Graham, M., Hogan, B., Straumann, R. K., \& Medhat, A. (2014) Uneven geographies of usergenerated information: Patterns of increasing informational poverty. Annals of the Association of American Geographers, 104(4), 746-764.

Gurstein, M. B. (2011) Open data: Empowering the empowered or effective data use for everyone?. First Monday, 16(2).

Hagen, E. (2011) Mapping change. Innovations, 6(1), 69-94.

Heeks, R., \& Renken, J. (2018) Data justice for development: What would it mean? Information Development, 34(1), 90-102.

Heeks, R., \& Shekhar, S. (2019) Datafication, development and marginalised urban communities: an applied data justice framework. Information, Communication \& Society, 22(7), 992-1011.

Liboiron, M., Zahara, A., \& Schoot, I. (2018) Community peer review: A method to bring consent and self-determination into the sciences. Preprints 2018, 2018060104.

Liu, X., Song, Y., Wu, K., Wang, J., Li, D., \& Long, Y. (2015) Understanding urban China with open data. Cities, 47, 53-61.

Matos, J. (1986) Desborde Popular y Crisis del Estado (3 ${ }^{\text {rd }}$ ed.). Lima: IEP.

Ministerio de Vivienda (2012) Situación de los Barrios Marginales en el Perú. Lima: Dirección Nacional de Urbanismo, Ministerio de Vivienda.

http://www3.vivienda.gob.pe/dgprvu/docs/Estudios/08\%20Situaci\%C3\%B3n\%20BUM\% C2\%B4s\%20en\%20el\%20Per\%C3\%BA\%202012\%20-\%202da\%20Aprox.pdf

Petty, T., Saba, M., Lewis, T., Gangadharan, S. P., \& Eubanks, V. (2018) Our Data Bodies: Reclaiming our Data (interim report). Detroit: ODB Project.

Plöger, J. (2012) Gated barriadas: Responses to urban insecurity in marginal settlements in Lima, Peru. Singapore Journal of Tropical Geography, 33, 212-225.

Redacción Gestión (2017) Midis: Ahora existen más pobres urbanos que pobres rurales en el Perú. Gestion, 5 Jan. https://gestion.pe/economia/midis-existen-pobres-urbanospobres-rurales-peru-126049

Rosas, Y. (2018) SJL: 70\% de habitantes de asentamientos vive en riesgo ante deslizamientos. Diario El Comercio, 17 Oct. https://elcomercio.pe/lima/sucesos/sanjuan-miraflores-asentamientos-son-vulnerables-deslizamientos-noticia-568615 
Scott, J. C. (1998) Seeing like a State: How Certain Schemes to Improve the Human Condition have Failed. New Haven: Yale University Press.

Simpson, A. (2007) On ethnographic refusal: Indigeneity, 'voice' and colonial citizenship. Junctures: The Journal for Thematic Dialogue, 9, 67-80. http://junctures.org/index.php/junctures/issue/view/11/showToc

Taylor, L. (2017) What is data justice? The case for connecting digital rights and freedoms on the global level. Big Data \& Society, Jul-Dec, 1-14.

TECHO-Perú. (2018) Relevamiento de Asentamientos Populares - San Juan de Miraflores. Lima: TECHO-Perú. http://datos.techo.org/dataset/39047c97-5b38-478a-a958f8d9d7bd28be/resource/99e59185-d06e-4921-b0b5-baee3b8cd9ad/download/informerelevamiento-de-asentamientos-populares-sjm.pdf

Thatcher, J., O'Sullivan, D., \& Mahmoudi, D. (2016) Data colonialism through accumulation by dispossession: New metaphors for daily data. Environment and Planning D: Society and Space, 34(6), 990-1006.

Uhde, Z. (2010) On sources of structural injustice: A feminist reading of the theory of Iris M. Young. Human Affairs, 20(2), 151-166.

Young, I. M. (1990) Justice and the Politics of Difference. Princeton: Princeton University Press.

Young, I. M. (2006) Responsibility and global justice: A social connection model. Social Philosophy \& Policy, 23, 102-130.

Young, I. M. (2012) Five faces of oppression. In: The Community Development Reader $\left(2^{\text {nd }}\right.$ ed.), J. Defilippis \& S. Saegert (eds). New York: Routledge, 328-337. 


\section{Acknowledgements}

The "Urban Data, Inequality and Justice in the Global South" case studies form part of a Senior Research Fellowship funded by the University of Manchester's Sustainable Consumption Institute with additional financial support from Canada's International Development Research Centre. We would like to acknowledge the trust and support provided by TECHO-Perú and the community leaders of San Juan de Miraflores to conduct this study.

\section{About the Authors}

Denisse Albornoz holds a BA in International Development and Sociology from the University of Toronto. Her research and advocacy work in India, Canada and Peru has looked at questions of power and inequality in knowledge production, science, technology and education. She currently works for Hiperderecho, a digital rights organization based in Peru where she investigates gender and technology, data justice and feminist digital culture.

Katherine Reilly is Associate Professor in the School of Communication at Simon Fraser University, Canada. Her work focuses on the role of communications in international relations and international development. Her areas of research interest include the impact of information and communications technologies on political and social processes in Latin America, the role of open data in development processes, and the political economy of media reform in Latin America. Most recently she has begun to study the sharing economy in Latin America.

Marieliv Flores holds a BA in Communication for Development from the Pontificia Universidad Católica del Perú and is an MA candidate on Gender Studies at Ottawa University, Canada. She currently works for Hiperderecho in Lima, Perú. 


\section{Annex: Social Connection Model by Iris Marion Young}

1. Social Connection Model of Responsibility developed by Iris Marion Young. Concepts and definitions retrieved from Section IV of Responsibility and Global Justice (Young, 2006). Table created by the authors.

\begin{tabular}{|l|l|}
\hline Feature & Definition \\
\hline Not isolating & $\begin{array}{l}\text { In a context of structural injustice, finding a few people guilty of perpetrating specific } \\
\text { wrongful actions does not absolve from bearing responsibility others whose actions } \\
\text { contribute to the outcomes. A social connection model of responsibility recognizes how } \\
\text { the actions of every actor who participates in the structure has an impact over the just or } \\
\text { unjust outcomes of the structure. }\end{array}$ \\
\hline $\begin{array}{l}\text { Judging background } \\
\text { conditions }\end{array}$ & $\begin{array}{l}\text { A model of responsibility understands the mediated connection that agents have to } \\
\text { structural injustices. It often brings into question the background conditions - historical } \\
\text { legacies, institutional rules, accepted cultural norms - that shape decision making of } \\
\text { actors who belong to the structure and perpetuate injustice. }\end{array}$ \\
\hline $\begin{array}{l}\text { More forward- } \\
\text { looking than } \\
\text { backward-looking }\end{array}$ & $\begin{array}{l}\text { Assigning and taking responsibility for injustice is more forward-looking than backward- } \\
\text { looking. This recognizes there are an ongoing set of processes that will likely continue } \\
\text { producing harms unless there are interventions. The point is not to blame, punish, or } \\
\text { seek redress from those who created a specific act of injustice, but rather to enjoin those } \\
\text { who participate by their actions in the process of collective action to change it. }\end{array}$ \\
\hline $\begin{array}{l}\text { Shared } \\
\text { responsibility }\end{array}$ & $\begin{array}{l}\text { Shared responsibility recognizes each individual is personally responsible for the risks of } \\
\text { harmful outcomes produced by a group of persons in a partial way. The specific part that } \\
\text { each person plays in producing the outcome cannot be isolated and identified, thus the } \\
\text { responsibility is essentially shared. }\end{array}$ \\
\hline $\begin{array}{l}\text { Discharged only } \\
\text { through collective } \\
\text { action }\end{array}$ & $\begin{array}{l}\text { Forward-looking responsibility can be discharged only if many actors in diverse social } \\
\text { positions work together to intervene in these processes to produce different outcomes. }\end{array}$ \\
\hline
\end{tabular}

2. Parameters of reasoning social actors can use to think about their own action in relation to structural injustice. Concepts retrieved from p137 of Responsibility and Global Justice (Young, 2006). Table created by the authors.

\begin{tabular}{|l|l|l|}
\hline Parameter & Definition & Young's reflections regarding action and justice \\
\hline Power & $\begin{array}{l}\text { The degree of potential or actual } \\
\text { power or influence over the processes } \\
\text { that produce the outcomes. }\end{array}$ & $\begin{array}{l}\text { Agents do not always have sufficient energy and } \\
\text { resources to respond to all structural injustices to } \\
\text { which they are connected. They should focus on } \\
\text { those where they have a greater capacity to } \\
\text { influence structural processes. }\end{array}$ \\
\hline Interest & $\begin{array}{l}\text { Degree of interests in the maintenance } \\
\text { or transformation of structures that } \\
\text { produce injustice. }\end{array}$ & $\begin{array}{l}\text { Victims of structural injustice often have a greater } \\
\text { interest in structural transformation. But those with } \\
\text { the greatest interest in perpetuating the structures } \\
\text { are those with the greatest power to influence their } \\
\text { transformation. }\end{array}$ \\
\hline Privilege & $\begin{array}{l}\text { Degree of privilege acquired by virtue } \\
\text { of the structures. Privilege often } \\
\text { coincides with power. }\end{array}$ & $\begin{array}{l}\text { Persons who benefit relatively from structural } \\
\text { injustices have special moral responsibilities to } \\
\text { contribute to organized efforts to correct them, not } \\
\text { because they are to blame, but because they are } \\
\text { able to adapt to changed circumstances without } \\
\text { suffering serious deprivation. }\end{array}$ \\
\hline $\begin{array}{l}\text { Collective } \\
\text { ability }\end{array}$ & $\begin{array}{l}\text { When interest, power, and existing } \\
\text { organization enables people to act } \\
\text { collectively to influence processes } \\
\text { more easily regarding one issue of } \\
\text { justice than another. }\end{array}$ & $\begin{array}{l}\text { The structural processes can be altered only if many } \\
\text { actors in diverse social positions have the } \\
\text { capabilities to work together and intervene in these } \\
\text { processes to produce different outcomes. }\end{array}$ \\
\hline
\end{tabular}




\title{
Case 10: Making Informal Settlements 'Visible' Through Datafication A Case Study of Quarry Road West Informal Settlement, Durban, South Africa
}

\author{
Catherine Sutherland, Bahle Mazeka, Sibongile Buthelezi, Duduzile Khumalo and Patrick \\ Martel \\ School of Built Environment and Development Studies \\ University of KwaZulu-Natal, Durban
}

\begin{abstract}
Can datafication increase the 'visibility' of informal settlements in South Africa, in the context of a national and local state that holds both progressive and repressive approaches towards informal settlements? This case study explores a datafication process that has been in place for five years in an informal settlement in Durban, which has been established through an inclusionary, participatory data collection and production process.

It examines how and when the data moves in the information value chain, and the implications this movement has for achieving rights-based, instrumental, structural and distributive justice. It argues that procedural and rights-based justice can be achieved to a certain extent through the construction of an inclusionary datafication process. However, instrumental, structural and distributive justice is dependent on how the interventionist and developmental state of South Africa engages with the data, and whether it takes it up in a meaningful way, thus enabling it to lead to fundamental shifts in discourses, approaches and practices towards informality.
\end{abstract}

The results reveal that the 'governance and knowledge platforms' that are built through the datafication process are more important and powerful at first, than the actual data itself. However, informal settlers and other data intermediaries, who have learnt how to engage data to secure the 'right of informal settlers to the city', have begun to use the data in interesting ways, acting as champions, and re-shaping citizens' relations with the state. While this does not secure tangible changes in informal settlements, it begins to shift discourses and power relations, which is critical to informal settlement upgrading. 


\section{A. Introduction}

This case study focuses on the role that urban datafication, including participatory mapping, is playing in building social and environmental justice in Quarry Road West informal settlement, Durban, South Africa. Quarry Road West informal settlement, which comprises approximately 1083 households, is located on the Palmiet River, in the urban core of Durban (see Figure 1). Researchers from the School of Built Environment and Development Studies, University of KwaZulu-Natal (UKZN), Durban, and 'mapmakers' from Quarry Road West informal settlement have established a five year partnership within the Palmiet Catchment Rehabilitation Project (PCRP) as part of an action research project, to improve quality of life in the settlement. The PCRP is a pilot project of the uMngeni Ecological Infrastructure Partnership (UEIP), which focuses on improving water security in the uMngeni Catchment using ecological infrastructure (Sutherland \& Roberts 2014). The researchers and mapmakers are co-constructing a range of data and maps at the local scale, producing knowledge on the settlement and its governance. This datafication of the settlement has the goal of improving the living environment of residents through informal settlement upgrading, supporting social learning, river rehabilitation, climate adaptation, and the building of resilience (Martel \& Sutherland 2019; Mazeka et al 2019; Sim et al 2019; Vogel et al 2016; Williams et al 2019).

The university researchers and mapmakers continually reflect on 'if, how and why' this data contributes to, and shapes, the well-being, resilience and development of the community and whether it has helped to build state-citizen relations, which have emerged as being critical to 'good' urban governance in Durban (Martel \& Sutherland 2019; Mazeka et al 2019). Has this long-term, participatory and time-consuming data production process supported the transformation of the community and addressed development deficits in any way? Has it shaped city decision making with respect to the relocation or upgrading of the settlement and service provision within it? And has it contributed to shifting broader city discourses around the 'rights' and 'place' of informal settlers in the city? The case study therefore reflects on whether 'data justice for development' is emerging through the Quarry Road West datafication project, and if so, whose interests does it serve. It identifies the levers of change in the datafication project, which have led to development outcomes. It also reflects on the barriers and structural constraints in achieving a higher level of data justice. Heeks \& Shekhar's (2019) model of data justice is used as a framework to assess data justice in the Durban case study. This model is expanded to include governance and 'critical moments' as additional elements of data justice, based on evidence from the Quarry Road West informal settlement datafication project. 


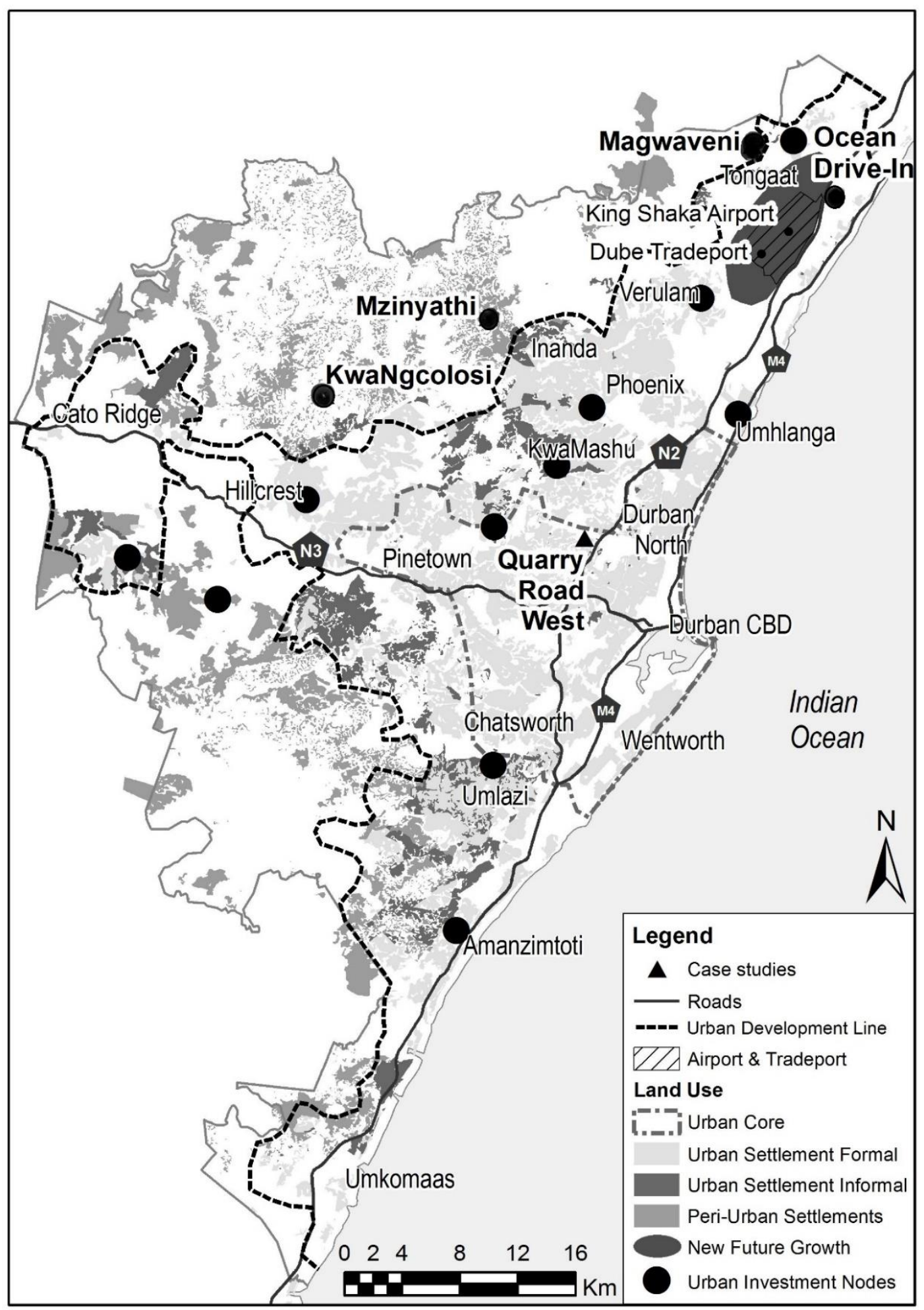

Figure 1: The location of Quarry Road West informal settlement within the urban core of Durban (eThekwini Municipality) (map produced by Eduaction in 2019)

The case study provides a critical reflection on the form and level of data justice achieved through the participatory methodologies that have been employed in the settlement to date. It explores the way in which the data has been produced and travelled between the community, the university and the municipality, in most instances through 'bridges' or 'data 
intermediaries' (Heeks \& Shekhar 2019), informing community adaptations, as well as municipal responses. The case study therefore explores:

- how the process of co-constructing and producing data is leading to greater social and environmental justice (procedural justice);

- if and how the data has been used to improve quality of life in the informal community and if it has shaped municipal decisions and responses to informal housing (instrumental justice);

- the power relations produced both by the data production process and the data collected, with an emphasis on the role of bridges or data intermediaries (structural data justice);

- to what extent making the settlement more 'visible' has shifted discourses about informal housing in the city, particularly in terms of informal settlers' 'rights to the city' (rights-based justice);

- who has benefited and who has lost through the datafication process (distributive justice).

Given that relatively few analyses of real-world initiatives of data justice for development have been undertaken (Heeks \& Shekhar 2019), this case study makes a contribution by both providing an empirical case of emerging data justice in an African city, and by expanding Heeks \& Shekhar's (2019) model to include two other elements that shape data justice in cities in the South, namely governance and 'critical moments'. It has also broadened the understanding of rights-based justice in the model.

\section{B. Background}

\section{B1. Datafication for Development}

Development depends on data or information for decision making (Heeks \& Shekhar 2019; Milan \& Treré 2017; UN-Habitat 2017). However, the production of, and control over data used for development has predominantly been in the hands of scientists and experts, who have provided data to the state and non-state actors for decision making through administrative rationalism (Dryzek 2012). According to Dryzek (2012:75) "administrative rationalism emphasizes the role of the expert rather than the citizen or producer/consumer in social problem solving, and stresses social relationships of hierarchy rather than equality or competition". However, data is now making its way into decision making through multiple actors and multiple pathways. This is a result of the democratisation of decision making through the shift from government to governance, the development of the network society (Castells 2000; Hajer \& Wagenaar 2003), and the growing volume, velocity, variety and visibility of data, as a result of the digital technologies of the $21^{\text {st }}$ century (Heeks 2018). This is leading to the 'datafication of development', which is the growing presence, use and impact of data in social processes, leading to opportunities for increased developmental impact through new forms of data streams being produced, shared and translated at different scales (Heeks \& Shekhar 2019; Mazeka et al 2019; Spratt \& Baker 2015; Taylor \& Broeders 2015). The production, sharing and use of data is particularly important for the urban poor, who to date have been largely excluded from data production processes in 
cities in the South, due to their perceived and constructed illegibility, informality and lack of power.

In focusing on the power of datafication in supporting development, it is critical to differentiate between big data, digital data and 'local' or community-produced data. Taylor (2017) argues that datafication tends to focus on digital data or the data people emit through the technologies that citizens, the private sector and the state employ to both participate in and be accountable to society. However, what happens to development, if the data emitted by people does not focus on or address the challenges of urban poverty, marginalisation, and informality in the city? Large numbers of the urban poor do not emit digital data on a regular basis. For example, the contribution of informal settlers to state coffers through payment for rates and services is often limited or non-existent, as their presence in the city is seldom digitally recorded, and they do not pay for services through formal administrative systems, as services in informal settlements are often free or illegally obtained. The urban poor are connected to digital systems of data collection through smart phone technology and the use of the internet, but this is often intermittent due to the cost of, and hence their lack of access to, data. As Milan \& Treré suggest (2017: 3019), "the underprivileged, the silenced, the subaltern, and the "have nots," whose presence outdoes geographical boundaries, often remain in the blind spot" and hence they remain invisible.

At the same time, datafication has provided institutions and corporations, whose interest it is to manage and govern people, with new 'technologies of rule' and hence power (Li 2007). This can lead to development when undertaken in a socially transformative manner, but it can also produce greater inequality and marginalisation in spaces where human rights are most fragile (Heeks \& Shekhar 2019; Milan \& Treré 2017). Taylor \& Broeders (2015) argue that big data and its processes of informational capitalism serves the interest of the elite or those in power, rather than securing socially-just development interventions. This leads to a geography of disempowerment as datafication recognises, makes visible and benefits some, while excluding and making others invisible and illegal, as they attempt to claim their 'right to the city' from the 'bottom of the data pyramid' (Arora 2016; McQuillan 2015). Does datafication support individuals and communities with different histories and geographies including diverse racial, class, legal and socio-cultural conditions? Or does it reproduce these inequalities?

A point of departure in responding to these questions is to reflect of who is doing the collecting of the data, for what purpose and how. The advent of digital technologies has increased the production of data on cities, as new forms and streams of data in decision making have emerged and are impacting on urban development particularly through the discourses and practices of the 'smart cities' agenda (Heeks 2018). Cities are now being mapped using remote sensing, sensors that record environmental data, and by tracking mobile phone use, which generates new patterns of life in the city (Lokanathan et al 2016; Willis 2017). In all these cases, technology is producing the data to support decision making for development with experts controlling both the production and use of data. Datafication therefore has the potential to support development through increased knowledge and understanding of citizens' needs and everyday lived worlds; through ensuring efficiency in decision making; and in supporting evidence-based and more transparent development (Samarajiva et al 2015; van Veenstra et al 2014). 
However, there is a growing body of literature which critically reflects on the datafication of the city, arguing that the way in which data is collected is not fair or equal; that the use of data does not always achieve just outcomes and that some benefit more than others from this process (Baud 2016; Milan \& Treré 2017; Taylor \& Richter 2015). This has led to the call for pro-equity data initiatives (PEDIs), where new forms of data sets and data flows are being created to draw the poor and marginalised into the decision-making processes of the city through open data and community-based mapping (Chakraborty et al 2015; Heeks \& Shekhar 2019; Willis 2017). This approach is supported by a well-established body of knowledge on the value and practices of participatory community-based mapping; an important tool in participatory research which emerged in the 1960s (Brown \& Kyttä 2014; Chambers 2006; Elwood 2006; Mazeka et al 2019; Rambaldi et al 2006). According to Rambaldi et al (2006), community-based maps act as vehicles for (spatial) learning, discussion, information exchange, analysis, decision making and advocacy and they facilitate communication between insiders (the community) and outsiders (researchers, government officials). The mapping process also has the potential to transform power relations as a result of the empowerment that takes place when communities are engaged in the mapping of their settlements (Lydon 2003; Mazeka et al 2019; Piccolella 2013).

Community-based mapping has been supported through the dissemination of spatial information technologies such as global positioning systems (GPS), (open source) geographic information systems (GIS) and open access to spatial data through the internet (Chambers 2006). This has opened up a new range of possibilities for 'participatory GIS', through which local community members record attributes of their community relevant to them in locallyscaled maps (Gaillard et al 2013; Mazeka et al 2019). Participatory community-based data collection and mapping produces different forms of data and data streams to those produced through digital technologies, as the data collected is 'localised' and 'embedded' and is produced through collaborative processes that draw on local knowledge and experience. This data can be digitised through the use of GPS and GIS, leading to its inclusion in digital data analysis.

This case study explores the datafication of an informal settlement in Durban through participatory data practices, produced through a community-university partnership, which is attempting to enhance data justice for development. It therefore aims to address the call to analyse real-world data production initiatives in the global South, to reflect on how new data streams and datafication are influencing and shaping development at the local scale (Heeks \& Shekhar 2019; Sengupta et al 2017; Spratt \& Baker 2015; Taylor \& Broeders 2015). Evaluative frameworks are required to determine to what extent data initiatives for the urban poor in cities in the South are leading to greater social justice and transformation (Heeks \& Shekhar 2019). Heeks \& Shekhar's (2019) model for data justice for development is employed to critically analyse the datafication process which is emerging in Quarry Road West informal settlement in Durban.

\section{B2. A Framework to Assess Data Justice for Development}

Heeks \& Shekhar (2019) have developed a model, or applied data justice framework, which explores five dimensions of data justice (see Figure 2). In developing their model and drawing on the data justice literature, they have highlighted three critical elements of data 
justice. First, it must be critical and must support procedural, instrumental and rights-based justice. Second, the way data is produced, flows and is used, determines its transformative potential far more than the technology used to produce, process and display it. Third, the socio-political context within which the 'data assemblage' is produced, including the discourses, institutions, social relations and material resources of that context, will shape data-related outcomes (Heeks \& Shekhar 2019). The case study presented here reflects the importance of these three elements of data justice.

Heeks \& Shekhar's (2019) model of the data system for datafication focuses on the different forms of justice that emerge out of and support the information value chain, which reflect the steps through which data is transformed into development outcomes.

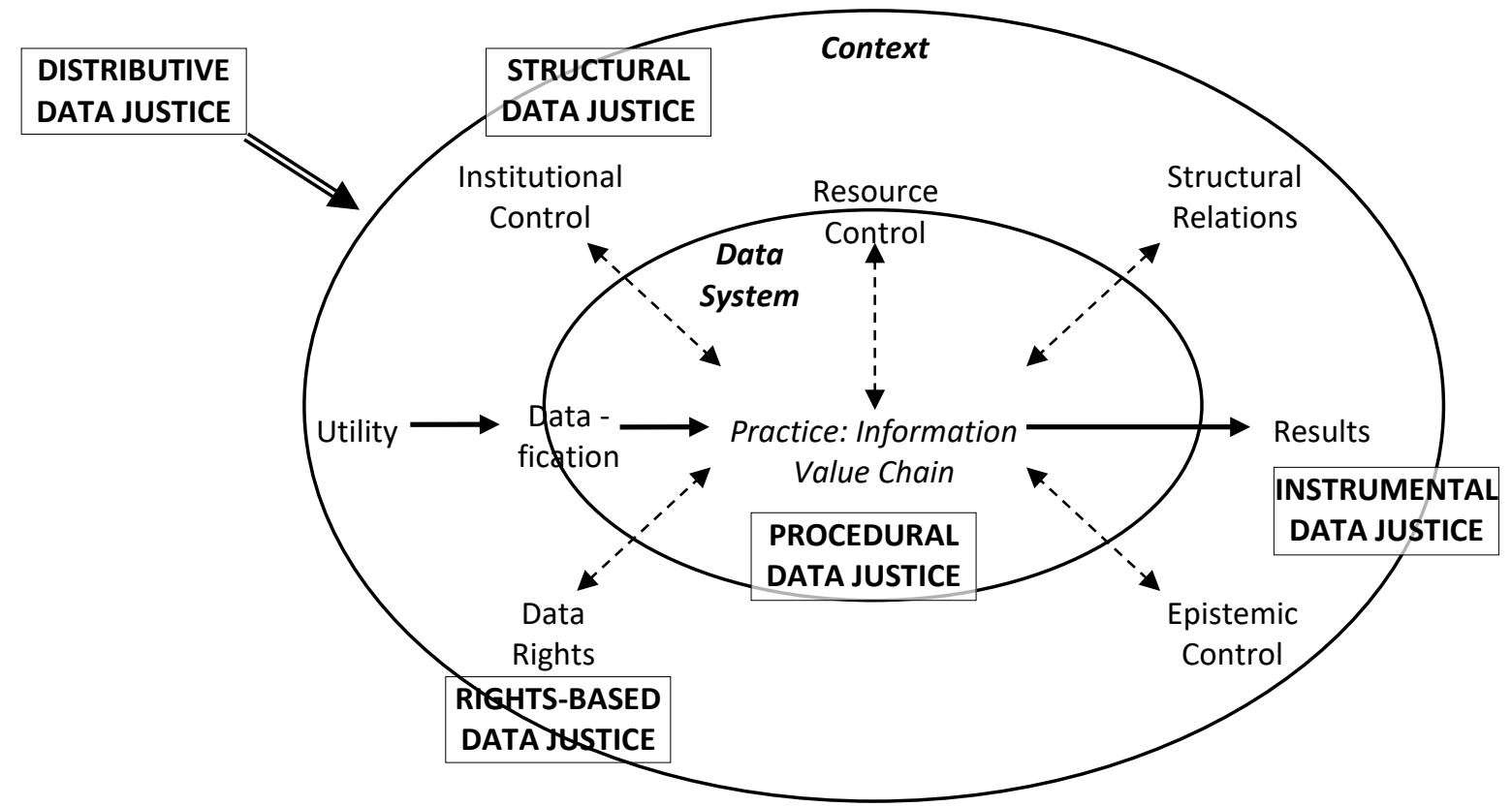

Figure 2: Heeks \& Shekhar (2019) conceptual model of data justice

The five dimensions of data justice as defined by Heeks \& Shekhar (2019: 995) are:

- "Procedural justice: fairness in the way in which data is handled.

- Instrumental justice: fairness in the results [or outcomes] of data being used.

- Rights-based justice: adherence to basic data rights such as representation, privacy, access and ownership.

- Structural justice: the degree to which the interests and power in wider society support fair outcomes in other forms of data justice.

- Distributive justice: an overarching dimension relating to the (in)equality of datarelated outcomes that can be applied to each of the other dimensions of data justice."

The information value chain, which is shaped by and which shapes the five dimensions of data justice and the particular socio-economic and political context within which it is produced, comprises of three steps: upstream steps of data capture or collection; midstream steps of data processing and visualisation; and downstream steps of data use in decision making. This is shown in Figure 3. 


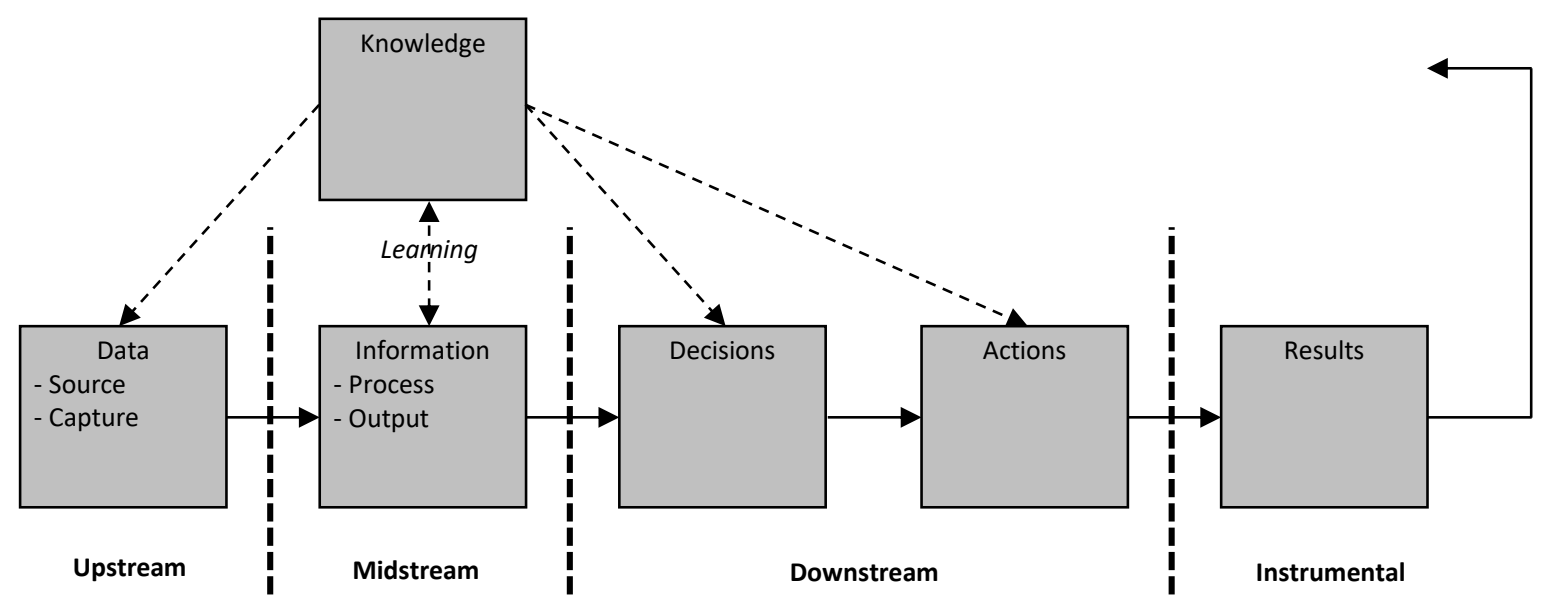

Figure 3: The information value chain (Heeks \& Shekhar 2019)

This case study will use the information value chain and data justice model - developed by Heeks (2017) and applied by Heeks \& Shekhar (2019) to four PEDIs in the developing world as an analytical framework to reflect on datafication and data justice in an informal settlement in Durban, South Africa. It will expand on a number of elements included in the model, as a result of the analysis of datafication undertaken in Quarry Road West informal settlement. Context is considered critical to data justice analysis and hence the final part of the background section reflects on informality and informal settlements in the global South; particularly in South Africa.

\section{B3. Informality and Datafication in Cities in the South}

Informality is a way of life both globally and in Durban, with just over $25 \%$ of the global population and $27 \%$ of Durban residents living in informal settlements (eThekwini Municipality 2017; UN-Habitat 2018). Poverty, the rapid pace of urbanisation, a lack of affordable housing, the decompression of existing crowded urban settlements, migration, a decrease in urban household size, natural population increase and environmental risk are contributing to the growth in both the number and size of informal settlements (Braathen et al 2016; eThekwini Municipality 2017; UN-Habitat 2018). Formal planning processes, financial and social resources and state capacity are not able to keep pace with housing demand in Southern cities, leading to significant housing and service backlogs. As a result, the urban poor illegally invade land and develop informal settlements, which reflect their efforts at securing their 'right to the city' (Lefebvre 1968). Informal settlers typically have no security of tenure, only somewhat rarely being granted tenure by the state in progressive cities and countries that recognise informal housing as part of urban life (e.g. some locations in India, Brazil and South Africa); they lack access to basic infrastructure and services; they have poor standards of housing that usually do not comply with planning and building regulations; and they live on marginal or environmentally hazardous sites (Braathen et al 2016; Davis 2006; UN-Habitat 2018).

National and city governments in the global South adopt a wide range of responses to informal settlements including repressive approaches, where evictions and forced relocations are common; ambivalence, where informal settlers inhabit the city with little 
support from the state; to progressive approaches, where informal settlements are considered to be part of the solution to housing the urban poor, with national and local governments planning and implementing upgrading programmes (Braathen et al 2016; Dupont 2013; Huchzermeyer 2011; Satterthwaite et al 2018; Sutherland et al 2016).

Understanding the discourses that national and city authorities and informal settlers adopt towards informal housing is therefore critical in reflecting on their place and future in the city. Knowledge and hence data about informal settlements plays a critical role in framing the discourses associated with informal settlements and shapes the way in which they are governed (Huchzermeyer 2011; Jordhus-Lier et al 2016). City authorities in the global South struggle to address the multiple challenges associated with informal settlements, which are distributed across the urban landscape, with their different characteristics, which emerge from their varied contexts. Human settlement or housing departments in local governments therefore tend to focus on informal settlements across the city, collecting data on the number, location and boundaries of informal settlements. However, they often have limited knowledge on their internal configuration: their history; age; political organisation and social capital; and the number and composition of individual households. This is reflected for example, in the significant variation in data on the number and percentage of informal households in Kisumu in Kenya (Karanja 2010) and in six cities in India, Peru, Brazil and South Africa (Dupont et al 2016). For example, in Durban the percentage of informal households varies from 12 percent to 31 percent depending on which state authority is doing the counting (Sutherland 2016). Given their scale, informality, dynamic nature and complexity, most informal settlements are therefore only 'known' or 'mapped' at the settlement scale by local governments in cities, which renders the 'human-ness', 'organisation' and 'resilience' of life in an informal settlement invisible to the state (Karanja 2010; Mazeka et al 2019; Sim et al 2019).

In South Africa, city authorities have lacked the political will, capacity and resources to collect detailed data on individual households in informal settlements. Some officials argue that given that informal settlements are so dynamic, it is not useful to map or collect data on settlements at the household scale, as they grow and change at such a rapid rate (Human Settlements Official pers comm 04/07/2017). South African municipalities record data on individual households in informal settlements through informal residents registering their informal house with their local government Human Settlements Unit, thereby obtaining a housing number, which protects their right to be there and which will be used to allocate them a formal state-subsidised house, should relocation take place (see Figure 4). 


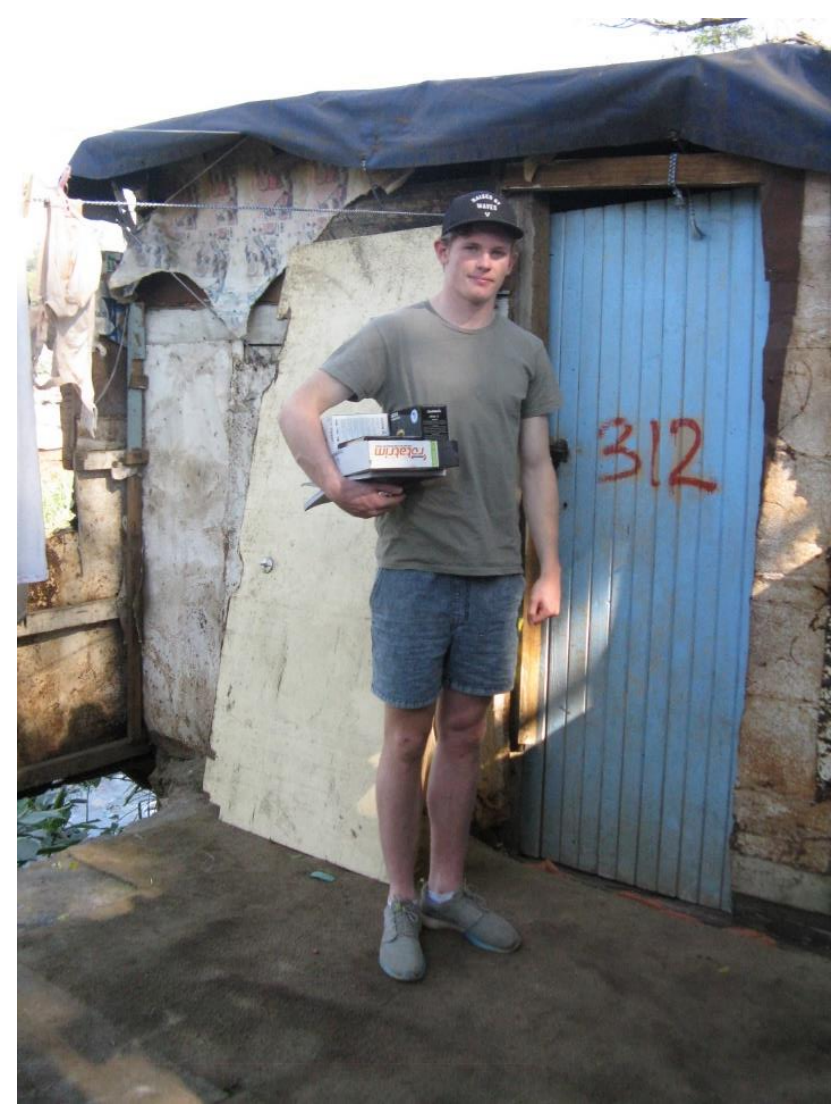

Figure 4: Housing number in Quarry Road West informal settlement registered with the Human Settlements Unit (Source: C. Sutherland 06/07/2017)

However, this data is not regularly updated which leads to outdated data being held by the city on the size and composition of informal settlements (Mazeka et al 2019). Durban, as part of the implementation of the city's Resilience Strategy, is currently conducting an enumeration exercise in its informal settlements in an attempt to obtain more accurate data on its 556 informal settlements and 226,000 informal households (eThekwini Municipality 2017).

eThekwini Municipality has always had a relatively progressive approach to informal housing, which is reflected in, for example, its incremental service provision programme, where the local state provides basic services, including communal water points, communal ablution blocks and electricity, to informal settlements which are not due to be relocated in the near future. Efforts around informal settlement upgrading have recently been intensified through the iQhaza Lethu Partnership Project, which is a partnership between Project Preparation Trust (PPT), Slum/Shack Dwellers International and the Human Settlements Unit of eThekwini Municipality. This applied partnership project is funded by the European Union (2018 to 2020). iQhaza Lethu aims to create a cohesive and collaborative effort towards upgrading of informal settlements, drawing on the knowledge and expertise of the municipality, NGOs, researchers and communities. Settlements selected as pilot studies will become sites of innovation and experimentation in informal settlement upgrading (eThekwini Municipality \& PPT 2018).

Datafication of development can play a role in achieving social and environmental transformation. However, it can also produce greater inequality and social injustice due to 
the power embedded in data processes: collection, production and use of data. Informal settlements represent the most unequal, precarious and vulnerable sites of human habitation or 'a place to put your head' (Quarry Road West Mapmaker pers comm 14/08/2019), in cities in the South. They are also largely excluded from urban datafication processes. For data justice for development to be achieved where it matters the most, greater research and empirical testing of the datafication of informal settlements is required.

\section{C. Methods}

Quarry Road West informal settlement is a precarious settlement, as it is located on the narrow floodplain of the Palmiet River adjacent to a major freeway and secondary roads (Figures 5 and 6). The settlement is characterised by its poor living conditions, high levels of poverty, its lack of basic services and poor housing, and its vulnerability to multiple environmental and social risks, including flooding, poor drainage, illegal electricity, fire, disease and crime (Mazeka et al 2019; Williams et al 2019).

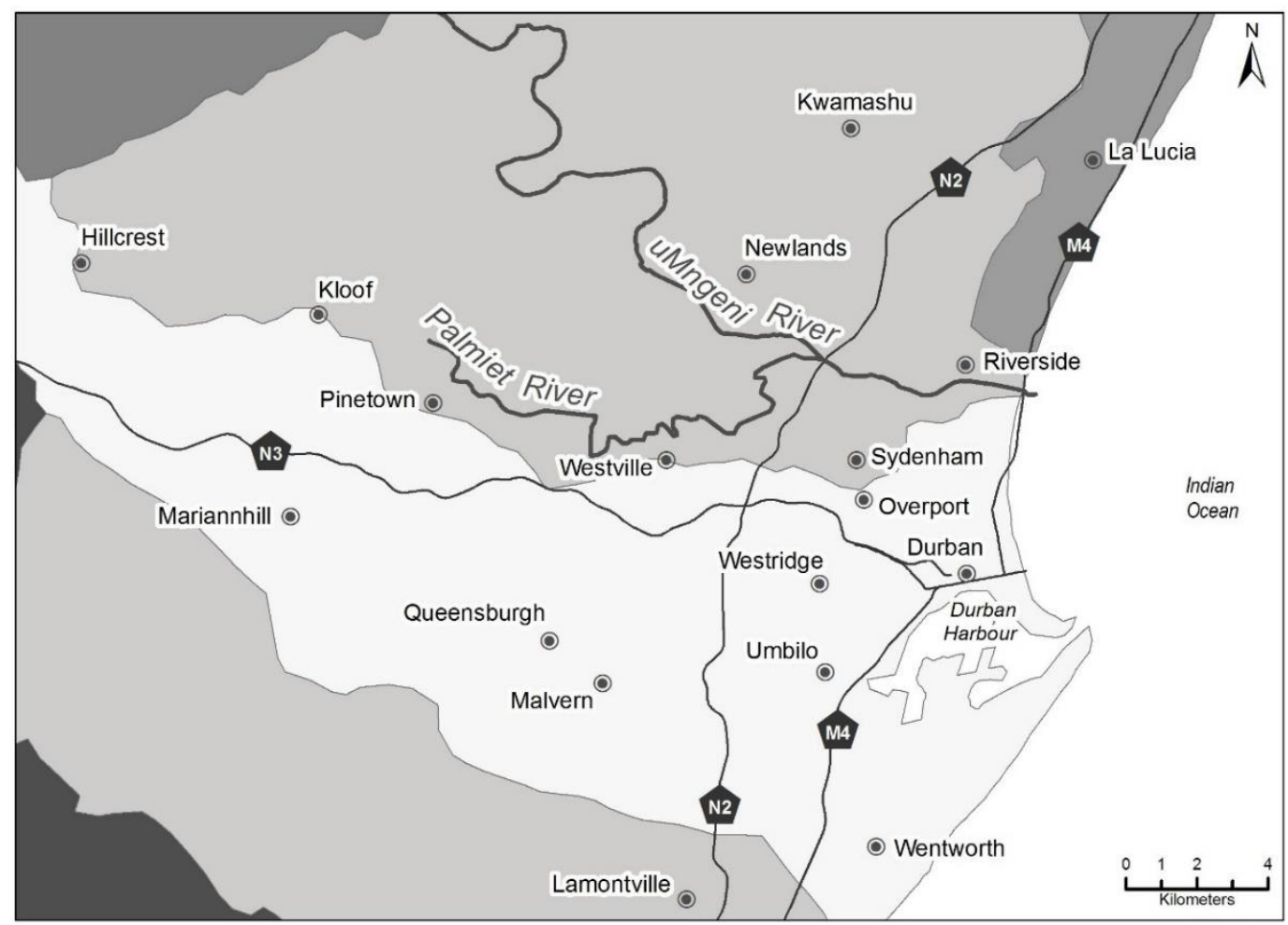

Figure 5: The location of the Palmiet River and Palmiet Catchment in the uMngeni Catchment (map produced by Eduaction in 2016) 


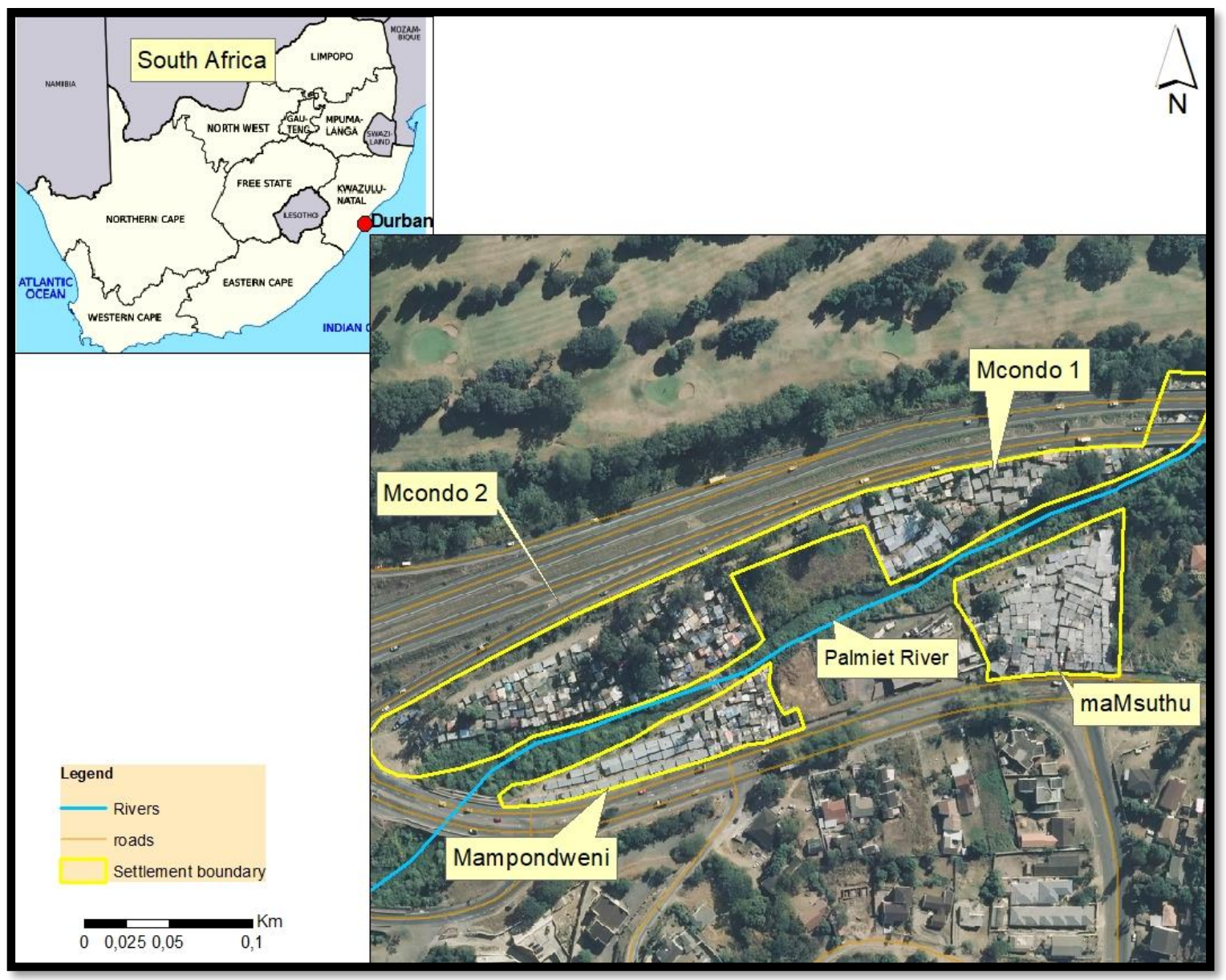

Figure 6: The location of the Quarry Road West informal settlement and its four subsections Mcondo 1, Mcondo 2, maMpondweni and maMsuthu, on the Palmiet River (Source: Mazeka et al 2019)

Quarry Road West informal settlement is categorised as a 'deferred relocation' by the Human Settlements Unit, due the lack of availability of state-subsidised low cost housing in the city. It is located on a high risk site, the narrow floodplain of the Palmiet River, which is prone to flooding after storm events (Williams et al 2019). It will therefore be challenging to upgrade the settlement in-situ. The settlement is well established, it has been in existence for over 32 years and it is not likely that it will be moved in its entirety in the near future, due to the large housing backlogs and slower delivery of formal low cost housing in the city, as well as the resistance of the community to move to state-subsidised housing on the periphery of the city. Under the iQhaza Lethu project, the municipality is considering innovative approaches to addressing the environmental risk of the site, to determine if insitu upgrading is possible, given the broad socio-economic benefits the location of the site offers its residents (Mazeka et al 2019; Sim et al 2019).

The datafication project in Quarry Road West informal settlement forms part of the Palmiet Catchment Rehabilitation Project. When the PCRP was established in 2014, the UKZN researchers argued, in their initial meetings with the eThekwini Water and Sanitation Unit (EWS) from eThekwini Municipality, that it was critical to co-produce knowledge on the catchment with community-based organisations using participatory approaches, if resilient and sustainable water and climate governance was to be built (Vogel et al 2016). From the 
outset of the project, the UKZN researchers set about building relations and constructing knowledge with the community of Quarry Road West informal settlement, to understand their relations with the Palmiet River. This knowledge production process is what is critically analysed in this case study, to explore the extent to which it has achieved data justice.

This case study was selected for analysis because data has been co-produced between the informal settlers and university researchers over a long period of time and hence there is a well-established data production process or information value chain. This reveals the changing nature of data produced as issues in the settlement change and as researchers and community members build their capacity in collecting data in an informal space. Quarry Road West informal settlement is exposed to high environmental risk, is politically and socially well organised and it displays high levels of social cohesion and identity, which makes it a good case study to explore data justice (Sim et al 2019). Perhaps what is most important, is that at the outset of the PCRP, state officials could not enter the settlement without high levels of security, due to the conflictual and confrontational relationship between the state and the informal settlers, as a result of a lack of trust on both sides. By 2016, a relationship between the state and citizens had been established and by 2018 informal settlers were conducting river clean-ups in municipal uniforms funded by municipal supported co-operatives (see Figure 7). The relations between citizens and the state had shifted as a result of procedural justice which opened up possibilities to build instrumental, structural, rights-based and distributive justice.

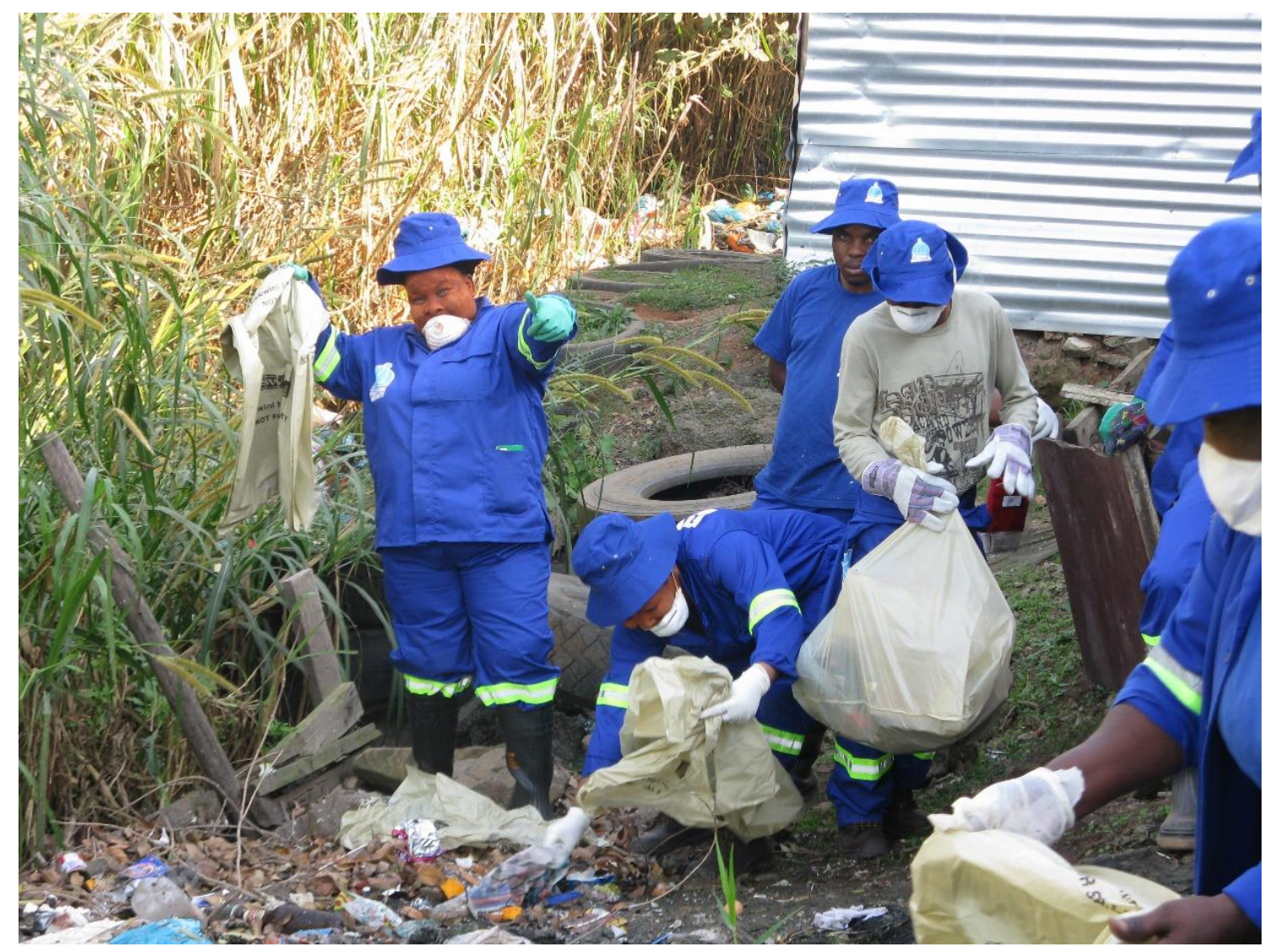

Figure 7: Cleaning up the Palmiet River: informal settlers as municipal workers during a week of river rehabilitation (Source: C. Sutherland 28/06/2018) 
The data production process which is analysed in this case study produced the data, maps and knowledge outlined in Box 1.

Box 1: Data co-produced between university researchers and informal settlers in Quarry Road West informal settlement

- Baseline data: history and geography of the settlement

- Engagement in the PCRP and the production of the PCRP Action Plan (Martel \& Sutherland 2019; Williams et al 2018; Williams et al 2019)

- Community-based and participatory GIS mapping (Mazeka et al 2019)

- Participation in development of Durban's Resilience Strategy (100RC) (eThekwini Municipality 2017)

- Risk mapping (community-based, GIS and drone mapping analysis) (Mazeka et al 2019).

- Development of a climate smart informal settlement handbook (Sutherland et al 2019a)

- Exploring the 'narratives of home' in an informal settlement (Sim et al 2019)

- Innovative sanitation technologies: Gates Foundation's 'Reinvent the Toilet Challenge'

Interviews on the concept of data justice were conducted with four officials from the Human Settlements Unit, Environmental Planning and Climate Protection Department (EPCPD), Coastal Stormwater and Catchment Management Department in eThekwini Municipality through action research in the PCRP. A focus group was held on 20 March 2019 with 14 members of the mapmakers team from Quarry Road West informal settlement to explore the question of whether the data they have produced has achieved social and environmental transformation in the settlement. This was facilitated by Open Data Durban. The data and reports that have been produced for the PCRP, listed in Box 1, were critically evaluated on an ongoing basis between January 2019 and July 2019. This was undertaken in meetings held in the community and at the university between the mapmakers, university researchers and municipal officials as they continued to engage in the work of upgrading the settlement and improving water and climate governance within it. The authors who have written this case study are the researchers involved in the datafication of Quarry Road West informal settlement. We therefore acknowledge our positionality in the project and the way in which this will have shaped the analysis presented here, as we are embedded researchers. The data justice model by Heeks \& Shekhar (2019) is used as a framework to reflect on the information value chain that is emerging through the project and to critically analyse the datafication taking place in Quarry Road West informal settlement. This includes a reflection on how the datafication process has built state-citizen relations (structural and procedural justice), has helped to address challenges in the settlement (instrumental, procedural and structural justice) and how it has supported the upgrading and transformation of the settlement to date (instrumental, procedural and rights-based justice). 


\section{D. Findings}

Mapmakers from Quarry Road West informal settlement have been co-producing data with a team of researchers from UKZN since 2014 (see Box 1). However, life in the settlement remains precarious, and has become even more challenging after a major flood which devastated the settlement on 22 April, 2019. This raises questions about the value of the datafication process in achieving development. Data has been collected, processed and produced through participatory knowledge production practices, in the upstream and midstream activities of the information value chain. Some data has moved downstream in the information chain, to the spaces of decision making and implementation, largely through the efforts of 'bridges' or data intermediaries. Two university researchers, two municipal officials and three mapmakers, who have developed their skills in data presentation through the datafication project, have acted as the main 'bridges' in the project. These data intermediaries have actively sought opportunities to present, both individually and collectively, the data on the settlement in multiple platforms in the city.

This activism, through the way in which the data has been constructed and presented to support progressive discourses on informality, has therefore played an important role in both moving the data along the information value chain, and in the form the embedding of the data in the value chain takes. This includes presenting data in PCRP meetings, in international conferences held in the city that had a strong municipal presence (IAIA 2017), in stakeholder workshops for the development of Durban's Resilient City (2016-2017), in videos produced for the Bill and Melinda Gates Foundations Re-Invent the Toilet Challenge (2018) for a global toilet fair in China in 2018, in the KwaZulu-Natal Province's Climate Change Summit (14/08/2019), in municipal forums and meetings held to address critical water, climate and housing issues in the city, and in events to showcase the data produced in the settlement, including the Narratives of Home photographic exhibition held in the settlement (21/03/2019). The data intermediaries have therefore acted as 'champions' for informal settlement upgrading in the city through the datafication process being undertaken in Quarry Road West informal settlement. The role of champions is well recognised as being critical to just transformation and sustainable development (Roberts 2016).

However, the extent to which the data has resulted in meaningful change in the settlement is questioned in a city grappling with informality. Some instrumental outcomes have emanated from the co-production of data. However, these outcomes relate more to changes in governance, shifts in discourses towards informal settlements and their 'right to the city', empowerment of the community and having their voices heard, and opportunities for engaging with the municipality in innovative projects, than tangible outcomes related to changes in the built environment of the settlement. In time, these may yield more substantive outcomes on the ground, such as the provision of improved services, most notably sanitation and stormwater drainage, the reduction of the risk of the river to the community, the upgrading of the settlement, or even the relocation of the settlement in its entirety. These substantive outcomes require significant shifts in political will and bold governance by the state. However, the 'soft' outcomes are important in creating institutional shifts, which can lead to social and environmental transformation. They therefore may be just as valuable over the longer term for development, as 'hard' outcomes reflected in changes in the built environment. The knowledge that has been built has made 
the settlement more 'visible' and this visibility has brought other actors and projects to the settlement, which has led to change both in the settlement, and in the institutions engaging with it (see Figure 10). However, these efforts are also being constrained by the broader political struggles around informality that are dominant in the municipality at present, both between political parties and within them. In most instances, the changes in Quarry Road West informal settlement represent 'little victories in the face of big defeats', as the gains are small, and are often overwhelmed by the challenges and politics of living in an informal settlement in a city struggling to address and cope with increasing informality. However, they bring hope of change in the settlement, and it is this hope that motivates informal settlers to persevere in data collection processes (Open Data Workshop 21/03/2019).

This case study analyses the value of datafication in two ways. It first presents the value of the data itself in supporting social and environmental transformation in the settlement and reflects on the structural elements that constrain or enable the movement of data downstream in the information value chain. Second, it reveals the value of the data production process and the state-citizen-university relations it has built, in leading to change through data justice. The first section reflects on the data produced, which is multi-modal and in most cases is not the digital data of development informatics, but rather qualitative data that opens up opportunities for listening and learning (Kennedy et al 2019). The case study reveals that qualitative data produced at the local scale can play a valuable role, along with quantitative and digital data, in making informal settlements more visible through 'just' datafication. This finding is supported by Kennedy et al's (2019) case study on informational politics in Hyderabad and Chakraborty et al's (2015) and Willis' (2017) research on community-based mapping.

\section{D1. Valuing Different Forms of Data in Different Contexts for City Datafication}

Individuals and communities at the 'bottom of the data pyramid' (Arora 2016) are often excluded from big data, digital data and the datafication of the city. They do not always emit data, nor are they digitally captured or recorded as citizens in the same way as those that are connected to the global and national economy; to the benefits and services of formal city life; and to the dominant political and social networks of a particular society. Informal settlers find themselves on the periphery of city datafication, due to their particular histories and geographies, their informality, poverty and inequality, and the way in which others who have power, construct their 'place' and 'identity' in the city.

As the urban poor, they claim their 'right to the city' through illegal land invasions. They claim land, build their own housing and attempt to access basic services. They seek representation and hence they organise themselves politically. However, they often remain invisible, due to the repressive discourses of informality in the city, which construct informal settlements as places to be removed, relocated or as places that are 'not meant to be there' or are 'not known' (Councillor 1 pers comm 23/04/2019). So how do informal settlers begin the process of being represented in the data of the city?

An analysis of the data, maps and images co-produced by the mapmakers and UKZN researchers from 2014 to 2019 on Quarry Road West informal settlement, reveals the wide range of data that has been collected, processed and more recently transferred into 
decision-making spaces through 'bridges' or data intermediaries (Heeks \& Shekhar 2019). The data ranges from creative, qualitative data to technical and digital data, collected and represented using participatory GIS. The different forms of data have travelled within and from the informal settlement outwards, and hence have played a role in ensuring some level of data justice in the settlement, albeit in small ways. The types of data collected and the purpose of collecting the data was decided upon collaboratively, as the mapmakers and the university researchers explored both the relationship between the informal settlers and the Palmiet River, and critical issues that emerged in the settlement, as the research partnership evolved. The role of different forms of data (see Table 1) in achieving some level of data justice and examples of this data (see Figure 8 ) are presented below. Table 1 describes the type of data collected and produced and the impact it has had, and it reflects on the type and level of data justice achieved.

\section{Table 1: The role of different types of data in achieving data justice}

\begin{tabular}{|c|c|c|}
\hline Type of data & Impact of data & Data justice \\
\hline $\begin{array}{l}\text { A: Community-based } \\
\text { maps: maps sketched by } \\
\text { the community showing } \\
\text { main sections, features } \\
\text { and risks }\end{array}$ & $\begin{array}{l}\text { Develops a context of the settlement, } \\
\text { helps data producers to understand the } \\
\text { organisation of the settlement and its } \\
\text { main characteristics and risks. } \\
\text { Many informal settlements in South } \\
\text { Africa are divided into sections that have } \\
\text { historical, geographical and political } \\
\text { meaning, and this is critical to } \\
\text { understand in any development process, } \\
\text { but is often missed in interventions } \\
\text { planned from 'outside' the settlement. } \\
\text { Supports qualitative open-ended } \\
\text { listening and dialogue about the } \\
\text { settlement and its social, economic, } \\
\text { environmental and political dimensions. }\end{array}$ & $\begin{array}{l}\text { This form of data is valuable to data } \\
\text { producers as it provides a platform } \\
\text { upon which an understanding of the } \\
\text { context of the settlement and other } \\
\text { data is built. It is used in upstream } \\
\text { activities. It supports procedural } \\
\text { justice as the community constructs } \\
\text { and provides the first baseline map } \\
\text { of the settlement, setting the } \\
\text { boundaries of and framing the } \\
\text { datafication process at the outset. }\end{array}$ \\
\hline $\begin{array}{l}\text { B: Participatory GIS } \\
\text { maps and risk maps: } \\
\text { maps co-produced } \\
\text { between informal } \\
\text { settlers and researchers; } \\
\text { data collected on each } \\
\text { household, which is } \\
\text { included in an attribute } \\
\text { table. Each household is } \\
\text { spatially geo-referenced } \\
\text { as are the risks in the } \\
\text { settlement }\end{array}$ & $\begin{array}{l}\text { GIS data and maps provide an accurate } \\
\text { spatial record of households in the } \\
\text { settlement at a particular point in time. } \\
\text { The settlement is mapped at the } \\
\text { household scale, which protects } \\
\text { residents against evictions, as their 'right } \\
\text { to the city', enshrined in the South } \\
\text { African Constitution and housing } \\
\text { legislation, is recorded and spatially geo- } \\
\text { referenced on the map. The GIS map } \\
\text { provides a temporal record, which is } \\
\text { critical in determining which residents } \\
\text { have rights to the settlement after } \\
\text { natural and human-induced disasters } \\
\text { disrupt the settlement. }\end{array}$ & $\begin{array}{l}\text { Procedural, instrumental, structural } \\
\text { and rights-based justice is built } \\
\text { through communities owning and } \\
\text { producing GIS maps of their } \\
\text { settlement in partnership with } \\
\text { university researchers. Community } \\
\text { members decided which attributes } \\
\text { were mapped for each household. } \\
\text { Power relations are challenged as } \\
\text { informal settlers, rather than only } \\
\text { the municipality, hold data on the } \\
\text { households in the settlement and } \\
\text { their 'right to the city'. The GIS } \\
\text { maps have been used in legally } \\
\text { challenging evictions, thereby } \\
\text { protecting 'mapped' residents since } \\
2017 .\end{array}$ \\
\hline
\end{tabular}




\begin{tabular}{|c|c|c|}
\hline Type of data & Impact of data & Data justice \\
\hline $\begin{array}{l}\text { C: Data on climate } \\
\text { adaptation for climate } \\
\text { smart informal } \\
\text { settlement booklet. Data } \\
\text { on impact of and } \\
\text { response to natural } \\
\text { disasters reflected in } \\
\text { drone maps which are } \\
\text { being used in the iQhaza } \\
\text { Lethu project }\end{array}$ & $\begin{array}{l}\text { Mixed qualitative and spatially- } \\
\text { referenced data in the form of } \\
\text { community-based maps, community } \\
\text { sketches and photographs of climate } \\
\text { smart informal houses, GIS risk maps of } \\
\text { environmental and human-induced } \\
\text { hazards in the settlement, as well as } \\
\text { drone maps which are being used in the } \\
\text { construction of a Disaster Risk } \\
\text { Management Plan for the municipality. }\end{array}$ & $\begin{array}{l}\text { Procedural justice as informal } \\
\text { settlers define adaptation and } \\
\text { resilience in the settlement on their } \\
\text { terms. Data on adaptation } \\
\text { practices, is evaluated in relation to } \\
\text { knowledge on adaptation from the } \\
\text { literature. Potential instrumental } \\
\text { justice as informal settlers are using } \\
\text { this data to inform and produce a } \\
\text { Disaster Risk Management Plan for } \\
\text { the settlement for use by EPCPD } \\
\text { and the Disaster Risk Management } \\
\text { Department. }\end{array}$ \\
\hline $\begin{array}{l}\text { D: Photographic images } \\
\text { and narratives on the } \\
\text { meaning of home in an } \\
\text { informal settlement: } \\
\text { collected using a range } \\
\text { of qualitative } \\
\text { methodologies including } \\
\text { focus groups, } \\
\text { photovoice } 68 \text { and } \\
\text { interviews }\end{array}$ & $\begin{array}{l}\text { Powerful data, which has shifted } \\
\text { multiple actors' understanding and } \\
\text { discourses about informal settlements. } \\
\text { Data humanises informal settlements } \\
\text { and their residents. }\end{array}$ & $\begin{array}{l}\text { Procedural justice as the narratives } \\
\text { and visions of home were } \\
\text { constructed by informal settlers, } \\
\text { using an established qualitative } \\
\text { methodology. This ensures that the } \\
\text { voice of informal settlers is the } \\
\text { main voice in the data presented. } \\
\text { Instrumental, rights-based and } \\
\text { structural justice are being } \\
\text { enhanced as the narratives of home } \\
\text { project has played a role in shifting } \\
\text { repressive state discourses on } \\
\text { informal settlements through } \\
\text { presentations made by both } \\
\text { researchers and informal settlers in } \\
\text { public forums. }\end{array}$ \\
\hline $\begin{array}{l}\text { E: Data collected on } \\
\text { water and sanitation } \\
\text { access, practices and use } \\
\text { by informal settlers in } \\
\text { partnership with } \\
\text { university researchers } \\
\text { for Engineering Field } \\
\text { Testing of EAWAG } \\
\text { Waterwall as part of the } \\
\text { Gates Foundation's } \\
\text { 'Reinvent the Toilet } \\
\text { Challenge' }\end{array}$ & $\begin{array}{l}\text { Data is informing an international project } \\
\text { on the development of innovative } \\
\text { sanitation technologies and hence has } \\
\text { local and global impact. }\end{array}$ & $\begin{array}{l}\text { Procedural and instrumental data } \\
\text { justice, which ensures the voice of } \\
\text { beneficiaries is heard in the } \\
\text { development of global technologies } \\
\text { for innovative sanitation systems } \\
\text { and is included in the planning and } \\
\text { service provision strategies of } \\
\text { eThekwini Water and Sanitation } \\
\text { Unit. }\end{array}$ \\
\hline
\end{tabular}

68 Photovoice is a qualitative methodology developed by Wang and Burris (1997), where participants provide narratives of photographic images they have taken to reflect the topic under research (Sim et al 2019). 


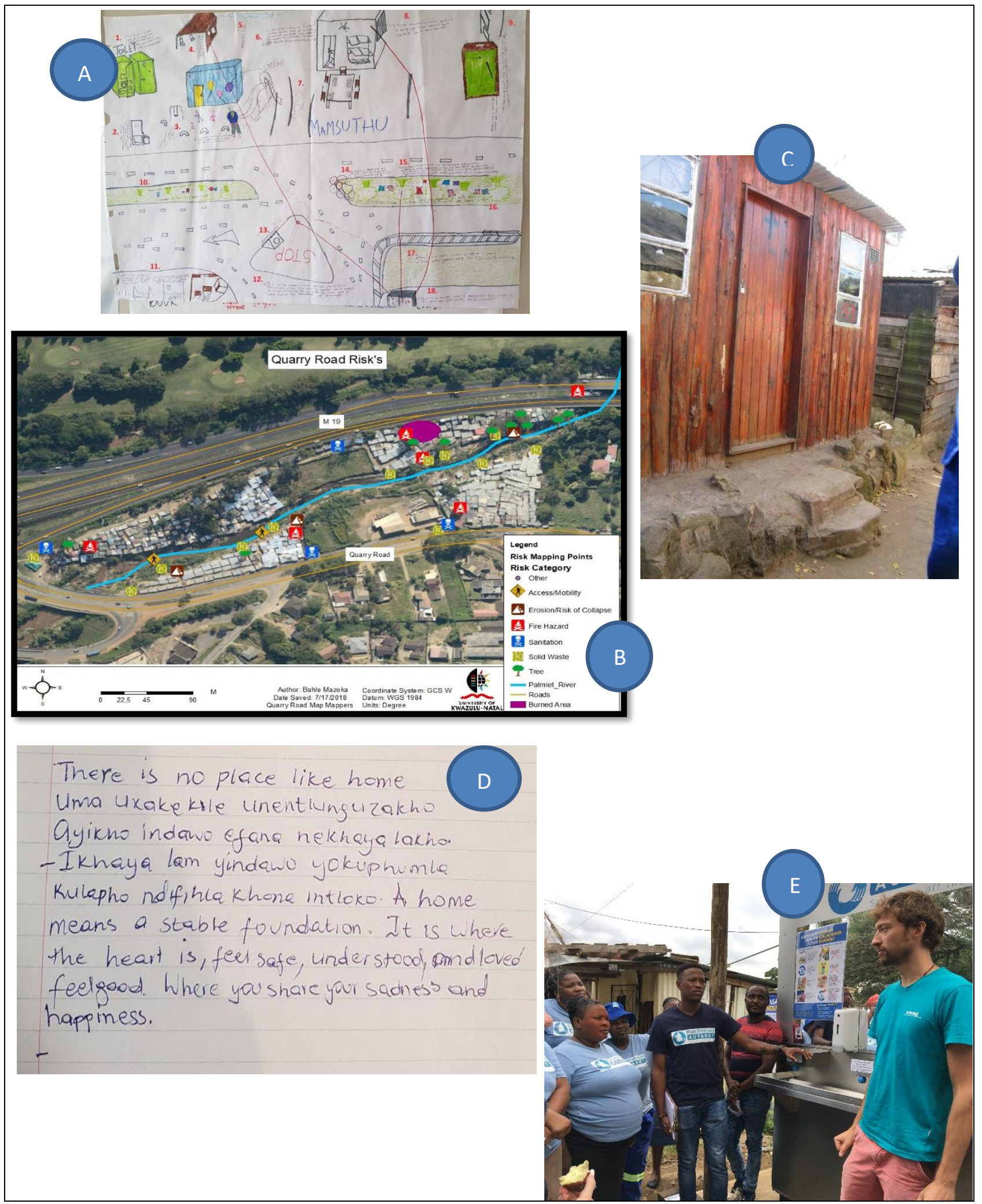

Figure 8: The different types of data produced (the letters A - E refer to the letters in Table 1 above) (Sources: A \& D: Sim et al (2019); B: Mazeka et al (2019); C \& E: C. Sutherland 17/04/2019) 
The multi-modal data collected and processed in Quarry Road West informal settlement reflects procedural justice and rights-based justice in terms of how it has been produced, as the community has ownership over the data construction process and over the data itself. The mapmakers' frustration lies in how this data can move downstream and be used to transform their everyday lived worlds, as they argue that they produce the data through their own civic duty, but then the data "gets stuck and does not change our lives" (Open Data Workshop 21/03/2019). The mapmakers have had to rely largely on 'bridges' or data intermediaries to move the data downstream in the information value chain. The 'bridges' are all engaged in the PCRP and so are committed to the datafication process over the longer term. Except for one official, they have all been participants in the project for over five years. This has created institutional memory and strong partnerships, which have supported the advocacy role of the 'bridges', who have acted collectively to reduce risk and improve quality of life in the settlement. As a result, data developed from the outset of the project continues to be transferred into various decision-making spaces within the municipality, which open up when the politics of the city allows this to happen. Having explored the different types of data collected and produced, the second part of the results of this case study reflects on the value of the data production process, the relations it has built and the outcomes it has achieved.

\section{D2. The Value of the Datafication Process}

The value of the datafication process is analysed by reflecting on the outcomes of the process, as it has evolved over time. Two phases are identified: the first phase, where the datafication process had a limited influence on instrumental, structural and distributive justice, and the second phase, where the datafication process built on what was achieved in the first phase, and began to influence downstream activities, leading to potential instrumental, rights-based, structural and distributive justice.

This became possible when the data began to flow into an innovative upgrading programme, iQhaza Lethu, in the municipal department with the most power to transform life in Quarry Road West: the Human Settlements Unit. While data had been presented to officials in this Unit in the first phase, it had had little impact as there was resistance to the data, with housing officials explaining that they had 556 settlements to deal with in the city, and so data at this 'microscale' and level of detail was not helpful to them. They also argued that it was unreliable as informal settlements are dynamic and hence this data 'would change all the time'. They argued that the informal settlers were registered with their housing numbers on the municipal database, and this is what they worked from. They also stated that Quarry Road West was a deferred relocation and hence they would not invest in upgrading efforts in the settlement (Human Settlements Unit Official pers comm 04/07/2017).

The major flood in the settlement in April 2019, also resulted in movement of the data downstream in the information value chain, as the GIS mapping and evidence of 'life in the settlement' contained in the Narratives of Home Report (Sim et al 2019; see also Figure 10) became critical to protecting people's rights to the settlement. Both iQhaza Lethu and the major flood, therefore acted as levers of change. A certain level of procedural justice was achieved in both phases, as data was produced by the community, based on their identification of data needs and transformed into development results. This was in the form 
of both 'soft' outcomes, focused on building knowledge, a governance arena, and capacity and power to act in the first phase, and downstream activities embedded in municipal, research and international projects in the second phase, which are starting to contribute to instrumental, structural, rights-based and distributive justice.

\section{Phase 1 of the datafication process}

The first phase of the datafication process, which took place between 2014 and 2017, emerged through the building of a relationship between the mapmakers and the School of Built Environment and Development Studies (BEDS) researchers, with a focus on exploring the relationship between the community and the Palmiet River ${ }^{69}$. The datafication process was therefore initiated as part of connected state-citizen-university action research projects: one part of the UEIP and the other two, national and internationally funded research projects located in BEDS, UKZN. The data that was produced during this phase included the community-based and GIS maps of the settlement (data types $A$ and $B$, see Table 1 and Figure 8).

The datafication process had a relatively small sphere of influence. The data was predominantly moved downstream into the PCRP, which focuses on building multistakeholder action for improved water and climate governance in the Palmiet Catchment. The data was used to shape the Action Plan developed as part of the PCRP. It also played a critical role in illuminating the challenges and risks facing the Quarry Road West informal community in the catchment and their desire to participate in decision making affecting their 'right to the city'. It therefore shifted both PCRP municipal and civic science actors' views of informality, as a platform was created for community voices to be heard. The data also began to travel into more significant epistemic and decision-making spaces, including committees and programmes in the municipality, largely through municipal champions. This led to 'soft' outcomes, such as raising awareness, questioning of dominant repressive discourses on informality, and humanising informal settlers (see Figure 9).

\footnotetext{
69 This research formed part of the PCRP and UEIP, a National Research Foundation (NRF) and Norwegian Research Council SANCOOP research project (CLIMWAYS) and a Water Research Commission project, WRC 2354.
} 


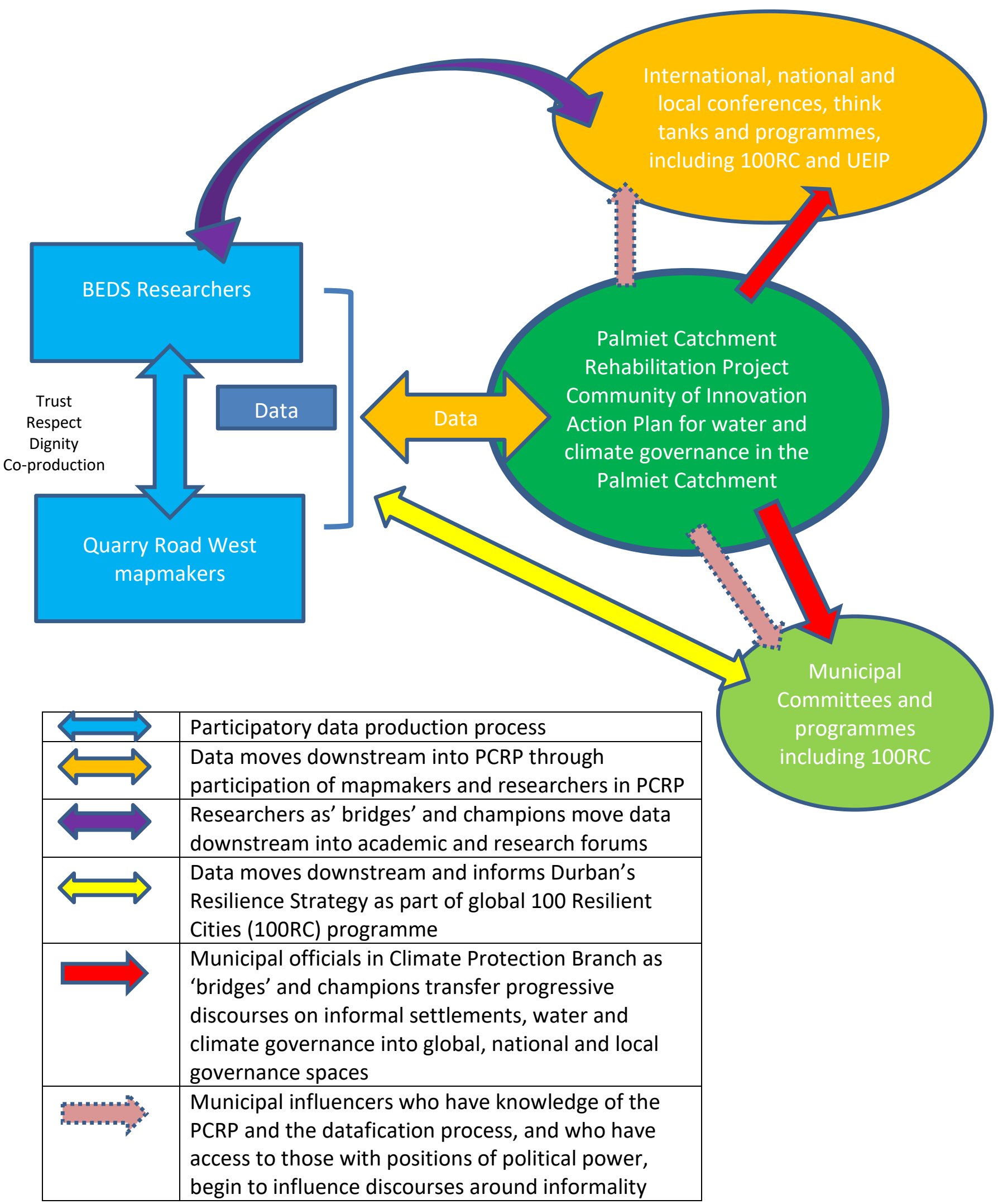

Figure 9: Phase 1 of the datafication process 
The initial decision to construct data in, and on, Quarry Road West informal settlement, was taken jointly by members of the informal community, led initially by an African National Congress (ANC) Branch Committee and sub-ward committee member, and university researchers ${ }^{70}$. The datafication process therefore started from the bottom up, using the political structures present in the settlement. The university researchers' first meeting with the community was organised by EWS as part of the initiation of the PCRP, policed by undercover security, given the conflictual relationship between the state and citizens in the informal settlement prior to 2015. This conflictual relationship was due to poor service delivery, the threat of evictions and the community members' desire to participate in decisions about their future, in the face of an interventionist and managerial local state (Sutherland et al 2018).

The first meeting provided the researchers with an opportunity to explain the focus and purpose of the PCRP, namely improved water and climate governance across the catchment, by focusing on people's relationship with the Palmiet River. The focus on the river attracted the interest of community members, as they have a close relationship with the river, which provides both benefits and risks to the community. Questions about how people relate to the river in the informal settlement did not initially trigger politics. This meant that the early processes of engagement were not thwarted by power struggles between political actors, including councillors, who wanted to control the process. The relations between the community and the river have since emerged as being highly political, particularly after the flood in April 2019, which has been part of the learning in the PCRP. The researchers met regularly with the informal settlement committee after the first meeting, openly discussing the framing of a research agenda. Trust began to be established and discussions held about what the first data gathering exercise in the settlement should be.

Exactly why and how this initial trust was established is difficult to determine. The team of researchers from UKZN, who have worked in other medium-sized informal settlements across the city over the past ten years, attribute the building of relationships to three factors. The willingness and desire of informal settlers to participate in the politics and transformation of urban life and to be made 'visible' and 'known'; the openness of a participatory research process which has inclusivity and the co-production of knowledge as its focus; and the continual 'going-back' of researchers to the settlement, to listen and learn. Informal settlers state that relationships are built because of the on-going engagement between the community and the researchers; because of their desire to engage in and learn about knowledge production processes, an opportunity provided by the university; because they wish to be 'made known' and be recognised in the city; and because they want to make a difference to the development trajectory of their settlement and their individual lives.

Research projects offer a new space of learning and engagement, which is shaped by the politics of the settlement, but which is also not defined and controlled by it. This was

\footnotetext{
${ }^{70}$ In 2014 when the project was initiated, Quarry Road West informal settlement was an ANC-led settlement in an ANC ward, Ward 23. In 2016 after the local government elections, the ward was won by the Democratic Alliance (DA) and is now a DA ward (2016-2021), with the sub-committee in Quarry Road West informal settlement being DA led. The ANC still has a strong presence in the community and the representative councillor from the ANC, as well as the previous ANC councillor continue to engage with the community.
} 
evident in 2016 when the ward within which the settlement is located, changed from being an ANC-led ward to a Democratic Alliance (DA)-led ward, as a result of local government elections. This introduced an interesting dynamic, as the mapmakers supported both political parties, as well as others. However, they agreed to work together, respecting their political identities, but not allowing them to define and control the datafication process. This outcome is extraordinary in the political landscape of South Africa, as it is not common for a group of people involved in a process as political as datafication, to be able to work across different political alliances. The social learning and relationships that had been built in the data production process, has created a space of inclusiveness in the community, that has enabled the team of mapmakers to work together, cutting across not only political lines, but gender and age lines too.

The data produced in Phase 1 remained largely an upstream and midstream activity (see Figure 9). Both community members and university researchers argued that the data had become stuck. It was not helping to change the living environment in the settlement, as it did not move easily into the spaces of decision making in eThekwini Municipality, particularly the Human Settlements Unit and EWS, where the data potentially could have greatest impact. The data was presented and reported in the PCRP, of which EPCPD is a lead actor, and in which other municipal departments participate. However, as an environmental planning and climate protection department, EPCPD is more of a facilitating and coordinating agency, rather than an implementing agency of the local state and could therefore "not operationalise and invest in the elements on the action plan, this was not what EPCPD does" (EPCPD Municipal Official pers comm 04/02/2019).

The datafication of the settlement provided insight and learning about the settlement, which was shared by EPCPD officials in other municipal forums, but it did not lead to significant outcomes in terms of service delivery or changes in the built environment. The data supported the progressive discourses of the local state, in terms of informal settlement upgrading, and so it flowed easily into, and was taken up in spaces where these discourses were evident. However, it was 'blocked' by the repressive discourses of some senior managers and departments in the municipality, in spaces where informal settlement upgrading was presented. However, an innovative city-wide programme located in EPCD, Durban's 100 Resilient Cities journey, provided an opportunity for instrumental, rightsbased and structural justice. Data flowed downstream in 2016 and 2017, as the Quarry Road West informal settlers and university researchers used the knowledge gained in the PCRP to provide input into the construction of Durban's Resilience Strategy, which has a strong focus on collaborative informal settlement action in the city (eThekwini Municipality 2017; Sutherland et al 2019b).

\section{Phase 2 of the datafication process}

The second phase of the datafication process started in 2018, and is ongoing (data collected: types C, D and E, see Table 1 and Figure 8). As shown in Figure 10, a major breakthrough in the value of the datafication process was achieved when the Human Settlements Unit, in partnership with Project Preparation Trust and Slum/Shack Dwellers International launched the iQhaza Lethu upgrading project, which is funded by the European Union. This opened the door for the data collected in the PCRP and Quarry Road West informal settlement to 
flow downstream and to start shaping state policy and discourse within the Human Settlements Unit, as the unit began to explore options and practices for informal settlement upgrading based on a partnership approach.

However, this was dependent on two important factors: one of the 'bridges' or champions of the datafication process was placed in iQhaza Lethu in the Human Settlements Unit as an official; and a second 'bridge' influencing the iQhaza Lethu programme, presented data from Quarry Road West informal settlement at initial planning meetings. The large amount of data that had been collected in the settlement, and hence the knowledge about it, as well as the influence of the data intermediaries, resulted in Quarry Road West being selected as an iQhaza Lethu pilot project, even though it is an unlikely candidate for in-situ upgrading, being categorised by the municipality as a deferred relocation. iQhaza Lethu is building up knowledge on informal settlement upgrading and will shape policy and practice in the future, so the datafication of Quarry Road West informal settlement, will shape the discourses and practices of informal settlement upgrading in the city, leading to improved instrumental, rights-based and distributive justice.

The data on the settlement is starting to flow into other spaces too, as the informal settlement has become the site of the implementation of a number of innovative projects in the municipality. This includes the Engineering Field Testing (EFT) being undertaken by EWS as part of the Bill and Melinda Gates Foundation's Re-Invent the Toilet Challenge (RTTC) and the drafting of a Disaster Risk Management Plan, as part of the 'EPIC A' project, which is a learning partnership between the municipality and the university. The choice of Quarry Road West informal settlement as a site for experimentation and social learning, through externally funded municipal projects, is attributed to the datafication of the settlement.

The role of 'bridges' or data intermediaries, who promote the value of engaging with the settlement, due to the knowledge and capacity that exists within it, as well as the governance platform that supports it, is important. This represents a form of instrumental justice as the datafication of the settlement has led to the implementation of these different projects within the settlement. These in turn have begun to address development deficits, through for example, constructing development options for the upgrading of the settlement, and building a playground, as a result of the participation of the community in the EFT. The settlement was also selected as a case study for a research project funded by the National Research Foundation: Narratives of Home and Neighbourhood: Possibilities for re-imagining Urban Planning. 


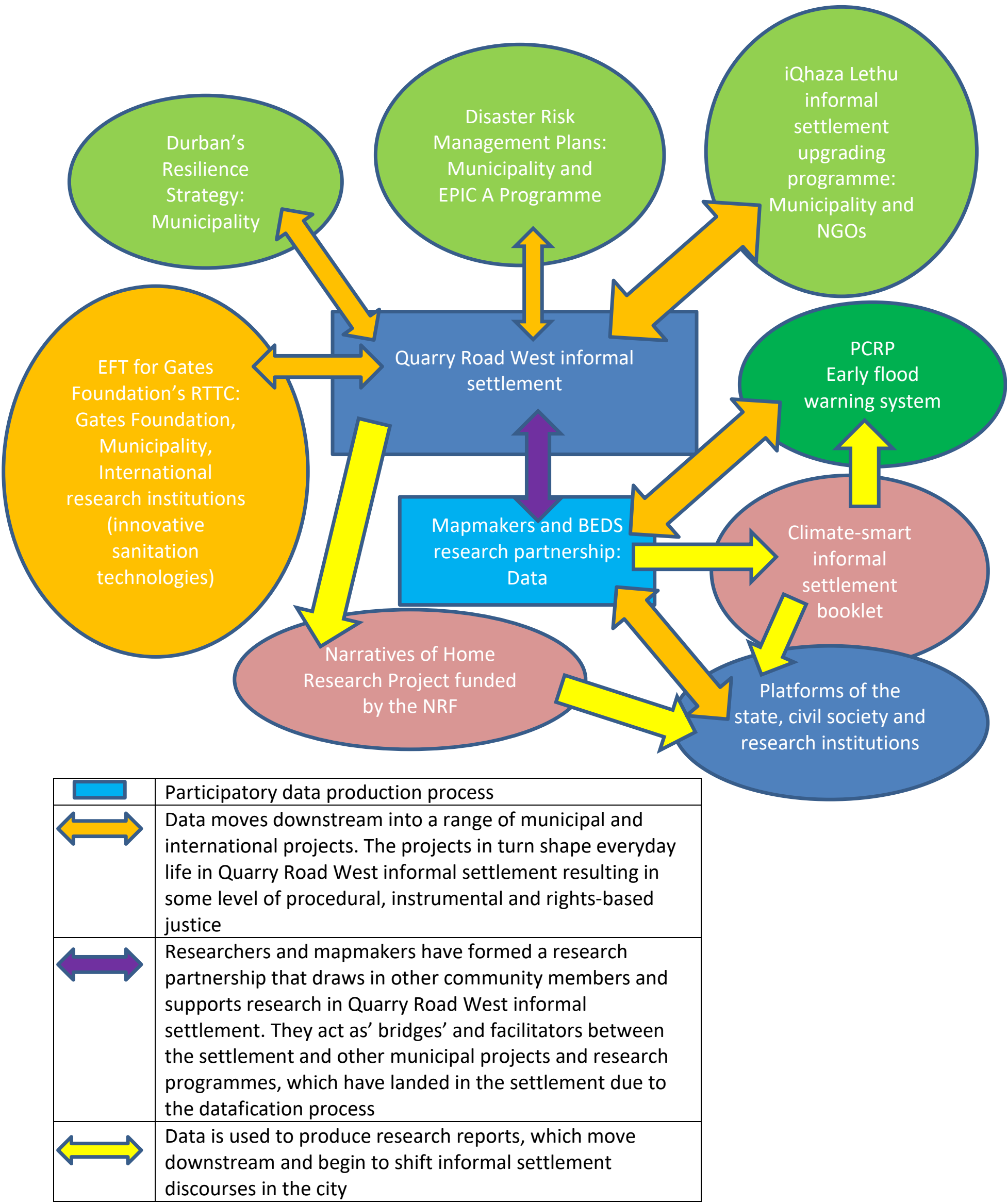

Figure 10: Phase 2 of the datafication process 
The in-depth data produced in this research project, which was made possible due to the strong relationships that exist between the mapmakers and the BEDS researchers as part of the datafication process, has had a significant impact in a number of forums in the city, as it has humanised informal settlers for those that hold more repressive positions related to informality.

A second event, the April 2019 flood, has created opportunities for the value of the datafication process to emerge. It has also revealed how challenging it is for data to result in instrumental, structural and distributive justice in a city grappling with rising informality, which holds both progressive and repressive discourses towards informal settlements. The flood had a dramatic impact on the settlement, as both land and informal houses were lost. As a result of lack of meaningful disaster response from the state after the flood, informal residents began to rebuild houses on all remaining open space in the settlement. This prompted a response from the Land Invasions Unit in the municipality, who identified these houses as 'new builds' and hence activated their process of removing all 'new builds' as part of the policy of the Human Settlements Unit. They placed red crosses on the doors of all the new builds, even though they had housing numbers on them, and warned residents that these houses would be taken down by the state. Residents, who were not newcomers after the flood, responded by stating that they had lived in the settlement for many years and had rebuilt on the open space, as they had lost their land in the flood. Housing officials told them they needed to provide evidence of this. The residents then activated the data, to claim their rights to the settlement. One resident, who is also a mapmaker, used the image of her household from the Narratives of Home research, to claim her right to the settlement (see Figure 11). She placed a copy of the image she took of her original house (before the flood washed her home away), as part of the photovoice methodology in the Narratives of Home research, on the door of her 'new build', to protect herself from the actions of the Land Invasion Unit. This image is contained and referenced in the Narratives of Home report (Sim et al 2019) and hence it has led to rights-based and instrumental justice for herself and her family. The GIS maps and database and the drone maps that have been flown of the settlement from June 2018 to July 2019 are also being used by community members who lived in the settlement prior to the flood, to protect their right to land in Quarry Road West, as the response to the floods and the 'new builds' unfolds. 


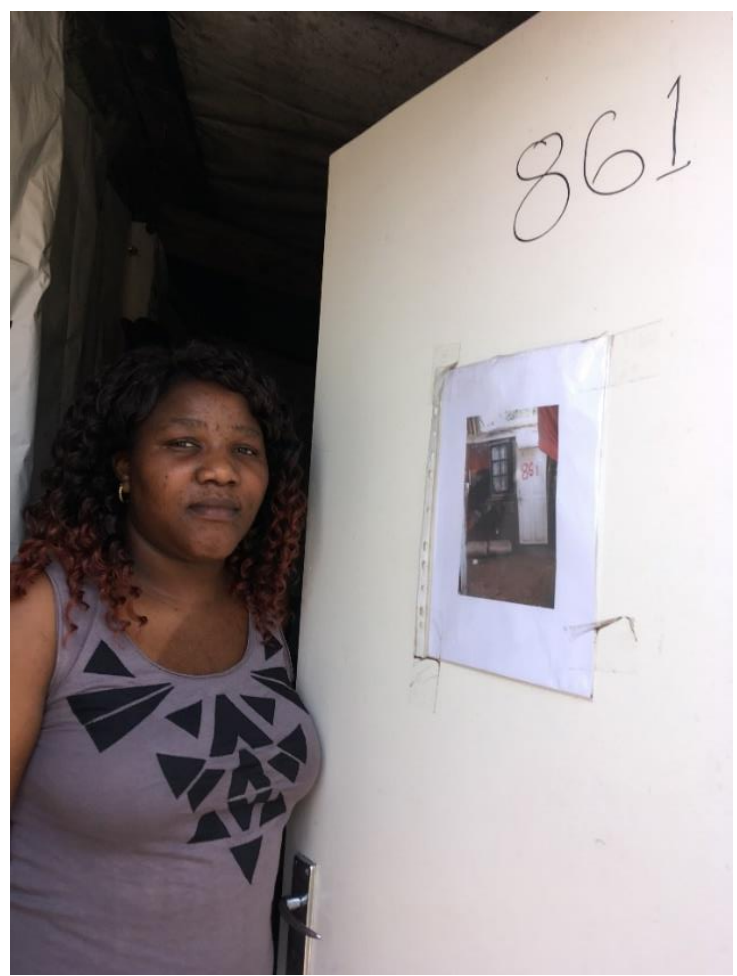

Figure 11: Using data to claim the right to the settlement (Source: C. Sutherland 28/07/2019)

Residents of Quarry Road West informal settlement adopted two strategies in the aftermath of the floods: the one was to protest and the other was to present a memorandum of demands to the Deputy Mayor of the Municipality. This memorandum stated that the community wanted to work in partnership with the municipality, drawing on the data and knowledge they have of their settlement, partly as a result of the datafication process, to plan a future for their community, that addresses the impact of the flood and reduces the risk of the river on the settlement in the future.

Protest action resulted in the Deputy Mayor visiting the settlement. She asked the community not to protest and rather to present a memorandum to the city, by delivering it to her office. Protest always achieves an immediate reaction from politicians and senior officials, although it seldom leads to longer term action and change. The community, through a participatory political process, drafted a memorandum, drawing on the datafication process, and submitted this to the Deputy Mayor. To date (August 2019) there has been no response to the memorandum, but this is most likely due to the recent replacement of the Mayor and the Deputy Mayor and executive committee of the municipality, due to corruption charges, which has led to significant political changes at the senior level. This political crisis has therefore impacted on the efforts of the Quarry Road West informal community to engage with the city. Bigger political struggles therefore play a major role in how data is taken up in downstream activities. 


\section{E. Discussion and Conclusions}

The datafication process in Quarry Road West informal settlement has made the settlement more 'visible' to the informal settlers who live within it. They state that they have learnt more about the place they live in and how it is shaped by its social, economic, environmental and political context. They have also improved their understanding of the mandates and capacity of local government and the limitations that it faces in meeting the needs of the urban poor (Open Data Workshop 21/03/2019). The settlement has also been made more 'visible' to the BEDS researchers, who are engaged in learning and knowledge production processes on how to govern for social and environmental transformation in informal settlements in cities in the global South; and to the state, which is tasked with managing the ongoing challenge of the growth of informal settlements in Durban, while trying to build urban resilience and sustainability. Over time, the datafication process has expanded the reach and influence of the settlement in city politics and decision making around informality, but this reach and influence is yet to have significant impacts on the everyday lives of those who live there and on the discourses and politics of informal settlement upgrading in the city. It has supported and strengthened a new governance arena that has emerged through the PCRP, which includes state, university and civil society actors, which may lead to instrumental and structural justice in the future, as a platform for dialogue and change has been built. The platform is perceived as being legitimate and having influence by a wide range of actors both within and outside of the state, because it is underpinned by multi-modal data and knowledge and this gives it power.

The case study has revealed that it is the coming together of actors, data, and opportunities or windows for change, at particular moments in time, in the life and politics of the city, which leads to some level of data justice for development. It is also evident that datafication has supported procedural and rights-based justice due to the epistemic control the mapmakers have had of the data produced within the settlement (see Figure 12). A critical question in the datafication process is whether the mapmakers are accepted by the broader community as trustworthy data producers and data intermediaries. While some community members have raised issues around how the mapmakers benefit from the datafication process, which in some instances has included small stipends, it has been evident throughout the project that they are trusted in this position in the community. This was most clear when they engaged in the highly political process of collecting data on households in the settlement for the participatory GIS mapping project. The mapmakers mapped the settlement in a very short period of time, they were assisted by community members who all wanted to be part of the process and they encountered no resistance to the process they were undertaking (Mazeka et al 2019). Thus far, they are respected and trusted as researchers in the community (Open Data Workshop 21/03/2019). However, the political struggles over land that have emerged as a result of the flood, with newcomers moving into the settlement, has begun to create tension over the meaning and use of the data.

It is also evident from the case study that trust cannot be taken for granted, that it can be broken very quickly, and that the politics in the settlement can change, shifting or breaking down relationships between the state, citizens and university researchers. This tension is beginning to emerge, as a result of the significant impact of the April floods on the 
settlement and the land crisis this has evoked. Trust is essential in ensuring procedural justice, as it relates to ethics in data production, respect for different forms of knowledge, the ownership and control of knowledge, and the willingness and faith to allow others to act as 'bridges', data intermediaries and champions, to move data downstream in the information value chain.

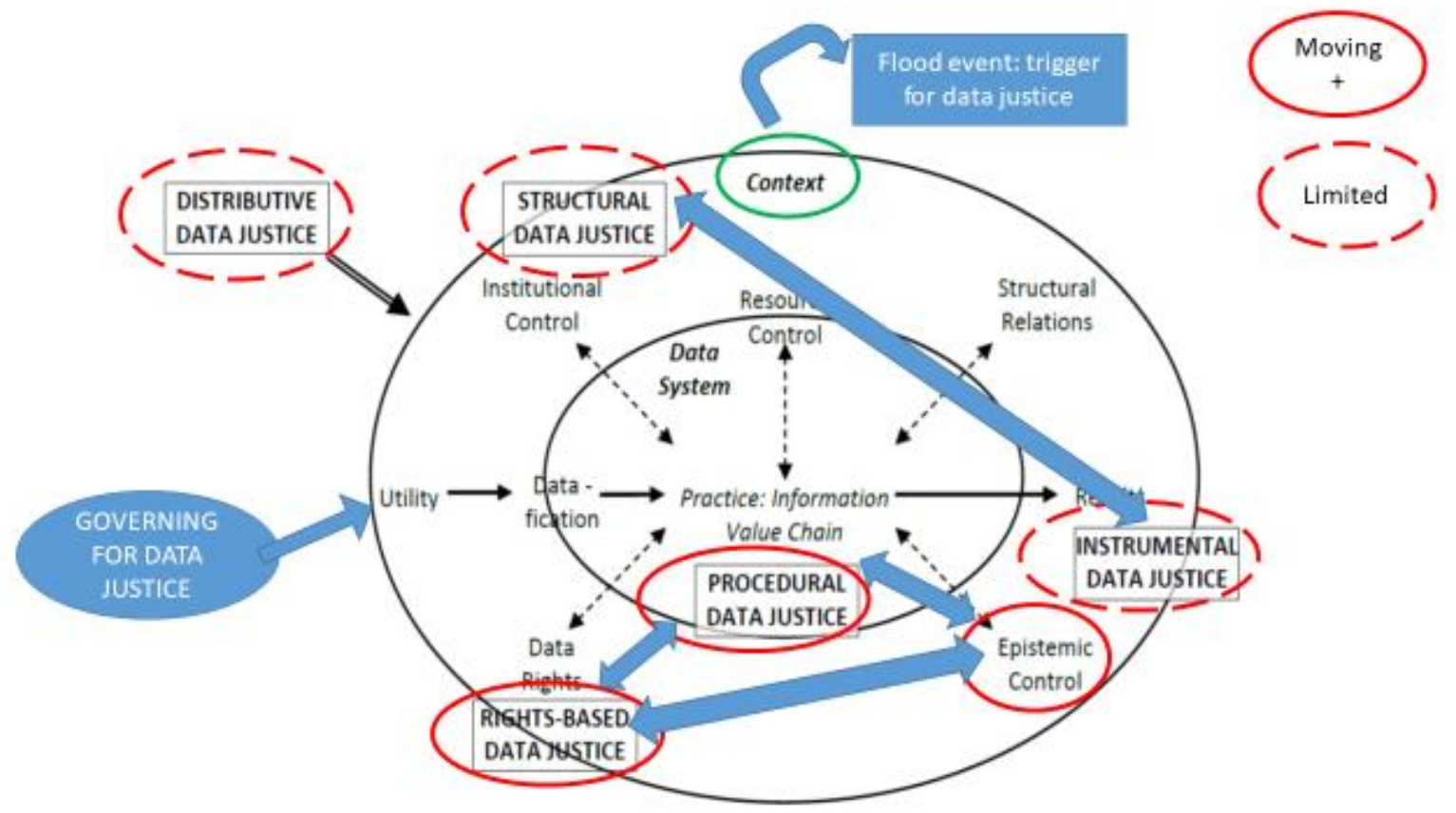

Figure 12: A data justice model for Quarry Road West informal settlement (adapted from Heeks \& Shekhar 2019)

Forms of instrumental and structural justice are beginning to emerge, with these two forms of justice being connected. The research has shown that it is very difficult to obtain 'hard' outcomes in the settlement without there being significant changes in the structures of the city, which result in more progressive discourses, planning for and investment in, informal settlements. However, 'bridges' or data intermediaries have played a positive role here, and have ensured that the 'soft' outcomes of the datafication process, including the building of a governance arena, social learning and opportunities that are created to shift conceptions of informality in the city, have gained traction and made a difference.

Governing for data justice has emerged as being critical to advancing data justice for development as this case study has shown and hence Heeks \& Shekhar's (2019) model has been expanded to include governance as a critical element. Perhaps the most critical aspect of governing for data justice, is the relations built between the state and citizens, with researchers (or NGOs) acting as 'bridges' to support the building of these relationships and the movement of data downstream between citizens and the state. The impact and role of triggers or opportunities for change created by 'critical moments or events' such as a flood or a major protest, is also recognised as a result of the research undertaken in Quarry Road West informal settlement.

The case study has "gone beyond 'justice as a set of theoretical principles' to 'justice-inpractice'" (Heeks \& Renken, 2018: 96). The final section presents the main lessons of the project and the recommendations that emerge from these lessons. 


\section{E1. Recommendations}

- Building state-citizen relations is critical in supporting data justice for development.

- Qualitative and GIS data that is collected and produced at the local scale, can, with the support of data intermediaries and champions, move downstream into the decision-making spaces of the state. This form of data, when collected, produced and presented using established and rigorous research processes, is powerful in shifting conceptions and discourses on informality.

- Building trust and ensuring respect for all actors in the knowledge production process, and the different forms of knowledge they produce, is critical to data justice for development.

- Datafication, when undertaken in inclusionary spaces that are defined by all actors in the process, can enable people to work across political, gender and age boundaries, moving development beyond the 'gains' of party politics or a particular group's interests.

- Datafication in an informal settlement makes the settlement visible to the informal settlers, to the state and to researchers and NGOs, providing new perspectives on how development can unfold and who needs to engage in the development process.

- Informal settlers are empowered in terms of their 'rights to the city' when they hold data on the number of households and their characteristics in the settlement.

- Datafication processes produce data, but often the 'governance and knowledge platforms' created through the process of inclusive datafication are more powerful than the data itself in achieving transformation. These platforms consist of: epistemics (what all parties have learned about each other) and social relations (the formation of a new social structure). It is these, rather than the data per se, that form the basis for impacts and interventions.

- The datafication project, rather than the data produced directly in the project, has led to some shifts of power in the relations between citizens and the state.

- Data produced through participatory processes are time consuming and rely on committed relationships to see the process through. This effort and commitment is undermined when data does not move downstream in the information value chain. Here data becomes 'stuck' and actors involved in the process question why they are collecting and producing data, if the conditions of their everyday lives do not change. Only when this data enters the spaces of powerful actors in the state, when the state sets the agenda to engage with the data as it serves their interests, does change begin to happen and the data becomes meaningful in terms of what it may achieve in shifts in policy and practice in informal settlements. The powerful actors in the state therefore hold the most power in producing tangible 'built environment' outcomes from datafication processes.

- Datafication when it is inclusive and builds procedural, rights-based, instrumental, structural and distributive justice supports 'the right to the city' which is "the right to the city is, therefore, far more than a right of individual access to the resources that the city embodies: it is a right to change ourselves by changing the city more after our heart's desire. It is, moreover, a collective rather than an individual right since changing the city inevitably depends upon the exercise of a collective power over the processes of urbanization. The freedom to make and remake ourselves and our cities is, I want to argue, one of the most precious yet most neglected of our human rights" (Harvey 2008: 1). 


\section{E2. Future Research Agenda}

This case study has explored the extent to which a well-established research partnership, between researchers within a university and 'mapmakers' from an informal settlement in Durban, has produced data that has made informal settlements more 'visible' to a wide range of state and non-state actors in the city, and achieved some level of social and environmental transformation. The instrumental and structural justice outcomes of the data process are only just beginning to emerge. It is therefore important to undertake a similar reflection, or case study, in three years, to reflect on whether, and how, life has changed for the residents in Quarry Road West informal settlement as a result of the datafication process, drawing on concepts from a data justice framework, which also will have evolved. It is also important to determine whether big data or digital data becomes more prominent in the settlement over time, and what form the 'datafication of development' takes. Will informal settlements remain in the more marginalised space of community-produced data? This data is valuable, as this case study has shown, but it is often neglected and not recognised in decision making; it is time consuming to produce; and it relies on significant effort from the community, data champions and data intermediaries. Or will big data, digital data and the new forms of data streams being produced, which support those connected in to the formal systems of the city, begin to reach into, or become accessible to informal settlements, thereby connecting informal settlers to broader 'datafication for development' processes (Heeks \& Shekhar 2019; Spratt \& Baker 2015; Taylor \& Broeders 2015).

Based on the results of this case study, it is evident that a future research agenda should include a focus on governance. How is data governed or 'steered' and who has the power to govern its 'outcomes'? This could include an analysis of the different forms of 'governmentality' of data for development. Future research needs to determine what form of governance and institutions provides the best support for data produced, to ensure it moves according to just principles, down the information value chain and impacts on decision making. What sets of rules, norms and social values, in terms of both formal and informal institutions, act as levers of change for data justice for development? Should data be governed through multi-actor partnerships? What is the role of the state in ensuring that procedural, instrumental, rights-based, structural and distributive justice is achieved? What kind of state can ensure this? As this case study has shown, data becomes stuck, when it remains outside of the critical decision-making and implementing agencies of the state.

Change in informal settlements, in terms of state interventions, is a slow process, given the regulations, bureaucratic and decision-making processes of the state. However, change, in terms of the shocks and stresses faced by informal settlements and their ability to adapt to them, are far more rapid, as informal settlements are dynamic environments that never 'stand still'. Data collection and production, when undertaken by informal settlers in partnership with universities, is a relatively quick process when human and financial resources are available. Further research needs to be undertaken on levers of change that can be activated to move data down the information value chain more quickly, and can ensure a more responsive, adaptive and flexible state, that can act on data produced at the local scale, and which is 'smart' enough to be able to 'read this data' and scale it up, and apply it to other informal settlements across this city, with a commitment to 'data justice for development', while not losing site of the importance of context. A big challenge, but one that is required and is essential, to ensure the rights of informal settlers to the city. 


\section{References}

Arora, P. (2016). Bottom of the data pyramid: Big data and the global South. International Journal of Communication, 10, 1681-99.

Baud, I. (2016). Digitisation and participation in urban governance. In Local Governance, Economic Development and Institutions, G.M. Gomez and P. Knorringa (eds), Palgrave Macmillan, Basingstoke, UK, 86-97.

Braathen, E., Dupont, V., Jordhus-Lier, D. and Sutherland, C. (2016). Introduction: situating the politics of slums within the 'urban turn'. In The Politics of Slums in the Global South: Urban Informality in Brazil, India, South Africa and Peru, V. Dupont, D. Jordhus-Lier, C. Sutherland, and E. Braathen (eds.), Routledge, London, UK, 1-29.

Brown, G. and Kyttä, M. (2014). Key issues and research priorities for public participation GIS (PPGIS): A synthesis based on empirical research. Applied Geography, 46(1), 122136.

Castells, M. (2000). The Information Age Economy, Society, and Culture. Volume 1. The Network Society, Blackwell Publishing, Chichester, UK.

Chakraborty, A., Wilson, B., Sarraf, S. and Jana, A. (2015). Open data for informal settlements. Journal of Urban Management, 4(2), 74-91.

Chambers, R. (2006). Participatory mapping and Geographic Information Systems: Whose map? Who is empowered and who disempowered? Who gains and who loses. The Electronic Journal on Information Systems in Developing Countries, 25(2), 1-11.

Davis, M. (2006). Planet of Slums, Verso, London.

Dryzek, J. (2012). The Politics of the Earth. Environmental Discourses, $3^{\text {rd }}$ Edition, Oxford University Press, Oxford.

Dupont, V. (2013). Which place for the homeless in Delhi? Scrutiny of a mobilisation campaign in the 2010 Commonwealth Games context. South Asia Multidisciplinary Academic Journal, 8, 2-18.

Dupont, V., Jordhus-Lier, D., Sutherland, C., and Braathen, E. (eds.) (2016). The Politics of Slums in the Global South: Urban informality in Brazil, India, South Africa and Peru, Routledge, London.

Elwood, S. (2002). GIS use in community planning: A multidimensional analysis of empowerment. Environment and Planning A, 34(5), 905-922.

eThekwini Municipality (2017). Durban's Resilience Strategy, eThekwini Municipality, Durban.

eThekwini Municipality and PPT (2018). The iQhaza Lethu Partnership Project, eThekwini Municipality, Durban.

Gaillard, C., Monteil, C., Perrillat-Collomb, A., Chaudhary, S., Chaudhary, M., Chaudhary, O., and Cadag, J.R.D. (2013). Participatory 3-dimension mapping: A tool for encouraging multi-caste collaboration to climate change adaptation and disaster risk reduction. Applied Geography, 45, 158-166.

Hajer, M. and Wagenaar, H. (2003). Deliberative Policy Analysis: Understanding Governance in the Network Society, Cambridge University Press, Cambridge, UK.

Harvey, D. (2008). The right to the city, New Left Review, II(53), 23-40.

Heeks, R. (2017). A Structural Model and Manifesto for Data Justice for International Development, GDI Development Informatics Working Paper no.69, University of Manchester, UK. 
Heeks, R. (2018). Information and Communication Technology for Development, Routledge, Abingdon, UK.

Heeks, R. and Renken, J. (2018). Data justice for development: What would it mean? Information Development, 34(1), 90-102.

Heeks, R. and Shekhar, S. (2019). Datafication, development and marginalised urban communities: An applied data justice framework. Information, Communication and Society, 22(7), 992-1011.

Huchzermeyer, M. (2011). Cities with 'Slums': From Informal Settlement Eradication to a Right to the City in Africa, University of Cape Town Press, Cape Town.

Jordhus-Lier, D. Braathen, E., Dupont, V. and Sutherland, C. (2016). Knowledge and power in upgrading and resettlement initiatives. In The Politics of Slums in the Global South: Urban Informality in Brazil, India, South Africa and Peru, V. Dupont, D. Jordhus-Lier, C. Sutherland, and E. Braathen (eds.), Routledge, London, UK, 115-143.

Karanja, I. (2010). An enumeration and mapping of informal settlements in Kisumu, Kenya, implemented by their inhabitants. Environment and Urbanisation, 22(1), 217-239.

Kennedy, L., Sood, A., Chakraborty, D. and Chitta, R.M. (2019). Data Justice through the Prism of Information Politics and Resource Injustice: A Case Study from Hyderabad's Urban Frontier, Development Informatics Working Paper no.78, University of Manchester, UK.

Lefebvre, H. (1968). Le Droit à la Ville, Anthropos, Paris.

Li, T.M. (2007). The Will to Improve: Governmentality, Development and the Practice of Politics, Duke University Press, Durham.

Lokanathan, S., Kreindler, G.E., de Silva, N.N., Miyauchi, Y., Dhananjaya, D. and Samarajiva, R. (2016). The potential of mobile network big data as a tool in Colombo's transportation and urban planning. Information Technologies and International Development, 12(2), 6373.

Lydon, M. (2003). Community mapping: The recovery (and discovery) of our Common Ground. Geomatica, 57(2), 131-43.

Martel, P. and Sutherland, C. (2019). Governing river rehabilitation for climate adaptation and water security in Durban, South Africa. In The Geography of Climate Change Adaptation in Urban Africa, P.B. Cobbinah and M. Addaney, M. (eds), Palgrave MacMillan, Switzerland, 355-387.

Mazeka, B., Sutherland, C., Buthelezi, S. and Khumalo, D. (2019). Community-based mapping methodology for climate change adaptation: A case study of Quarry Road West informal settlement, Durban, South Africa, In The Geography of Climate Change Adaptation in Urban Africa, P.B. Cobbinah and M. Addaney (eds), Palgrave MacMillan, Switzerland, 57-88.

McQuillan, D. (2015). Algorithmic states of exception. European Journal of Cultural Studies, 18(4/5), 564-76.

Milan, S. and Treré, E. (2019). Big data from the South(s): Beyond data universalism. Television and New Media, 20(4) 319-335.

Piccolella, A. (2013). Participatory mapping for adaptation to climate change: The case of Boe Boe, Solomon Islands. Knowledge Management for Development Journal, 9(1), 24 36.

Rambaldi, G., Kwaku Kyem, P.A., McCall, M.K., and Weiner, D. (2006). Participatory spatial information management and communication in developing countries. The Electronic Journal of Information Systems in Developing Countries, 25(1), 1-9. 
Roberts, D. (2016). The new climate calculus: $1.5^{\circ} \mathrm{C}=$ Paris Agreement, cities, local government, science and champions (PLSC). Urbanisation, 1(2), 1-8.

Samarajiva, R., Lokanathan, S., Madhawa, K., Kreindler, G. and Maldeniya, D. (2015). Big data to improve urban planning. Economic and Political Weekly, 50(22), 43-48.

Sengupta, R., Heeks, R., Chattapadhyay, S. and Foster, C. (2017). Exploring Big Data for Development, GDI Development Informatics Working Paper no.66. University of Manchester, UK.

Satterthwaite, D., Archer, D., Colenbrander, S., Dodman, D., Hardoy, D. and Patel, S. (2018). Responding to Climate Change in Cities and in their Informal Settlements and Economies, Paper prepared for the IPCC for the International Scientific Conference on Cities and Climate Change in Edmonton, March 2018, IIED, Sussex.

Sim, V., McCarthy, A., Buthelezi, S. and Khumalo, D. (2019). Narratives of Home and Neighbourhood: Possibilities for Reimagining Urban Planning Exploring an In-Situ Upgrade: Quarry Road West Informal Settlement, report produced for Urban Futures Centre, Durban University of Technology, Durban.

Spratt, S. and Baker, J. (2015). Big Data and International Development, IDS, University of Sussex, UK.

Sutherland, C. (2016). Fact Sheet 2.3 South Africa. In The Politics of Slums in the Global South: Urban Informality in Brazil, India, South Africa and Peru, V. Dupont, D. JordhusLier, C. Sutherland, and E. Braathen (eds.), Routledge, London, UK, 34-35.

Sutherland, C. and Roberts, D. (2014). Why Leadership Matters in Water and Climate Governance, Opinion Paper 12, Chance2Sustain, EADI, Bonn.

Sutherland, C., Braathen, E., Dupont, V. and Jordhus-Lier, D. (2016). Policies towards substandard settlements. In The Politics of Slums in the Global South: Urban informality in Brazil, India, South Africa and Peru, V. Dupont, D. Jordhus-Lier, C. Sutherland, and E. Braathen (eds.), Routledge, London, UK, 49-78.

Sutherland, C., Scott, D., Nel, E. and Nel, A. (2018). Conceptualising 'the urban' through the lens of Durban, South Africa. Urban Forum, 29(4), 333-350.

Sutherland, C., Mazeka, B., Buthelezi, S., Khumalo, D., Martel, P., Reid, J., Xolo, L., Zondani, S.D., Nomlala, T., Xhakaza, S. Khumalo, T., Msibi, G., Sbuthu, Z., Thuthu, N., Hlongwe, S., Miya, M., Ndzimande, T., Khuhle, O.D., Nqanula, N., Ntuli, Z., Mgwacu, M., Gwayi, L., Zukulu, B., Dube, H., Nzimande, C., Cele, T., Mzandi, N., Khumalo, T., and Nyawuza, B. (2019a). Climate Smart Informal Settlements, report prepared for City of Bremen and GIZ, School of Built Environment and Development Studies, University of KwaZulu-Natal, Durban.

Sutherland, C., Roberts, D. and Douwes, J. (2019b). Constructing resilience at three different scales: The 100 Resilient Cities programme, Durban's resilience journey and everyday resilience in the Palmiet Catchment. Human Geography, 12(1), 33-49.

Taylor, L. (2017). What is data justice? The case for connecting digital rights and freedoms on the global level. Big Data and Society, 4(2), 1-14.

Taylor, L. and Broeders, D. (2015). In the name of development. Geoforum, 64, 229-237. Taylor, L. and Richter, C. (2015). Big data and urban governance. In Geographies of Urban Governance, J. Gupta, K. Pfeffer, H. Verrest and M. Ros-Tonen (eds), Springer, Cham, Switzerland, 175-191.

UN-Habitat (2017). New Urban Agenda. UN-Habitat, Nairobi, Kenya.

UN-Habitat (2018) Pro-Poor Climate Action in Informal Settlements, UN-Habitat, Nairobi, Kenya. 
van Veenstra, A.F., Esmeijer, J., Bakker, T. and Kotterink, B. (2014). Data and the City. TNO, Delft.

Vogel, C., Scott, D., Culwick, C. and Sutherland, C. (2016). Environmental problem solving in South Africa: Harnessing creative imaginaries to address 'wicked' challenges and opportunities. South African Geographical Journal, 98(3), 515-530.

Wang, C. and Burris, M. (1997). Photovoice: concept, methodology, and use for participatory needs assessment. Health, Education and Behaviour, 24(3), 369-387.

Williams, D., Manez Costa, M., Sutherland, C., Celliers, L. and Scheffran, J. (2019). Vulnerability of informal settlements in the context of rapid urbanization and climate change. Environment and Urbanisation, 31(1), 157-176.

Williams, D.S., Manez Costa, M., Celliers, L. and Sutherland, C. (2018). Informal settlements and flooding: Identifying strengths and weaknesses in local governance for water management. Water, 10, 871.

Willis, K. (2017). Whose Right to the Smart City? Plymouth University, UK.

\section{Acknowledgements}

The "Urban Data, Inequality and Justice in the Global South" case studies form part of a Senior Research Fellowship funded by the University of Manchester's Sustainable Consumption Institute with additional financial support from Canada's International Development Research Centre. The contribution of the Quarry Road West 'mapmakers' in the production of this case study is acknowledged and recognised as without them, this research would not have been possible. Open Data Durban is also acknowledged for their contribution to the research, as are the members of the PCRP. We would also like to thank Richard Heeks and James Evans for including us in this project, and for their valuable contributions to our paper.

\section{About the Authors}

Catherine Sutherland is an urban geographer and senior lecturer in the School of Built Environment and Development Studies at the University of KwaZulu-Natal (UKZN), Durban. Her research focuses on environmental governance in cities, with a specific focus on water and climate governance and the relations between peri-urban housing, informal settlements and the environment. Her research is locally focused and action based, as result of her strong commitment to building participatory governance in cities in the South.

Bahle Mazeka is a PhD candidate in the School of Built Environment and Development Studies, University of KwaZulu-Natal. He is an urban geographer who is interested in social justice and sustainable human settlements. He is born and raised in Bizana, in typical socioeconomic conditions of rural Eastern Cape, South Africa. He received his junior degree at UKZN where his interest of cities and sustainable development developed. He holds a BSc Honours in Geographic Information System (GIS) from the Nelson Mandela University, and a Master of Housing from UKZN. He is currently an area manager for the iQhaza Lethu informal settlement upgrading project and hence is employed in the Human Settlements Unit, eThekwini Municipality.

Sibongile Buthelezi is a researcher in the School of Built Environment and Development Studies at the University of KwaZulu-Natal. She has extensive experience in conducting community-based research in cities, with a focus on water and climate governance, housing, 
the economic development trajectories of the urban periphery and innovative sanitation technologies. She has a strong interest in participatory environmental governance and is engaged in a large number of action research projects in Durban in partnership with eThekwini Municipality. She is an expert in methodologies for the co-production of knowledge, combining scientific knowledge with local knowledge.

Duduzile Khumalo is a researcher and environmental activist in the School of Built Environment and Development Studies at the University of KwaZulu-Natal Durban. She has extensive experience in community-based research in urban areas, with a focus on water and climate governance and housing. She is currently working on research related to the nexus between food, environment and health. She has a strong interest in integrating local knowledge and experience into policy making and so strongly supports the practice of the co-production of knowledge. She is engaged in a number of action based research projects with eThekwini Municipality.

Patrick Martel is a PhD Candidate in the School of Built Environment and Development Studies at the University of KwaZulu-Natal, South Africa. Patrick works at the interface of the social and natural sciences, and is interested in governance processes. Initially trained as a geographer, his PhD thesis topic is titled "A temporal analysis of changing hydrosocial relationships in Durban, South Africa". Patrick is funded by the Water Research Commission of South Africa (WRC 2354). He is part of a research team at UKZN that is actively involved in a range of water and climate change-related action research projects in eThekwini Municipality. 